\title{
Force Systems from T-Loop Orthodontic Space Closure Springs: The Effects of Asymmetric Placement and Angulation on the Alpha-Beta Moment Differential
}

Andrew J. Kuhlberg

Follow this and additional works at: https://opencommons.uconn.edu/sodm_masters Part of the Orthodontics and Orthodontology Commons

\section{Recommended Citation}

Kuhlberg, Andrew J., "Force Systems from T-Loop Orthodontic Space Closure Springs: The Effects of Asymmetric Placement and Angulation on the Alpha-Beta Moment Differential" (1992). SoDM Masters Theses. 73.

https://opencommons.uconn.edu/sodm_masters/73 
FORCE SYSTEMS FROM "T-LOOP ORTHODONTIC SPACE CLOSURE SPRINGS:

THE EFFECTS OF ASYMMETRIC PLACEMENT AND

\title{
ANGULATION ON THE ALPHA-BETA MOMENT DIFFERENTIAL
}

\author{
Andrew J. Kuhlberg \\ B.A., Hartwick College, 1984 \\ D.M.D., University of Connecticut, 1989
}

A Thesis

Submitted in Partial Fulfillment of the

Requirements for the Degrees of

Master of Dental Science

at

The University of Connecticut

1992 


\section{APPROVAL PAGE}

Master of Dental Science

FORCE SYSTEMS FROM "T-LOOP ORTHODONTIC SPACE CLOSURE SPRINGS: THE EFFECTS OF ASYMMETRIC PLACEMENT AND ANGULATION ON THE ALPHA-BETA MOMENT DIFFERENTIAL

Presented by

Andrew J. Kuhlberg, B.A., D. M. D.

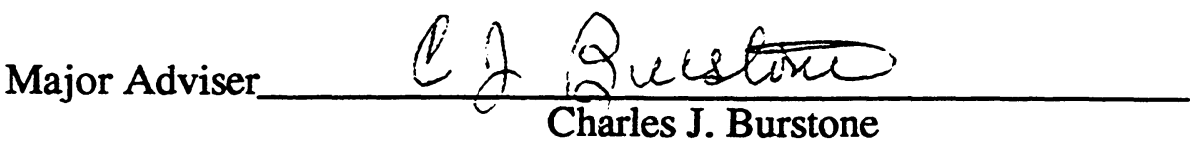

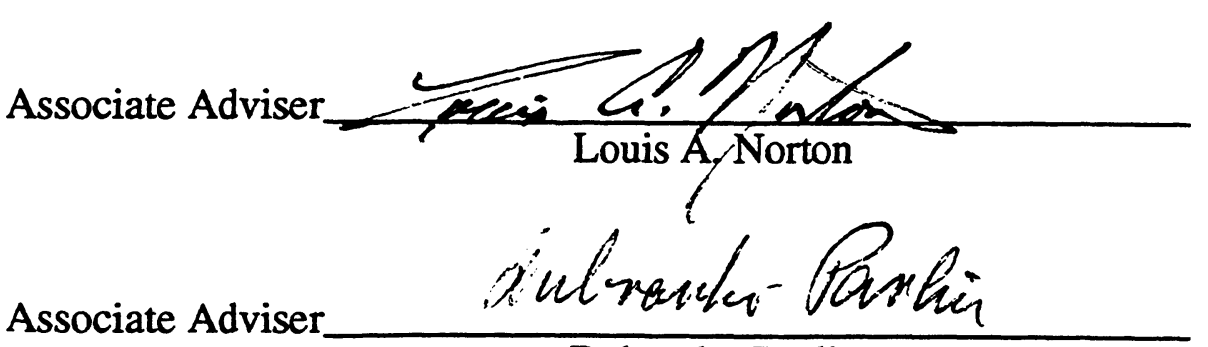
Dubravko Pavlin

The University of Connecticut

1992 


\section{ACKNOWLEDGEMENTS}

I would like to thank the members of my advisory committee, Dr. Louis A. Norton and Dr. Dubravko Pavlin for their guidance with this project. I would especially like to thank Dr. Charles Burstone for his invaluable contributions to my training and education, his knowledge and wisdom have guided me throughout my career at the University of Connecticut.

I would also like to thank John Morton and John Ratches, as well as all the past research technicians and students who have worked in the Biomechanics Laboratory, for their contributions to the creation and evolution of the equipment needed to accomplish this research.

A very grateful thank you to my parents for their support and encouragement as I've pursued my education.

And most of all, thank you to my wife, Laura, for her love, support, and inspiration.. 
TABLE OF CONTENTS

$\begin{array}{ll}\text { INTRODUCTION } & 1 \\ \text { LITERATURE REVIEW } & 4 \\ \text { RATIONALE } & 17 \\ \text { GENERAL OBJECTIVES } & 18 \\ \text { THE RESEARCH PLAN } & 19 \\ \text { RESULTS } & 25 \\ \text { DISCUSSION } & 31 \\ \text { CONCLUSIONS } & 35 \\ \text { FUTURE STUDIES } & 36 \\ \text { REFERENCES } & 37 \\ \text { APPENDIX I: TABLES } & 39 \\ \text { APPENDIX II: FIGURES } & 86\end{array}$




\section{LIST OF TABLES}

Table \#

Title

Page

1: $\quad$ SUMMARY OF MEASURED FORCE SYSTEM

Symmetric Angulation, Centered Position,

Preactivation Angulation $=0$ degrees

2: $\quad$ SUMMARY OF MEASURED FORCE SYSTEM

Symmetric Angulation, Centered Position,

Preactivation Angulation $=10$ degrees

3: SUMMARY OF MEASURED FORCE SYSTEM

Symmetric Angulation, Centered Position,

Preactivation Angulation $=20$ degrees

4: $\quad$ SUMMARY OF MEASURED FORCE SYSTEM

Symmetric Angulation, Centered Position,

Preactivation Angulation $=30$ degrees

5: $\quad$ SUMMARY OF MEASURED FORCE SYSTEM

Symmetric Angulation, Centered Position,

Preactivation Angulation $=40$ degrees

6: SUMMARY OF MEASURED FORCE SYSTEM

Symmetric Angulation, Centered Position,

Preactivation Angulation $=50$ degrees

7: $\quad$ SUMMARY OF MEASURED FORCE SYSTEM

Symmetric Angulation, Centered Position,

Preactivation Angulation $=60$ degrees

8: $\quad$ SUMMARY OF MEASURED FORCE SYSTEM

Symmetric Angulation, Centered Position,

Preactivation Angulation $=70$ degree

9: $\quad$ SUMMARY OF MEASURED FORCE SYSTEM

Symmetric Moments, Centered Position (Control),

10: SUMMARY OF MEASURED FORCE SYSTEM

Symmetric Moments, Positioned $1 \mathrm{~mm}$ toward Anterior (Alpha)

11: SUMMARY OF MEASURED FORCE SYSTEM

Symmetric Moments, Positioned $2 \mathrm{~mm}$ toward Anterior (Alpha)

12: SUMMARY OF MEASURED FORCE SYSTEM

Symmetric Moments, Positioned $3 \mathrm{~mm}$ toward Anterior (Alpha)

13: SUMMARY OF MEASURED FORCE SYSTEM

Symmetric Moments, Positioned $4 \mathrm{~mm}$ toward Anterior (Alpha) 
14: SUMMARY OF MEASURED FORCE SYSTEM

Symmetric Moments, Positioned $1 \mathrm{~mm}$ toward Posterior (Beta)

15: SUMMARY OF MEASURED FORCE SYSTEM

Symmetric Moments, Positioned $2 \mathrm{~mm}$ toward Posterior (Beta)

16: SUMMARY OF MEASURED FORCE SYSTEM

Symmetric Moments, Positioned $3 \mathrm{~mm}$ toward Posterior (Beta)

17: SUMMARY OF MEASURED FORCE SYSTEM

Symmetric Moments, Positioned $4 \mathrm{~mm}$ toward Posterior (Beta)

18: SUMMARY OF MEASURED FORCE SYSTEM

Asymmetric Angulation: Alpha $=0$ degrees, Beta $=75$ degrees, Centered Position

19: SUMMARY OF MEASURED FORCE SYSTEM Asymmetric Angulation: Alpha $=15$ degrees, Beta $=75$ degrees, Centered Position

20: SUMMARY OF MEASURED FORCE SYSTEM

Asymmetric Angulation: Alpha $=30$ degrees, Beta $=75$ degrees, Centered Position

21: SUMMARY OF MEASURED FORCE SYSTEM

Asymmetric Angulation: Alpha $=45$ degrees, Beta $=75$ degrees, Centered Position

22: SUMMARY OF MEASURED FORCE SYSTEM

Asymmetric Angulation: Alpha $=60$ degrees, Beta $=75$ degrees, Centered Position

23: SUMMARY OF MEASURED FORCE SYSTEM

Asymmetric Angulation: Alpha $=75$ degrees, Beta $=0$ degrees, Centered Position

24: SUMMARY OF MEASURED FORCE SYSTEM

Asymmetric Angulation: Alpha $=75$ degrees, Beta $=15$ degrees, Centered Position

25: SUMMARY OF MEASURED FORCE SYSTEM

Asymmetric Angulation: Alpha $=75$ degrees, $B$ eta $=30$ degrees, Centered Position

26: SUMMARY OF MEASURED FORCE SYSTEM

Asymmetric Angulation: Alpha $=75$ degrees, Beta $=45$ degrees, Centered Position 
27: SUMMARY OF MEASURED FORCE SYSTEM

Asymmetric Angulation: Alpha $=75$ degrees, Beta $=60$ degrees, Centered Position

28: REGRESSION ANALYSIS: WHOLE MODEL - Alpha Moment

Symmetric Angulation, Centered Position

29: REGRESSION ANALYSIS: WHOLE MODEL - Beta Moment

Symmetric Angulation, Centered Position

30: REGRESSION ANALYSIS: WHOLE MODEL - Horizontal Force

68

Symmetric Angulation, Centered Position

31: REGRESSION ANALYSIS: WHOLE MODEL - Vertical Force

Symmetric Angulation, Centered Position

32: REGRESSION ANALYSIS: WHOLE MODEL -

Alpha Moment/Beta Moment, Symmetric Angulation, Centered Position

33: REGRESSION ANALYSIS: WHOLE MODEL - Alpha Moment

Symmetric Moments, Off-Centered Position

34: REGRESSION ANALYSIS: WHOLE MODEL - Beta Moment

Symmetric Moments, Off-Centered Position

35: REGRESSION ANALYSIS: WHOLE MODEL - Horizontal Force Symmetric Moments, Off-Centered Position

36: REGRESSION ANALYSIS: WHOLE MODEL - Vertical Force

Symmetric Moments, Off-Centered Position

37: REGRESSION ANALYSIS: WHOLE MODEL -

Alpha Moment/Beta Moment, Symmetric Moments, Off-Centered Position

38: REGRESSION ANALYSIS: WHOLE MODEL - Alpha Moment

Asymmetric Angulation - Varying Alpha, Centered Position

39: REGRESSION ANALYSIS: WHOLE MODEL - Beta Moment

Asymmetric Angulation - Varying Alpha, Centered Position

40: REGRESSION ANALYSIS: WHOLE MODEL - Horizontal Force Asymmetric Angulation - Varying Alpha, Centered Position

41: REGRESSION ANALYSIS: WHOLE MODEL - Vertical Force Asymmetric Angulation - Varying Alpha, Centered Position

42: REGRESSION ANALYSIS: WHOLE MODEL -

Asymmetric Angulation - Varying Alpha, Centered Position 
43: REGRESSION ANALYSIS: WHOLE MODEL - Alpha Moment

44: REGRESSION ANALYSIS: WHOLE MODEL - Beta Moment

Asymmetric Angulation - Varying Beta, Centered Position

47: REGRESSION ANALYSIS: WHOLE MODEL -

Asymmetric Angulation - Varying Beta, Centered Position 


\section{LIST OF FIGURES}

Figure \#

Title

Page

1: Schematic Diagram of Spring Tester Apparatus, University of Connecticut, Division of Orthodontics, Biomechanics Laboratory

2: $\quad$ The Force System from a T-loop Space Closing Spring

3: $\quad$ Segmented T-loop prior to the placement of Preactivation Bends 88

4: $\quad$ Templates for T-loop Springs with Symmetric Angulation and Centered Position

5: Templates for T-loop Springs producing Symmetric Moments

90 in the Centered Position, Used for Off-Centered Positioning

6: Templates for T-loop Springs with Asymmetric Angulation, Constant Alpha Angulation, Varying Beta Angulation

7: Templates for T-loop Springs with Asymmetric Angulation, Constant Beta Angulation, Varying Alpha Angulation

8: $\quad$ Alpha moment versus spring activation for T-loop springs with symmetric 93 alpha and beta angulation and centered positioning

9: $\quad$ Alpha moment versus spring angulation for T-loop springs with symmetric 94 alpha and beta angulation and centered positioning

10: Beta moment versus spring activation for T-loop springs with symmetric 95 alpha and beta angulation and centered positioning

11: Beta moment versus spring angulation for T-loop springs with symmetric 96 alpha and beta angulation and centered positioning

12: Horizontal Force versus spring activation for T-loop springs with symmetricalpha and beta angulation and centered positioning

13: Horizontal Force versus spring angulation for T-loop springs with symmetricalpha and beta angulation and centered positioning

14: Vertical Force versus spring activation for T-loop springs with symmetric alpha and beta angulation and centered positioning

99

15: Vertical Force versus spring angulation for T-loop springs with symmetric 100 alpha and beta angulation and centered positioning

16: Ratio of the alpha moment/beta moment versus spring activation for T-loop 101 springs with symmetric alpha and beta angulation and centered positioning 
17: Ratio of the alpha moment/beta moment versus spring angulation for

102

T-loop springs with symmetric alpha and beta angulation and centered positioning

18: Alpha moment-to-force ratio versus spring activation for

103 T-loop springs with symmetric alpha and beta angulation and centered positioning

19: Beta moment-to-force ratio versus spring activation for T-loop springs

104 with symmetric alpha and beta angulation and centered positioning

20: Alpha moment versus spring activation for symmetric T-loop springs

105 at various off-centered positions

21: Alpha moment versus spring position for symmetric $\mathrm{T}$-loop springs at various off-centered positions

106

22: $\quad$ Beta moment versus spring activation for symmetric $\mathrm{T}$-loop springs at various off-centered position

107

23: Beta moment versus spring position for symmetric T-loop springs at various off-centered positions

108

24: Horizontal Force versus spring activation for symmetric T-loop springs at various off-centered positions

109

25: Horizontal Force versus spring position for symmetric T-loop springs 110 at various off-centered positions

26: Vertical Force versus spring activation for symmetric T-loop springs at various off-centered positions

27: Vertical Force versus spring position for symmetric T-loop springs at various off-centered positions

28: Ratio of the alpha moment/beta moment versus spring activation for symmetric T-loop springs at various off-centered positions

29: Ratio of the alpha moment/beta moment versus spring position for symmetric $\mathrm{T}$-loop springs at various off-centered positions 
30: Alpha moment-to-force ratio versus spring activation for symmetric T-loop 115 springs with at various off-centered positions

31: Beta moment-to-force ratio versus spring activation for symmetric T-loop 116 springs with at various off-centered positions

32: Alpha moment versus spring activation for T-loop springs with asymmetric alpha and beta angulation and centered position, variation of alpha angulation $(0,15,30,45$, and 60 degrees) with constant beta angulation (75 degrees)

33: Alpha moment versus alpha angulation for T-loop springs with asymmetric alpha and beta angulation and centered position, variation of alpha angulation $(0,15,30,45$, and 60 degrees) with constant beta angulation (75 degrees)

34: $\quad$ Beta moment versus spring activation for T-loop springs with asymmetric alpha and beta angulation and centered position, variation of alpha angulation $(0,15,30,45$, and 60 degrees) with constant beta angulation (75 degrees)

35: Beta moment versus alpha angulation for T-loop springs with asymmetric alpha and beta angulation and centered position, variation of alpha angulation $(0,15,30,45$, and 60 degrees) with constant beta angulation (75 degrees)

36: Horizontal Force versus spring activation for T-loop springs with asymmetric alpha and beta angulation and centered position, variation of alpha angulation $(0,15,30,45$, and 60 degrees) with constant beta angulation (75 degrees)

37: Horizontal Force versus alpha angulation for T-loop springs with asymmetric alpha and beta angulation and centered position, variation of alpha angulation $(0,15,30,45$, and 60 degrees) with constant beta angulation ( 75 degrees)

38: Vertical Force versus spring activation for T-loop springs with asymmetric alpha and beta angulation and centered position, variation of alpha angulation $(0,15,30,45$, and 60 degrees) with constant beta angulation ( 75 degrees)

39: Vertical Force versus alpha angulation for T-loop springs with asymmetric alpha and beta angulation and centered position, variation of alpha angulation $(0,15,30,45$, and 60 degrees) with constant beta angulation ( 75 degrees)

40: Ratio of the alpha moment/beta moment versus spring activation for T-loop springs with asymmetric alpha and beta angulation and centered position, variation of alpha angulation $(0,15,30,45$, and 60 degrees) with constant beta angulation ( 75 degrees) 
41: Alpha moment-to-force ratio versus spring activation for $\mathrm{T}$-loop

springs with asymmetric alpha and beta angulation and centered position, variation of alpha angulation $(0,15,30,45$, and 60 degrees)

with constant beta angulation ( 75 degrees)

42: Beta moment-to-force ratio versus spring activation for T-loop springs with asymmetric alpha and beta angulation and centered position, variation of alpha angulation $(0,15,30,45$, and 60 degrees) with constant beta angulation ( 75 degrees)

43: Alpha moment versus spring activation for T-loop springs with asymmetric alpha and beta angulation and centered position, variation of beta angulation $(0,15,30,45$, and 60 degrees) with constant alpha angulation ( 75 degrees)

44: Alpha moment versus beta angulation for T-loop springs with asymmetric alpha and beta angulation and centered position, variation of beta angulation $(0,15,30,45$, and 60 degrees) with constant alpha angulation (75 degrees)

45: Beta moment versus spring activation for T-loop springs with asymmetric alpha and beta angulation and centered position, variation of beta angulation $(0,15,30,45$, and 60 degrees) with constant alpha angulation (75 degrees)

46: Beta moment versus beta angulation for T-loop springs with asymmetric with asymmetric alpha and beta angulation and centered position, variation of beta angulation $(0,15,30,45$, and 60 degrees) with constant alpha angulation (75 degrees)

47: Horizontal Force versus spring activation for T-loop springs with asymmetric alpha and beta angulation and centered position, variation of beta angulation $(0,15,30,45$, and 60 degrees) with constant alpha angulation (75 degrees)

48: Horizontal Force versus beta angulation for T-loop springs with asymmetric alpha and beta angulation and centered position, variation of beta angulation $(0,15,30,45$, and 60 degrees) with constant alpha angulation (75 degrees)

49: Vertical Force versus spring activation for T-loop springs with asymmetric alpha and beta angulation and centered position, variation of beta angulation $(0,15,30,45$, and 60 degrees) with constant alpha angulation (75 degrees)

50: Vertical Force versus beta angulation for T-loop springs with asymmetric alpha and beta angulation and centered position, variation of beta angulation $(0,15,30,45$, and 60 degrees) with constant alpha angulation (75 degrees) 
51: Ratio of the alpha moment/beta moment versus spring activation

for T-loop springs with asymmetric alpha and beta angulation and centered position, variation of beta angulation

$(0,15,30,45$, and 60 degrees) with constant alpha angulation (75 degrees)

52: Ratio of the alpha moment/beta moment versus beta angulation for T-loop springs with asymmetric alpha and beta angulation and centered position, variation of beta angulation $(0,15,30,45$, and 60 degrees) with constant alpha angulation (75 degrees)

53: Alpha moment-to-force ratio versus spring activation for T-loop springs with asymmetric alpha and beta angulation and centered position, variation of alpha angulation $(0,15,30,45$, and 60 degrees $)$ with constant alpha angulation (75 degrees)

54: Beta moment-to-force ratio versus spring activation for T-loop springs with asymmetric alpha and beta angulation and centered position, variation of beta angulation $(0,15,30,45$, and 60 degrees) with constant alpha angulation ( 75 degrees) 


\section{INTRODUCTION}

Closure of extraction spaces is an integral stage of many orthodontic treatment plans. In goal oriented orthodontics the closure of these spaces requires an understanding of the mechanical system utilized. Space closure can be classified by the amount of anchorage loss (or mesial movement of the posterior segments) into retraction, attraction, and protraction cases based on the treatment plan goals. Retraction cases are those cases in which maintenance of the anchorage is critical, little or no mesial movement is allowable. Attraction cases utilize symmetric space closure where the space is equally closed by movement of the anterior teeth distally and mesial movement of the posterior teeth. Protraction is where the significant proportion of the space is closed through mesial movement of the posterior teeth. In each of these three cases different mechanical systems are required to attain the treatment goals.

Knowledge of the mechanics required to achieve specific treatment goals is necessary for efficient correction of the malocclusion. Selecting the appropriate force system provides the orthodontist with better control of the tooth movement. Three important variables which are under the control of the orthodontist are the moment-toforce ratio, the magnitude of the force and/or moment, and the force constancy. The moment-to-force ratio determines the center of rotation of a tooth or segment of teeth, thus allowing translation, tipping or root movement. An optimal force magnitude can be found which will rapidly move the teeth while minimizing patient pain or discomfort and having little or no tissue damage. Force constancy refers to the maintenance of the desired force level throughout the orthodontic tooth movement (Burstone, 1966). Consideration of each of these variables allows the clinician to specifically adjust the orthodontic appliance to obtain the desired tooth movement.

The history of orthodontics reveals a number of techniques have been developed to move teeth. Many of these methods were developed without an adequate 
understanding of the force systems produced by the appliance designs. The mechanics involved in controlled space closure are complex and subject to the influences of a number of variables, many of which have not been carefully examined, especially in experimental or analytical studies. There have been many appliances designed for space closure but few have been thoroughly studied so that the orthodontist can completely control the mechanics to obtain the precise tooth movement.

Space closing mechanics can be broadly divided into two categories, systems in which friction may be a factor and frictionless systems. Space closing techniques utilizing sliding movement of the orthodontic bracket(s) along the archwire must contend with the problem of friction at the bracket/wire interface. Friction prevents the orthodontist from having full knowledge of the forces acting on the teeth and, therefore, the operator loses a degree of control of the tooth movement. Alternatively, a frictionless system does not depend on sliding the bracket along the archwire. Rather, a spring is designed to generate the forces and moments needed to close the space.

The force systems from orthodontic appliances may produce forces and moments in each of the three planes of space. Viewing a dental arch from the side or buccally, an orthodontic spring may be produce a horizontal force compelling the teeth in a mesiodistal direction toward one another and a vertical force extruding or intruding a tooth or teeth. Also, moments may be produced, the moment acting on the anterior segment is termed an alpha moment and the moment acting on the posterior teeth the beta moment.

One of the more common space closure appliances is the "T-loop", it has been used in both continuous archwire mechanics and in segmental arch mechanics. When the "T-loop" is utilized as a space closing spring in segmented arch orthodontics, the force systems generated by its design can be accurately studied in a laboratory setting It is the objective of this research to experimentally evaluate two methods of varying the moments and forces generated to the anterior and posterior segments to obtain differential 
tooth movement in a laboratory setting and to provided specific clinical assessments permitting the orthodontist to adjust the appliance to meet their treatment goals. Specifically, the present study will experimentally compare the effects of varying the angulation of the arms of the "T-loop" and varying the position of the spring between the segments. It is hypothesized that the alpha and beta moments can be differentially controlled by either of these methods. 


\section{LITERATURE REVIEW}

\section{Mechanics of Tooth Movement}

The orthodontic movement of teeth is accomplished by the application of forces on the teeth, generally through the use of brackets, wires, springs and elastics. The type of tooth movement which occurs is dependent upon the force system utilized. The movement can be translational (bodily), rotational, or a combination of each, as determined by the applied force system. Translation is pure bodily movement in the direction of the line of action of a force applied at the center of resistance. The center of resistance is analogous to a center of gravity or a center of mass, a force applied at the center of resitance will produce no rotation. The center of resistance for a given tooth is dependent of the root length, root surface area, and alveolar bone height. Any force which does not pass through the center of resistance will produce some rotation due to the moment of the force. The magnitude of this moment is equal to the force multiplied by the perpendicular distance of line of action of that force to the center of resistance. Purely rotational movement can only be accomplished by a couple, which is two forces of equal magnitude with parallel noncolinear lines of action and opposite directions. The orthodontist is able to control the type of tooth movement by proper application of the forces and moments produced by the orthodontic appliance (Smith and Burstone, 1984).

The concept of static equilibrium is also important. Static equilibrium relates to Newton's first law of motion, "Everybody continues in its state of rest, or of uniform motion in a straight line, unless it is compelled to change by the state of forces impressed on it". For any body in equilibrium the sum of the forces and moments acting upon it is zero. Knowledge of the magnitudes and directions of the forces and moments produced by the wire in equilibrium aids the orthodontist in predicting the tooth movement.

Prediction of orthodontic tooth movement may be accomplished if one keeps the above mechanical principles in mind. For a particular malocclusion, the orthodontist may 
accurately predict and treat the problem by following these steps: 1) problem identification, 2) establish the required direction and center of rotation of the tooth movement, 3) determine the necessary force system to achieve the required direction and center of rotation, 4) evaluate the equilibrium state of the appliance, 5) appliance selection (material and shape), and 6) appliance activation. This systematic approach to correction of a malocclusion permits individualized, goal-oriented treatments.

\section{Moment-to-Force Ratios and Centers of Rotation}

Description of tooth movement is often based on the concept of the center of rotation. Pure translatory movements are considered to have a center of rotation an infinite distance away from the center of resistance and pure rotational movements occur when the center of rotation is at the center of resistance. All other tooth movements result from a center of rotation somewhere in between these two points.

Determination of the center of rotation for various force systems have been studied theoretically and experimentally. Burstone and Pryputniewicz (1980) used laser holography to determine the required force systems placed on a maxillary central incisor to produce different centers of rotation in an in vitro model. Their study used a 10:1 model of a maxillary central incisor loaded with a labiolingual force of $200 \mathrm{~g}$. They found that center of resistance of the tooth was about one third of the distance of the alveolar crest to the apex. The experimentally determined moment-to-force ratio for translation was 9.9:1, for tipping about the apex, 7.1:1, and for tipping about the incisal edge, 11.4:1. These values were in agreement with their theoretically predicted values.

Tanne, Koenig, and Burstone (1988) investigated the relationship between moment-to-force ratios and centers of rotation by use of the finite element method. A three-dimensional model of a maxillary right central incisor was modeled. The center of resistance and centers of rotation for various moment-to-force ratios applied at the center of the crown were found. They found that a $\mathrm{M} / \mathrm{F}$ ratio of $6.52: 1$ for tipping about the 
apex, 8.39:1 for translation, and 9.53:1 for root movement. It was determined that even small changes in the $\mathrm{M} / \mathrm{F}$ ratio could produce large changes in the center of rotation.

Kusy and Tulloch (1986) analyzed moment-to-force ratios at the bracket and at the center of resistance in relation to the tooth movement produced. They concluded that the only accurate method for determining the tooth movement was by evaluation of the moment-to-force ratio at the center of resistance. At the center of resistance all the moments applied to the tooth by the force system are included.

The studies examining the relationship of the moment-to-force ratio indicate that it is very important for the orthodontist to be aware of this variable during treatment. Small errors in the moment-to-force ratio may lead to tooth movements which are not desirable for a given clinical case. Also, incorrect assumptions regarding the moment to force ratio may lead to the use of improper mechanical systems. Clearly, it is advantageous for the orthodontist to have the ability to adequately control this aspect of a force system.

\section{Optimum Orthodontic Forces}

The magnitude of the applied orthodontic force is important for efficient tooth movement. Various hypotheses have been developed relating force magnitude to the rate of tooth movement. Hixon, et al (1970) studied the rate of bodily tooth movement as a function of the applied force. The subjects were all children requiring extraction of four first premolars and distal retraction of the canines. Rigid segments were placed (.045" stainless steel) in an attempt to prevent tipping movement of the canines. They found that even with rigid wires flexion still occurred resulting in tipping movement in some cases. Great variation in the root surface area, time of beginning tooth movement, and rates of tooth movement were observed. The magnitude of these differences were greater than the differences in the magnitude of force that can be controlled by the orthodontist. 
They felt that their results did not support a differential force theory (posterior segments will move less because of increased root surface area compared to a canine tooth).

Boester and Johnston (1974) reported on a clinical investigation of the concepts of differential and optimal force in canine retraction. The experimental design included the application of four different force levels to each quadrant of ten orthodontic patients receiving four premolar extraction therapy. The assignment of retraction force to quadrant was random within each patient. The canine retraction was performed with Ricketts' $0.016 " \mathrm{x} 0.016 "$ sectional retraction springs. The rate of tooth movement was measured intraorally on a weekly basis for ten weeks. The results of the study suggested that a low force level produced significantly less tooth movement than the three higher force levels but there was no statistical difference between the higher force levels. The data did not support the differential force concept of anchorage control, relative anchorage loss was independent of the force used.

Quinn and Yoshikawa (1985) reviewed four hypotheses representing the relationship of the applied force magnitude and the rate of tooth movement. Comparing the results of six clinical studies, they found that the data supported the hypothesis that the relationship of the rate of tooth movement and stress magnitude is linear up to a point, after that point an increase in stress causes no significant increase in the rate of tooth movement. This hypothesis implies that particular mechanical solutions can be arranged to increase the preservation of anchorage during canine retraction, including, incorporation of the second molars into the anchorage unit and maximizing stress magnitudes for the canine to coincide with maximal rates of tooth movement. The authors advocate the use of appliances with a low load-deflection rate and relatively constant moment-to-force ratios for most efficient tooth movement.

The data on optimal forces for maximizing rates of tooth movement are controversial. It appears that there may not be a given force magnitude that is most efficient in all cases, but there may be a optimal force for each patient. Recognizing this, 
it is important that the orthodontist have a variety of methods available in order to adjust the force systems for individualized treatments.

\section{Loop Design on Canine Retraction}

The closure of extraction spaces orthodontically can be accomplished with a variety of different methods. Space closure techniques involving sliding mechanics in which the orthodontic bracket is moved along a continuous archwire are widely used. The most common mechanisms include the use of either elastics or coil springs as means to obtain a driving force to close interdental spaces. These techniques have limitations, especially problems with wire/bracket friction, high load/deflection rates, and a lack of anchorage control. Alternatively, several loop systems have been developed. These systems provide the driving force through activation of the loop, this removes the effects of friction. These types of appliances may incorporate bends in the wire which increase anchorage control by providing differential moments on the anterior and posterior segments. Also, loops may be designed with a lower load/deflection rate, providing better force constancy.

Poul Gjessing (1985) designed a canine retraction spring for use in the sectional arch technique. This spring was developed on the basis of a series of theoretical considerations intended to create an optimal force system for controlled canine retraction. The spring was constructed from 0.016" x 0.022" stainless steel wire with the principle element being a double ovoid loop of $10 \mathrm{~mm}$ in height. A "sweep" bend was incorporated distally to avoid unwanted side effects on the second premolar. An antirotation moment was also added to prevent distal-in rotation of the canine.

Gjessing bench tested different canine retraction spring designs in an electronic spring tester apparatus. The finalized spring utilized many design elements incorporated to maximize efficient tooth movement with a minimum of unwanted side effects. A double ovoid loop was the predominant active element. This loop extended $10 \mathrm{~mm}$ 
apically reducing the load/deflection rate of the spring. Activation of this loop caused tipping of the shorter horizontal arm attached to the canine which increased the moment acting on this tooth. The greatest amount of wire was in the vertical direction which further maximized the reduction of the horizontal load/deflection rate. Further, a minimum of horizontal wire increased rigidity in the vertical plane. A smaller loop placed more occlusally lowered levels of activation insertion into the brackets. The mesial and distal extensions were angulated horizontally and vertically to provide differential alpha and beta moments as well as an antirotation moment.

Bench testing of this spring found an initial force of $180 \mathrm{~g}$ at an activation of $3 \mathrm{~mm}$ with a force decay of $45 \mathrm{~g} / \mathrm{mm}$. Full deactivation of this force occurred at between 3 and $4 \mathrm{~mm}$. The alpha moment-to-force ratios were reported as approximately 9:1 at initial activation $(3 \mathrm{~mm})$, rising to approximately $11: 1$ with $1.5 \mathrm{~mm}$ deactivation and greater than 16:1 at $3 \mathrm{~mm}$ deactivation. The beta moment-to-force ratios started at $4: 1$ and climbed to approximately 8:1 at $3 \mathrm{~mm}$ deactivation. Incorporation of a "sweep" bend in the distal arm resulted in decreased beta moments. It was clinically observed that the beta moment was delivering too great of a moment to the second premolar resulting in an undesirable degree of mesial root movement.

The canine retraction spring designed by Gjessing was used in a clinical study comparing maxillary canine retraction with a spring to retraction with sliding mechanics (Ziegler and Ingervall, 1989). Twenty-one subjects were included in the study, each subject had one canine retracted with the spring while the other side had retraction with sliding mechanics using 0.018 " stainless steel arch wire and elastic chains. They found that the spring provided faster retraction of the canine with less tipping compared to the sliding mechanics. However, they found that space closure with the spring may result in more rotational side effects. It was concluded that, overall, the spring system was superior to sliding mechanics due to its more rapid tooth movement with less tipping in spite of problems with rotation of the canine because correction of rotations is easier than 
canine root correction and is less taxing on the anchorage. They recommended increasing the antirotational moment to minimize this side effect.

Gjessing's canine retraction spring may be an to effective appliance for orthodontic space closure. The reported force system does, however, reveal limitations in its design. First, the horizontal force decays over a distance of $3 \mathrm{~mm}$ to values which may be too low for efficient tooth movement. This requires several re-activations of the spring to close a typical extraction space of seven millimeters. Also, the reported initial beta moment-to-force ratios (4:1 without the "sweep" bend, about 1:1 with the "sweep" bend) make effective anchorage control questionable. Further, the vertical forces and side effects due to differential alpha-beta moments are not reported and may be of clinical significance.

Haskell, Spencer, and Day (1990) introduce an auxiliary retraction spring for use in continuous arch treatment. They designed and modified an auxiliary space closure spring utilizing finite-element analysis for use in retraction, attraction, and protraction cases. They designed separate springs for the maxillary and mandibular arches. The mandibular spring included double vertical loops with helices and an additional helix in the anterior portion. The maxillary spring had a single vertical loop with a helix and it also and the additional anterior helix. Both springs were specially fabricated by Rocky Mountain Orthodontics (Denver, Colorado) from 0.017" x 0.022" heat treated Elgiloy. A special canine bracket was designed with an auxiliary tube placed gingivally for spring insertion. These appliances had three important angles incorporated for differential moment control. They reported the differential angulations for each on the basis of the type of tooth movement desired (retraction, attraction, or protraction). The results of finite-element analysis indicated an increasing moment-to-force ratio with spring deactivation from approximately 5:1 to greater than 15:1 for both springs over a deactivation range of $4 \mathrm{~mm}$ to less than $1 \mathrm{~mm}$. The reported results were for only maximum reciprocal attraction springs, The alpha and beta moments were of similar 
magnitude. The authors recognize the potential vertical forces present in their appliance design and the reported values at $4 \mathrm{~mm}$ activation for the retraction spring (126g) may be high enough to generate clinical effects. It is their postulation that the main continuous arch wire prevents the vertical side effects associated with unbalanced moments.

Haskell, et al, consider their design superior to present segmented arch techniques because it incorporates the "fail-safe" mechanism of the continuous arch while permitting the use of differential force systems for space closure. This design combines sliding mechanics with precalibrated springs. Also they consider their system to be more "userfriendly" through its use of sliding mechanics and simpler design compared to the multiple components of the segmented arch technique.

The use of the above auxiliary springs in conjunction with a continuous arch wire may be an improved method of sliding mechanics for space closure. Their design is limited by the effects of bracket/wire friction during space closure which may require large horizontal forces for efficient tooth movement. Friction may produce unwanted side effects, taxing anchorage units and possibly hindering the clinicians control of the tooth movement.

The segmented arch technique, as developed by Burstone, uses "T-loop" springs for space closure. The "T-loop" spring incorporates design considerations intended to provide optimum mechanical systems during space closure. The segmentation of the arch into anterior and posterior portions creates the equivalent of a two tooth system, allowing it to become a statically determinate system. The increased interbracket distance (between canine and first molar) enables long activations which lowers the load deflection rate. Further, the use of segments permits prefabrication of calibrated orthodontic springs (Burstone, 1962).

Experimental and theoretical analysis of space closing loops led to the design of the present "T-loop". Force systems from vertical loops were analyzed (Burstone and Koenig, 1976). The results of these studies showed that the higher the vertical loop the 
larger the moment and smaller the force from the spring. Higher vertical loops also had greater ranges of activation without permanent deformation. Increasing the horizontal dimension of the loop had the effect of decreasing the moment-to-force ratio, decreasing the forces and the moments at yield, but the moment-to-force ratio was not as greatly effected by horizontal changes compared to vertical changes.

The results of the studies on vertical loops indicated that a "T-loop" may be an improved spring design. The "T" shape of the space closing spring places additional wire apically within the loop, this raises the moment-to-force ratio while also decreasing the load deflection rate. Increasing the amount of wire in the gingival portion of the loop increases the moment-to-force ratio so that it approaches the vertical height of the loop. The moment-to-force ratio can never be greater than the vertical height of the "T-loop" unless further design modifications are incorporated.

To further optimize the design of anterior and canine retraction springs, the effects of loop centering were studied. Comparison of off-centered vertical loops was done by using a ratio of the length of the wire from the center of the loop to its distal end over the complete length of the wire. This analysis showed that asymmetric placement had a strong effect on the force system delivered by the spring. Even small off-center placements can produce significant vertical forces through altering the alpha and beta moments as well as changes in the horizontal forces. The moment was found to be greater at the end closer to the loop, for example, moving the loop mesially generates a greater alpha moment.

The angulation of the horizontal legs of the vertical loop were also studied. Angulating the horizontal legs (gable bends)produced significant changes in the force systems generated by the vertical loop. However, because even small variations in spring geometry caused significant changes in the moment-to-force ratio, one must be very cautious about making any generalizations unless the spring shape is very accurately determined (Burstone and Koenig, 1976). 
The "T-loop" spring was refined for use in the segmented arch technique (Burstone, 1982). Differential space closure is achieved through variations in the force system between the anterior and posterior segments. Specific predetermined geometries were developed for producing the desired force systems needed for the individual needs of each case. These spring geometries were designed for narrow ranges of use dependent upon both type of tooth movement and the interbracket distance. These springs were constructed from beta-titanium wire which has improved material qualities compared to conventional stainless steel wires.

Two important considerations in the design and use of " $\mathrm{T}$ " springs is the preactivation spring geometry and the loop placement (centricity) between the attachments. The angulations of the mesial and distal arms of the spring are varied to obtain the appropriate alpha and beta moments. The large interbracket distance aids in reducing the deviations from the desired force system due to errors spring shape. Spring centricity is also reported as being important, especially reciprocal attraction cases. For the spring designs presented, it is recommended that the loop be centrally placed in cases where the anterior and posterior teeth move equal amounts. If the posterior teeth are to be held, the spring is placed nearer the anterior teeth, the loop is placed posteriorly if the anterior teeth are to be maintained (Burstone, 1982).

A study of space closure with "T-loop" retraction springs in adult patients was done by Manhartsberger, Morton, and Burstone (1989). The springs were tested in the laboratory with consideration to the special of orthodontic treatment in adult patients. In adult patients with periodontal bone loss there must be changes in the force system due to changes in the crown-to-root ratios. Additionally, the springs tested in this study had curvature to the mesial and distal arms as opposed to discrete angular bends for the creation of differential alpha and beta moments. Specific recommendations for changes in the "T-loop" design include a reduction in the magnitude of the force level and an increase in the moment-to-force ratio. This can be achieved through changing the cross- 
section of the wire from $0.017^{\prime \prime} \times 0.025^{\prime \prime}$ TMA to $0.016^{\prime \prime} \times 0.022^{\prime \prime T M A}$ and/or changing the amount of activation of the spring. The moment-to-force ratio can be increased by increasing the angulation bends (Manhartsberger, Morton, and Burstone, 1989).

\section{Analytical and Experimental Studies of Space Closing Loops}

Finite element method is a useful technique for stress analysis of orthodontic appliances. This is a powerful method for determining the force systems from complex spring geometry's and results may be compared to experimental findings for verification. Yang and Baldwin (1974) examined space closing loops of two designs, a vertical loop and a double helical space closing spring used in the segmented arch technique. They compared the results of their finite element method to experimental testing of these springs. The theoretical results of the finite element analysis closely matched the experimental results. The magnitude of the moment changed considerably with each millimeter of activation of the vertical loop. The vertical loop also displayed a nearly constant moment-to-force ratio. The helical spring displayed a very slight change of the moment for each millimeter of activation. With the helical spring it is possible to have an increasing moment-to-force ratio as the spring deactivates. The findings suggested that the helical closing spring offered a desirable force system enabling space closure and root correction with the same device.

They concluded that this spring had several advantages compared to the vertical loop. In addition to producing a more efficient force system, the compactness of the spring compared to a $10 \mathrm{~mm}$ vertical loop may be more tolerable by the patient. The helical spring provided a more constant application of force. It was also easier to gauge the activation force by measuring the distance between the legs of the loop. In the vertical loop, angular rotations of the ends of the vertical arms produced large changes in the applied force. 
Sachdeva (1985) experimentally studied the force systems produced by TMA "Tloop" retraction springs in a laboratory setting. This study examined the effect of interbracket distance, loop placement, and design on the force systems produced by "Tloop" space closure springs. Specifically, retraction, attraction, and protraction springs were compared over four interbracket distances and the effects of placement on attraction (symmetric) "T-loop" springs were analyzed.

The significant conclusions drawn from Sachdeva's investigation were: 1) "Tsprings" without preactivation bends are not effective for space closure, 2) Spring design must be varied for different interbracket distances for optimal mechanics, precalibrated spring designs for four interbracket distances were presented, 3) the effects of spring placement and interbracket distance on the load deflection rate were not significant while preactivation bends do have an effect of lowering the load deflection rate, 4) off-centered placement of the spring resulted in changes in the moment magnitudes and with increasing eccentricity there was increased differential in the alpha and beta moments, 5) the principle factors governing the moment-to-force ratio of the "T-springs" were the activation moment, moment/displacement rate , the residual moment, and the load deflection rate of the appliance, 6) greater angular activation bends were necessary as the interbracket distance increased.

Faulkner, Fuchshuber, Haberstock, and Mioduchowski (1989) considered the effects of several parameters of the force system produced by "T-loop" retraction springs. They used both finite element analysis and experimental procedures in their evaluation of various spring designs. They compared the effects of spring height, activation angle, non-centered placement, and the addition of helices on the force systems of "T-loop" retraction springs. From their results, they concluded: 1) increasing spring height resulted in a smaller relative decrease in moment compared to horizontal force, resulting in increased moment-to-force ratios as loop height increased, 2) asymmetric changes in the alpha and beta activation angles did not produce significant changes in the horizontal 
force but did have a considerable effect on the alpha and beta moments creating substantial vertical forces of clinical significance, 3) non-centered placement of the loop also generates vertical forces by significantly altering the moment magnitudes, 4) the addition of helices at the top of the spring have only small effects on the force system and therefore are of no practical value.

The study by Faulkner, et al (1989) provided insights into the effects of various parameters on retraction spring force systems. However, the experimental design used prevented easy clinical application of their results. First, the specific geometry of a standard (baseline) spring were not given limiting comparability of the force system changes as a result of experimental manipulation. Second, the variation of the differential alpha and beta activation angulations was not systematic making it difficult to recognize trends related to the changing force systems. Finally, the effects of non-centered placement of the spring are not clear due to an apparent error in the presentation of the results. 


\section{RATIONALE}

Based on previous studies, it can be seen that the force systems generated by various space closure mechanisms are of interest to the orthodontist. Accurate knowledge of the force system produced by the orthodontic appliance is important in the optimal design of a space closure spring. Factors influenced by spring design under control of the orthodontist are the moment-to-force ratio, force and moment magnitude, and force constancy. Therefore, an understanding of the techniques that an orthodontist may utilize to alter these factors to obtain an ideal force system are beneficial in determining individual patient treatment/mechanics plans.

The force systems from "T-loop" springs have been previously studied, however, several parameters require further investigation. A systematic approach to the effects of spring placement on the forces produced by "T-loops" has not been done which can readily provide the clinician with data permitting an accurate prediction of the force system changes due to their position changes. An investigation of the effects of off centered placement and asymmetric geometry, on the force system would provide the orthodontist with information regarding "T-loop" mechanics and methods for reliably adjusting these parameters for individualized treatment needs.

Previous comprehensive studies of "T-loop" springs have utilized discretely positioned angled bends in the mesial and distal arms in order to alter the moment magnitude. Manhartsberger, et al (1989) used curvature to these arms for generating the moments. Advantages of this spring design change include production of a more reproducible force system, less permanent deformation, a decreased effect of small errors in geometry, and increased ease of insertion and spring re-activation. The present study incorporated this design change into the springs examined. 


\section{GENERAL OBJECTIVES}

The purpose of this study was to determine the effects of different pre-activation bends and positioning on the force systems produced by segmented "T-loop" orthodontic space closure springs. It is hypothesized that the force system can be altered by changing the angle of the preangulation bends by and by the mesiodistal position of the "T-loop". Further, it was hypothesized that the magnitude of the difference between the alpha and beta moments will increase with increasing differences in the angulations of the anterior (alpha) and posterior (beta) ends of the spring. The alpha-beta moment differential will also increase with increasing eccentricity in spring positioning.

\section{Specific Objectives}

The specific objectives of the present study were:

1) To experimentally determine the effects of altering the mesio-distal position (centricity) of symmetric "T-loops" on the force systems produced, specifically the changes in the alpha-beta moment differential.

2) To experimentally determine the effects of asymmetric angulations of the anterior and posterior arms of centered "T-loops" (orthodontic space closing springs) on the force systems produced, specifically the changes in the alpha-beta moment differential.

3) To compare the force systems produced by each of the above methods to determine which method is a more predictable procedure for orthodontic space closure. 


\section{THE RESEARCH PLAN}

\section{Materials and Methods - The Experimental Apparatus}

The experimental studies were be performed on the spring tester located in the Bioengineering laboratory of the Department of Orthodontics, School of Dental Medicine, University of Connecticut Health Center (Solonche, Burstone, and Vanderby, 1977). This device measures uniplanar forces and moments of orthodontic appliances which are statically indeterminate. Forces and moments are converted into linear and angular displacements respectively, and then transduced into electrical signals. These analog signals are then converted into digital signals which are received by a computer for analysis. Figures 1 and 2 provide schematic diagrams of the forces and moments measured by the apparatus.

To measure the force system from an orthodontic appliance, the appliance is mounted in two chucks on the spring tester. Each chuck is attached to an angular displacement transducer (TRANS-TEK, Ellington, CT) whose movable member is restrained by a torque element, therefore the angular displacement sensed by each transducer is proportional to the torque applied by the orthodontic spring. This provides measurements of the moments produced.

To measure the forces, one chuck is mounted on a cantilever beam whose vertical dispacements are proportional to the force delivered by the spring and is monitored by a LVDT displacement transducer (TRANS-TEK). The second chuck is mounted to a movable carriage (Velmex, E. Bloomfield, NY) whose motion can be controlled by a variable speed motor and monitored by another LVDT displacement transducer. This displacement transducer measures forces along the horizontal axis. The movable carriage activates the appliance permitting measurement of the forces delivered.

The data from the transducers are fed into a computer for processing. The computer program calculates the forces and moments produced by the appliance. The 
data provided includes the horizontal and vertical forces as well as the moments felt at each chuck. A calculation of the equilibrium condition is also performed which verifies the calibration of the device.

This equipment simulates a two-tooth or two-segment situation (the orthodontic springs are attached at two points). This model is equivalent to the clinical use of these "T-loops in segmented arch orthodontic techniques.

\section{Materials and Methods - Apparatus Calibration}

The spring tester was calibrated prior to the experimental tests using dead weights of known values. Horizontal and vertical forces, alpha and beta moments were applied to the apparatus attachments and the voltage output from the transducers was compared to unloaded voltages for each sensor. The difference between the loaded and unloaded readings provide values which are proportional to the applied loads. These values are multiplied by calibration constants to convert the data to units of force (grams), and moments (grams*millimeters). These calibration constants were adjusted to obtain accurate readings. The calibration tests were regulary repeated throughout the data collection period to insure accuracy.

\section{Materials and Methods - The "T-loop" Spring}

The orthodontic appliances to be tested were space closure springs of a "T-loop" design as utilized in segmented arch orthodontics. These springs are prefabricated (Ormco Corp., Glendale, CA) from .017" x .025" TMA wire. Figure 3 depicts a "T-loop" and its dimensions prior to the placement of any preactivation bends. The alpha or anterior portion of the spring is recognizable by its longer vertical arm. The beta or posterior part of the spring has the shorter vertical arm. The vertical offset between the alpha and beta arms compensates for the difference in the levels between the canine bracket and the auxillary tube of the Burstone molar bracket. 


\section{Materials and Methods - Preactivation Bending of The Springs}

Preactivation bends were placed into the "T-loop" in order to provide alpha and beta moments which are necessary to obtain differential tooth movement of the mesial and distal segments. Previous studies used preactivation geometries which have discrete angled bends in the arms of the "T-loop". Prelimary work completed in the University of Connecticut Orthodontic Bioengineering laboratory has indicated that curvilinear bending of these arms is preferrable. This geometry provides less premanent deformation. Further, the arc-form of the arms makes reactivation of the "T-loops" easier by removing the possiblity of the angled bend(s) binding in the auxillary tube of the molar bracket. The present study used the "T-loops" with these curved preactivation bends.

Preactivation bends were made on each spring with orthodontic light wire pliers. Templates were designed for each spring geometry. Gradual, smooth curvature of the $\operatorname{leg}(\mathrm{s})$ of the spring within that portion of the spring between the T-loop and the bracket and a neutral position of zero millimeters were specific considerations in the design in each template. The neutral position is defined at the position of the spring "with the activation moments placed on the spring, the neutral position is defined as the position of the helices (or the vertical arms of the spring) when the force is zero" (Burstone and Hanley, 1985). With the present spring design, the neutral position should have the vertical arms of the loop just touching one another (neutral position equal to zero). The angulation of the bends were measured as the angle between the horizontal aspect of the "T-loop" and the bent leg. The horizontal part of the loop provided a reference line which was parallel to the legs of the spring prior to any bending.

In order to obtain the proper shape of each spring, each angulation must be over bent and the spring then trial activated by hand. This was done by grasping each end of the spring with orthodontic pliers at the point where it would be attached to the apparatus and opening the spring to the full activation of six millimeters while maintaining parallelism of the alpha and beta (anterior and posterior) sring legs. Following trial 
activation, the springs were compared to the templates and the necessary adjustments were made to create the proper spring geometry. The trial activation procedure was repeated and adjustments were made until each spring matched the appropriate template. Every effort was made to minimize overworking the orthodontic wire by too frequent bending or bending angles too acutely.

\section{Materials and Methods - Spring Positioning}

The range of activation of the springs for was six millimentrs for this study. The interbracket distances were from seventeen millimeters (zero millimeters activation) to twenty-three millimeters (full activation). These distances were selected as approximations of typical interbracket distances between a permanent first molar and canine. The distance from the inner edge of the attachments to the "T-loop"'s center (whre the vertical legs touched) was measured with electronic calipers which were accurate to 0.01 millimeters.

\section{The Experiments .Part I - Symmetric Geometry. Centered Position}

For this experiment, the springs were designed with equal angulations to the alpha and beta arms. Also, these springs were centrally positioned between the anterior and posterior attachments, at zero millimeters activation the distance from the center of the "T-loop" to either attachment was 8.5 millimeters. The angulations were varied from zero to 70 degrees. Figure 4 shows the templates utilized for bending the springs. These springs of each angulation were made and three trials for each spring were done. This provided 72 separate trials (nine trials for eight different angulations). Each spring was activated six millimeters for each trial. 


\section{The Experiments. Part II - Symmetric Springs, Off-centered Positioning}

Based on data gathered from the previous experiment, a spring template was designed to deliver equal and opposite moments at full activation (six millimeters) with a moment-to-force ratio equal to six, Figure 5 provides a template of this spring. This spring had different angulations for the alpha and beta arms due to the one millimeter offset in the vertical dimensions of the "T-loop". Three springs were fit to this template. Each spring was tested three times at positions of , centered, 1, 2, 3, and 4 millimeters toward each the anterior and posterior attachments. A total of 81 individual tests were performed in this part.

\section{The Experiments .Part III - Asymmetric Geometry, Centered Positioning}

To determine the effect of unequal angulation of the bends, asymmetric springs were designed. For one set of springs the alpha angulation was kept at 75 degrees and the beta angualtion varied from $0,15,30,45$, and 60 degrees. Three springs of each geometry were fabricated for a total of fifteen springs of each geometry. The second set of springs reversed the angulations, the beta angualtion was kept at 75 degrees and the alpha angulation varied from $0,15,30,45$, and 60 degrees. A total of 15 springs were also tested in this geometry. For this experiment, a total of 90 separate trials were done. In all cases the springs were centered between the attachments in a manner similiar to the technique used in Part I. Figures 6 and 7 are templates for these springs.

\section{Data Collection}

The force systems from each spring were measured on the spring tester. Each spring was placed and tightened into proper position on the test apparatus with an initial interbracket distance of seventeen millimeters. The spring was activated by the motorized carriage to the full six millimeter activation and returned to the neutral position (seventeen millimeter interbracket distance). The carriage moved at an approximate rate 
of one millimeter per 50 seconds. Readings of the horizontal force, vertical force, alpha moment and beta moment were taken at 0.5 millimeter intervals. The data was complied by the computer and a printout of the results was obtained. The output data included each of the above listed measurements at the 0.5 millimeter intervals as well as the alpha and beta moment-to-force ratios, the force deflection rate and a sum of the moments. The sum of the moments provided an assessment of the overall accuracy of the measurements (with perfect calibration, the sum of the moments would equal zero). When the sum of the moments was excessively large (greater than 250 gram*millimeters for the majority of the data samples of a trial), the trial was redone. This measurement was also used as an indicator for deciding when to recalibrate the test equipment. 


\section{RESULTS}

\section{Part I: Symmetric Geometry, Centered Position}

Tables 1 through 8 present the overall results. These tables list the experimentally observed means and standard deviations for the alpha moment, beta moment, horizontal force, and vertical force. Also listed are the alpha moment-to-force ratio, the beta moment-to-force ratio, the force deflection rate, and the ratio of the moments (alpha moment/beta moment).

The magnitude of the alpha and beta moments were found to be dependent on the angulation of the preactivation bends as well as the amount of activation. These results are represented in Figures 8, 9, 10, and 11. By multiple linear regression analysis, activation and angulation were found to explain a significant amount of the variation on the magnitudes of each of the moments (F-ratio alpha $=6383.5$, p. $=0.000$, F-ratiobeta $=$ 7250.3, p. $=0.000$ ). The moments increased with increasing activation and angulation. These models capture over $90 \%$ of the variation in the magnitude of the alpha and beta moments $\left(\mathrm{R}^{2}=0.9\right.$ for both models $)$ The multivariable statistical analyses are summarized in Table 28 for the alpha moments and Table 29 for the beta moments.

Comparison of the parameter estimates for the alpha and beta moments indicates that the beta moment increases more for an increase in activation and it also increases more for an increase in the angulation. This is seen in the greater parameter estimates (or slopes) of the regression model (parameter estimates:, Activation alpha $=126.6$, Angulation $_{\text {alpha }}=14.7$, Activation $b e t a=187.3$, Angulation $\left.b e t a=18.8\right)$ for the beta moment than the alpha moment.

The horizontal force was found to be dependent on both the activation and the angulation $(\mathrm{F}$-ratio $=10806.3, \mathrm{p} .=0.000)$. The force increases with increasing activation. Also, the horizontal force was found to be inversely related to the angulation, the force decreased with increasing angulation (parameter estimate, activation $=66.9, \mathrm{t}=$ 
144.8, $\mathrm{p}_{.}=0.000 ;$ parameter estimate, angle $=-1.0, \mathrm{t}=-25.3, \mathrm{p} .=0.000$ ). Of the two, activation had the greater effect on the magnitude of the horizontal force. The coefficient of determination $\left(\mathrm{R}^{2}\right)$ was 1.0 for this model. Figures 12 and 13 depict these results and Table 30 summarizes the statistical analysis.

There was the greatest variation found in the vertical forces generated from springs with symmetric geometry and centered positioning. The variation as represented by the standard deviations (see Tables 1 through 8) was a large proportion of the observed means. The vertical force was dependent on both the activation and the angulation, with the activation having the greater role in determining the magnitude of the force $(\mathrm{F}$-ratio $=319.3, \mathrm{p} .=0.000$; parameter estimates, Activation $=4.8, \mathrm{t}=4.8, \mathrm{p}=$ 0.000 , Angulation $=0.2, \mathrm{t}=13.5, \mathrm{p} .=0.000$ ). The linear model based on angulation and activation captured $40 \%$ of the variation $\left(R^{2}=0.4\right)$. Figures 14 and 15 summarize the findings on the vertical force, Table 31 shows the statistical results.

The ratio of the alpha moment and the beta moment, representing the moment differential produced by the springs, was not found to be significantly related to the amount of activation nor angulation (F-ratio $=3.8, p=0.023$ ) Neither activation nor angulation were found to be significant variables in determining the ratio of the moments (parameter estimates, activation $=-0.2, \mathrm{t}=-1.9, \mathrm{p} .=0.053$, angulation $=0.0, \mathrm{t}=-1.9, \mathrm{p}$. 0.052). These results are shown in Figures 16 and 17, the statistical analysis is listed in Table 32.

The moment-to-force ratios are given in Figures 18 and 19. These figures show an increasing moment to force ratio with deactivation of the spring. The beta moment-toforce ratio is higher than the alpha activation for each angulation. The moment-to-force ratios increased with increasing angulation. 


\section{Part II. Symmetric Springs, Off-centered Positioning}

The results of position on a "T-loop" with symmetric moments are presented in Tables 9 through 17. The spring was designed to deliver equal and opposite moments with a moment-to-force ratio equal to six. The spring was positioned $1,2,3$, and 4 millimeters anteriorly and posteriorly from this centered position.

The effects of the positioning and activation on the alpha and beta moments are shown in Figures 20, 21, 22 and 23. Each of the moments increased with increasing activation. As the springs were positioned anteriorly, the alpha moments increased and the beta moments decreased, the opposite occurred with posterior positioning. The position had a greater effect on the change in the moments than activation. The linear regression model using position and activation as independent variables exhibited an $R^{2}$ $=0.9$ for each the alpha and beta moments(F-ratio $a l p h a=3377.6$, p. $=0.000 ;$ F-ratiobeta $=3501.1$, p.0.000). These results are summarized in Tables 33 and 34 .

Off center positioning had a slight effect on the horizontal force. The position of the spring was only marginally significant in determining the magnitude of the force, (parameter estimate $=0.6, t=2.1, \mathrm{p} .=0.036$ ), while the activation was a highly significant determinant (parameter estimate $=62.5, \mathrm{t}=157, \mathrm{p}=0.000$ ). The horizontal force increases linearly with increasing activation. these results are shown in Figures 24 and 25, the statistical analysis in Table 35.

The position had a significant effect on the vertical force, this was expected because the vertical force will occur with different alpha and beta moments due to equilibrium considerations. The vertical force also increased with increasing activation. the whole model explains a significant amount of the variation $(\mathrm{F}$-ratio $=5042.0, \mathrm{p} .=$ 0.000). Off-center positioning does produce vertical forces which may be of clinical significance. Tables 9 through 17 show the mean values of the vertical forces for each position and activation. Figures 26,27 , and Table 36 summarize these findings. 
The ratio of the alpha and beta moments as a function of position is shown in Figures 28 and 29. The ratio of the moments is not significantly related to the activation (parameter estimate activation $=0.0, t=0.5, \mathrm{p} .=0.000$ ), but it is dependent on the position of the spring (parameter estimate position $=0.5, \mathrm{t}=42.8, \mathrm{p} .=0.000$ ). The ratio decreased with positioning toward the posterior or beta segment, and it increased as it was positioned more anteriorly. The ratio remained nearly constant (for a given position) with changes in activation. However, the whole model was found to be significant for describing the variation in the ratio of the moments ( F-ratio $=914.2$, p. $=0.000$ ). These findings are summarized in Table 37 . Figures 30 and 31 show the moment-to-force ratios versus the activation.

\section{Part III. Asymmetric Geometry, Centered Positioning}

\section{A) Varying Alpha Angulation, Constant Beta Angulation}

Tables 18 through 22 summarized the measured force systems produced by these springs. Variation of the alpha angulation effected both the alpha moment and the beta moment. The alpha moment was more effected by the change in alpha angulation, but the beta moment was also determined in part by the alpha angulation (parameter estimates, Alpha moment, angle $=-22.0, \mathrm{t}=-87.6, \mathrm{p} .=0.000$, Beta moment $=-7.1, \mathrm{t}=-$ 25.8 , p. $=0.000$ ). As the alpha angulation was increased, the alpha moment increased. The beta moment decreased with increasing alpha angulation. The multiple linear regression model with angulation and activation as independent variables was significant for both the alpha and beta moments (F-ratio alpha $=5379.8$, p. $=0.000$, F-ratiobeta $=$ 1444.2, p. $=0.000$ ). These results are summarized in Tables 38 and 39, and Figures 32, 33,34 and 35 .

The horizontal force was significantly determined by both the activation and the alpha angulation ( $F$-ratio $=6175.9, \mathrm{p} .=0.000$ ). As with the symmetric springs and offcenter springs, the activation was the primary determinant of the magnitude of the 
horizontal force (parameter estimates, angulation $=-0.9, \mathrm{t}=-18.1, \mathrm{p} .=0.000$, activation $=$ $61.2, \mathrm{t}=109.7, \mathrm{p} .=0.000$ ). Figures 36 and 37 , as well as Table 40 , show these results.

The vertical force was inversely related to the alpha angulation, as the angulation increased, the vertical force decreased. The vertical force was in the intrusive direction on the anterior segment. As with off-centering the vertical forces were expected due to the different alpha and beta moments. These results are depicted in Figures 38, 39 and Table 41 shows the statistical results.

The ratio of the alpha and beta moments was significantly related to both the alpha angulation and the activation $(\mathrm{F}-$ ratio $=2859.5, \mathrm{p} .=0.000)$. Activation and angulation both were found to be significant variables in determining this ratio. The ratio of the alpha moment/beta moment decreased with both increasing angulation and increasing activation. See Figures 40 and Table 42 for these results. Figures 41 and 42 show the moment-to-force ratios versus the activation.

B) Constant Alpha Angulation, Varying Beta Angulation

The effect of varying the beta angulation on the force system was similar to varying the alpha angulation. The beta moment increased with increasing angulation and activation $(F$-ratio $=2180.0, p=0.000)$. With increasing beta angulation, the alpha moment decreased, but to a lesser degree than the change in the beta moment. More important in determining the magnitude of the alpha angulation was the activation. See Tables 23 to 27 for the overall results; Tables 43 and 44 for the statistical analysis; and Figures 43, 44, 45, and 46.

With the asymmetrically shaped springs it is notable that the moment for the side being varied (that is, the alpha moment for the springs with varying alpha angulation and vice versa), the direction of the moment would change direction at the lower angulations and activations. This effect was seen more strongly with the changing beta angulation. 
The horizontal force was again determined primarily by the activation and only minor role was played by the angulation. These results are given in Figures 47, 48 and Table 46.

Large vertical forces were found with these springs. The forces were in the extrusive direction on the anterior segment. These forces increased with decreasing angulation and decreased with increasing activation. See figures 49 and 50 and Table 46.

The ratio of the beta moment/alpha moment was determined by both the beta angulation and the activation (F-ratio $=1805.4, \mathrm{p} .=0.000$ ) This is similar to the effect of altering the alpha angulation on the alpha moment/beta moment ratio.. See Table 47 and Figures 51 and 52 for these results. Figures 53 and 54 show the moment-to force ratios versus the activation. 


\section{DISCUSSION}

This study demonstrates the importance of proper preactivation bends and spring positioning in designing "T-loop" springs for controlled orthodontic space closure. The force systems produced by the "T-loop" springs can be very effectly manipulated by either changes in the angulation or in the position. The differences in the alpha and beta moments is the most critical consideration because the moment magnitudes determine the moment-to-force ratios. The moment-to-force ratios are related to the type of tooth movement and anchorage control for the anterior andposterior segments. The moment differential also determines the vertical forces produced by the spring. Effect control of the moment differential will then have a great influence on the orthodontist's ability to obtain predictable tooth movement.

The ratio of the moments (alpha moment/beta moment) were determined by different variables for the off-centered springs and the asymmetric angulated springs. For the off-centered springs, the position was the only significant determinant of this ratio, while for the asymmetric springs this ratio was determined by both the angulation and the activation of the spring.

The amount of spring activation did not significantly influence the ratio of the moments in the off-centerd springs. For these springs, the activation played about equal roles for the alpha and beta moments, the position was the variable which played the primary role in predicting the moment differential. Alternatively, the moments produced by the asymmetric springs were influenced by the both activation and the angulation. Further, the activation had a different effect on the alpha moment than on the beta moment. The side of the spring with the constant angle was less effected by the angular variations, while the angle had a greater impact on the varied side. Because the activation effected the alpha and beta moments unequally in the asymmetric springs, it was important in determining the ratio of these moments. 
This has important clinical applications, controlling the ratio of the moments permits predictable space closure. Maintiaining a more constant ratio of the moments over the range of activation of the spring allows consistent control of the differential space closure. This is the situation with the off-centered springs, the alpha-beta moment differential is independent of the activation. For the springs with asymmetric angulation, the ratio of the moments is both angulation and activation dependent. To obtain a consistent ratio, one only has to monitior the position for the off-centered springs, but for the asymmetric springs one must consider both the angulation and the activation.

While closing extraction spaces, anchorage control is obtained by producing proper force systems. Application of unequal moments to the anterior and posterior segments can augment the anchorage unit. Consistent production of a moment differential is advantagous for space closure. Utilizing a spring designed to produce equal and opposite moments at the centered position and placing it eccentrically may be a more effective means of anchrage control than creating springs of asymmetric shapes (angulations). This study shows that the ratio of the moments is maintainted throughout the range of activation with off centered positioning. A postion two millimeters from the center (toward the anchorage unit) would be sufficient for reinforcing the anchorage of that segment. Whe the T-loop was placed two millimeters toward the anterior segment, the alpha moment/beta moment ratio is approximately two. Doubling the alpha moment relative to the beta moment would strengthen the anterior anchorage. A similiar result is seen when the spring is positioned two millimeters toward the posterior, the beta moment becomes twice the alpha moment.

The asymmetric angulation of the preactivation bends of T-loop springs may permit these springs to be used as root correction appliances. Efficient root movement is best achieved with the application of a moment-to-force ratio of 12 to 15/1. These moment-to-force ratios are acheived with several of the spring shapes tested. Using the T-loop with small activations (one to three millimeters) has lower horizontal force 
magnitudes enabling the clincian to control any residual space closure while also minimzing second order rotational side effects .

The direction of the moment on the less angled side will reverse if the angle is small enough in comparison to the other side. This is particularly noticable at the lower activations. This would produce undesirable tooth movements in conventional space closure. Aside from loss of control of the root movement, the production of very high vertical forces may result in extreme side effects.

Examination of the symmetrically angulated, centered springs, reveals that the low angulations do not general produce moments of a magnitude which would be consistent with contolled tipping $(M / F=7$ to 8$)$ or translation $(M / F=10)$ except at low activationlevels. In order to obtain more optimal moment-to-force ratios, the angulation bends need to be quite high.

The horizontal forces are primarily deteremined by the activation, with angulation and/or position only exhibiting a minor influence. The force levels can reasonable be predicted solely from the activation. The force/deflection rate was approximately $60 \mathrm{~g} / \mathrm{mm}$ for the range of activations, but the force/deflection rate was partially dependent on the angulation or position. The angulation had only a small effect, as the angulation increased, the horizontal forces decreased.

Sachdeva (1985) examined the force systems produced by T-loop springs and specific designs were recommended. Control of the anchorage units was established by the placement of specific preactivation bend angulation. Off-center positioning was found to be a factor in generating unequal moments and it was suggested that eccentric placement of theT-loop for "convenience" sake could lead to unwanted side effects, especially unwanted vertical forces.

Sachdeva found two factors which determined the magnitude of the moments produced by the T-springs, the residual moment and the activation moment. The residual momnet was the moment produced by the preangulation bends, it produces a moment 
even in the neutral position. The activation moment is the moment produced by the activation of the spring, the moment increases with activation. This finding is similiar to the present study, where the ratio of the moments was dependent on both the activation and the angulation of the bends.

While Sachdeva's study recommended the use of specific templates designed for the control of the anchorage needed, this study found off centering was a more suitable method of achieving anchorage control. Off-centering maintained a more constant alpha/beta moment ratio than variation of the angles. The use of a single spring template and variation of th position also simplifies the clinical use of the springs.

Faulkner found that both changes in angulation and position were effective methods of obtaining differential moments. The vertical forces produced by the changes in either the position or the angulation could be clinically significant. The horizontal forces were not significantly affected by the changes in the spriing position or activation. This is in agreement with the present study, changes in position or angulation do produce changes in the vertical forces while the horizontal force is primarily dependent on the activation. However, the present study did find that the horizontal force was altered by the positional or shape changes. 


\section{CONCLUSIONS}

1) The force system produced by T-loop springs can be varyied by altering either the preactivation bends or by changing the position of the spring (centering) in relation to the attachments.

2) The alpha/beta moment differential is dependent on different parameters for the offcenter springs and the asymetrically angled springs. The alpha/beta moment ratio is determined primarily by the position in the off centered springs and the activation is not a significant parameter. In the asymetrically angled springs, the ratio of the moments is dependent on both the angulation of the bends and also on the activation of the spring.

3) The horizontal force is primarily determined by the activation, increasing the angle decreases the force, the force increases linearly with activation, decreases with increasing angulation.

3) The vertical force is primarily a result of the differential moments and reaches magnitudes of clinical significance with either method of generating unequal moments.

4) Large angulations are needed to obtain moment-to-force ratios (force systems) which are most desirable for efficient tooth movement.

5) Based on this study, off-centering may be a more suitable method for producing the differential moments desirable for anchorage control in orhtodontic space closure. 


\section{FUTURE STUDIES}

Futher investigaion in T-loop mechanics shoud focus on the effects of interbracket distance on the force systems produced. Specifically, examination of the alpha-beta moment differential in springs used with small interbracket distances should be evaluated. This would benefit the clinician in control of anchorage during the final stages of space closure.

A second area of future studies should consider the effect of shortened T-loop heights. The use of short T-loops in space closure is beneficial in patients with shallow vestibules. Shortening the T-loop alters the spring geometry significantly and an examination of the force systems produced by these springs would enhance their application in patient care.

A three dimensional evaluation of the T-loop force system is needed to determine the second order rotational side effects produced. The magnitude of these side effects can be significant and their measurement may aid in developing effective means of antirotational control.

Finally, a controlled clinical study is needed to determine the efficacy of these space closure springs. While the force systems produced can be readily measured in the laboratory, their clinical effects are less well understood. A carefully designed prospective clinical trial with precalibrated springs would be useful. 


\section{REEERENCES}

Boester, C. H. and Johnston, L. E., A clinical investigation of the concepts of differential and optimal force in canine retraction. Angle Orthodontist 44; 113-119: 1974.

Burstone, C. J., Rationale of the segmented arch. American Journal of Orthodontics 48(11); 805-822: 1962.

Burstone, C. J., The mechanics of the segmented arch techniques. Angle Orthodontist 36(2); 99-120: 1966.

Burstone, C. J., The segmented arch approach to space closure. American Journal of Orthodontics 82(5); 361-378: 1982.

Burstone, C. J. and Hanley, K. J., Modern Edgewise Mechanics Segmented Arch Technique. University of Connecticut Health Center, 1985.

Burstone C. J. and Koenig, H. A., Optimizing anterior and canine retraction. American Journal of Orthodontics 70(1); 1-19: 1976.

Burstone, C. J. and Pryputniewicz, Holographic determination of centers of rotation produced by orthodontic forces. American Journal of Orthodontics 77(4); 396-409: 1980.

Chaconas, S. J., Caupto, A. A., and Hayashi, R. K., Effects of wire size, loop configuration and gabling on canine retraction springs. American Journal of Orthodontics 65(1); 58-66: 1974.

Chaconas, S. J., Caupto, A. A., and Miyashita, K., Force distribution comparisons of various retraction archwires. Angle Orthodontist 59(1) 25-30.

Faulker, M. G., Fuchshuber, P., Haberstock, D., and Mioduchowski, A., A paramentric study of the force/moment systems produced by T-loop retraction springs. Journal of Biomechanics 22(6/7); 637-647: 1989.

Gjessing, P., Biomechanical design and clinical evaluation of a new canine retraction spring. American Journal of Orthodontics 87(5); 353-362: 1985.

Haskell, B. S., Spencer, W. A., and Day, M., Auxillary springs in continuous arch treatment: Part 1. An analytical study employing the finite element method. American Journal of Orthodontics 98(5); 387-397: 1990.

Haskell, B. S., Spencer, W. A., and Day, M., Auxillary springs in continuous arch treatment: Part 2. Appliance use and case reports. American Journal of Orthodontics 98(6); 488-498: 1990.

Hixon, E. H., Aasen, T. O., Arango, J., Clark, R. A., Kloisterman, R., Miller, S. S., and Odom, W. M., On force and tooth movement. American Journal of Orthodontics 57(5); 476-488: 1970.

Kusy, R. P. and Tulloch, J. F., Analysis of moment/force ratios in the mechanics of tooth movement. American Journal of Orthodontics 90; 127-131: 1986. 
Manhartsberger, C., Morton, J. Y., and Burstone, C. J., Space closure in adult patients using the segmented arch technique. Angle Orthodontist 59(3); 205-210: 1989.

Marcotte, M. R., Prediction of orthodontic tooth movement. American Journal of Orthodontics 69(5); 511-523: 1976.

Nikolai, R. J., On optimum orthodontic force theory as applied to canine retraction. American Journal of Orthodontics 68(3); 290-302: 1975.

Quinn, R. S. and Yoshikawa, D. K., A reassessment of force magnitude in orthodontics. American Journal of Orthodontics 88(3); 252-260: 1985.

Sachdeva, R. C., A study of force systems produced by TMA 'T' loop retraction springs. Masters Thesis, The University of Connecticut School of Dental Medicine, 1985.

Smith, R. J., and Burstone, C. J., Mechanics of tooth movement. American Journal of Orthodontics 85(4); 294-307: 1984.

Solonche, D. J., Burstone, C. J., and Vanderby, R., A device for determining the mechanical behavior of orthodontic appliances. IEEE Transactions on Biomedical Engineering Vol BME 24(6); 538-539: 1977.

Tanne, K., Koenig, H. A., and Burstone, C. J., Moment to Force ratios and the center of rotation.

American Journal of Orthodontics 94; 426-431: 1988.

Yang, T. Y., and Baldwin, J. J., Analysis of space closing springs in orthodontics. Journal of Biomechanics 7; 210-228.

Zeigler, P. and Ingervall, B., A clinical study of maxillary canine retraction with a retraction spring and sliding mechanics. American Journal of Orthodontics 95(2); 99106: 1989 . 
TABLE 1: SUMMARY OF MEASURED FORCE SYSTEM

SPRING GEOMETRY: SYMMETRIC ANGULATION

SPRING POSITION: CENTERED

PREACTIVATION ANGULATION: 0 degrees

\begin{tabular}{c|cccccccc} 
& \multicolumn{2}{|c}{ ALPHA } & \multicolumn{2}{c}{ BETA } & \multicolumn{2}{c}{ HORIZONTAL } & \multicolumn{2}{c}{ VERTICAL } \\
$\begin{array}{c}\text { ACTIVATION } \\
(\mathrm{mm})\end{array}$ & MOMENT $(\mathrm{g} * \mathrm{~mm})$ & MOMENT & $(\mathrm{g} * \mathrm{~mm})$ & \multicolumn{2}{c}{ FORCE (g) } & \multicolumn{2}{c}{ FORCE (g) } \\
\hline MEAN & S.D. & MEAN & S.D. & MEAN & S.D & MEAN & S.D. \\
\hline 0 & 43.6 & 29.5 & -281.9 & 86.1 & -18.6 & 12.6 & -18.4 & 9.3 \\
0.5 & 149.1 & 27.1 & -97.3 & 71.8 & 35.6 & 12.7 & -11.3 & 5.9 \\
1 & 261.8 & 27.3 & 48.6 & 68.4 & 79.2 & 13.3 & -8.9 & 5.9 \\
1.5 & 365.1 & 22.0 & 183.7 & 73.3 & 128.9 & 19.6 & -6.9 & 5.9 \\
2 & 462.3 & 34.9 & 312.2 & 68.8 & 169.4 & 17.7 & -0.2 & 8.3 \\
2.5 & 566.9 & 44.0 & 431.2 & 69.2 & 214.7 & 20.4 & -1.0 & 6.4 \\
3 & 634.1 & 44.8 & 541.4 & 69.9 & 257.6 & 24.1 & 4.8 & 4.6 \\
3.5 & 687.8 & 45.7 & 627.3 & 72.6 & 298.0 & 25.3 & 4.2 & 8.3 \\
4 & 749.6 & 40.9 & 721.0 & 72.6 & 340.2 & 26.8 & 7.0 & 7.7 \\
4.5 & 811.3 & 40.7 & 811.9 & 69.5 & 378.9 & 30.5 & 8.7 & 6.5 \\
5 & 860.9 & 47.1 & 883.7 & 75.9 & 421.4 & 33.5 & 11.0 & 8.5 \\
5.5 & 883.2 & 41.8 & 952.3 & 77.2 & 466.2 & 35.4 & 12.4 & 10.2 \\
6 & 914.3 & 42.8 & 1020.9 & 73.3 & 503.6 & 39.8 & 16.6 & 8.8
\end{tabular}

\begin{tabular}{c|ccc}
$\begin{array}{c}\text { ACTIVATION } \\
(\mathbf{m m})\end{array}$ & $\begin{array}{c}\text { M/F } \\
\text { ALPHA }\end{array}$ & $\begin{array}{c}\text { M/F } \\
\text { BETA }\end{array}$ & $\begin{array}{c}\text { RATIO } \\
\text { ALPHA/BETA }\end{array}$ \\
\hline 0 & -2.3 & 15.2 & 0.15 \\
0.5 & 4.2 & -2.7 & -4.62 \\
1 & 3.3 & 0.6 & -5.16 \\
1.5 & 2.8 & 1.4 & -2.62 \\
2 & 2.7 & 1.8 & -1.56 \\
2.5 & 2.6 & 2.0 & -1.35 \\
3 & 2.5 & 2.1 & -1.19 \\
3.5 & 2.3 & 2.1 & -1.11 \\
4 & 2.2 & 2.1 & -1.05 \\
4.5 & 2.1 & 2.1 & -1.01 \\
5 & 2.0 & 2.1 & -0.98 \\
5.5 & 1.9 & 2.0 & -0.93 \\
6 & 1.8 & 2.0 & -0.90
\end{tabular}


TABLE 2: SUMMARY OF MEASURED FORCE SYSTEM

SPRING GEOMETRY: SYMMETRIC ANGULATION

SPRING POSITION: CENTERED

PREACTIVATION ANGULATION: 10 degrees

\begin{tabular}{|c|c|c|c|c|c|c|c|c|}
\hline \multirow{2}{*}{$\begin{array}{l}\text { ACTIVATION } \\
\text { (mm) }\end{array}$} & \multicolumn{2}{|c|}{$\begin{array}{c}\text { ALPHA } \\
\text { MOMENT }\left(\mathrm{g}^{*} \mathrm{~mm}\right)\end{array}$} & \multicolumn{2}{|c|}{$\begin{array}{c}\text { BETA } \\
\text { MOMENT }\left(\mathrm{g}^{*} \mathrm{~mm}\right)\end{array}$} & \multicolumn{2}{|c|}{$\begin{array}{c}\text { HORIZONTAL } \\
\text { FORCE (g) }\end{array}$} & \multicolumn{2}{|c|}{$\begin{array}{l}\text { VERTICAL } \\
\text { FORCE (g) }\end{array}$} \\
\hline & MEAN & S.D. & MEAN & S.D. & $M E A N$ & $S . D$ & $M E A N$ & S.D. \\
\hline 0 & 326.7 & 52.9 & -86.1 & 78.6 & -2.9 & 6.8 & -25.6 & $\overline{13.7}$ \\
\hline 0.5 & 433.2 & 53.4 & 92.3 & 72.8 & 45.7 & 7.2 & -21.2 & 11.7 \\
\hline 1 & 536.0 & 55.4 & 251.2 & 73.8 & 90.4 & 7.3 & -14.6 & 9.9 \\
\hline 1.5 & 615.4 & 61.7 & 389.3 & 64.1 & 134.8 & 9.6 & -11.1 & 9.9 \\
\hline 2 & 708.4 & 65.7 & 535.4 & 69.3 & 175.9 & 10.6 & -5.1 & 9.3 \\
\hline 2.5 & 788.4 & 60.7 & 655.3 & 62.1 & 213.9 & 8.9 & -2.1 & 9.0 \\
\hline 3 & 854.0 & 61.7 & 765.4 & 67.8 & 251.2 & 14.2 & 2.0 & 6.0 \\
\hline 3.5 & 920.1 & 64.0 & 878.1 & 61.0 & 289.8 & 14.0 & 5.1 & 8.5 \\
\hline 4 & 968.3 & 65.5 & 960.2 & 69.8 & 328.6 & 16.6 & 7.0 & 7.6 \\
\hline 4.5 & 1025.3 & 65.6 & 1051.9 & 75.8 & 364.9 & 17.0 & 10.0 & 7.4 \\
\hline 5 & 1058.4 & 65.4 & 1140.4 & 74.8 & 403.2 & 20.0 & 12.2 & 9.2 \\
\hline 5.5 & 1093.3 & 69.1 & 1227.7 & 75.3 & 441.3 & 20.1 & 16.1 & 8.4 \\
\hline 6 & 1137.3 & 69.6 & 1308.0 & 83.7 & 478.8 & 23.4 & 18.9 & 9.8 \\
\hline
\end{tabular}

\begin{tabular}{c|ccc}
$\begin{array}{c}\text { ACTIVATION } \\
\text { (mm) }\end{array}$ & $\begin{array}{c}\text { M/F } \\
\text { ALPHA }\end{array}$ & $\begin{array}{c}\text { M/F } \\
\text { BETA }\end{array}$ & $\begin{array}{c}\text { RATIO } \\
\text { ALPHA/BETA }\end{array}$ \\
\hline 0 & -113.1 & 29.8 & 3.41 \\
0.5 & 9.5 & 2.0 & -24.13 \\
1 & 5.9 & 2.8 & -2.31 \\
1.5 & 4.6 & 2.9 & -1.62 \\
2 & 4.0 & 3.0 & -1.34 \\
2.5 & 3.7 & 3.1 & -1.21 \\
3 & 3.4 & 3.0 & -1.12 \\
3.5 & 3.2 & 3.0 & -1.05 \\
4 & 2.9 & 2.9 & -1.01 \\
4.5 & 2.8 & 2.9 & -0.98 \\
5 & 2.6 & 2.8 & -0.93 \\
5.5 & 2.5 & 2.8 & -0.89 \\
6 & 2.4 & 2.7 & -0.87
\end{tabular}




\section{TABLE 3: SUMMARY OF MEASURED FORCE SYSTEM}

SPRING GEOMETRY: SYMMETRIC ANGULATION

SPRING POSITION: CENTERED

PREACTIVATION ANGULATION: 20 degrees

\begin{tabular}{c|cccccccc}
\multirow{2}{*}{$\begin{array}{c}\text { ACTIVATION } \\
(\mathrm{mm})\end{array}$} & \multicolumn{2}{|c}{ ALPHA } & \multicolumn{2}{c}{ BETA } & \multicolumn{2}{c}{ HORIZONTAL } & \multicolumn{2}{c}{ VERTICAL } \\
MOMENT & MEAN & ( & S.D. & \multicolumn{2}{c}{ MOMENT } & MEAN & (gmm) & \multicolumn{2}{c}{ FORCE (g) } & MEAN & S.D & MEAN & S.D. \\
\hline 0 & 369.7 & 54.5 & 378.4 & 37.4 & 8.8 & 5.8 & 5.0 & 2.6 \\
0.5 & 540.9 & 65.3 & 664.6 & 52.0 & 82.8 & 17.2 & 14.7 & 3.2 \\
1 & 615.7 & 61.7 & 780.9 & 54.5 & 120.8 & 13.2 & 19.2 & 3.3 \\
1.5 & 684.9 & 65.3 & 898.9 & 55.5 & 154.8 & 11.8 & 22.7 & 3.3 \\
2 & 746.1 & 65.3 & 995.8 & 57.9 & 188.7 & 12.5 & 25.6 & 3.8 \\
2.5 & 797.7 & 66.7 & 1092.3 & 59.6 & 224.8 & 26.5 & 29.2 & 4.2 \\
3 & 847.0 & 64.7 & 1184.3 & 51.9 & 251.2 & 13.4 & 32.7 & 4.5 \\
3.5 & 887.2 & 70.0 & 1267.9 & 63.2 & 284.6 & 16.6 & 35.4 & 4.0 \\
4 & 935.4 & 68.2 & 1352.2 & 61.3 & 316.4 & 12.7 & 37.7 & 4.5 \\
4.5 & 968.9 & 70.0 & 1424.8 & 62.2 & 347.9 & 14.8 & 40.2 & 5.0 \\
5 & 989.1 & 72.3 & 1492.0 & 59.5 & 379.3 & 16.1 & 42.4 & 5.1 \\
5.5 & 1008.0 & 78.1 & 1556.9 & 73.7 & 412.4 & 15.1 & 44.9 & 5.2 \\
6 & 1029.3 & 81.9 & 1628.4 & 72.6 & 443.0 & 17.5 & 47.6 & 5.5
\end{tabular}

\begin{tabular}{c|ccc}
$\begin{array}{c}\text { ACTIVATION } \\
(\mathrm{mm})\end{array}$ & $\begin{array}{c}\text { M/F } \\
\text { ALPHA }\end{array}$ & $\begin{array}{c}\text { M/F } \\
\text { BETA }\end{array}$ & $\begin{array}{c}\text { RATIO } \\
\text { ALPHA/BETA }\end{array}$ \\
\hline 0 & 42.1 & 43.1 & -0.98 \\
0.5 & 6.5 & 8.0 & -0.82 \\
1 & 5.1 & 6.5 & -0.79 \\
1.5 & 4.4 & 5.8 & -0.76 \\
2 & 4.0 & 5.3 & -0.75 \\
2.5 & 3.5 & 4.9 & -0.73 \\
3 & 3.4 & 4.7 & -0.72 \\
3.5 & 3.1 & 4.5 & -0.70 \\
4 & 3.0 & 4.3 & -0.69 \\
4.5 & 2.8 & 4.1 & -0.68 \\
5 & 2.6 & 3.9 & -0.66 \\
5.5 & 2.4 & 3.8 & -0.65 \\
6 & 2.3 & 3.7 & -0.63
\end{tabular}


TABLE 4: SUMMARY OF MEASURED FORCE SYSTEM

SPRING GEOMETRY: SYMMETRIC ANGULATION

SPRING POSITION: CENTERED

PREACTIVATION ANGULATION: 30 degrees

\begin{tabular}{c|cccccccc}
\multirow{2}{*}{$\begin{array}{c}\text { ACTIVATION } \\
(\mathrm{mm})\end{array}$} & \multicolumn{2}{|c}{ ALPHA } & \multicolumn{2}{c}{ BETA } & \multicolumn{2}{c}{ HORIZONTAL } & \multicolumn{2}{c}{ VERTICAL } \\
MOMENT & $(\mathrm{g} * \mathrm{~mm})$ & MOMENT & $(\mathrm{g} * \mathrm{~mm})$ & \multicolumn{2}{c}{ FORCE $(\mathrm{g})$} & \multicolumn{2}{c}{ FORCE (g) } \\
\hline 0 & MEAN & S.D. & MEAN & S.D. & MEAN & S.D & MEAN & S.D. \\
\hline 0.5 & 453.2 & 202.8 & 664.2 & 121.8 & 4.3 & 6.3 & 15.1 & 19.7 \\
1 & 671.2 & 200.7 & 914.9 & 96.7 & 80.8 & 12.2 & 20.7 & 15.5 \\
1.5 & 761.7 & 190.6 & 1007.7 & 89.9 & 110.1 & 12.6 & 22.2 & 14.4 \\
2 & 847.3 & 184.1 & 1107.1 & 84.6 & 139.0 & 15.0 & 23.7 & 14.4 \\
2.5 & 922.6 & 190.1 & 1190.3 & 77.6 & 167.2 & 12.6 & 24.9 & 12.2 \\
3 & 1005.4 & 184.2 & 1265.2 & 74.7 & 195.7 & 14.8 & 25.9 & 11.4 \\
3.5 & 1064.1 & 169.9 & 1339.2 & 70.2 & 223.9 & 13.7 & 27.6 & 10.1 \\
4 & 1124.1 & 166.7 & 1423.7 & 68.8 & 254.1 & 16.4 & 29.0 & 9.5 \\
4.5 & 1173.6 & 174.2 & 1485.8 & 61.6 & 283.4 & 17.6 & 30.3 & 8.6 \\
5 & 1234.3 & 170.7 & 1551.0 & 56.0 & 312.0 & 18.6 & 31.7 & 8.5 \\
5.5 & 1278.0 & 175.7 & 1610.6 & 61.5 & 339.1 & 18.4 & 32.8 & 7.7 \\
6 & 1320.2 & 165.6 & 1674.0 & 57.5 & 370.0 & 20.9 & 34.3 & 7.6 \\
& 1347.6 & 166.8 & 1725.8 & 55.0 & 399.0 & 21.8 & 35.4 & 7.3
\end{tabular}

\begin{tabular}{c|ccc}
$\begin{array}{c}\text { ACTIVATION } \\
(\mathrm{mm})\end{array}$ & $\begin{array}{c}\text { M/F } \\
\text { ALPHA }\end{array}$ & $\begin{array}{c}\text { M/F } \\
\text { BETA }\end{array}$ & $\begin{array}{c}\text { RATIO } \\
\text { ALPHA/BETA }\end{array}$ \\
\hline 0 & 104.6 & 153.3 & -0.73 \\
0.5 & 8.3 & 11.3 & -0.75 \\
1 & 6.9 & 9.2 & -0.77 \\
1.5 & 6.1 & 8.0 & -0.78 \\
2 & 5.5 & 7.1 & -0.78 \\
2.5 & 5.1 & 6.5 & -0.80 \\
3 & 4.8 & 6.0 & -0.80 \\
3.5 & 4.4 & 5.6 & -0.79 \\
4 & 4.1 & 5.2 & -0.79 \\
4.5 & 4.0 & 5.0 & -0.80 \\
5 & 3.8 & 4.7 & -0.79 \\
5.5 & 3.6 & 4.5 & -0.79 \\
6 & 3.4 & 4.3 & -0.78
\end{tabular}


TABLE 5: SUMMARY OF MEASURED FORCE SYSTEM

SPRING GEOMETRY: SYMMETRIC ANGULATION

SPRING POSITION: CENTERED

PREACTIVATION ANGULATION: 40 degrees

\begin{tabular}{c|cccccccc} 
& \multicolumn{2}{|c}{ ALPHA } & \multicolumn{2}{c}{ BETA } & \multicolumn{2}{c}{ HORIZONTAL } & \multicolumn{2}{c}{ VERTICAL } \\
$\begin{array}{c}\text { ACTIV ATION } \\
(\mathrm{mm})\end{array}$ & \multicolumn{2}{c}{ MOMENT $\left(\mathrm{g}^{*} \mathrm{~mm}\right)$} & \multicolumn{2}{c}{ MOMENT $\left(\mathrm{g}^{*} \mathrm{~mm}\right)$} & \multicolumn{2}{c}{ FORCE $(\mathrm{g})$} & \multicolumn{2}{c}{ FORCE (g) } \\
\hline 0 & $\mathbf{M E A N}$ & S.D. & MEAN & S.D. & MEAN & S.D & MEAN & S.D. \\
\hline 0.5 & 899.0 & 119.5 & 591.0 & 89.4 & -1.6 & 19.2 & -7.7 & 17.4 \\
1 & 982.7 & 122.6 & 744.4 & 68.0 & 46.9 & 10.6 & -3.0 & 15.5 \\
1.5 & 1056.3 & 119.8 & 996.8 & 52.8 & 110.0 & 11.9 & 3.3 & 14.3 \\
2 & 1125.9 & 122.4 & 1110.0 & 50.5 & 141.4 & 13.6 & 4.9 & 14.2 \\
2.5 & 1205.8 & 131.3 & 1232.3 & 46.1 & 171.3 & 13.5 & 8.0 & 13.4 \\
3 & 1265.1 & 132.3 & 1338.8 & 42.1 & 206.9 & 16.6 & 10.8 & 14.9 \\
3.5 & 1326.8 & 133.3 & 1428.7 & 39.4 & 236.1 & 17.4 & 12.3 & 13.4 \\
4 & 1365.6 & 128.8 & 1526.7 & 42.7 & 264.7 & 17.3 & 18.3 & 15.2 \\
4.5 & 1411.2 & 134.3 & 1608.8 & 37.2 & 296.3 & 17.2 & 20.6 & 13.4 \\
5 & 1461.6 & 119.9 & 1701.7 & 33.8 & 330.9 & 19.2 & 18.9 & 13.4 \\
5.5 & 1504.9 & 124.8 & 1768.9 & 33.7 & 357.6 & 19.5 & 23.3 & 14.0 \\
6 & 1539.0 & 127.3 & 1848.0 & 31.0 & 388.6 & 23.6 & 22.3 & 13.6
\end{tabular}

\begin{tabular}{c|ccc}
$\begin{array}{c}\text { ACTIVATION } \\
(\mathbf{m m})\end{array}$ & $\begin{array}{c}\text { M/F } \\
\text { ALPHA }\end{array}$ & $\begin{array}{c}\text { M/F } \\
\text { BETA }\end{array}$ & $\begin{array}{c}\text { RATIO } \\
\text { ALPHA/BETA }\end{array}$ \\
\hline 0 & -527.1 & -379.9 & -1.44 \\
0.5 & 19.2 & 15.9 & -1.23 \\
1 & 13.1 & 11.6 & -1.14 \\
1.5 & 9.6 & 9.1 & -1.06 \\
2 & 8.0 & 7.8 & -1.02 \\
2.5 & 7.0 & 7.2 & -0.98 \\
3 & 6.1 & 6.5 & -0.95 \\
3.5 & 5.6 & 6.1 & -0.93 \\
4 & 5.2 & 5.8 & -0.90 \\
4.5 & 4.8 & 5.4 & -0.88 \\
5 & 4.4 & 5.1 & -0.86 \\
5.5 & 4.2 & 4.9 & -0.85 \\
6 & 4.0 & 4.8 & -0.83
\end{tabular}


TABLE 6: SUMMARY OF MEASURED FORCE SYSTEM

SPRING GEOMETRY: SYMMETRIC ANGULATION

SPRING POSITION: CENTERED

PREACTIVATION ANGULATION: 50 degrees

\begin{tabular}{c|cccccccc} 
& \multicolumn{2}{|c}{$\begin{array}{c}\text { ALPHA } \\
\begin{array}{c}\text { ACTIVATION } \\
(\mathrm{mm})\end{array}\end{array}$} & $\begin{array}{c}\text { MOMENT } \\
\text { ME*mm) }\end{array}$ & \multicolumn{2}{c}{ MOMETA } & \multicolumn{2}{c}{ HORIZONTAL } & \multicolumn{2}{c}{ VERTICAL } \\
MEAN & S.D. & MEAN & S.D. & MEAN & S.D & MEAN & S.D. \\
\hline 0 & 827.2 & 72.0 & 880.3 & 50.6 & -2.9 & 7.3 & 5.3 & 3.8 \\
0.5 & 1034.8 & 65.0 & 1139.1 & 69.3 & 69.6 & 10.2 & 12.0 & 4.2 \\
1 & 1112.1 & 53.7 & 1233.2 & 69.0 & 98.1 & 11.8 & 14.7 & 4.2 \\
1.5 & 1188.1 & 53.0 & 1328.9 & 74.2 & 128.1 & 9.3 & 16.9 & 4.2 \\
2 & 1253.4 & 41.3 & 1424.7 & 69.8 & 156.8 & 11.9 & 19.0 & 4.2 \\
2.5 & 1327.9 & 54.6 & 1515.6 & 79.3 & 186.4 & 9.3 & 20.6 & 4.3 \\
3 & 1386.4 & 41.2 & 1580.4 & 80.9 & 215.0 & 9.7 & 22.6 & 5.2 \\
3.5 & 1431.1 & 46.2 & 1661.8 & 86.5 & 242.7 & 8.5 & 24.9 & 5.6 \\
4 & 1478.2 & 29.5 & 1745.3 & 87.3 & 274.8 & 10.6 & 26.9 & 6.3 \\
4.5 & 1516.1 & 46.5 & 1819.7 & 85.8 & 302.3 & 10.0 & 28.3 & 6.6 \\
5 & 1570.4 & 48.6 & 1866.0 & 90.7 & 330.9 & 11.4 & 30.2 & 6.6 \\
5.5 & 1610.6 & 45.4 & 1929.3 & 98.3 & 359.4 & 11.3 & 31.6 & 6.5 \\
6 & 1629.8 & 47.8 & 1985.3 & 99.6 & 390.9 & 11.4 & 33.7 & 6.9
\end{tabular}

\begin{tabular}{c|ccc}
$\begin{array}{c}\text { ACTIVATION } \\
(\mathbf{m m})\end{array}$ & $\begin{array}{c}\text { M/F } \\
\text { ALPHA }\end{array}$ & $\begin{array}{c}\text { M/F } \\
\text { BETA }\end{array}$ & $\begin{array}{c}\text { RATIO } \\
\text { ALPHA/BETA }\end{array}$ \\
\hline 0 & -286.3 & -304.7 & -0.94 \\
0.5 & 14.9 & 16.4 & -0.91 \\
1 & 11.3 & 12.6 & -0.90 \\
1.5 & 9.3 & 10.4 & -0.89 \\
2 & 8.0 & 9.1 & -0.88 \\
2.5 & 7.1 & 8.1 & -0.88 \\
3 & 6.4 & 7.4 & -0.88 \\
3.5 & 5.9 & 6.8 & -0.86 \\
4 & 5.4 & 6.4 & -0.85 \\
4.5 & 5.0 & 6.0 & -0.83 \\
5 & 4.7 & 5.6 & -0.84 \\
5.5 & 4.5 & 5.4 & -0.84 \\
6 & 4.2 & 5.1 & -0.82
\end{tabular}


TABLE 7: SUMMARY OF MEASURED FORCE SYSTEM

SPRING GEOMETRY: SYMMETRIC ANGULATION

SPRING POSITION: CENTERED

PREACTIVATION ANGULATION: 60 degrees

\begin{tabular}{c|cccccccc}
\multirow{2}{*}{$\begin{array}{c}\text { ACTIVATION } \\
(\mathrm{mm})\end{array}$} & \multicolumn{2}{c}{ ALPHA } & \multicolumn{2}{c}{ BETA } & \multicolumn{2}{c}{ HORIZONTAL } & \multicolumn{2}{c}{ VERTICAL } \\
MOMENT (g*mm) & MOMENT $\left(\mathbf{g}^{*} \mathrm{~mm}\right)$ & \multicolumn{2}{c}{ FORCE (g) } & \multicolumn{2}{c}{ FORCE (g) } \\
\hline 0 & MEAN & S.D. & MEAN & S.D. & MEAN & S.D & MEAN & S.D. \\
\hline 0.5 & 1073.2 & 37.0 & 1023.3 & 83.7 & 8.6 & 10.9 & 0.0 & 7.0 \\
1 & 1156.9 & 37.6 & 1156.2 & 82.9 & 45.3 & 6.9 & 2.8 & 5.9 \\
1.5 & 1238.7 & 37.7 & 1272.4 & 85.3 & 80.2 & 10.2 & 8.6 & 6.3 \\
2 & 1308.2 & 36.2 & 1379.0 & 81.0 & 112.9 & 7.5 & 9.9 & 6.3 \\
2.5 & 1381.3 & 36.3 & 1488.9 & 82.2 & 145.4 & 7.8 & 12.4 & 5.7 \\
3 & 1448.0 & 27.8 & 1582.4 & 90.9 & 175.4 & 8.6 & 15.4 & 7.4 \\
3.5 & 1515.8 & 32.6 & 1687.4 & 88.4 & 207.1 & 7.9 & 18.8 & 5.4 \\
4 & 1568.8 & 25.9 & 1774.0 & 86.1 & 238.6 & 9.5 & 19.0 & 5.3 \\
4.5 & 1606.6 & 24.4 & 1858.4 & 89.1 & 271.2 & 10.6 & 21.1 & 5.3 \\
5 & 1657.4 & 27.3 & 1939.7 & 93.3 & 300.3 & 10.9 & 24.3 & 5.8 \\
5.5 & 1693.1 & 26.6 & 2011.1 & 89.8 & 333.0 & 8.7 & 26.9 & 4.8 \\
6 & 1729.1 & 26.8 & 2080.1 & 91.7 & 362.6 & 9.6 & 28.3 & 4.9 \\
& 1758.8 & 32.3 & 2151.7 & 91.4 & 393.2 & 10.8 & 30.3 & 4.4
\end{tabular}

\begin{tabular}{c|ccc}
$\begin{array}{c}\text { ACTIVATION } \\
(\mathrm{mm})\end{array}$ & $\begin{array}{c}\text { M/F } \\
\text { ALPHA }\end{array}$ & $\begin{array}{c}\text { M/F } \\
\text { BETA }\end{array}$ & $\begin{array}{c}\text { RATIO } \\
\text { ALPHAMETA }\end{array}$ \\
\hline 0 & 125.4 & 119.6 & -1.06 \\
0.5 & 25.5 & 25.5 & -1.01 \\
1 & 15.4 & 15.9 & -0.98 \\
1.5 & 11.6 & 12.2 & -0.95 \\
2 & 9.5 & 10.2 & -0.93 \\
2.5 & 8.3 & 9.0 & -0.92 \\
3 & 7.3 & 8.1 & -0.90 \\
3.5 & 6.6 & 7.4 & -0.89 \\
4 & 5.9 & 6.9 & -0.87 \\
4.5 & 5.5 & 6.5 & -0.86 \\
5 & 5.1 & 6.0 & -0.84 \\
5.5 & 4.8 & 5.7 & -0.83 \\
6 & 4.5 & 5.5 & -0.82
\end{tabular}


TABLE 8: SUMMARY OF MEASURED FORCE SYSTEM

SPRING GEOMETRY: SYMMETRIC ANGULATION

SPRING POSITION: CENTERED

PREACTIVATION ANGULATION: 70 degrees

\begin{tabular}{c|cccccccc} 
& \multicolumn{2}{|c}{$\begin{array}{c}\text { ALPHA } \\
\text { ACTIVATION }\end{array}$} & \multicolumn{2}{c}{ BETA } & \multicolumn{2}{c}{ HORIZONTAL } & \multicolumn{2}{c}{ VERTICAL } \\
$(\mathrm{mm})$ & MENT & $\left(\mathrm{g}^{*} \mathrm{~mm}\right)$ & \multicolumn{2}{c}{ MOMENT } & $\left(\mathrm{g}^{*} \mathrm{~mm}\right)$ & \multicolumn{2}{c}{ FORCE $(\mathrm{g})$} & \multicolumn{2}{c}{ FORCE $(\mathrm{g})$} \\
\hline 0 & 1094.2 & 69.0 & 1313.3 & 81.8 & -0.4 & 9.8 & 15.8 & 5.4 \\
0.5 & 1293.3 & 73.5 & 1532.8 & 88.1 & 62.3 & 11.4 & 19.2 & 4.6 \\
1 & 1368.2 & 71.6 & 1619.7 & 84.4 & 87.4 & 10.5 & 20.6 & 4.1 \\
1.5 & 1438.7 & 71.6 & 1702.9 & 87.0 & 112.6 & 11.5 & 21.7 & 4.1 \\
2 & 1512.8 & 69.1 & 1778.4 & 86.4 & 136.0 & 13.9 & 22.9 & 4.0 \\
2.5 & 1577.6 & 72.6 & 1841.7 & 88.3 & 162.9 & 13.3 & 24.0 & 3.5 \\
3 & 1652.4 & 66.3 & 1920.4 & 95.0 & 187.8 & 12.3 & 24.9 & 3.6 \\
3.5 & 1715.0 & 75.6 & 1981.3 & 101.9 & 212.8 & 12.5 & 26.2 & 4.1 \\
4 & 1768.0 & 65.8 & 2051.3 & 99.5 & 236.9 & 11.7 & 27.2 & 4.1 \\
4.5 & 1809.0 & 58.2 & 2110.8 & 101.2 & 262.2 & 15.6 & 28.2 & 4.5 \\
5 & 1850.6 & 61.3 & 2171.6 & 101.8 & 289.2 & 13.2 & 29.6 & 4.3 \\
5.5 & 1893.2 & 62.4 & 2218.6 & 102.6 & 317.0 & 14.4 & 30.6 & 4.3 \\
6 & 1929.9 & 60.0 & 2264.7 & 109.2 & 340.6 & 13.0 & 31.8 & 4.5
\end{tabular}

\begin{tabular}{c|ccc}
$\begin{array}{c}\text { ACTIVATION } \\
(\mathbf{m m})\end{array}$ & $\begin{array}{c}\text { M/F } \\
\text { ALPHA }\end{array}$ & $\begin{array}{c}\text { M/F } \\
\text { BETA }\end{array}$ & $\begin{array}{c}\text { RATIO } \\
\text { ALPHA/BETA }\end{array}$ \\
\hline 0 & -2462.0 & -2955.0 & -0.84 \\
0.5 & 20.7 & 24.6 & -0.85 \\
1 & 15.6 & 18.5 & -0.85 \\
1.5 & 12.8 & 15.1 & -0.85 \\
2 & 11.1 & 13.1 & -0.85 \\
2.5 & 9.7 & 11.3 & -0.86 \\
3 & 8.8 & 10.2 & -0.86 \\
3.5 & 8.1 & 9.3 & -0.87 \\
4 & 7.5 & 8.7 & -0.86 \\
4.5 & 6.9 & 8.0 & -0.86 \\
5 & 6.4 & 7.5 & -0.85 \\
5.5 & 6.0 & 7.0 & -0.85 \\
6 & 5.7 & 6.6 & -0.85
\end{tabular}


TABLE 9: SUMMARY OF MEASURED FORCE SYSTEM

SPRING GEOMETRY: SYMMETRIC MOMENTS

SPRING POSITION: CENTERED, (CONTROL)

\begin{tabular}{c|cccccccc} 
& \multicolumn{2}{|c}{ ALPHA } & \multicolumn{2}{c}{ BETA } & \multicolumn{2}{c}{ HORIZONTAL } & \multicolumn{2}{c}{ VERTICAL } \\
$\begin{array}{c}\text { ACTIVATION } \\
(\mathrm{mm})\end{array}$ & MOMENT $\left(\mathrm{g}^{*} \mathrm{~mm}\right)$ & MOMENT & $\left(\mathrm{g}^{*} \mathrm{~mm}\right)$ & \multicolumn{2}{c}{ FORCE $(\mathrm{g})$} & \multicolumn{2}{c}{ FORCE (g) } \\
\hline 0 & MEAN & S.D. & MEAN & S.D. & MEAN & S.D & MEAN & S.D. \\
\hline 0.5 & -1234.1 & 89.2 & 1194.7 & 92.0 & -16.0 & 18.3 & 6.1 & 7.3 \\
1 & -1329.1 & 88.1 & 1303.8 & 95.5 & 24.7 & 19.3 & 8.8 & 7.4 \\
1.5 & -1428.1 & 80.1 & 1406.7 & 104.8 & 54.1 & 19.1 & 11.1 & 9.4 \\
2 & -1518.9 & 86.1 & 1496.4 & 113.7 & 82.1 & 14.2 & 11.4 & 9.4 \\
2.5 & -1605.1 & 79.0 & 1588.9 & 122.7 & 115.2 & 17.8 & 13.4 & 6.1 \\
3 & -1687.1 & 76.5 & 1672.8 & 130.4 & 140.3 & 16.9 & 12.9 & 7.0 \\
3.5 & -1766.1 & 87.0 & 1750.9 & 136.3 & 170.9 & 19.8 & 14.6 & 7.4 \\
4 & -1841.1 & 87.0 & 1829.9 & 143.1 & 201.7 & 17.7 & 14.7 & 9.2 \\
4.5 & -1901.9 & 82.6 & 1894.7 & 155.5 & 229.9 & 21.0 & 16.4 & 8.2 \\
5 & -1950.1 & 74.3 & 1956.1 & 159.6 & 254.6 & 16.9 & 17.6 & 5.1 \\
5.5 & -1986.2 & 71.4 & 2018.0 & 168.2 & 283.4 & 18.8 & 19.6 & 5.5 \\
6 & -2033.7 & 72.0 & 2072.8 & 176.3 & 316.3 & 20.5 & 21.1 & 6.8 \\
& -2079.2 & 73.2 & 2126.8 & 176.8 & 344.3 & 20.6 & 21.4 & 9.8
\end{tabular}

\begin{tabular}{c|ccc}
$\begin{array}{c}\text { ACTIVATION } \\
(\mathrm{mm})\end{array}$ & $\begin{array}{c}\text { M/F } \\
\text { ALPHA }\end{array}$ & $\begin{array}{c}\text { M/F } \\
\text { BETA }\end{array}$ & $\begin{array}{c}\text { RATIO } \\
\text { ALPHA/BETA }\end{array}$ \\
\hline 0 & 77.1 & -74.7 & \\
0.5 & -53.9 & 52.9 & 1.03 \\
1 & -26.4 & 26.0 & 1.02 \\
1.5 & -18.5 & 18.2 & 1.02 \\
2 & -13.9 & 13.8 & 1.01 \\
2.5 & -12.0 & 11.9 & 1.01 \\
3 & -10.3 & 10.2 & 1.01 \\
3.5 & -9.1 & 9.1 & 1.01 \\
4 & -8.3 & 8.2 & 1.01 \\
4.5 & -7.7 & 7.7 & 1.00 \\
5 & -7.0 & 7.1 & 1.00 \\
5.5 & -6.4 & 6.6 & 0.98 \\
6 & -6.0 & 6.2 & 0.98
\end{tabular}


TABLE 10: SUMMARY OF MEASURED FORCE SYSTEM

SPRING GEOMETRY: SYMMETRIC MOMENTS

SPRING POSITION: $1 \mathrm{~mm}$ TOWARD ANTERIOR $(-1 \mathrm{~mm})$

\begin{tabular}{c|cccccccc} 
& \multicolumn{3}{|c}{ ALPHA } & \multicolumn{2}{c}{ BETA } & \multicolumn{2}{c}{ HORIZONTAL } & \multicolumn{2}{c}{$\begin{array}{c}\text { VERTCAL } \\
\text { ACTIVATION } \\
(\mathrm{mm})\end{array}$} & $\begin{array}{c}\text { MOMENT } \\
\text { MOmm) }\end{array}$ & \multicolumn{2}{c}{ MOMENT $\left(\mathrm{g}^{*} \mathrm{~mm}\right)$} & \multicolumn{2}{c}{ FORCE $(\mathrm{g})$} & \multicolumn{2}{c}{ FORCE (g) } \\
\hline 0 & -1375.9 & 115.2 & 973.8 & 67.0 & -8.0 & 17.0 & -20.1 & 11.9 \\
0.5 & -1491.9 & 122.2 & 1070.3 & 65.6 & 28.0 & 12.9 & -17.9 & 12.4 \\
1 & -1604.6 & 126.4 & 1145.1 & 75.3 & 59.9 & 11.7 & -18.9 & 12.5 \\
1.5 & -1707.7 & 135.5 & 1217.2 & 78.8 & 88.1 & 14.0 & -18.2 & 12.5 \\
2 & -1802.8 & 140.0 & 1285.7 & 87.3 & 118.1 & 15.6 & -19.9 & 12.3 \\
2.5 & -1909.3 & 156.5 & 1364.6 & 99.2 & 144.1 & 16.7 & -18.2 & 12.2 \\
3 & -1996.4 & 160.8 & 1430.9 & 104.1 & 175.8 & 14.5 & -18.6 & 14.4 \\
3.5 & -2097.7 & 176.7 & 1502.1 & 113.3 & 202.3 & 13.7 & -13.7 & 12.2 \\
4 & -2170.4 & 181.0 & 1556.1 & 120.7 & 236.8 & 17.0 & -15.8 & 11.6 \\
4.5 & -2234.8 & 184.6 & 1607.9 & 124.8 & 261.4 & 13.4 & -15.6 & 12.3 \\
5 & -2289.9 & 184.5 & 1659.4 & 128.6 & 293.3 & 17.3 & -16.3 & 14.5 \\
5.5 & -2357.1 & 190.1 & 1708.3 & 134.3 & 324.0 & 18.1 & -14.6 & 15.6 \\
6 & -2408.2 & 185.0 & 1747.1 & 129.0 & 349.4 & 14.1 & -14.2 & 14.2
\end{tabular}

\begin{tabular}{c|ccc}
$\begin{array}{c}\text { ACTIVATION } \\
(\mathbf{m m})\end{array}$ & $\begin{array}{c}\text { M/F } \\
\text { ALPHA }\end{array}$ & $\begin{array}{c}\text { M/F } \\
\text { BETA }\end{array}$ & $\begin{array}{c}\text { RATIO } \\
\text { ALPHABETA }\end{array}$ \\
\hline 0 & 172.0 & -121.7 & \\
0.5 & -53.3 & 38.2 & 1.41 \\
1 & -26.8 & 19.1 & 1.39 \\
1.5 & -19.4 & 13.8 & 1.40 \\
2 & -15.3 & 10.9 & 1.40 \\
2.5 & -13.2 & 9.5 & 1.40 \\
3 & -11.4 & 8.1 & 1.40 \\
3.5 & -10.4 & 7.4 & 1.40 \\
4 & -9.2 & 6.6 & 1.40 \\
4.5 & -8.5 & 6.2 & 1.39 \\
5 & -7.8 & 5.7 & 1.39 \\
5.5 & -7.3 & 5.3 & 1.38 \\
6 & -6.9 & 5.0 & 1.38
\end{tabular}




\section{TABLE 11: SUMMARY OF MEASURED FORCE SYSTEM}

SPRING GEOMETRY: SYMMETRIC MOMENTS

SPRING POSITION: $2 \mathrm{~mm}$ TOWARD ALPHA (ANTERIOR)

\begin{tabular}{|c|c|c|c|c|c|c|c|c|}
\hline \multirow{2}{*}{$\begin{array}{c}\text { ACTIVATION } \\
(\mathrm{mm})\end{array}$} & \multicolumn{2}{|c|}{$\begin{array}{c}\text { ALPHA } \\
\text { MOMENT }\left(\mathrm{g}^{*} \mathrm{~mm}\right)\end{array}$} & \multicolumn{2}{|c|}{$\begin{array}{c}\text { BETA } \\
\text { MOMENT }\left(g^{*} \mathrm{~mm}\right)\end{array}$} & \multicolumn{2}{|c|}{$\begin{array}{c}\text { HORIZONTAL } \\
\text { FORCE (g) }\end{array}$} & \multicolumn{2}{|c|}{$\begin{array}{l}\text { VERTICAL } \\
\text { FORCE (g) }\end{array}$} \\
\hline & MEAN & S.D. & MEAN & S.D. & MEAN & S.D & MEAN & S.D. \\
\hline 0 & -1509.7 & $\overline{174.1}$ & 740.7 & 180.1 & -16.3 & $\overline{12.6}$ & -25.7 & $\overline{33.5}$ \\
\hline 0.5 & -1657.3 & 164.4 & 810.1 & 176.7 & 27.8 & 14.0 & -34.0 & 20.9 \\
\hline 1 & -1793.9 & 163.7 & 867.8 & 183.3 & 58.4 & 12.4 & -37.8 & 21.5 \\
\hline 1.5 & -1920.2 & 161.7 & 922.6 & 187.3 & 92.4 & 15.9 & -38.7 & 21.5 \\
\hline 2 & -2045.2 & 165.6 & 973.9 & 187.5 & 121.3 & 13.9 & -40.9 & 20.5 \\
\hline 2.5 & -2185.2 & 147.5 & 1034.2 & 190.2 & 153.0 & 14.2 & -43.2 & 20.6 \\
\hline 3 & -2277.2 & 162.4 & 1083.1 & 183.0 & 176.7 & 12.0 & -40.9 & 19.6 \\
\hline 3.5 & -2380.3 & 166.9 & 1128.7 & 192.7 & 209.1 & 12.6 & -43.1 & 17.2 \\
\hline 4 & -2487.1 & 170.0 & 1179.0 & 194.7 & 238.8 & 18.1 & -43.4 & 21.1 \\
\hline 4.5 & -2584.0 & 164.9 & 1231.3 & 189.2 & 264.3 & 17.2 & -44.0 & 22.3 \\
\hline 5 & -2661.6 & 162.3 & 1264.6 & 197.8 & 298.3 & 18.8 & -41.0 & 19.8 \\
\hline 5.5 & -2731.2 & 144.9 & 1298.1 & 204.8 & 328.9 & 19.6 & -42.2 & 20.1 \\
\hline 6 & -2798.3 & 136.2 & 1330.1 & 211.3 & .359 .3 & 21.5 & -43.2 & 22.6 \\
\hline
\end{tabular}

\begin{tabular}{c|ccc}
$\begin{array}{c}\text { ACTIVATION } \\
(\mathrm{mm})\end{array}$ & $\begin{array}{c}\text { M/F } \\
\text { ALPHA }\end{array}$ & $\begin{array}{c}\text { M/F } \\
\text { BETA }\end{array}$ & $\begin{array}{c}\text { RATIO } \\
\text { ALPHA/BETA }\end{array}$ \\
\hline 0 & 92.4 & -45.3 & \\
0.5 & -59.7 & 29.2 & 2.04 \\
1 & -30.7 & 14.8 & 2.05 \\
1.5 & -20.8 & 10.0 & 2.07 \\
2 & -16.9 & 8.0 & 2.08 \\
2.5 & -14.3 & 6.8 & 2.10 \\
3 & -12.9 & 6.1 & 2.11 \\
3.5 & -11.4 & 5.4 & 2.10 \\
4 & -10.4 & 4.9 & 2.11 \\
4.5 & -9.8 & 4.7 & 2.11 \\
5 & -8.9 & 4.2 & 2.10 \\
5.5 & -8.3 & 3.9 & 2.10 \\
6 & -7.8 & 3.7 & 2.10
\end{tabular}


TABLE 12: SUMMARY OF MEASURED FORCE SYSTEM

SPRING GEOMETRY: SYMMETRIC MOMENTS

SPRING POSITION: $3 \mathrm{~mm}$ TOWARD ALPHA (ANTERIOR)

\begin{tabular}{c|cccccccc} 
& \multicolumn{2}{|c}{ ALPHA } & \multicolumn{2}{c}{ BETA } & \multicolumn{2}{c}{ HORIZONTAL } & \multicolumn{2}{c}{ VERTICAL } \\
$\begin{array}{c}\text { ACTIVATION } \\
(\mathrm{mm})\end{array}$ & \multicolumn{2}{|c}{ MOMENT $\left(\mathrm{g}^{*} \mathrm{~mm}\right)$} & MOMENT $\left(\mathrm{g}^{*} \mathrm{~mm}\right)$ & \multicolumn{2}{c}{ FORCE (g) } & \multicolumn{2}{c}{ FORCE (g) } \\
\hline 0 & -1558.1 & 146.4 & 610.1 & 189.1 & -14.6 & 15.3 & -53.2 & 27.5 \\
0.5 & -1731.0 & 159.4 & 662.2 & 183.5 & 29.7 & 12.4 & -56.9 & 27.8 \\
1 & -1887.0 & 153.1 & 713.3 & 192.8 & 70.7 & 16.4 & -60.4 & 26.1 \\
1.5 & -2029.4 & 153.7 & 757.8 & 193.5 & 99.0 & 13.7 & -62.6 & 26.1 \\
2 & -2170.9 & 159.1 & 801.2 & 196.3 & 132.8 & 20.6 & -65.7 & 25.4 \\
2.5 & -2307.7 & 159.3 & 839.7 & 198.4 & 163.9 & 16.3 & -65.6 & 22.8 \\
3 & -2438.7 & 170.9 & 889.4 & 194.6 & 193.8 & 22.1 & -67.1 & 25.1 \\
3.5 & -2559.1 & 181.1 & 944.8 & 180.0 & 221.6 & 20.9 & -57.4 & 44.9 \\
4 & -2676.3 & 175.1 & 973.2 & 198.1 & 253.9 & 21.4 & -70.6 & 22.2 \\
4.5 & -2777.9 & 157.7 & 1003.9 & 198.4 & 284.3 & 25.7 & -69.6 & 21.5 \\
5 & -2877.4 & 166.0 & 1036.9 & 200.9 & 314.1 & 26.6 & -72.0 & 23.1 \\
5.5 & -2959.9 & 161.9 & 1060.6 & 200.6 & 346.8 & 30.6 & -70.0 & 22.4 \\
6 & -3046.7 & 164.1 & 1083.2 & 201.4 & 376.2 & 32.0 & -69.3 & 21.5
\end{tabular}

\begin{tabular}{c|ccc}
$\begin{array}{c}\text { ACTIVATION } \\
(\mathbf{m m})\end{array}$ & $\begin{array}{c}\text { M/F } \\
\text { ALPHA }\end{array}$ & $\begin{array}{c}\text { M/F } \\
\text { BETA }\end{array}$ & $\begin{array}{c}\text { RATIO } \\
\text { ALPHA/BETA }\end{array}$ \\
\hline 0 & 107.0 & -41.9 & \\
0.5 & -58.3 & 22.3 & 2.55 \\
1 & -26.7 & 10.1 & 2.61 \\
1.5 & -20.5 & 7.7 & 2.65 \\
2 & -16.3 & 6.0 & 2.68 \\
2.5 & -14.1 & 5.1 & 2.71 \\
3 & -12.6 & 4.6 & 2.75 \\
3.5 & -11.6 & 4.3 & 2.74 \\
4 & -10.5 & 3.8 & 2.71 \\
4.5 & -9.8 & 3.5 & 2.75 \\
5 & -9.2 & 3.3 & 2.77 \\
5.5 & -8.5 & 3.1 & 2.78 \\
6 & -8.1 & 2.9 & 2.79
\end{tabular}




\section{TABLE 13: SUMMARY OF MEASURED FORCE SYSTEM}

SPRING GEOMETRY: SYMMETRIC MOMENTS

SPRING POSITION: $4 \mathrm{~mm}$ TOWARD ALPHA (ANTERIOR)

\begin{tabular}{c|cccccccc} 
& \multicolumn{2}{|c}{ ALPHA } & \multicolumn{2}{c}{ BETA } & \multicolumn{2}{c}{ HORIZONTAL } & \multicolumn{2}{c}{ VERTICAL } \\
$\begin{array}{c}\text { ACTIV ATION } \\
\text { (mm) }\end{array}$ & \multicolumn{2}{|c}{ MOMENT $(\mathrm{g} * \mathrm{~mm})$} & \multicolumn{2}{c}{ MOMENT $(\mathrm{g} * \mathrm{~mm})$} & \multicolumn{2}{c}{ FORCE $(\mathrm{g})$} & \multicolumn{2}{c}{ FORCE (g) } \\
\hline 0 & MEAN & S.D. & MEAN & S.D. & MEAN & S.D & MEAN & S.D. \\
\hline 0.5 & -1455.9 & 129.1 & 507.8 & 227.6 & -9.2 & 15.4 & -48.6 & 18.4 \\
1 & -1645.3 & 126.3 & 534.2 & 223.9 & 40.7 & 10.9 & -54.7 & 16.9 \\
1.5 & -1819.1 & 122.2 & 562.9 & 218.9 & 73.4 & 10.7 & -59.1 & 16.3 \\
2 & -1984.1 & 117.4 & 582.7 & 209.0 & 106.7 & 8.0 & -64.0 & 16.3 \\
2.5 & -2139.8 & 120.2 & 609.3 & 198.2 & 140.0 & 11.3 & -67.6 & 14.7 \\
3 & -2302.6 & 131.1 & 645.2 & 167.8 & 171.3 & 8.6 & -70.7 & 13.2 \\
3.5 & -2451.8 & 129.7 & 675.0 & 174.9 & 201.3 & 10.8 & -72.4 & 13.1 \\
4 & -2588.6 & 137.6 & 704.1 & 174.6 & 231.1 & 13.7 & -75.8 & 11.7 \\
4.5 & -2716.8 & 130.4 & 711.8 & 181.8 & 263.2 & 12.1 & -77.3 & 10.8 \\
5 & -2845.2 & 143.8 & 744.2 & 172.7 & 292.3 & 12.3 & -78.9 & 12.1 \\
5.5 & -2956.7 & 139.5 & 762.0 & 177.7 & 322.2 & 13.4 & -80.8 & 11.4 \\
6 & -3053.9 & 141.2 & 776.8 & 186.2 & 356.2 & 14.2 & -82.7 & 12.1 \\
& -3150.4 & 123.0 & 788.6 & 196.9 & 387.1 & 15.8 & -82.2 & 12.4
\end{tabular}

\begin{tabular}{c|ccc}
$\begin{array}{c}\text { ACTIVATION } \\
(\mathrm{mm})\end{array}$ & $\begin{array}{c}\text { M/F } \\
\text { ALPHA }\end{array}$ & $\begin{array}{c}\text { M/F } \\
\text { BETA }\end{array}$ & $\begin{array}{c}\text { RATIO } \\
\text { ALPHA/BETA }\end{array}$ \\
\hline 0 & 157.9 & -55.1 & \\
0.5 & -40.5 & 13.1 & 2.87 \\
1 & -24.8 & 7.7 & 3.08 \\
1.5 & -18.6 & 5.5 & 3.23 \\
2 & -15.3 & 4.4 & 3.41 \\
2.5 & -13.4 & 3.8 & 3.51 \\
3 & -12.2 & 3.4 & 3.57 \\
3.5 & -11.2 & 3.0 & 3.63 \\
4 & -10.3 & 2.7 & 3.68 \\
4.5 & -9.7 & 2.5 & 3.82 \\
5 & -9.2 & 2.4 & 3.82 \\
5.5 & -8.6 & 2.2 & 3.88 \\
6 & -8.1 & 2.0 & 3.93
\end{tabular}


TABLE 14: SUMMARY OF MEASURED FORCE SYSTEM

SPRING GEOMETRY: SYMMETRIC MOMENTS

SPRING POSITION: $1 \mathrm{~mm}$ TOWARD BETA (POSTERIOR)

\begin{tabular}{|c|c|c|c|c|c|c|c|c|}
\hline \multirow{2}{*}{$\begin{array}{c}\text { ACTIVATION } \\
(\mathbf{m m}) \\
\end{array}$} & \multicolumn{2}{|c|}{$\begin{array}{c}\text { ALPHA } \\
\text { MOMENT }\left(g^{*} \mathrm{~mm}\right)\end{array}$} & \multicolumn{2}{|c|}{$\begin{array}{c}\text { BETA } \\
\text { MOMENT }\left(g^{*} \mathrm{~mm}\right)\end{array}$} & \multicolumn{2}{|c|}{$\begin{array}{c}\text { HORIZONTAL } \\
\text { FORCE (g) }\end{array}$} & \multicolumn{2}{|c|}{$\begin{array}{l}\text { VERTICAL } \\
\text { FORCE (g) }\end{array}$} \\
\hline & MEAN & S.D. & MEAN & S.D. & MEAN & S.D & MEAN & S.D. \\
\hline 0 & -838.0 & 128.9 & 1409.4 & 72.5 & 2.1 & 16.4 & 42.3 & 6.3 \\
\hline 0.5 & -912.7 & 129.8 & 1556.1 & 81.6 & 37.1 & 17.1 & 47.3 & 6.9 \\
\hline 1 & -975.4 & 135.9 & 1670.7 & 101.7 & 66.7 & 17.7 & 49.3 & 5.5 \\
\hline 1.5 & -1041.3 & 136.5 & 1790.1 & 118.3 & 100.4 & 21.2 & 52.4 & 5.5 \\
\hline 2 & -1105.7 & 139.8 & 1901.8 & 123.6 & 132.3 & 23.1 & 54.1 & 8.2 \\
\hline 2.5 & -1169.1 & 145.1 & 2012.2 & 146.6 & 162.8 & 24.4 & 56.4 & 6.0 \\
\hline 3 & -1223.7 & 149.8 & 2122.4 & 156.1 & 194.4 & 25.0 & 57.8 & 6.9 \\
\hline 3.5 & -1289.7 & 163.9 & 2225.0 & 171.2 & 224.7 & 27.1 & 59.8 & 8.1 \\
\hline 4 & -1306.4 & 145.2 & 2295.2 & 170.0 & 255.4 & 29.1 & 61.4 & 7.0 \\
\hline 4.5 & -1342.3 & 140.1 & 2371.6 & 175.0 & 289.1 & 34.2 & 64.6 & 7.4 \\
\hline 5 & -1370.8 & 136.3 & 2450.0 & 188.8 & 315.1 & 32.3 & 64.7 & 7.7 \\
\hline 5.5 & -1389.8 & 135.9 & 2520.4 & 193.6 & 348.1 & 35.0 & 65.7 & 7.3 \\
\hline 6 & -1411.7 & 129.4 & 2578.7 & 201.4 & 381.9 & 38.9 & 66.8 & 9.0 \\
\hline
\end{tabular}

\begin{tabular}{c|ccc}
$\begin{array}{c}\text { ACTIVATION } \\
(\mathrm{mm})\end{array}$ & $\begin{array}{c}\text { M/F } \\
\text { ALPHA }\end{array}$ & $\begin{array}{c}\text { M/F } \\
\text { BETA }\end{array}$ & $\begin{array}{c}\text { RATIO } \\
\text { ALPHABETA }\end{array}$ \\
\hline 0 & -396.9 & 667.6 & \\
0.5 & -24.6 & 41.9 & 0.59 \\
1 & -14.6 & 25.1 & 0.59 \\
1.5 & -10.4 & 17.8 & 0.58 \\
2 & -8.4 & 14.4 & 0.58 \\
2.5 & -7.2 & 12.4 & 0.58 \\
3 & -6.3 & 10.9 & 0.58 \\
3.5 & -5.7 & 9.9 & 0.58 \\
4 & -5.1 & 9.0 & 0.58 \\
4.5 & -4.6 & 8.2 & 0.57 \\
5 & -4.4 & 7.8 & 0.57 \\
5.5 & -4.0 & 7.2 & 0.56 \\
6 & -3.7 & 6.8 & 0.55
\end{tabular}


TABLE 15: SUMMARY OF MEASURED FORCE SYSTEM

SPRING GEOMETRY: SYMMETRIC MOMENTS

SPRING POSITION: $2 \mathrm{~mm}$ TOWARD BETA (POSTERIOR)

\begin{tabular}{c|cccccccc} 
& \multicolumn{2}{|c}{ ALPHA } & \multicolumn{2}{c}{ BETA } & \multicolumn{2}{c}{ HORIZONTAL } & \multicolumn{2}{c}{ VERTICAL } \\
$\begin{array}{c}\text { ACTIVATION } \\
(\mathrm{mm})\end{array}$ & MOMENT $(\mathrm{g} * \mathrm{~mm})$ & MOMENT & $(\mathrm{g} * \mathrm{~mm})$ & \multicolumn{2}{c}{ FORCE $(\mathrm{g})$} & \multicolumn{2}{c}{ FORCE (g) } \\
\hline 0 & MEAN & S.D. & MEAN & S.D. & MEAN & S.D & MEAN & S.D. \\
\hline 0.5 & -720.0 & 37.3 & 1384.9 & 77.2 & -4.0 & 4.3 & 53.2 & 4.2 \\
1 & -771.7 & 43.4 & 1557.6 & 82.8 & 32.0 & 10.4 & 60.6 & 7.0 \\
1.5 & -819.1 & 62.3 & 1690.4 & 74.4 & 63.8 & 7.2 & 65.3 & 4.6 \\
2 & -878.2 & 67.9 & 1822.3 & 70.4 & 97.2 & 11.4 & 68.0 & 4.6 \\
2.5 & -924.6 & 75.4 & 1953.2 & 73.3 & 129.6 & 11.1 & 73.3 & 6.5 \\
3 & -967.2 & 80.8 & 2079.3 & 86.2 & 157.3 & 11.9 & 77.0 & 6.1 \\
3.5 & -1013.8 & 80.7 & 2205.2 & 87.6 & 193.0 & 13.1 & 78.9 & 6.0 \\
4 & -1059.6 & 96.5 & 2308.0 & 99.4 & 222.8 & 16.3 & 81.1 & 6.0 \\
4.5 & -1089.7 & 104.6 & 2414.3 & 102.4 & 252.6 & 18.6 & 84.3 & 6.3 \\
5 & -1108.9 & 113.2 & 2505.4 & 105.6 & 279.4 & 17.9 & 88.2 & 6.4 \\
5.5 & -1136.2 & 126.7 & 2598.2 & 121.6 & 313.8 & 22.4 & 89.2 & 7.9 \\
6 & -1156.2 & 131.2 & 2689.4 & 124.8 & 346.4 & 22.8 & 91.0 & 7.1 \\
& -1173.2 & 138.3 & 2772.6 & 133.1 & 376.6 & 26.5 & 90.8 & 6.6
\end{tabular}

\begin{tabular}{c|ccc}
$\begin{array}{c}\text { ACTIVATION } \\
(\mathbf{m m})\end{array}$ & $\begin{array}{c}\text { M/F } \\
\text { ALPHA }\end{array}$ & $\begin{array}{c}\text { M/F } \\
\text { BETA }\end{array}$ & $\begin{array}{c}\text { RATIO } \\
\text { ALPHA/BETA }\end{array}$ \\
\hline 0 & 180.0 & -346.2 & \\
0.5 & -24.1 & 48.7 & 0.52 \\
1 & -12.8 & 26.5 & 0.50 \\
1.5 & -9.0 & 18.7 & 0.48 \\
2 & -7.1 & 15.1 & 0.48 \\
2.5 & -6.1 & 13.2 & 0.47 \\
3 & -5.3 & 11.4 & 0.47 \\
3.5 & -4.8 & 10.4 & 0.46 \\
4 & -4.3 & 9.6 & 0.46 \\
4.5 & -4.0 & 9.0 & 0.45 \\
5 & -3.6 & 8.3 & 0.44 \\
5.5 & -3.3 & 7.8 & 0.44 \\
6 & -3.1 & 7.4 & 0.43
\end{tabular}


TABLE 16: SUMMARY OF MEASURED FORCE SYSTEM

SPRING GEOMETRY: SYMMETRIC MOMENTS SPRING POSITION: $3 \mathrm{~mm}$ TOWARD BETA (POSTERIOR)

\begin{tabular}{|c|c|c|c|c|c|c|c|c|}
\hline \multirow{2}{*}{$\begin{array}{l}\text { ACTIVATION } \\
\text { (mm) }\end{array}$} & \multicolumn{2}{|c|}{$\begin{array}{c}\text { ALPHA } \\
\text { MOMENT }\left(\mathrm{g}^{*} \mathrm{~mm}\right)\end{array}$} & \multicolumn{2}{|c|}{$\begin{array}{c}\text { BETA } \\
\text { MOMENT }\left(\mathrm{g}^{*} \mathrm{~mm}\right)\end{array}$} & \multicolumn{2}{|c|}{$\begin{array}{c}\text { HORIZONTAL } \\
\text { FORCE (g) }\end{array}$} & \multicolumn{2}{|c|}{$\begin{array}{l}\text { VERTICAL } \\
\text { FORCE (g) }\end{array}$} \\
\hline & MEAN & S.D. & MEAN & S.D. & MEAN & S.D & MEAN & S.D. \\
\hline 0 & -606.1 & 36.6 & 1397.6 & 147.8 & -1.7 & $\overline{17.2}$ & 59.4 & 11.5 \\
\hline 0.5 & -635.0 & 40.7 & 1564.2 & 144.7 & 33.6 & 19.9 & 68.1 & 11.2 \\
\hline 1 & -678.7 & 44.0 & 1723.4 & 141.3 & 70.9 & 16.9 & 73.2 & 11.3 \\
\hline 1.5 & -713.7 & 47.3 & 1875.0 & 133.6 & 103.1 & 18.0 & 80.0 & 11.3 \\
\hline 2 & -743.6 & 52.8 & 2023.6 & 137.3 & 134.6 & 19.8 & 85.0 & 9.3 \\
\hline 2.5 & -778.2 & 57.8 & 2167.2 & 147.3 & 171.1 & 19.9 & 89.1 & 8.7 \\
\hline 3 & -812.1 & 57.6 & 2305.0 & 146.4 & 199.7 & 23.2 & 93.8 & 7.5 \\
\hline 3.5 & -829.1 & 55.2 & 2424.9 & 142.2 & 231.7 & 23.3 & 97.8 & 7.4 \\
\hline 4 & -837.6 & 50.6 & 2537.7 & 144.9 & 264.2 & 24.5 & 100.6 & 7.7 \\
\hline 4.5 & -849.0 & 50.8 & 2653.7 & 155.1 & 293.7 & 27.5 & 105.2 & 7.0 \\
\hline 5 & -857.2 & 51.8 & 2768.3 & 161.9 & 325.4 & 28.2 & 109.3 & 7.6 \\
\hline 5.5 & -868.2 & 51.1 & 2873.3 & 175.4 & 355.8 & 32.0 & 110.7 & 5.8 \\
\hline 6 & -873.2 & 45.7 & 2967.7 & 173.2 & 388.9 & 35.0 & 112.1 & 5.7 \\
\hline
\end{tabular}

\begin{tabular}{c|ccc}
$\begin{array}{c}\text { ACTIVATION } \\
(\mathrm{mm})\end{array}$ & $\begin{array}{c}\text { M/F } \\
\text { ALPHA }\end{array}$ & $\begin{array}{c}\text { M/F } \\
\text { BETA }\end{array}$ & $\begin{array}{c}\text { RATIO } \\
\text { ALPHA/BETA }\end{array}$ \\
\hline 0 & 363.7 & -838.5 & \\
0.5 & -18.9 & 46.6 & 0.43 \\
1 & -9.6 & 24.3 & 0.41 \\
1.5 & -6.9 & 18.2 & 0.39 \\
2 & -5.5 & 15.0 & 0.38 \\
2.5 & -4.5 & 12.7 & 0.37 \\
3 & -4.1 & 11.5 & 0.36 \\
3.5 & -3.6 & 10.5 & 0.35 \\
4 & -3.2 & 9.6 & 0.34 \\
4.5 & -2.9 & 9.0 & 0.33 \\
5 & -2.6 & 8.5 & 0.32 \\
5.5 & -2.4 & 8.1 & 0.31 \\
6 & -2.2 & 7.6 & 0.30
\end{tabular}


TABLE 17: SUMMARY OF MEASURED FORCE SYSTEM

SPRING GEOMETRY: SYMMETRIC MOMENTS

SPRING POSITION: $4 \mathrm{~mm}$ TOWARD BETA (POSTERIOR)

\begin{tabular}{|c|c|c|c|c|c|c|c|c|}
\hline \multirow{2}{*}{$\begin{array}{l}\text { ACTIVATION } \\
\text { (mm) }\end{array}$} & \multicolumn{2}{|c|}{$\begin{array}{c}\text { ALPHA } \\
\text { MOMENT }\left(\mathrm{g}^{*} \mathrm{~mm}\right)\end{array}$} & \multicolumn{2}{|c|}{$\begin{array}{c}\text { BETA } \\
\text { MOMENT }\left(g^{*} \mathrm{~mm}\right)\end{array}$} & \multicolumn{2}{|c|}{$\begin{array}{l}\text { HORIZONTAL } \\
\text { FORCE (g) }\end{array}$} & \multicolumn{2}{|c|}{$\begin{array}{l}\text { VERTICAL } \\
\text { FORCE (g) }\end{array}$} \\
\hline & MEAN & S.D. & MEAN & S.D. & MEAN & S.D & MEAN & S.D. \\
\hline 0 & -517.5 & 132.8 & 1270.1 & 113.5 & -17.9 & $\overline{28.6}$ & 58.1 & 14.7 \\
\hline 0.5 & -528.0 & 127.6 & 1459.8 & 109.7 & 20.4 & 30.1 & 66.6 & 16.1 \\
\hline 1 & -544.4 & 126.5 & 1634.5 & 104.5 & 60.0 & 30.8 & 76.0 & 15.0 \\
\hline 1.5 & -562.4 & 122.0 & 1797.8 & 99.0 & 93.8 & 33.5 & 83.9 & 15.0 \\
\hline 2 & -585.0 & 122.3 & 1962.8 & 106.6 & 125.3 & 34.0 & 90.6 & 12.5 \\
\hline 2.5 & -606.0 & 115.9 & 2120.3 & 114.5 & 162.8 & 41.2 & 97.1 & 13.8 \\
\hline 3 & -615.9 & 109.5 & 2283.0 & 114.9 & 192.9 & 41.0 & 102.0 & 13.6 \\
\hline 3.5 & -624.6 & 109.6 & 2420.9 & 118.7 & 226.9 & 42.7 & 106.3 & 14.8 \\
\hline 4 & -624.4 & 103.1 & 2553.3 & 120.5 & 256.6 & 42.9 & 111.8 & 13.1 \\
\hline 4.5 & -636.4 & 87.3 & 2693.4 & 139.7 & 290.3 & 49.6 & 115.1 & 13.2 \\
\hline 5 & -635.5 & 81.5 & 2819.9 & 150.1 & 322.3 & 52.6 & 119.0 & 15.0 \\
\hline 5.5 & -641.9 & 73.0 & 2939.3 & 164.8 & 352.6 & 51.7 & 123.4 & 13.2 \\
\hline 6 & -640.6 & 66.4 & 3039.4 & 170.8 & 386.0 & 56.5 & 123.3 & 13.3 \\
\hline
\end{tabular}

\begin{tabular}{c|ccc}
$\begin{array}{c}\text { ACTIVATION } \\
(\mathrm{mm})\end{array}$ & $\begin{array}{c}\text { M/F } \\
\text { ALPHA }\end{array}$ & $\begin{array}{c}\text { M/F } \\
\text { BETA }\end{array}$ & $\begin{array}{c}\text { RATIO } \\
\text { ALPHA/BETA }\end{array}$ \\
\hline 0 & 29.0 & -71.1 & \\
0.5 & -25.9 & 71.6 & 0.41 \\
1 & -9.1 & 27.2 & 0.36 \\
1.5 & -6.0 & 19.2 & 0.33 \\
2 & -4.7 & 15.7 & 0.31 \\
2.5 & -3.7 & 13.0 & 0.30 \\
3 & -3.2 & 11.8 & 0.29 \\
3.5 & -2.8 & 10.7 & 0.27 \\
4 & -2.4 & 9.9 & 0.26 \\
4.5 & -2.2 & 9.3 & 0.24 \\
5 & -2.0 & 8.8 & 0.24 \\
5.5 & -1.8 & 8.3 & 0.23 \\
6 & -1.7 & 7.9 & 0.22
\end{tabular}


TABLE 18: SUMMARY OF MEASURED FORCE SYSTEM

SPRING GEOMETRY: ASYMMETRIC ANGULATION

ALPHA ANGULATION: O degrees

SPRING POSITION: CENTERED

BETA ANGULATION: 75 degrees

\begin{tabular}{c|cccccccc}
\multirow{2}{*}{$\begin{array}{c}\text { ACTIVATION } \\
(\mathrm{mm})\end{array}$} & \multicolumn{2}{|c}{ ALPHA } & \multicolumn{2}{c}{ BETA } & \multicolumn{2}{c}{ HORIZONTAL } & \multicolumn{2}{c}{ VERTICAL } \\
MOMENT & $(\mathrm{g} * \mathrm{~mm})$ & MOMENT & $(\mathrm{g} * \mathrm{~mm})$ & \multicolumn{2}{c}{ FORCE $(\mathrm{g})$} & \multicolumn{2}{c}{ FORCE $(\mathrm{g})$} \\
\hline 0 & MEAN & S.D. & MEAN & S.D. & MEAN & S.D & MEAN & S.D. \\
\hline 0.5 & 497.6 & 30.7 & 1956.4 & 232.8 & 3.8 & 17.1 & 163.4 & 17.6 \\
1 & 344.0 & 45.9 & 2061.8 & 215.6 & 55.4 & 30.5 & 160.0 & 15.5 \\
1.5 & 225.0 & 47.0 & 2150.1 & 220.5 & 91.8 & 31.0 & 153.3 & 12.6 \\
2 & 115.2 & 57.3 & 2245.9 & 221.1 & 129.2 & 32.2 & 147.2 & 12.6 \\
2.5 & 18.3 & 60.5 & 2325.7 & 221.0 & 162.2 & 34.8 & 144.4 & 14.0 \\
3 & -96.7 & 74.7 & 2411.4 & 219.1 & 198.2 & 33.8 & 137.2 & 13.3 \\
3.5 & -171.6 & 71.3 & 2470.4 & 221.7 & 229.0 & 36.0 & 134.1 & 12.9 \\
4 & -256.6 & 64.8 & 2530.2 & 219.6 & 263.0 & 33.4 & 129.6 & 13.4 \\
4.5 & -336.2 & 74.5 & 2581.2 & 226.2 & 291.6 & 39.7 & 126.4 & 13.1 \\
5 & -388.6 & 78.4 & 2624.1 & 228.4 & 326.7 & 41.8 & 123.9 & 13.2 \\
5.5 & -456.1 & 74.6 & 2665.9 & 226.5 & 357.6 & 45.9 & 120.2 & 12.0 \\
6 & -513.6 & 85.6 & 2703.2 & 224.7 & 390.4 & 44.4 & 116.7 & 12.9 \\
& -569.8 & 81.2 & 2737.8 & 224.9 & 421.8 & 48.0 & 113.3 & 13.7
\end{tabular}

\begin{tabular}{c|ccc}
$\begin{array}{c}\text { ACTIVATION } \\
(\mathbf{m m})\end{array}$ & $\begin{array}{c}\text { M/F } \\
\text { ALPHA }\end{array}$ & $\begin{array}{c}\text { M/F } \\
\text { BETA }\end{array}$ & $\begin{array}{c}\text { RATIO } \\
\text { ALPHA/BETA }\end{array}$ \\
\hline 0 & 131.7 & 517.9 & \\
0.5 & 6.2 & 37.2 & 0.25 \\
1 & 2.5 & 23.4 & 0.17 \\
1.5 & 0.9 & 17.4 & 0.10 \\
2 & 0.1 & 14.3 & 0.05 \\
2.5 & -0.5 & 12.2 & 0.01 \\
3 & -0.7 & 10.8 & -0.04 \\
3.5 & -1.0 & 9.6 & -0.07 \\
4 & -1.2 & 8.9 & -0.10 \\
4.5 & -1.2 & 8.0 & -0.13 \\
5 & -1.3 & 7.5 & -0.15 \\
5.5 & -1.3 & 6.9 & -0.17 \\
6 & -1.4 & 6.5 & -0.19
\end{tabular}


TABLE 19: SUMMARY OF MEASURED FORCE SYSTEM

SPRING GEOMETRY: ASYMMETRIC ANGULATION

ALPHA ANGULATION: 15 degrees

BETA ANGULATION: 75 degrees

SPRING POSITION: CENTERED

\begin{tabular}{c|cccccccc} 
& \multicolumn{2}{|c}{ ALPHA } & \multicolumn{2}{c}{ BETA } & \multicolumn{2}{c}{ HORIZONTAL } & \multicolumn{2}{c}{ VERTICAL } \\
$\begin{array}{c}\text { ACTIVATION } \\
(\mathrm{mm})\end{array}$ & \multicolumn{2}{|c}{ MOMENT $(\mathrm{g} * \mathrm{~mm})$} & \multicolumn{2}{c}{ MOMENT $\left(\mathrm{g}^{*} \mathrm{~mm}\right)$} & \multicolumn{2}{c}{ FORCE (g) } & \multicolumn{2}{c}{ FORCE (g) } \\
\hline 0 & MEAN & S.D. & MEAN & S.D. & MEAN & S.D & MEAN & S.D. \\
\hline 0.5 & 233.7 & 146.4 & 1819.8 & 120.9 & 0.4 & 13.6 & 135.0 & 7.5 \\
1 & 114.3 & 148.7 & 1942.7 & 114.9 & 29.9 & 17.1 & 131.7 & 9.2 \\
1.5 & -1.1 & 145.2 & 2047.4 & 100.6 & 64.2 & 21.3 & 127.4 & 8.6 \\
2 & -96.9 & 140.8 & 2149.9 & 101.6 & 98.8 & 20.2 & 125.2 & 8.6 \\
2.5 & -196.2 & 144.3 & 2248.9 & 102.7 & 130.1 & 25.1 & 121.1 & 7.6 \\
3 & -291.2 & 153.1 & 2340.7 & 95.6 & 161.6 & 24.9 & 118.1 & 7.7 \\
3.5 & -383.0 & 159.9 & 2437.7 & 98.8 & 193.9 & 26.2 & 116.1 & 7.5 \\
4 & -469.7 & 159.8 & 2514.9 & 99.3 & 224.9 & 23.7 & 112.7 & 9.6 \\
4.5 & -531.3 & 154.2 & 2578.2 & 96.4 & 254.1 & 24.8 & 108.6 & 9.4 \\
5 & -579.2 & 136.0 & 2624.7 & 100.1 & 284.8 & 25.8 & 107.9 & 10.3 \\
5.5 & -637.3 & 119.3 & 2680.9 & 104.6 & 316.9 & 27.5 & 105.9 & 8.8 \\
6 & -684.3 & 123.9 & 2726.8 & 105.5 & 347.4 & 26.5 & 101.2 & 10.9 \\
& -733.2 & 114.6 & 2767.3 & 104.1 & 378.4 & 29.1 & 99.8 & 9.7
\end{tabular}

\begin{tabular}{c|ccc}
$\begin{array}{c}\text { ACTIVATION } \\
(\mathbf{m m})\end{array}$ & $\begin{array}{c}\text { M/F } \\
\text { ALPHA }\end{array}$ & $\begin{array}{c}\text { M/F } \\
\text { BETA }\end{array}$ & $\begin{array}{c}\text { RATIO } \\
\text { ALPHABETA }\end{array}$ \\
\hline 0 & 525.7 & 4094.5 & \\
0.5 & 3.8 & 65.0 & 0.13 \\
1 & 0.0 & 31.9 & 0.06 \\
1.5 & -1.0 & 21.8 & 0.00 \\
2 & -1.5 & 17.3 & -0.05 \\
2.5 & -1.8 & 14.5 & -0.09 \\
3 & -2.0 & 12.6 & -0.12 \\
3.5 & -2.1 & 11.2 & -0.16 \\
4 & -2.1 & 10.1 & -0.19 \\
4.5 & -2.0 & 9.2 & -0.21 \\
5 & -2.0 & 8.5 & -0.22 \\
5.5 & -2.0 & 7.8 & -0.24 \\
6 & -1.9 & 7.3 & -0.25
\end{tabular}


TABLE 20: SUMMARY OF MEASURED FORCE SYSTEM

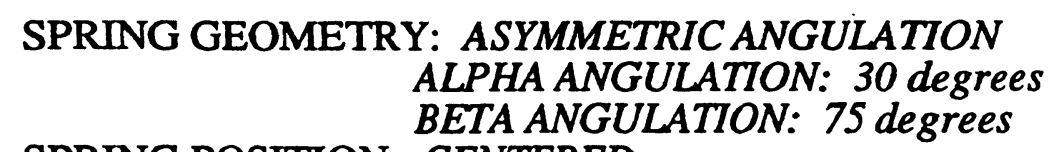

SPRING POSITION: CENTERED

\begin{tabular}{c|cccccccc} 
& \multicolumn{2}{|c}{ ALPHA } & \multicolumn{2}{c}{ BETA } & \multicolumn{2}{c}{ HORIZONTAL } & \multicolumn{2}{c}{ VERTICAL } \\
$\begin{array}{c}\text { ACTIVATION } \\
(\mathrm{mm})\end{array}$ & \multicolumn{2}{c}{ MOMENT $\left(\mathrm{g}^{*} \mathrm{~mm}\right)$} & \multicolumn{2}{c}{ MOMENT } & $\left(\mathrm{g}^{*} \mathrm{~mm}\right)$ & \multicolumn{2}{c}{ FORCE (g) } & \multicolumn{2}{c}{ FORCE (g) } \\
\hline 0 & -159.8 & 115.7 & 1708.8 & 165.4 & -8.8 & 10.4 & 103.0 & 13.0 \\
0.5 & -281.7 & 121.7 & 1822.9 & 148.0 & 28.1 & 11.7 & 100.9 & 11.2 \\
1 & -385.1 & 118.3 & 1921.9 & 143.4 & 61.7 & 13.9 & 99.1 & 10.4 \\
1.5 & -484.2 & 119.8 & 2014.9 & 137.5 & 91.1 & 14.5 & 95.3 & 10.4 \\
2 & -575.0 & 119.8 & 2108.1 & 134.8 & 123.4 & 14.4 & 92.7 & 11.9 \\
2.5 & -671.1 & 126.0 & 2190.3 & 127.8 & 158.0 & 13.4 & 88.3 & 14.0 \\
3 & -765.1 & 132.1 & 2269.9 & 116.2 & 187.2 & 15.9 & 87.7 & 12.6 \\
3.5 & -860.3 & 146.5 & 2357.8 & 111.1 & 218.9 & 15.0 & 85.2 & 12.2 \\
4 & -937.3 & 133.0 & 2424.6 & 115.9 & 246.7 & 15.2 & 84.4 & 12.7 \\
4.5 & -995.1 & 118.5 & 2462.9 & 119.0 & 279.9 & 15.9 & 82.2 & 13.0 \\
5 & -1049.3 & 108.5 & 2508.7 & 122.1 & 310.4 & 15.1 & 81.1 & 12.1 \\
5.5 & -1093.9 & 97.6 & 2551.8 & 128.5 & 340.2 & 17.5 & 79.1 & 11.8 \\
6 & -1153.7 & 92.6 & 2599.0 & 125.3 & 371.8 & 18.6 & 79.0 & 11.7
\end{tabular}

\begin{tabular}{c|ccc}
$\begin{array}{c}\text { ACTIVATION } \\
(\mathbf{m m})\end{array}$ & $\begin{array}{c}\text { M/F } \\
\text { ALPHA }\end{array}$ & $\begin{array}{c}\text { M/F } \\
\text { BETA }\end{array}$ & $\begin{array}{c}\text { RATIO } \\
\text { ALPHAMETA }\end{array}$ \\
\hline 0 & 18.2 & -194.7 & \\
0.5 & -10.0 & 64.8 & -0.09 \\
1 & -6.2 & 31.2 & -0.15 \\
1.5 & -5.3 & 22.1 & -0.20 \\
2 & -4.7 & 17.1 & -0.24 \\
2.5 & -4.2 & 13.9 & -0.27 \\
3 & -4.1 & 12.1 & -0.31 \\
3.5 & -3.9 & 10.8 & -0.34 \\
4 & -3.8 & 9.8 & -0.36 \\
4.5 & -3.6 & 8.8 & -0.39 \\
5 & -3.4 & 8.1 & -0.40 \\
5.5 & -3.2 & 7.5 & -0.42 \\
6 & -3.1 & 7.0 & -0.43
\end{tabular}


TABLE 21: SUMMARY OF MEASURED FORCE SYSTEM

SPRING GEOMETRY: ASYMMETRIC ANGULATION

ALPHA ANGULATION: 45 degrees

BETA ANGULATION: 75 degrees

SPRING POSITION: CENTERED

\begin{tabular}{c|cccccccc} 
& \multicolumn{2}{|c}{ ALPHA } & \multicolumn{2}{c}{ BETA } & \multicolumn{2}{c}{ HORIZONTAL } & \multicolumn{2}{c}{ VERTICAL } \\
$\begin{array}{c}\text { ACTIVATION } \\
(\mathrm{mm})\end{array}$ & \multicolumn{2}{|c}{ MOMENT $(\mathrm{g} * \mathrm{~mm})$} & \multicolumn{2}{c}{ MOMENT } & $(\mathrm{g} * \mathrm{~mm})$ & \multicolumn{2}{c}{ FORCE (g) } & \multicolumn{2}{c}{ FORCE $(\mathrm{g})$} \\
\hline 0 & $-5 E A N$ & S.D. & MEAN & S.D. & MEAN & S.D & MEAN & S.D. \\
\hline 0.5 & -675.0 & 93.4 & 1745.9 & 121.0 & -2.1 & 8.3 & 67.2 & 6.3 \\
1 & -777.3 & 95.2 & 1850.7 & 98.1 & 61.7 & 14.7 & 69.6 & 6.1 \\
1.5 & -867.1 & 104.3 & 1940.4 & 95.4 & 90.1 & 17.6 & 68.0 & 6.1 \\
2 & -956.9 & 108.8 & 2012.9 & 86.9 & 118.3 & 17.3 & 67.0 & 7.2 \\
2.5 & -1035.8 & 119.8 & 2096.8 & 78.8 & 148.4 & 20.6 & 66.1 & 7.0 \\
3 & -1115.2 & 121.3 & 2172.0 & 82.2 & 176.4 & 22.5 & 64.7 & 7.1 \\
3.5 & -1191.7 & 133.3 & 2242.1 & 81.4 & 205.8 & 20.0 & 63.7 & 7.2 \\
4 & -1257.6 & 136.9 & 2309.3 & 85.0 & 233.2 & 23.8 & 63.4 & 7.6 \\
4.5 & -1316.9 & 137.9 & 2369.1 & 88.8 & 262.1 & 24.3 & 63.1 & 8.0 \\
5 & -1370.9 & 134.7 & 2420.3 & 90.5 & 290.1 & 25.8 & 61.0 & 7.8 \\
5.5 & -1422.7 & 139.5 & 2473.2 & 104.5 & 320.9 & 27.5 & 61.3 & 8.8 \\
6 & -1464.8 & 138.1 & 2523.7 & 109.7 & 349.4 & 28.9 & 61.0 & 8.6
\end{tabular}

\begin{tabular}{c|ccc}
$\begin{array}{c}\text { ACTIVATION } \\
(\mathbf{m m})\end{array}$ & $\begin{array}{c}\text { M/F } \\
\text { ALPHA }\end{array}$ & $\begin{array}{c}\text { M/F } \\
\text { BETA }\end{array}$ & $\begin{array}{c}\text { RATIO } \\
\text { ALPHABETA }\end{array}$ \\
\hline 0 & 265.3 & -779.6 & \\
0.5 & -20.5 & 53.3 & -0.34 \\
1 & -12.6 & 30.0 & -0.38 \\
1.5 & -9.6 & 21.5 & -0.42 \\
2 & -8.1 & 17.0 & -0.45 \\
2.5 & -7.0 & 14.1 & -0.48 \\
3 & -6.3 & 12.3 & -0.49 \\
3.5 & -5.8 & 10.9 & -0.51 \\
4 & -5.4 & 9.9 & -0.53 \\
4.5 & -5.0 & 9.0 & -0.54 \\
5 & -4.7 & 8.3 & -0.56 \\
5.5 & -4.4 & 7.7 & -0.57 \\
6 & -4.2 & 7.2 & -0.58
\end{tabular}


TABLE 22: SUMMARY OF MEASURED FORCE SYSTEM

SPRING GEOMETRY: ASYMMETRIC ANGULATION ALPHA ANGULATION: 60 degrees

SPRING POSITION: CENTERED BETA ANGULATION: 75 degrees

\begin{tabular}{c|cccccccc} 
& \multicolumn{2}{|c}{ ALPHA } & \multicolumn{2}{c}{ BETA } & \multicolumn{2}{c}{ HORIZONTAL } & \multicolumn{2}{c}{ VERTICAL } \\
$\begin{array}{c}\text { ACTIVATION } \\
\text { (mm) }\end{array}$ & \multicolumn{2}{c}{ MOMENT $\left(\mathrm{g}^{*} \mathrm{~mm}\right)$} & \multicolumn{2}{c}{ MOMENT $(\mathrm{g} * \mathrm{~mm})$} & \multicolumn{2}{c}{ FORCE $(\mathrm{g})$} & \multicolumn{2}{c}{ FORCE $(\mathrm{g})$} \\
\hline 0 & -951.8 & S.D. & MEAN & S.D. & MEAN & S.D & MEAN & S.D. \\
\hline 0.5 & -1047.8 & 103.6 & 1479.6 & 133.4 & -6.0 & 6.5 & 35.6 & 9.3 \\
1 & -1132.3 & 98.1 & 1701.2 & 122.4 & 32.1 & 14.3 & 39.3 & 7.2 \\
1.5 & -1214.3 & 93.2 & 1780.3 & 113.5 & 58.8 & 12.7 & 40.0 & 7.6 \\
2 & -1293.4 & 92.2 & 1872.1 & 108.8 & 112.1 & 12.3 & 39.1 & 7.6 \\
2.5 & -1364.7 & 90.5 & 1961.3 & 99.5 & 139.3 & 14.4 & 49.0 & 7.2 \\
3 & -1435.6 & 91.1 & 2033.3 & 104.1 & 166.0 & 16.3 & 40.7 & 6.4 \\
3.5 & -1505.6 & 94.9 & 2110.4 & 102.2 & 194.0 & 15.4 & 40.4 & 7.4 \\
4 & -1571.4 & 94.6 & 2183.7 & 89.7 & 220.2 & 16.9 & 41.2 & 6.7 \\
4.5 & -1623.0 & 99.0 & 2253.6 & 90.4 & 246.4 & 17.8 & 41.0 & 7.5 \\
5 & -1667.0 & 98.8 & 2305.6 & 81.4 & 273.6 & 18.9 & 41.8 & 7.1 \\
5.5 & -1722.0 & 100.4 & 2368.2 & 84.4 & 301.0 & 18.4 & 42.1 & 8.1 \\
6 & -1770.1 & 104.7 & 2421.8 & 79.0 & 328.4 & 18.2 & 41.9 & 8.4
\end{tabular}

\begin{tabular}{c|ccc}
$\begin{array}{c}\text { ACTIVATION } \\
(\mathrm{mm})\end{array}$ & $\begin{array}{c}\text { M/F } \\
\text { ALPHA }\end{array}$ & $\begin{array}{c}\text { M/F } \\
\text { BETA }\end{array}$ & $\begin{array}{c}\text { RATIO } \\
\text { ALPHA/BETA }\end{array}$ \\
\hline 0 & 158.6 & -246.6 & \\
0.5 & -32.6 & 49.9 & -0.64 \\
1 & -19.3 & 28.9 & -0.65 \\
1.5 & -14.2 & 20.9 & -0.67 \\
2 & -11.5 & 16.7 & -0.68 \\
2.5 & -9.8 & 14.1 & -0.69 \\
3 & -8.6 & 12.2 & -0.70 \\
3.5 & -7.8 & 10.9 & -0.71 \\
4 & -7.1 & 9.9 & -0.71 \\
4.5 & -6.6 & 9.1 & -0.72 \\
5 & -6.1 & 8.4 & -0.72 \\
5.5 & -5.7 & 7.9 & -0.72 \\
6 & -5.4 & 7.4 & -0.73
\end{tabular}


TABLE 23: SUMMARY OF MEASURED FORCE SYSTEM

SPRING GEOMETRY: ASYMMETRIC ANGULATION ALPHA ANGULATION: 75 degrees

SPRING POSITION: CENTERED BETA ANGULATION: 0 degrees

\begin{tabular}{c|cccccccc} 
& \multicolumn{2}{|c}{ ALPHA } & \multicolumn{2}{c}{ BETA } & \multicolumn{2}{c}{ HORIZONTAL } & \multicolumn{2}{c}{ VERTICAL } \\
$\begin{array}{c}\text { ACTIVATION } \\
(\mathrm{mm})\end{array}$ & \multicolumn{2}{|c}{ MOMENT $\left(\mathrm{g}^{*} \mathrm{~mm}\right)$} & \multicolumn{2}{c}{ MOMENT $\left(\mathrm{g}^{*} \mathrm{~mm}\right)$} & \multicolumn{2}{c}{ FORCE (g) } & \multicolumn{2}{c}{ FORCE (g) } \\
\hline 0 & MEAN & S.D. & MEAN & S.D. & MEAN & S.D & MEAN & S.D. \\
\hline 0.5 & -2306.0 & 188.4 & -1228.2 & 79.2 & -26.6 & 7.8 & -208.2 & 20.1 \\
1 & -2365.4 & 170.3 & -1014.7 & 56.7 & 32.9 & 14.9 & -186.9 & 13.5 \\
1.5 & -2447.9 & 164.4 & -886.4 & 60.1 & 64.6 & 12.6 & -181.1 & 15.0 \\
2 & -2523.8 & 167.8 & -762.6 & 52.3 & 98.2 & 13.0 & -170.1 & 15.0 \\
2.5 & -2596.6 & 170.3 & -640.9 & 57.2 & 130.2 & 14.3 & -161.1 & 14.3 \\
3 & -2641.6 & 168.1 & -522.6 & 52.4 & 160.4 & 8.1 & -163.9 & 31.9 \\
3.5 & -2703.7 & 181.1 & -405.7 & 59.5 & 196.4 & 14.7 & -145.0 & 12.6 \\
4 & -2743.0 & 187.6 & -290.7 & 56.5 & 227.0 & 10.7 & -136.7 & 11.6 \\
4.5 & -2797.1 & 207.4 & -181.8 & 58.6 & 262.0 & 10.1 & -129.2 & 9.8 \\
5 & -2843.9 & 243.0 & -90.6 & 52.8 & 293.8 & 16.1 & -123.1 & 9.9 \\
5.5 & -2818.7 & 183.7 & 32.0 & 71.8 & 330.0 & 13.8 & -114.0 & 10.7 \\
6 & -2820.7 & 178.9 & 107.4 & 57.6 & 365.2 & 17.2 & -107.2 & 8.6 \\
& -2824.6 & 173.9 & 191.8 & 60.9 & 402.4 & 20.0 & -99.6 & 7.4
\end{tabular}

\begin{tabular}{c|ccc}
$\begin{array}{c}\text { ACTIVATION } \\
(\mathbf{m m})\end{array}$ & $\begin{array}{c}\text { M/F } \\
\text { ALPHA }\end{array}$ & $\begin{array}{c}\text { M/F } \\
\text { BETA }\end{array}$ & $\begin{array}{c}\text { RATIO } \\
\text { ALPHA/BETA }\end{array}$ \\
\hline 0 & 86.8 & 46.3 & 0.54 \\
0.5 & -71.9 & -30.9 & 0.43 \\
1 & -37.9 & -13.7 & 0.36 \\
1.5 & -25.7 & -7.8 & 0.30 \\
2 & -19.9 & -4.9 & 0.25 \\
2.5 & -16.5 & -3.3 & 0.20 \\
3 & -13.8 & -2.1 & 0.15 \\
3.5 & -12.1 & -1.3 & 0.11 \\
4 & -10.7 & -0.7 & 0.07 \\
4.5 & -9.7 & -0.3 & 0.03 \\
5 & -8.5 & 0.1 & -0.01 \\
5.5 & -7.7 & 0.3 & -0.04 \\
6 & -7.0 & 0.5 & -0.07
\end{tabular}


TABLE 24: SUMMARY OF MEASURED FORCE SYSTEM

SPRING GEOMETRY: ASYMMETRIC ANGULATION

ALPHA ANGULATION: 75 degrees

BETA ANGULATION: 15 degrees

SPRING POSITION: CENTERED

\begin{tabular}{c|cccccccc} 
& \multicolumn{3}{|c}{ ALPHA } & \multicolumn{2}{c}{ BETA } & \multicolumn{2}{c}{ HORIZONTAL } & \multicolumn{2}{c}{ VERTICAL } \\
$\begin{array}{c}\text { ACTIVATION } \\
(\mathrm{mm})\end{array}$ & \multicolumn{2}{c}{ MOMENT $\left(\mathrm{g}^{*} \mathrm{~mm}\right)$} & MOMENT & $\left(\mathrm{g}^{*} \mathrm{~mm}\right)$ & \multicolumn{2}{c}{ FORCE $(\mathrm{g})$} & \multicolumn{2}{c}{ FORCE (g) } \\
\hline 0 & MEAN & S.D. & MEAN & S.D. & MEAN & S.D & MEAN & S.D. \\
\hline 0.5 & -2016.4 & 155.3 & -1128.1 & 288.6 & -34.0 & 11.4 & -187.6 & 26.0 \\
1 & -2135.4 & 154.0 & -997.9 & 304.3 & 0.4 & 24.1 & -179.1 & 21.4 \\
1.5 & -2248.9 & 144.6 & -901.4 & 287.4 & 26.6 & 30.0 & -167.6 & 20.9 \\
2 & -2358.6 & 139.2 & -792.9 & 308.1 & 59.6 & 21.4 & -159.8 & 20.9 \\
2.5 & -2462.9 & 138.3 & -678.7 & 310.1 & 93.1 & 23.8 & -152.8 & 18.8 \\
3 & -2543.8 & 126.5 & -581.2 & 302.6 & 117.9 & 22.8 & -147.7 & 15.4 \\
3.5 & -2618.6 & 124.3 & -482.8 & 303.2 & 153.0 & 24.6 & -142.6 & 15.0 \\
4 & -2698.1 & 117.8 & -376.3 & 298.5 & 182.0 & 25.4 & -135.9 & 12.9 \\
4.5 & -2748.7 & 110.5 & -276.8 & 310.7 & 212.2 & 24.7 & -128.2 & 14.5 \\
5 & -2812.4 & 97.7 & -193.2 & 289.3 & 238.1 & 27.0 & -122.2 & 13.1 \\
5.5 & -2862.4 & 90.3 & -111.4 & 293.5 & 275.9 & 32.1 & -115.6 & 9.0 \\
6 & -2897.1 & 80.4 & -21.9 & 292.2 & 306.0 & 32.5 & -111.2 & 7.7 \\
& -2913.8 & 97.3 & 51.3 & 292.0 & 336.3 & 35.8 & -105.1 & 6.7
\end{tabular}

\begin{tabular}{c|ccc}
$\begin{array}{c}\text { ACTIVATION } \\
(\mathrm{mm})\end{array}$ & $\begin{array}{c}\text { M/F } \\
\text { ALPHA }\end{array}$ & $\begin{array}{c}\text { M/F } \\
\text { BETA }\end{array}$ & $\begin{array}{c}\text { RATIO } \\
\text { ALPHABETA }\end{array}$ \\
\hline 0 & 59.3 & 33.2 & 0.56 \\
0.5 & -4804.7 & -2245.2 & 0.47 \\
1 & -84.7 & -33.9 & 0.40 \\
1.5 & -39.6 & -13.3 & 0.34 \\
2 & -26.5 & -7.3 & 0.28 \\
2.5 & -21.6 & -4.9 & 0.23 \\
3 & -17.1 & -3.2 & 0.18 \\
3.5 & -14.8 & -2.1 & 0.14 \\
4 & -13.0 & -1.3 & 0.10 \\
4.5 & -11.8 & -0.8 & 0.07 \\
5 & -10.4 & -0.4 & 0.04 \\
5.5 & -9.5 & -0.1 & 0.01 \\
6 & -8.7 & 0.2 & -0.02
\end{tabular}


TABLE 25: SUMMARY OF MEASURED FORCE SYSTEM

\section{SPRING GEOMETRY: ASYMMETRIC ANGULATION \\ ALPHA ANGULATION: 75 degrees \\ BETA ANGULATION: 30 degrees}

SPRING POSITION: CENTERED

\begin{tabular}{c|cccccccc} 
& \multicolumn{2}{|c}{ ALPHA } & \multicolumn{2}{c}{ BETA } & \multicolumn{2}{c}{ HORIZONTAL } & \multicolumn{2}{c}{ VERTICAL } \\
$\begin{array}{c}\text { ACTIVATION } \\
(\mathrm{mm})\end{array}$ & MOMENT $\left(\mathrm{g}^{*} \mathrm{~mm}\right)$ & \multicolumn{2}{c}{ MOMENT $\left(\mathrm{g}^{*} \mathrm{~mm}\right)$} & \multicolumn{2}{c}{ FORCE (g) } & \multicolumn{2}{c}{ FORCE (g) } \\
\hline 0 & MEAN & S.D. & MEAN & S.D. & MEAN & S.D & MEAN & S.D. \\
\hline 0.5 & -2076.7 & 170.3 & -150.9 & 129.6 & -23.3 & 22.0 & -136.7 & 16.9 \\
1 & -2180.2 & 165.3 & 13.8 & 150.0 & 73.7 & 32.7 & -122.3 & 15.0 \\
1.5 & -2268.2 & 162.5 & 139.1 & 149.9 & 104.2 & 26.6 & -116.7 & 15.4 \\
2 & -2338.9 & 158.6 & 246.9 & 161.0 & 139.2 & 28.4 & -108.9 & 15.4 \\
2.5 & -2416.2 & 152.1 & 350.2 & 167.1 & 172.4 & 24.6 & -103.4 & 14.8 \\
3 & -2476.2 & 156.8 & 459.7 & 169.5 & 202.6 & 26.1 & -96.6 & 16.7 \\
3.5 & -2525.3 & 154.9 & 545.4 & 174.5 & 236.1 & 26.7 & -91.4 & 16.5 \\
4 & -2580.6 & 141.4 & 646.2 & 161.2 & 272.1 & 23.9 & -85.0 & 16.5 \\
4.5 & -2601.7 & 144.9 & 737.8 & 161.8 & 299.1 & 22.8 & -80.3 & 15.9 \\
5 & -2626.6 & 148.9 & 812.7 & 171.7 & 338.3 & 24.9 & -75.0 & 17.2 \\
5.5 & -2654.0 & 140.3 & 881.9 & 184.6 & 372.2 & 30.0 & -70.3 & 18.1 \\
6 & -2674.8 & 131.2 & 951.4 & 187.6 & 407.2 & 30.4 & -66.4 & 17.9 \\
& -2684.0 & 131.8 & 1038.3 & 185.6 & 436.9 & 26.4 & -59.7 & 17.9
\end{tabular}

\begin{tabular}{c|ccc}
$\begin{array}{c}\text { ACTIVATION } \\
(\mathrm{mm})\end{array}$ & $\begin{array}{c}\text { M/F } \\
\text { ALPHA }\end{array}$ & $\begin{array}{c}\text { M/F } \\
\text { BETA }\end{array}$ & $\begin{array}{c}\text { RATIO } \\
\text { ALPHA/BETA }\end{array}$ \\
\hline 0 & 89.0 & 6.5 & 0.07 \\
0.5 & -29.6 & 0.2 & -0.01 \\
1 & -21.8 & 1.3 & -0.06 \\
1.5 & -16.8 & 1.8 & -0.11 \\
2 & -14.0 & 2.0 & -0.15 \\
2.5 & -12.2 & 2.3 & -0.19 \\
3 & -10.7 & 2.3 & -0.22 \\
3.5 & -9.5 & 2.4 & -0.25 \\
4 & -8.7 & 2.5 & -0.29 \\
4.5 & -7.8 & 2.4 & -0.31 \\
5 & -7.1 & 2.4 & -0.33 \\
5.5 & -6.6 & 2.3 & -0.36 \\
6 & -6.1 & 2.4 & -0.39
\end{tabular}


TABLE 26: SUMMARY OF MEASURED FORCE SYSTEM

SPRING GEOMETRY: ASYMMETRIC ANGULATION

ALPHA ANGULATION: 75 degrees

SPRING POSITION: CENTERED

BETA ANGULATION: 45 degrees

\begin{tabular}{|c|c|c|c|c|c|c|c|c|}
\hline \multirow{2}{*}{$\begin{array}{l}\text { ACTIVATION } \\
(\mathrm{mm})\end{array}$} & \multicolumn{2}{|c|}{$\begin{array}{c}\text { ALPHA } \\
\text { MOMENT }\left(g^{*} \mathrm{~mm}\right)\end{array}$} & \multicolumn{2}{|c|}{$\begin{array}{c}\text { BETA } \\
\text { MOMENT }(g * \mathrm{~mm})\end{array}$} & \multicolumn{2}{|c|}{$\begin{array}{l}\text { HORIZONTAL } \\
\text { FORCE (g) }\end{array}$} & \multicolumn{2}{|c|}{$\begin{array}{l}\text { VERTICAL } \\
\text { FORCE (g) }\end{array}$} \\
\hline & MEAN & S.D. & MEAN & S.D. & MEAN & S.D & MEAN & S.D. \\
\hline 0 & -1878.0 & 258.8 & 118.2 & 179.2 & -11.3 & $\overline{14.6}$ & -102.7 & 23.1 \\
\hline 0.5 & -1979.1 & 230.8 & 237.4 & 178.4 & 30.8 & 9.6 & -94.9 & 21.1 \\
\hline 1 & -2073.1 & 231.4 & 337.9 & 169.6 & 62.3 & 10.7 & -86.9 & 18.6 \\
\hline 1.5 & -2155.3 & 225.5 & 438.1 & 171.5 & 101.2 & 9.5 & -81.3 & 18.6 \\
\hline 2 & -2239.2 & 220.0 & 543.3 & 160.5 & 130.7 & 12.9 & -78.0 & 15.4 \\
\hline 2.5 & -2314.6 & 213.8 & 650.0 & 161.9 & 158.0 & 11.2 & -72.3 & 15.0 \\
\hline 3 & -2389.6 & 213.6 & 733.9 & 156.2 & 197.1 & 14.7 & -68.8 & 14.6 \\
\hline 3.5 & -2439.0 & 196.7 & 816.7 & 143.4 & 228.2 & 9.6 & -65.2 & 12.6 \\
\hline 4 & -2493.0 & 204.2 & 903.8 & 132.1 & 263.2 & 16.1 & -59.8 & 11.8 \\
\hline 4.5 & -2532.6 & 197.1 & 977.9 & 133.1 & 292.8 & 14.7 & -57.4 & 10.0 \\
\hline 5 & -2562.7 & 182.7 & 1056.7 & 135.7 & 325.4 & 14.8 & -52.1 & 10.4 \\
\hline 5.5 & -2602.7 & 165.8 & 1124.4 & 132.0 & 360.9 & 18.3 & -47.4 & 10.7 \\
\hline 6 & -2639.0 & 154.7 & 1194.9 & 129.1 & 392.9 & 20.5 & -44.3 & 10.8 \\
\hline
\end{tabular}

\begin{tabular}{c|ccc}
$\begin{array}{c}\text { ACTIVATION } \\
(\mathbf{m m})\end{array}$ & $\begin{array}{c}\text { M/F } \\
\text { ALPHA }\end{array}$ & $\begin{array}{c}\text { M/F } \\
\text { BETA }\end{array}$ & $\begin{array}{c}\text { RATIO } \\
\text { ALPHA/BETA }\end{array}$ \\
\hline 0 & 165.7 & -10.4 & -0.07 \\
0.5 & -64.3 & 7.7 & -0.13 \\
1 & -33.3 & 5.4 & -0.17 \\
1.5 & -21.3 & 4.3 & -0.21 \\
2 & -17.1 & 4.2 & -0.25 \\
2.5 & -14.6 & 4.1 & -0.29 \\
3 & -12.1 & 3.7 & -0.31 \\
3.5 & -10.7 & 3.6 & -0.34 \\
4 & -9.5 & 3.4 & -0.37 \\
4.5 & -8.7 & 3.3 & -0.39 \\
5 & -7.9 & 3.2 & -0.42 \\
5.5 & -7.2 & 3.1 & -0.44 \\
6 & -6.7 & 3.0 & -0.46
\end{tabular}


TABLE 27: SUMMARY OF MEASURED FORCE SYSTEM

SPRING GEOMETRY: ASYMMETRIC ANGULATION ALPHA ANGULATION: 75 degrees

SPRING POSITION: CENTERED BETA ANGULATION: 60 degrees

\begin{tabular}{c|cccccccc} 
& \multicolumn{2}{|c}{ ALPHA } & \multicolumn{2}{c}{ BETA } & \multicolumn{2}{c}{ HORIZONTAL } & \multicolumn{2}{c}{ VERTICAL } \\
$\begin{array}{c}\text { ACTIVATION } \\
(\mathrm{mm})\end{array}$ & MOMENT $\left(\mathrm{g}^{*} \mathrm{~mm}\right)$ & MOMENT $\left(\mathrm{g}^{*} \mathrm{~mm}\right)$ & \multicolumn{2}{c}{ FORCE (g) } & \multicolumn{2}{c}{ FORCE (g) } \\
\hline 0 & MEAN & S.D. & MEAN & S.D. & MEAN & S.D & MEAN & S.D. \\
\hline 0.5 & -1771.6 & 46.6 & 775.7 & 162.0 & 7.0 & 14.1 & -49.6 & 5.0 \\
1 & -1876.9 & 45.8 & 873.4 & 168.9 & 40.6 & 13.8 & -44.9 & 10.0 \\
1.5 & -1968.9 & 33.6 & 973.7 & 173.7 & 74.7 & 13.5 & -38.1 & 9.9 \\
2 & -2059.3 & 26.7 & 1057.4 & 189.7 & 102.3 & 18.8 & -37.6 & 9.9 \\
2.5 & -2143.3 & 22.3 & 1145.6 & 186.3 & 129.4 & 14.7 & -33.7 & 9.0 \\
3 & -2230.7 & 29.0 & 1230.8 & 192.0 & 160.8 & 12.3 & -32.4 & 10.2 \\
3.5 & -2312.8 & 32.0 & 1327.6 & 200.0 & 193.0 & 19.3 & -30.4 & 10.5 \\
4 & -2382.7 & 62.8 & 1411.1 & 193.4 & 220.2 & 14.2 & -26.4 & 10.7 \\
4.5 & -2442.1 & 75.4 & 1480.1 & 201.8 & 253.0 & 18.9 & -25.4 & 10.6 \\
5 & -2498.0 & 70.2 & 1553.1 & 208.2 & 276.2 & 20.9 & -24.3 & 9.7 \\
5.5 & -2527.2 & 54.0 & 1614.7 & 208.0 & 313.2 & 20.0 & -21.2 & 12.0 \\
6 & -2575.1 & 55.3 & 1678.1 & 217.3 & 344.9 & 19.9 & -20.6 & 11.8 \\
& -2624.4 & 63.3 & 1735.8 & 217.6 & 372.0 & 25.5 & -17.1 & 11.0
\end{tabular}

\begin{tabular}{c|ccc}
$\begin{array}{c}\text { ACTIVATION } \\
(\mathbf{m m})\end{array}$ & $\begin{array}{c}\text { M/F } \\
\text { ALPHA }\end{array}$ & $\begin{array}{c}\text { MF } \\
\text { BETA }\end{array}$ & $\begin{array}{c}\text { RATIO } \\
\text { ALPHA/BETA }\end{array}$ \\
\hline 0 & -253.1 & 110.8 & -0.44 \\
0.5 & -46.3 & 21.5 & -0.46 \\
1 & -26.4 & 13.0 & -0.49 \\
1.5 & -20.1 & 10.3 & -0.51 \\
2 & -16.6 & 8.8 & -0.53 \\
2.5 & -13.9 & 7.7 & -0.55 \\
3 & -12.0 & 6.9 & -0.57 \\
3.5 & -10.8 & 6.4 & -0.59 \\
4 & -9.7 & 5.9 & -0.61 \\
4.5 & -9.0 & 5.6 & -0.62 \\
5 & -8.1 & 5.2 & -0.64 \\
5.5 & -7.5 & 4.9 & -0.65 \\
6 & -7.1 & 4.7 & -0.66
\end{tabular}


TABLE 28

ALPHA MOMENT

SPRING GEOMETRY: SYMMETRIC ANGULATION

SPRING POSITION: CENTERED

REGRESSION ANALYSIS: WHOLE MODEL *

INDEPENDENT PARAMETER STD.ERROR

\begin{tabular}{lllll} 
VARIABLE & ESTIMATE & ESTIMATE & t-STATISTIC & PROB. $>t$ \\
\hline
\end{tabular}

\begin{tabular}{lcccc}
\hline \hline INTERCEPT & 206.8 & 8.9 & 23.3 & 0.000 \\
ACTIVATION & 126.6 & 2.0 & 64.9 & 0.000 \\
ANGULATION & 14.7 & 0.2 & 92.5 & 0.000
\end{tabular}

ANALYSIS OF VARIANCE

\begin{tabular}{lcccll} 
& SUM OF & \multicolumn{4}{c}{ MEAN } \\
SOURCE & SQUARES & $d f$ & SQUARES & F-RATIO & PROB > F \\
\hline \hline MODEL & 159189266.0 & 2 & 79594633.0 & 6383.5 & 0.000 \\
ERROR & 11633447.5 & 933 & 12468.9 & & \\
\hline TOTAL & 170822713.4 & 935 & & &
\end{tabular}

$\mathrm{R}^{2}=0.9$

$\mathrm{R}=1.0$

STANDARD ERROR OF ESTIMATE $=111.7$

*WHOLE MODEL: $\quad \mathbf{Y}=\beta_{0}+\beta_{1} \mathbf{X}_{1}+\beta_{2} \mathbf{X}_{2}+\mathbf{E}$

LEGEND:

$\mathrm{Y}=$ ALPHA MOMENT (DV)

$\mathrm{X}_{1}=$ ACTIVATION OF T-SPRING (millimeters), $\left(\mathrm{IV}_{1}\right)$

$\mathrm{X}_{2}=$ ANGULATION OF PREACTIVATION BENDS (degrees), $\left(\mathrm{IV}_{2}\right)$

$\beta_{0}=$ PARAMETER ESTIMATE OF Y-INTERCEPT

$\beta_{1}=$ PARAMETER ESTIMATE, SLOPE

$\beta_{2}=$ PARAMETER ESTIMATE, SLOPE

$\mathrm{E}=\mathrm{ERROR}$ 
BETA MOMENT

SPRING GEOMETRY: SYMMETRIC ANGULATION

SPRING POSITION: CENTERED

REGRESSION ANALYSIS: WHOLE MODEL *

INDEPENDENT PARAMETER STD.ERROR

\begin{tabular}{lllll} 
VARIABLE & ESTIMATE & ESTIMATE & t-STATISTIC & PROB. $>\mathbf{t}$ \\
\hline
\end{tabular}

\begin{tabular}{lcccc}
\hline \hline INTERCEPT & 27.1 & 11.2 & 2.4 & 0.016 \\
ACTIVATION & 187.3 & 2.5 & 75.9 & 0.000 \\
ANGULATION & 18.8 & 0.2 & 93.5 & 0.000
\end{tabular}

ANALYSIS OF VARIANCE

\begin{tabular}{lccccc} 
& SUM OF & \multicolumn{4}{c}{ MEAN } \\
SOURCE & SQUARES & $d f$ & SQUARES & F-RATIO & PROB > F \\
\hline \hline MODEL & 289132088.7 & 2 & 144566044.3 & 7250.3 & 0.000 \\
ERROR & 18603487.2 & 933 & 19939.4 & & \\
\hline TOTAL & 307735575.8 & 935 & & &
\end{tabular}

$\mathrm{R}^{2}=0.9$

$\mathrm{R}=1.0$

STANDARD ERROR OF ESTIMATE $=141.2$

*WHOLE MODEL: $\quad \mathbf{Y}=\beta_{0}+\beta_{1} \mathbf{X}_{1}+\beta_{2} \mathbf{X}_{2}+\mathbf{E}$

LEGEND:

$\mathrm{Y}=$ BETA MOMENT (DV)

$\mathrm{X}_{1}=$ ACTIVATION OF T-SPRING (millimeters), $\left(\mathrm{IV}_{1}\right)$

$\mathrm{X}_{2}=$ ANGULATION OF PREACTIVATION BENDS (degrees), $\left(\mathrm{IV}_{2}\right)$

$\beta_{0}=$ PARAMETER ESTIMATE OF Y-INTERCEPT

$\beta_{1}=$ PARAMETER ESTIMATE, SLOPE

$\beta_{2}=$ PARAMETER ESTIMATE, SLOPE

$\mathrm{E}=\mathrm{ERROR}$ 
HORIZONTAL FORCE

SPRING GEOMETRY: SYMMETRIC ANGULATION

SPRING POSITION: CENTERED

REGRESSION ANALYSIS: WHOLE MODEL *

INDEPENDENT PARAMETER STD.ERROR

\begin{tabular}{lllll} 
VARIABLE & ESTIMATE & ESTIMATE & t-STATISTIC & PROB. $>\mathbf{t}$ \\
\hline \hline
\end{tabular}

\begin{tabular}{lcccc}
\hline \hline INTERCEPT & 54.3 & 2.1 & 25.9 & 0.000 \\
ACTIVATION & 66.9 & 0.5 & 144.8 & 0.000 \\
ANGULATION & -1.0 & 0.0 & -25.3 & 0.000
\end{tabular}

ANGULATION

$-1.0$

0.0

$-25.3$

0.000

ANALYSIS OF VARIANCE

\begin{tabular}{lccccc} 
& SUM OF & \multicolumn{4}{c}{ MEAN } \\
SOURCE & SQUARES & $d f$ & SQUARES & F-RATIO & PROB > F \\
\hline \hline MODEL & 15107056.5 & 2 & 7553528.3 & 10806.3 & 0.000 \\
ERROR & 652161.9 & 933 & 699.0 & & \\
\hline TOTAL & 15759218.4 & 935 & & &
\end{tabular}

$\mathrm{R}^{2}=1.0$

$\mathrm{R}=1.0$

STANDARD ERROR OF ESTIMATE $=26.4$

*WHOLE MODEL: $\quad \mathbf{Y}=\beta_{0}+\beta_{1} \mathbf{X}_{1}+\beta_{2} \mathbf{X}_{2}+\mathbf{E}$

LEGEND:

$\mathrm{Y}=$ HORIZONTAL FORCE (DV)

$\mathrm{X}_{1}=$ ACTIVATION OF T-SPRING (millimeters), $\left(\mathrm{IV}_{1}\right)$

$\mathrm{X}_{2}=$ ANGULATION OF PREACTIVATION BENDS (degrees), $\left(\mathrm{IV}_{2}\right)$

$\beta_{0}=$ PARAMETER ESTIMATE OF Y-INTERCEPT

$\beta_{1}=$ PARAMETER ESTIMATE, SLOPE

$\beta_{2}=$ PARAMETER ESTIMATE, SLOPE

$E=E R R O R$ 
TABLE 31

VERTICAL FORCE

SPRING GEOMETRY: SYMMETRIC ANGULATION

SPRING POSITION: CENTERED

REGRESSION ANALYSIS: WHOLE MODEL *

INDEPENDENT PARAMETER STD.ERROR

\begin{tabular}{lllll} 
VARIABLE & ESTIMATE & ESTIMATE & t-STATISTIC & PROB. $>\mathbf{t}$ \\
\hline \hline
\end{tabular}

\begin{tabular}{lcccc}
\hline \hline INTERCEPT & -6.5 & 1.0 & -6.4 & 0.000 \\
ACTIVATION & 4.8 & 0.2 & 21.3 & 0.000 \\
ANGULATION & 0.2 & 0.0 & 13.5 & 0.000
\end{tabular}

ANALYSIS OF VARIANCE

\begin{tabular}{lrrrrr} 
SOURCE & $\begin{array}{c}\text { SUM OF } \\
\text { SQUARES }\end{array}$ & $d f$ & \multicolumn{1}{c}{ MEAN } \\
SQUARES & F-RATIO & PROB > F \\
\hline \hline MODEL & 105718.8 & 2 & 52859.4 & 319.3 & 0.000 \\
ERROR & 154443.6 & 933 & 165.5 & & \\
\hline TOTAL & 260162.4 & 935 & & &
\end{tabular}

$\mathrm{R}^{2}=0.4$

$\mathrm{R}=0.6$

STANDARD ERROR OF ESTIMATE $=12.9$

*WHOLE MODEL: $\quad \mathbf{Y}=\beta_{0}+\beta_{1} \mathbf{X}_{1}+\beta_{2} \mathbf{X}_{2}+\mathbf{E}$

LEGEND:

$\mathrm{Y}=$ VERTICAL FORCE (DV)

$\mathrm{X}_{1}=$ ACTIVATION OF T-SPRING (millimeters), $\left(\mathrm{IV}_{1}\right)$

$\mathrm{X}_{2}=$ ANGULATION OF PREACTIVATION BENDS (degrees), $\left(\mathrm{IV}_{2}\right)$

$\beta_{0}=$ PARAMETER ESTIMATE OF Y-INTERCEPT

$\beta_{1}=$ PARAMETER ESTIMATE, SLOPE

$\beta_{2}=$ PARAMETER ESTIMATE, SLOPE

$\mathrm{E}=\mathrm{ERROR}$ 
TABLE 32

RATIO, ALPHA MOMENT/BETA MOMENT

SPRING GEOMETRY: SYMMETRIC ANGULATION

SPRING POSITION: CENTERED

REGRESSION ANALYSIS: WHOLE MODEL *

INDEPENDENT PARAMETER STD.ERROR

\begin{tabular}{lllll} 
VARIABLE & ESTIMATE & ESTIMATE & t-STATISTIC & PROB. $>\mathbf{t}$ \\
\hline \hline
\end{tabular}

\begin{tabular}{lcccc}
\hline \hline INTERCEPT & 2.4 & 0.5 & 5.0 & 0.000 \\
ACTIVATION & -0.2 & 0.1 & -1.9 & 0.053 \\
ANGULATION & 0.0 & 0.0 & -1.9 & 0.052
\end{tabular}

ANGULATION

0.0

ANALYSIS OF VARIANCE

\begin{tabular}{lrrrrr} 
& SUM OF & \multicolumn{1}{c}{ MEAN } \\
SOURCE & SQUARES & $d f$ & SQUARES & F-RATIO & PROB > F \\
\hline \hline MODEL & 271.7 & 2 & 135.9 & 3.8 & 0.023 \\
ERROR & 33535.4 & 933 & 35.9 & & \\
\hline TOTAL & 33807.1 & 935 & & &
\end{tabular}

$\mathrm{R}^{2}=0.0$

$\mathrm{R}=0.0$

STANDARD ERROR OF ESTIMATE $=6.0$

*WHOLE MODEL: $\quad \mathbf{Y}=\beta_{0}+\beta_{1} \mathbf{X}_{1}+\beta_{2} \mathbf{X}_{2}+\mathbf{E}$

LEGEND:

$\mathrm{Y}=\mathrm{RATIO}$, ALPHA MOMENT/BETA MOMENT (DV)

$\mathrm{X}_{1}=$ ACTIVATION OF T-SPRING (millimeters), $\left(\mathrm{IV}_{1}\right)$

$\mathrm{X}_{2}=$ ANGULATION OF PREACTIVATION BENDS (degrees), $\left(\mathrm{IV}_{2}\right)$

$\beta_{0}=$ PARAMETER ESTIMATE OF Y-INTERCEPT

$\beta_{1}=$ PARAMETER ESTIMATE, SLOPE

$\beta_{2}=$ PARAMETER ESTIMATE, SLOPE

$\mathrm{E}=\mathrm{ERROR}$ 
ALPHA MOMENT

SPRING GEOMETRY: SYMMETRIC MOMENTS

SPRING POSITION: OFF - CENTERED

REGRESSION ANALYSIS: WHOLE MODEL *

INDEPENDENT PARAMETER STD.ERROR

\begin{tabular}{lllll} 
VARIABLE & ESTIMATE & ESTIMATE & t-STATISTIC & PROB. $>$ t \\
\hline
\end{tabular}

\begin{tabular}{lcccc}
\hline \hline INTERCEPT & -1135.2 & 16.1 & -70.3 & 0.000 \\
POSITION & 252.3 & 3.3 & 75.5 & 0.000 \\
ACTIVATION & -147.5 & 4.6 & -32.3 & 0.000
\end{tabular}

ANALYSIS OF VARIANCE

\begin{tabular}{lcccll} 
& SUM OF & \multicolumn{4}{c}{ MEAN } \\
SOURCE & SQUARES & $d f$ & SQUARES & F-RATIO & PROB > F \\
\hline \hline MODEL & 513138554.2 & 2 & 256569277.1 & 3377.6 & 0.000 \\
ERROR & 78772214.8 & 1037 & 75961.6 & & \\
\hline TOTAL & 591910769.0 & 1039 & & &
\end{tabular}

$\mathrm{R}^{2}=0.9$

$\mathrm{R}=0.9$

STANDARD ERROR OF ESTIMATE $=275.6$

*WHOLE MODEL: $\quad \mathbf{Y}=\beta_{0}+\beta_{1} \mathbf{X}_{1}+\beta_{2} \mathbf{X}_{2}+\mathbf{E}$

LEGEND:

$\mathrm{Y}=$ ALPHA MOMENT (DV)

$\mathrm{X}_{1}=$,SPRING POSITION, (millimeters from center position), $\left(\mathrm{IV}_{1}\right)$ (negative values are toward anterior)

$\mathrm{X}_{2}=$ ACTIVATION OF T-SPRING (millimeters), $\left(\mathrm{IV}_{2}\right)$

$\beta_{0}=$ PARAMETER ESTIMATE OF Y-INTERCEPT

$\beta_{1}=$ PARAMETER ESTIMATE, SLOPE

$\beta_{2}=$ PARAMETER ESTIMATE, SLOPE

$\mathrm{E}=\mathrm{ERROR}$ 


\section{TABLE 34}

BETA MOMENT

SPRING GEOMETRY: SYMMETRIC MOMENTS

SPRING POSITION: OFF - CENTER

REGRESSION ANALYSIS: WHOLE MODEL *

INDEPENDENT PARAMETER STD.ERROR

VARIABLE ESTIMATE ESTIMATE

INTERCEPT

POSITION

ACTIVATION

1114.2

222.9

164.3
14.6

3.0

4.1
t-STATISTIC PROB. $>$ t 0.000

0.000

0.000

\section{ANALYSIS OF VARIANCE}

\begin{tabular}{lccccc} 
& SUM OF & \multicolumn{4}{c}{ MEAN } \\
SOURCE & SQUARES & $d f$ & SQUARES & F-RATIO & PROB > F \\
\hline \hline MODEL & 435759924.4 & 2 & 217879962.2 & 3501.1 & 0.000 \\
ERROR & 64534900.2 & 1037 & 62232.3 & & \\
\hline TOTAL & 500294824.6 & 1039 & & &
\end{tabular}

$\mathrm{R}^{2}=0.9$

$\mathrm{R}=0.9$

STANDARD ERROR OF ESTIMATE $=249.5$

*WHOLE MODEL: $\quad \mathbf{Y}=\beta_{0}+\beta_{1} \mathbf{X}_{1}+\beta_{2} \mathbf{X}_{2}+\mathbf{E}$

LEGEND:

$\mathrm{Y}=$ BETA MOMENT (DV)

$\mathrm{X}_{1}=$,SPRING POSITION, (millimeters from center position), $\left(\mathrm{IV}_{1}\right)$ (negative values are toward anterior)

$\mathrm{X}_{2}=$ ACTIVATION OF T-SPRING (millimeters), $\left(\mathrm{IV}_{2}\right)$

$\beta_{0}=$ PARAMETER ESTIMATE OF Y-INTERCEPT

$\beta_{1}=$ PARAMETER ESTIMATE, SLOPE

$\beta_{2}=$ PARAMETER ESTIMATE, SLOPE

$\mathrm{E}=\mathrm{ERROR}$ 
TABLE 35

HORIZONTAL FORCE

SPRING GEOMETRY: SYMMETRIC MOMENTS

SPRING POSITION: OFF - CENTERED

REGRESSION ANALYSIS: WHOLE MODEL *

INDEPENDENT PARAMETER STD.ERROR

\begin{tabular}{lllll} 
VARIABLE & ESTIMATE & ESTIMATE & t-STATISTIC & PROB. $>\mathbf{t}$ \\
\hline
\end{tabular}

\begin{tabular}{lcccc}
\hline \hline INTERCEPT & -0.5 & 1.4 & -0.4 & 0.716 \\
POSITION & 0.6 & 0.3 & 2.1 & 0.036 \\
ACTIVATION & 62.5 & 0.4 & 157.0 & 0.000
\end{tabular}

ANALYSIS OF VARIANCE

\begin{tabular}{lccrrr} 
& SUM OF & \multicolumn{1}{c}{ MEAN } \\
SOURCE & SQUARES & $d f$ & SQUARES & F-RATIO & PROB > F \\
\hline \hline MODEL & 14189492.2 & 2 & 7094746.1 & 12324.4 & 0.000 \\
ERROR & 596964.2 & 1037 & 575.7 & & \\
\hline TOTAL & 14786456.4 & 1039 & & &
\end{tabular}

$\mathrm{R}^{2}=1.0$

$\mathrm{R}=1.0$

STANDARD ERROR OF ESTIMATE $=24.0$

*WHOLE MODEL: $\quad \mathbf{Y}=\beta_{0}+\beta_{1} \mathbf{X}_{1}+\beta_{2} \mathbf{X}_{2}+\mathbf{E}$

LEGEND:

$\mathrm{Y}=$ HORIZONTAL FORCE (DV)

$\mathrm{X}_{1}=$,SPRING POSITION, (millimeters from center position), $\left(\mathrm{IV}_{1}\right)$ (negative values are toward anterior)

$\mathrm{X}_{2}=$ ACTIVATION OF T-SPRING (millimeters), $\left(\mathrm{IV}_{2}\right)$

$\beta_{0}=$ PARAMETER ESTIMATE OF Y-INTERCEPT

$\beta_{1}=$ PARAMETER ESTIMATE, SLOPE

$\beta_{2}=$ PARAMETER ESTIMATE, SLOPE

$\mathrm{E}=\mathrm{ERROR}$ 
VERTICAL FORCE

SPRING GEOMETRY: SYMMETRIC MOMENTS

SPRING POSITION: OFF - CENTERED

REGRESSION ANALYSIS: WHOLE MODEL *

INDEPENDENT PARAMETER STD.ERROR

\begin{tabular}{lllll} 
VARIABLE & ESTIMATE & ESTIMATE & t-STATISTIC & PROB. $>$ t \\
\hline
\end{tabular}

\begin{tabular}{lcccc}
\hline \hline INTERCEPT & 9.0 & 1.2 & 7.7 & 0.000 \\
POSITION & 24.3 & 0.2 & 100.2 & 0.000 \\
ACTIVATION & 2.4 & 0.3 & 7.4 & 0.000
\end{tabular}

ANALYSIS OF VARIANCE

\begin{tabular}{lccrrr} 
& SUM OF & \multicolumn{1}{c}{ MEAN } \\
SOURCE & SQUARES & $d f$ & SQUARES & F-RATIO & PROB > F \\
\hline \hline MODEL & 14189492.2 & 2 & 7094746.1 & 12324.4 & 0.000 \\
ERROR & 596964.2 & 1037 & 575.7 & & \\
\hline TOTAL & 14786456.4 & 1039 & & &
\end{tabular}

$\mathrm{R}^{2}=1.0$

$\mathrm{R}=1.0$

STANDARD ERROR OF ESTIMATE $=20.0$

*WHOLE MODEL: $\quad \mathbf{Y}=\beta_{0}+\beta_{1} \mathbf{X}_{1}+\beta_{2} \mathbf{X}_{2}+\mathbf{E}$

LEGEND:

$\mathrm{Y}=$ VERTICAL FORCE (DV)

$\mathrm{X}_{1}=$,SPRING POSITION, (millimeters from center position), $\left(\mathrm{IV}_{1}\right)$ (negative values are toward anterior)

$\mathrm{X}_{2}=$ ACTIVATION OF T-SPRING (millimeters), $\left(\mathrm{IV}_{2}\right)$

$\beta_{0}=$ PARAMETER ESTIMATE OF Y-INTERCEPT

$\beta_{1}=$ PARAMETER ESTIMATE, SLOPE

$\beta_{2}=$ PARAMETER ESTIMATE, SLOPE

$\mathrm{E}=\mathrm{ERROR}$ 


\section{TABLE 37}

RATIO, ALPHA MOMENT/BETA MOMENT

SPRING GEOMETRY: SYMMETRIC MOMENTS

SPRING POSITION: OFF - CENTERED

\section{REGRESSION ANALYSIS: WHOLE MODEL *}

\begin{tabular}{lcccc}
$\begin{array}{l}\text { INDEPENDENT } \\
\text { VARIABLE }\end{array}$ & $\begin{array}{c}\text { PARAMETER } \\
\text { ESTIMATE }\end{array}$ & $\begin{array}{l}\text { STD.ERROR } \\
\text { ESTIMATE }\end{array}$ & t-STATISTIC & PROB. $>$ t \\
\hline \hline INTERCEPT & -1.5 & 0.1 & -28.9 & 0.000 \\
POSITION & 0.5 & 0.0 & 42.8 & 0.000 \\
ACTIVATION & 0.0 & 0.0 & 0.5 & 0.613
\end{tabular}

ANALYSIS OF VARIANCE

\begin{tabular}{lrrrrr} 
SOURCE & $\begin{array}{c}\text { SUM OF } \\
\text { SQUARES }\end{array}$ & \multicolumn{1}{c}{$\boldsymbol{d f}$} & $\begin{array}{c}\text { MEAN } \\
\text { SQUARES }\end{array}$ & F-RATIO & PROB > F \\
\hline \hline MODEL & 1398.7 & 2 & 699.4 & 914.2 & 0.000 \\
ERROR & 793.3 & 1037 & 0.8 & & \\
\hline TOTAL & 2192.0 & 1039 & & &
\end{tabular}

$\mathbf{R}^{2}=0.6$

$\mathrm{R}=0.6$

STANDARD ERROR OF ESTIMATE $=0.9$

*WHOLE MODEL: $\quad \mathbf{Y}=\beta_{0}+\beta_{1} \mathbf{X}_{1}+\beta_{2} \mathbf{X}_{2}+\mathbf{E}$

LEGEND:

$\mathrm{Y}=$ RATIO, ALPHA MOMENT/BETA MOMENT (DV)

$\mathrm{X}_{1}=$,SPRING POSITION, (millimeters from center position), $\left(\mathrm{IV}_{1}\right)$ (negative values are toward anterior)

$\mathrm{X}_{2}=$ ACTIVATION OF T-SPRING (millimeters), $\left(\mathrm{IV}_{2}\right)$

$\beta_{0}=$ PARAMETER ESTIMATE OF Y-INTERCEPT

$\beta_{1}=$ PARAMETER ESTIMATE, SLOPE

$\beta_{2}=$ PARAMETER ESTIMATE, SLOPE

$\mathrm{E}=\mathrm{ERROR}$ 
TABLE 38

ALPHA MOMENT

SPRING GEOMETRY: ASYMMETRIC ANGULATION ALPHA ANGULATION : 0, 15, 30, 45,60 degrees BETA ANGULATION: 75 degrees

SPRING POSITION: CENTERED

REGRESSION ANALYSIS: WHOLE MODEL *

INDEPENDENT PARAMETER STD.ERROR

\begin{tabular}{lllll} 
VARIABLE & ESTIMATE & ESTIMATE & t-STATISTIC & PROB. $>\mathbf{t}$ \\
\hline \hline
\end{tabular}

\begin{tabular}{|c|c|c|c|c|}
\hline INTERCEPT & 406.0 & 12.6 & $\overline{32.2}$ & 0.000 \\
\hline ANGULATION** & -22.0 & 0.3 & -87.6 & 0.000 \\
\hline ACTIVATION & -158.4 & 2.9 & -55.5 & 0.000 \\
\hline
\end{tabular}

ACTIVATION

$-158.4$

2.9

$-55.5$

ANALYSIS OF VARIANCE

\begin{tabular}{lccccc} 
& SUM OF & \multicolumn{1}{c}{ MEAN } \\
SOURCE & SQUARES & $d f$ & SQUARES & F-RATIO & PROB > F \\
\hline \hline MODEL & 179208917.2 & 2 & 89604458.6 & 5379.8 & 0.000 \\
ERROR & 9693543.8 & 582 & 16655.6 & & \\
\hline TOTAL & 170822713.4 & 584 & & &
\end{tabular}

$\mathrm{R}^{2}=0.9$

$\mathrm{R}=0.9$

STANDARD ERROR OF ESTIMATE $=129.1$

*WHOLE MODEL: $\quad \mathbf{Y}=\beta_{0}+\beta_{1} \mathbf{X}_{1}+\beta_{2} \mathbf{X}_{2}+\mathbf{E}$

LEGEND:

$\mathrm{Y}=$ ALPHA MOMENT (DV)

$\mathrm{X}_{1}=$ ANGULATION OF PREACTIVATION BENDS, ALPHA

ANGLE (degrees), $\left(\mathrm{IV}_{1}\right)$

$\mathrm{X}_{2}=$ ACTIVATION OF T-SPRING (millimeters), $\left(\mathrm{IV}_{2}\right)$

$\beta_{0}=$ PARAMETER ESTIMATE OF Y-INTERCEPT

$\beta_{1}=$ PARAMETER ESTIMATE, SLOPE

$\beta_{2}=$ PARAMETER ESTIMATE, SLOPE

$\mathrm{E}=\mathrm{ERROR}$

**ANGULATION refers to the alpha angle (See Legend, $\mathrm{X}_{1}$ ). 
TABLE 39

BETA MOMENT

SPRING GEOMETRY: ASYMMETRIC ANGULATION ALPHA ANGULATION : 0, 15, 30, 45,60 degrees BETA ANGULATION: 75 degrees

SPRING POSITION: CENTERED

\section{REGRESSION ANALYSIS: WHOLE MODEL *}

INDEPENDENT PARAMETER STD.ERROR

\begin{tabular}{lllll} 
VARIABLE & ESTIMATE & ESTIMATE & t-STATISTIC & PROB. $>\mathbf{t}$ \\
\hline
\end{tabular}

\begin{tabular}{lcccc}
\hline \hline INTERCEPT & 2005.7 & 13.8 & 145.7 & 0.000 \\
ANGULATION** & -7.1 & 0.3 & -25.8 & 0.000 \\
ACTIVATION & 146.9 & 3.1 & 47.1 & 0.000
\end{tabular}

ANALYSIS OF VARIANCE

\begin{tabular}{lccccc} 
& SUM OF & \multicolumn{4}{c}{ MEAN } \\
SOURCE & SQUARES & $d f$ & SQUARES & F-RATIO & PROB > F \\
\hline \hline MODEL & 57469257.4 & 2 & 28734628.7 & 1444.2 & 0.000 \\
ERROR & 11579955.0 & 582 & 19896.8 & & \\
\hline TOTAL & 69049212.4 & 584 & & &
\end{tabular}

$\mathrm{R}^{2}=0.8$

$\mathrm{R}=0.9$

STANDARD ERROR OF ESTIMATE $=141.1$

*WHOLE MODEL: $\quad Y=\beta_{0}+\beta_{1} X_{1}+\beta_{2} X_{2}+E$

LEGEND:

$\mathrm{Y}=\mathrm{BETA}$ MOMENT (DV)

$\mathrm{X}_{1}=$ ANGULATION OF PREACTIVATION BENDS, ALPHA ANGLE (degrees), $\left(\mathrm{IV}_{1}\right)$

$\mathrm{X}_{2}=$ ACTIVATION OF T-SPRING (millimeters), $\left(\mathrm{IV}_{2}\right)$

$\beta_{0}=$ PARAMETER ESTIMATE OF Y-INTERCEPT

$\beta_{1}=$ PARAMETER ESTIMATE, SLOPE

$\beta_{2}=$ PARAMETER ESTIMATE, SLOPE

$\mathrm{E}=\mathrm{ERROR}$

**ANGULATION refers to the alpha angle (See Legend, $\mathrm{X}_{1}$ ). 
TABLE 40

HORIZONTAL FORCE

SPRING GEOMETRY: ASYMMETRIC ANGULATION

ALPHA ANGULATION : 0, 15, 30, 45,60 degrees

BETA ANGULATION: 75 degrees

SPRING POSITION: CENTERED

REGRESSION ANALYSIS: WHOLE MODEL *

INDEPENDENT PARAMETER STD.ERROR

\begin{tabular}{|c|c|c|c|c|}
\hline VARIABLE & ESTIMATE & ESTIMATE & t-STATISTIC & PROB. $>\mathbf{t}$ \\
\hline INTERCEPT & 31.7 & 2.5 & 1212.9 & \\
\hline ANGULATION** & -0.9 & 0.0 & -18.1 & 0.000 \\
\hline ACTIVATION & 61.2 & 0.6 & 109.7 & 0.000 \\
\hline
\end{tabular}

ACTIVATION

61.2

0.6

109.7

0.000

ANALYSIS OF VARIANCE

\begin{tabular}{lccccc} 
& SUM OF & \multicolumn{4}{c}{ MEAN } \\
SOURCE & SQUARES & $d f$ & SQUARES & F-RATIO & PROB > F \\
\hline \hline MODEL & 7875099.1 & 2 & 3937549.6 & 6175.9 & 0.000 \\
ERROR & 371061.0 & 582 & 637.6 & & \\
\hline TOTAL & 8246160.2 & 584 & & &
\end{tabular}

$\mathrm{R}^{2}=1.0$

$\mathrm{R}=1.0$

STANDARD ERROR OF ESTIMATE $=25.2$

*WHOLE MODEL: $\quad \mathbf{Y}=\beta_{0}+\beta_{1} \mathbf{X}_{1}+\beta_{2} \mathbf{X}_{2}+\mathbf{E}$

LEGEND:

$$
\begin{aligned}
& \mathrm{Y}=\text { HORIZONTAL FORCE (DV) } \\
& \mathrm{X}_{1}=\text { ANGULATION OF PREACTIVATION BENDS, ALPHA } \\
& \text { ANGLE (degrees),(IV }) \\
& \mathrm{X}_{2}=\text { ACTIVATION OF T-SPRING (millimeters), }\left(\mathrm{IV}_{2}\right) \\
& \beta_{0}=\text { PARAMETER ESTIMATE OF Y-INTERCEPT } \\
& \beta_{1}=\text { PARAMETER ESTIMATE, SLOPE } \\
& \beta_{2}=\text { PARAMETER ESTIMATE, SLOPE } \\
& \text { E }=\text { ERROR }
\end{aligned}
$$

**ANGULATION refers to the alpha angle (See Legend, $\mathrm{X}_{1}$ ). 


\title{
TABLE 41
}

\author{
VERTICAL FORCE \\ SPRING GEOMETRY: ASYMMETRIC ANGULATION \\ ALPHA ANGULATION : 0, 15, 30, 45,60 degrees \\ BETA ANGULATION: 75 degrees \\ SPRING POSITION: CENTERED
}

\section{REGRESSION ANALYSIS: WHOLE MODEL *}

\begin{tabular}{lcccc}
$\begin{array}{l}\text { INDEPENDENT } \\
\text { VARIABLE }\end{array}$ & $\begin{array}{l}\text { PARAMETER } \\
\text { ESTIMATE }\end{array}$ & $\begin{array}{l}\text { STD.ERROR } \\
\text { ESTIMATE }\end{array}$ & t-STATISTIC & PROB. $>$ t \\
\hline \hline INTERCEPT & 149.5 & 1.1 & 132.4 & 0.000 \\
ANGULATION** & -1.6 & 0.0 & -71.8 & 0.000 \\
ACTIVATION & -3.9 & 0.3 & -15.1 & 0.000
\end{tabular}

ANALYSIS OF VARIANCE

\begin{tabular}{lrrrrc} 
& SUM OF & \multicolumn{1}{c}{ MEAN } \\
SOURCE & SQUARES & $d f$ & SQUARES & F-RATIO & PROB > F \\
\hline \hline MODEL & 721190.1 & 2 & 360595.1 & 2692.9 & 0.000 \\
ERROR & 77933.0 & 582 & 133.9 & & \\
\hline TOTAL & 799123.2 & 584 & & &
\end{tabular}

$\mathrm{R}^{2}=0.9$

$\mathrm{R}=0.9$

STANDARD ERROR OF ESTIMATE $=11.6$

*WHOLE MODEL: $\quad \mathbf{Y}=\beta_{0}+\beta_{1} \mathbf{X}_{1}+\beta_{2} \mathbf{X}_{2}+\mathbf{E}$

LEGEND:

$\mathrm{Y}=$ VERTICAL FORCE (DV)

$\mathrm{X}_{1}=$ ANGULATION OF PREACTIVATION BENDS, ALPHA

ANGLE (degrees) $\left(\mathrm{IV}_{1}\right)$

$\mathrm{X}_{2}=$ ACTIVATION OF T-SPRING (millimeters), $\left(\mathrm{IV}_{2}\right)$

$\beta_{0}=$ PARAMETER ESTIMATE OF Y-INTERCEPT

$\beta_{1}=$ PARAMETER ESTIMATE, SLOPE

$\beta_{2}=$ PARAMETER ESTIMATE, SLOPE

$\mathrm{E}=\mathrm{ERROR}$

**ANGULATION refers to the alpha angle (See Legend, $\mathrm{X}_{1}$ ). 
TABLE 42

RATIO, ALPHA MOMENT/BETA MOMENT

SPRING GEOMETRY: ASYMMETRIC ANGULATION ALPHA ANGULATION : 0, 15, 30, 45,60 degrees BETA ANGULATION: 75 degrees

SPRING POSITION: CENTERED

REGRESSION ANALYSIS: WHOLE MODEL *

INDEPENDENT PARAMETER STD.ERROR

$\begin{array}{lllll}\text { VARIABLE } & \text { ESTIMATE } & \text { ESTIMATE } & \text { t-STATISTIC } & \text { PROB. }>\text { t }\end{array}$

\begin{tabular}{lllcc}
\hline \hline INTERCEPT & 0.2 & 0.0 & 19.2 & 0.000 \\
ANGULATION** & 0.0 & 0.0 & -70.5 & 0.000 \\
ACTIVATION & 0.0 & 0.0 & -27.1 & 0.000
\end{tabular}

ANALYSIS OF VARIANCE

\begin{tabular}{lrrrrr} 
& SUM OF & \multicolumn{4}{c}{ MEAN } \\
SOURCE & SQUARES & $d f$ & SQUARES & F-RATIO & PROB > F \\
\hline \hline MODEL & 38.5 & 2 & 19.2 & 2859.5 & 0.000 \\
ERROR & 3.9 & 582 & 0.0 & & \\
\hline TOTAL & 42.4 & 584 & & &
\end{tabular}

$\mathrm{R}^{2}=0.9$

$\mathrm{R}=0.9$

STANDARD ERROR OF ESTIMATE $=11.6$

*WHOLE MODEL: $\quad \mathbf{Y}=\beta_{0}+\beta_{1} \mathbf{X}_{1}+\beta_{2} \mathbf{X}_{2}+\mathbf{E}$

LEGEND:

$$
\begin{aligned}
& \mathrm{Y}=\text { RATIO, ALPHA MOMENT/BETA MOMENT (DV) } \\
& \mathrm{X}_{1}=\text { ANGULATION OF PREACTIVATION BENDS, ALPHA } \\
& \text { ANGLE (degrees), (IV }) \\
& \mathrm{X}_{2}=\text { ACTIVATION OF T-SPRING (millimeters), }\left(\mathrm{IV}_{2}\right) \\
& \beta_{0}=\text { PARAMETER ESTIMATE OF Y-INTERCEPT } \\
& \beta_{1}=\text { PARAMETER ESTIMATE, SLOPE } \\
& \beta_{2}=\text { PARAMETER ESTIMATE, SLOPE } \\
& \text { E }=\text { ERROR }
\end{aligned}
$$

**ANGULATION refers to the alpha angle (See Legend, $\mathrm{X}_{1}$ ). 
ALPHA MOMENT

SPRING GEOMETRY: ASYMMETRIC ANGULATION

ALPHA ANGULATION : 75 degrees

BETA ANGULATION: $0,15,30,45,60$ degrees

SPRING POSITION: CENTERED

\section{REGRESSION ANALYSIS: WHOLE MODEL *}

\begin{tabular}{lcccc}
$\begin{array}{l}\text { INDEPENDENT } \\
\text { VARIABLE }\end{array}$ & $\begin{array}{l}\text { PARAMETER } \\
\text { ESTIMATE }\end{array}$ & $\begin{array}{l}\text { STD.ERROR } \\
\text { ESTIMATE }\end{array}$ & t-STATISTIC & PROB. >t \\
\hline \hline INTERCEPT & -2290.2 & 15.6 & -146.8 & 0.000 \\
ANGULATION** & 6.7 & 0.3 & 21.5 & 0.000 \\
ACTIVATION & -121.7 & 3.5 & -34.5 & 0.000
\end{tabular}

ANALYSIS OF VARIANCE

\begin{tabular}{lccccc} 
& SUM OF & \multicolumn{4}{c}{ MEAN } \\
SOURCE & SQUARES & $d f$ & SQUARES & F-RATIO & PROB > F \\
\hline \hline MODEL & 42087382.3 & 2 & 21043691.1 & 823.6 & 0.000 \\
ERROR & 14871089.4 & 582 & 25551.7 & & \\
\hline TOTAL & 56958471.7 & 584 & & &
\end{tabular}

$\mathrm{R}^{2}=0.7$

$\mathrm{R}=0.7$

STANDARD ERROR OF ESTIMATE $=159.8$

*WHOLE MODEL: $\quad \mathbf{Y}=\beta_{0}+\beta_{1} \mathbf{X}_{1}+\beta_{2} \mathbf{X}_{2}+\mathbf{E}$

LEGEND:

$\mathrm{Y}=$ ALPHA MOMENT (DV)

$\mathrm{X}_{1}=$ ANGULATION OF PREACTIVATION BENDS, BETA ANGLE (degrees), $\left(\mathrm{IV}_{1}\right)$

$\mathrm{X}_{2}=$ ACTIVATION OF T-SPRING (millimeters), $\left(\mathrm{IV}_{2}\right)$

$\beta_{0}=$ PARAMETER ESTIMATE OF Y-INTERCEPT

$\beta_{1}=$ PARAMETER ESTIMATE, SLOPE

$\beta_{2}=$ PARAMETER ESTIMATE, SLOPE

$\mathrm{E}=\mathrm{ERROR}$

**ANGULATION refers to the beta angle (See Legend, $\mathrm{X}_{1}$ ). 


\title{
TABLE 44
}

\author{
BETA MOMENT \\ SPRING GEOMETRY: ASYMMETRIC ANGULATION \\ ALPHA ANGULATION : 75 degrees \\ BETA ANGULATION: 0, 15, 30, 45,60 degrees \\ SPRING POSITION: CENTERED
}

\begin{tabular}{|c|c|c|c|c|}
\hline \multicolumn{5}{|c|}{ REGRESSION ANALYSIS: WHOLE MODEL * } \\
\hline $\begin{array}{l}\text { INDEPENDENT } \\
\text { VARIABLE }\end{array}$ & $\begin{array}{l}\text { PARAMETER } \\
\text { ESTIMATE }\end{array}$ & $\begin{array}{l}\text { STD.ERROR } \\
\text { ESTIMATE }\end{array}$ & t-STATISTIC & PROB. $>t$ \\
\hline $\begin{array}{l}\text { INTERCEPT } \\
\text { ANGULATION** }\end{array}$ & $\begin{array}{c}-1194.7 \\
31.1\end{array}$ & $\begin{array}{c}26.9 \\
0.5\end{array}$ & $\begin{array}{c}-44.5 \\
58.0\end{array}$ & $\begin{array}{l}0.000 \\
0.000\end{array}$ \\
\hline ACTIVATION & 191.9 & 6.1 & 31.5 & 0.000 \\
\hline
\end{tabular}

ANALYSIS OF VARIANCE

\begin{tabular}{lccccc} 
& SUM OF & \multicolumn{4}{c}{ MEAN } \\
SOURCE & SQUARES & $d f$ & SQUARES & F-RATIO & PROB > F \\
\hline \hline MODEL & 330634062.7 & 2 & 165317031.3 & 2180.8 & 0.000 \\
ERROR & 44118485.1 & 582 & 75805.0 & & \\
\hline TOTAL & 374752547.8 & 584 & & &
\end{tabular}

$\mathrm{R}^{2}=0.9$

$\mathrm{R}=0.9$

STANDARD ERROR OF ESTIMATE $=275.3$

*WHOLE MODEL: $\quad \mathbf{Y}=\beta_{0}+\beta_{1} \mathbf{X}_{1}+\beta_{2} \mathbf{X}_{2}+\mathbf{E}$

LEGEND:

$\mathrm{Y}=$ BETA MOMENT (DV)

$\mathrm{X}_{1}=$ ANGULATION OF PREACTIVATION BENDS, BETA ANGLE (degrees), $\left(\mathrm{IV}_{1}\right)$

$\mathrm{X}_{2}=$ ACTIVATION OF T-SPRING (millimeters), $\left(\mathrm{IV}_{2}\right)$

$\beta_{0}=$ PARAMETER ESTIMATE OF Y-INTERCEPT

$\beta_{1}=$ PARAMETER ESTIMATE, SLOPE

$\beta_{2}=$ PARAMETER ESTIMATE, SLOPE

$\mathrm{E}=\mathrm{ERROR}$

**ANGULATION refers to the beta angle (See Legend, $\mathrm{X}_{1}$ ). 
HORIZONTAL FORCE

SPRING GEOMETRY: ASYMMETRIC ANGULATION

ALPHA ANGULATION : 75 degrees

BETA ANGULATION: $0,15,30,45,60$ degrees

SPRING POSITION: CENTERED

\section{REGRESSION ANALYSIS: WHOLE MODEL *}

INDEPENDENT PARAMETER STD.ERROR

\begin{tabular}{lllll} 
VARIABLE & ESTIMATE & ESTIMATE & t-STATISTIC & PROB. $>\mathbf{t}$ \\
\hline
\end{tabular}

\begin{tabular}{lcccc}
\hline \hline INTERCEPT & -10.4 & 3.3 & -3.1 & 0.002 \\
ANGULATION** & 0.2 & 0.1 & 3.7 & 0.000 \\
ACTIVATION & 65.4 & 0.8 & 87.0 & 0.000
\end{tabular}

ANALYSIS OF VARIANCE

\begin{tabular}{lrrrrr} 
& SUM OF & \multicolumn{1}{c}{ MEAN } \\
SOURCE & SQUARES & $d f$ & SQUARES & F-RATIO & PROB > F \\
\hline \hline MODEL & 8784068.1 & 2 & 4392034.1 & 3789.0 & 0.000 \\
ERROR & 674625.2 & 582 & 1159.1 & & \\
\hline TOTAL & 9458693.4 & 584 & & &
\end{tabular}

$\mathrm{R}^{2}=0.9$

$\mathrm{R}=0.9$

STANDARD ERROR OF ESTIMATE $=34.0$

*WHOLE MODEL: $\quad \mathbf{Y}=\beta_{0}+\beta_{1} \mathbf{X}_{1}+\beta_{2} \mathbf{X}_{2}+\mathbf{E}$

LEGEND:

$\mathrm{Y}=$ HORIZONTAL FORCE (DV)

$\mathrm{X}_{1}=$ ANGULATION OF PREACTIVATION BENDS, BETA ANGLE (degrees), $\left(\mathrm{IV}_{1}\right)$

$\mathrm{X}_{2}=$ ACTIVATION OF T-SPRING (millimeters), $\left(\mathrm{IV}_{2}\right)$

$\beta_{0}=$ PARAMETER ESTIMATE OF Y-INTERCEPT

$\beta_{1}=$ PARAMETER ESTIMATE, SLOPE

$\beta_{2}=$ PARAMETER ESTIMATE, SLOPE

$\mathrm{E}=\mathrm{ERROR}$

**ANGULATION refers to the beta angle (See Legend, $X_{1}$ ). 
VERTICAL FORCE

SPRING GEOMETRY: ASYMMETRIC ANGULATION

ALPHA ANGULATION : 75 degrees

BETA ANGULATION: $0,15,30,45,60$ degrees

SPRING POSITION: CENTERED

REGRESSION ANALYSIS: WHOLE MODEL *

\begin{tabular}{|c|c|c|c|c|}
\hline $\begin{array}{l}\text { INDEPENDENT } \\
\text { VARIABLE }\end{array}$ & $\begin{array}{l}\text { PARAMETER } \\
\text { ESTIMATE }\end{array}$ & $\begin{array}{l}\text { STD.ERROR } \\
\text { ESTIMATE }\end{array}$ & t-STATISTIC & PROB. $>t$ \\
\hline INTERCEPT & -192.4 & 1.8 & -105.0 & 0.000 \\
\hline ANGULATION* & 2.0 & 0.0 & & 0.000 \\
\hline ACTIVATION & 11.4 & 0.4 & 27.5 & 0.000 \\
\hline
\end{tabular}

ANALYSIS OF VARIANCE

\begin{tabular}{lrrrrr} 
& SUM OF & \multicolumn{1}{c}{ MEAN } \\
SOURCE & SQUARES & $d f$ & SQUARES & F-RATIO & PROB > F \\
\hline \hline MODEL & 1364499.1 & 2 & 682249.5 & 1936.0 & 0.000 \\
ERROR & 205102.0 & 582 & 352.4 & & \\
\hline TOTAL & 1569601.1 & 584 & & &
\end{tabular}

$\mathrm{R}^{2}=0.9$

$\mathrm{R}=0.9$

STANDARD ERROR OF ESTIMATE $=18.0$

*WHOLE MODEL: $\quad \mathbf{Y}=\beta_{0}+\beta_{1} \mathbf{X}_{1}+\beta_{2} \mathbf{X}_{2}+\mathbf{E}$

LEGEND:

$\mathrm{Y}=$ VERTICAL FORCE (DV)

$\mathrm{X}_{1}=$ ANGULATION OF PREACTIVATION BENDS, BETA

ANGLE (degrees), $\left(\mathrm{IV}_{1}\right)$

$\mathrm{X}_{2}=$ ACTIVATION OF T-SPRING (millimeters), $\left(\mathrm{IV}_{2}\right)$

$\beta_{0}=$ PARAMETER ESTIMATE OF Y-INTERCEPT

$\beta_{1}=$ PARAMETER ESTIMATE, SLOPE

$\beta_{2}=$ PARAMETER ESTIMATE, SLOPE

$\mathrm{E}=\mathrm{ERROR}$

**ANGULATION refers to the beta angle (See Legend, $\mathrm{X}_{1}$ ). 
TABLE 47

RATIO, BETA MOMENT/ALPHA MOMENT

SPRING GEOMETRY: ASYMMETRIC ANGULATION

ALPHA ANGULATION : 75 degrees

BETA ANGULATION: $0,15,30,45,60$ degrees

SPRING POSITION: CENTERED

REGRESSION ANALYSIS: WHOLE MODEL *

INDEPENDENT PARAMETER STD.ERROR

\begin{tabular}{lllll} 
VARIABLE & ESTIMATE & ESTIMATE & $t$-STATISTIC & PROB. $>t$ \\
\hline
\end{tabular}

\begin{tabular}{|c|c|}
\hline & 0.5 \\
\hline ANGULATION** & $\begin{array}{r}0.0 \\
-0.1\end{array}$ \\
\hline
\end{tabular}

ANALYSIS OF VARIANCE

\begin{tabular}{lrrrrr} 
& SUM OF & \multicolumn{4}{c}{ MEAN } \\
SOURCE & SQUARES & $d f$ & SQUARES & F-RATIO & PROB > F \\
\hline \hline MODEL & 57.3 & 2 & 28.7 & 1805.4 & 0.000 \\
ERROR & 9.2 & 582 & 0.0 & & \\
\hline TOTAL & 66.5 & 584 & & &
\end{tabular}

$\mathrm{R}^{2}=0.9$

$\mathrm{R}=0.9$

STANDARD ERROR OF ESTIMATE $=0.1$

*WHOLE MODEL: $\quad \mathbf{Y}=\beta_{0}+\beta_{1} \mathbf{X}_{1}+\beta_{2} \mathbf{X}_{2}+\mathbf{E}$

LEGEND:

$\mathrm{Y}=\mathrm{RATIO}$, BETA MOMENT/ALPHA MOMENT (DV)

$\mathrm{X}_{1}=$ ANGULATION OF PREACTIVATION BENDS, BETA ANGLE (degrees), (IV $\left.{ }_{1}\right)$

$\mathrm{X}_{2}=$ ACTIVATION OF T-SPRING (millimeters), $\left(\mathrm{IV}_{2}\right)$

$\beta_{0}=$ PARAMETER ESTIMATE OF Y-INTERCEPT

$\beta_{1}=$ PARAMETER ESTIMATE, SLOPE

$\beta_{2}=$ PARAMETER ESTIMATE, SLOPE

$\mathrm{E}=\mathrm{ERROR}$

**ANGULATION refers to the beta angle (See Legend, $\mathrm{X}_{1}$ ). 


\section{APPENDIX II: FIGURES}

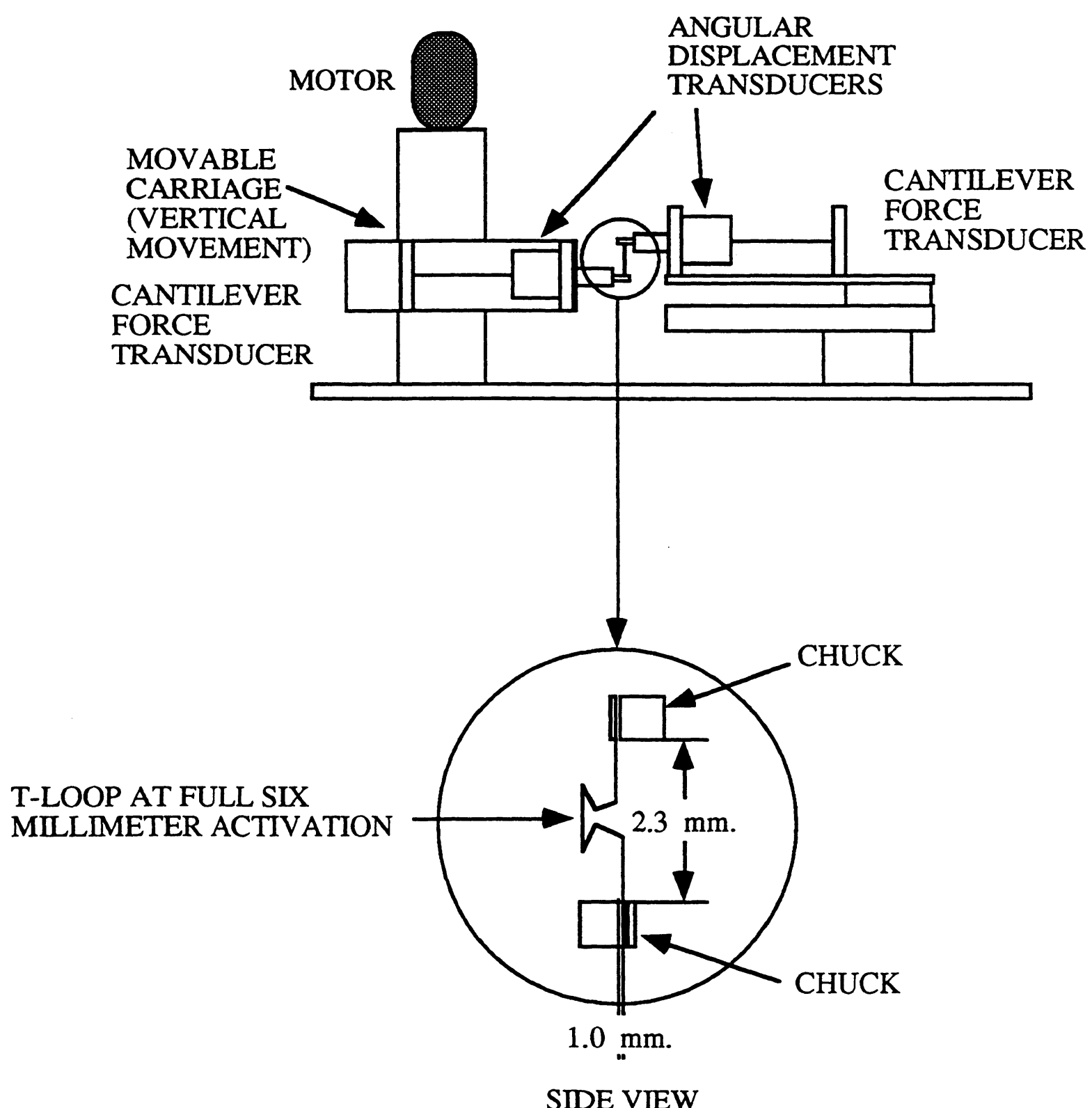

FIGURE 1: Schematic Diagram of Spring Tester Apparatus, University of Connecticut Division of Orthodontics, Biomechanics Laboratory 


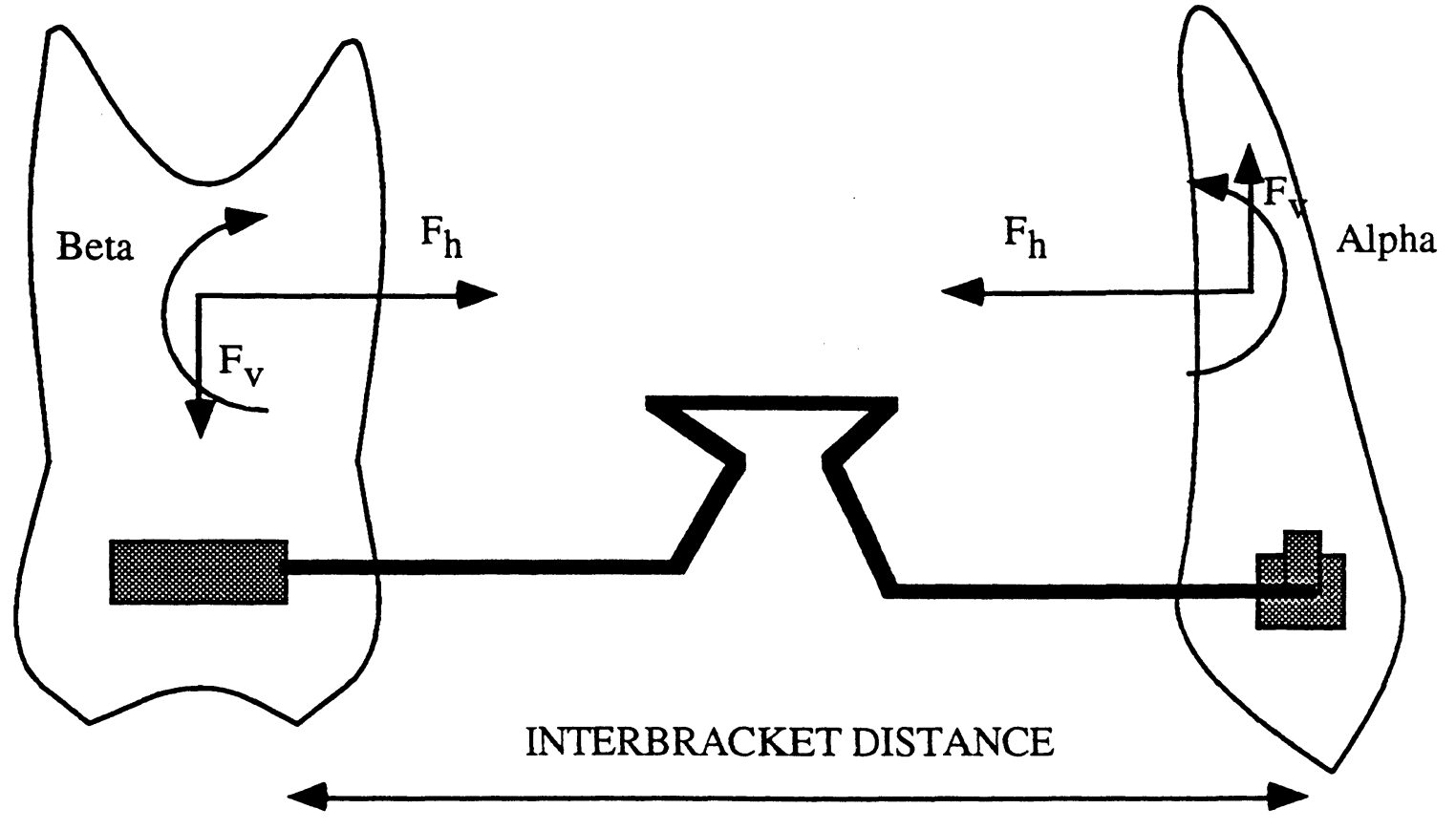

LEGEND

$\mathrm{F}_{\mathrm{h}}$ - Horizontal Force

$\mathrm{F}_{\mathrm{v}}$ - Vertical Force

Alpha - Alpha Moment

Beta - Beta Moment

FIGURE 2: The Force System from a T-loop Space Closing Spring 


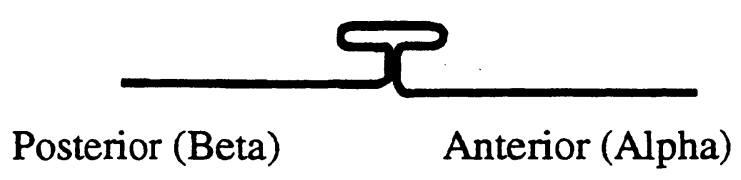

FIGURE 3: Segmented T-loop prior to the placement of Preactivation bends 

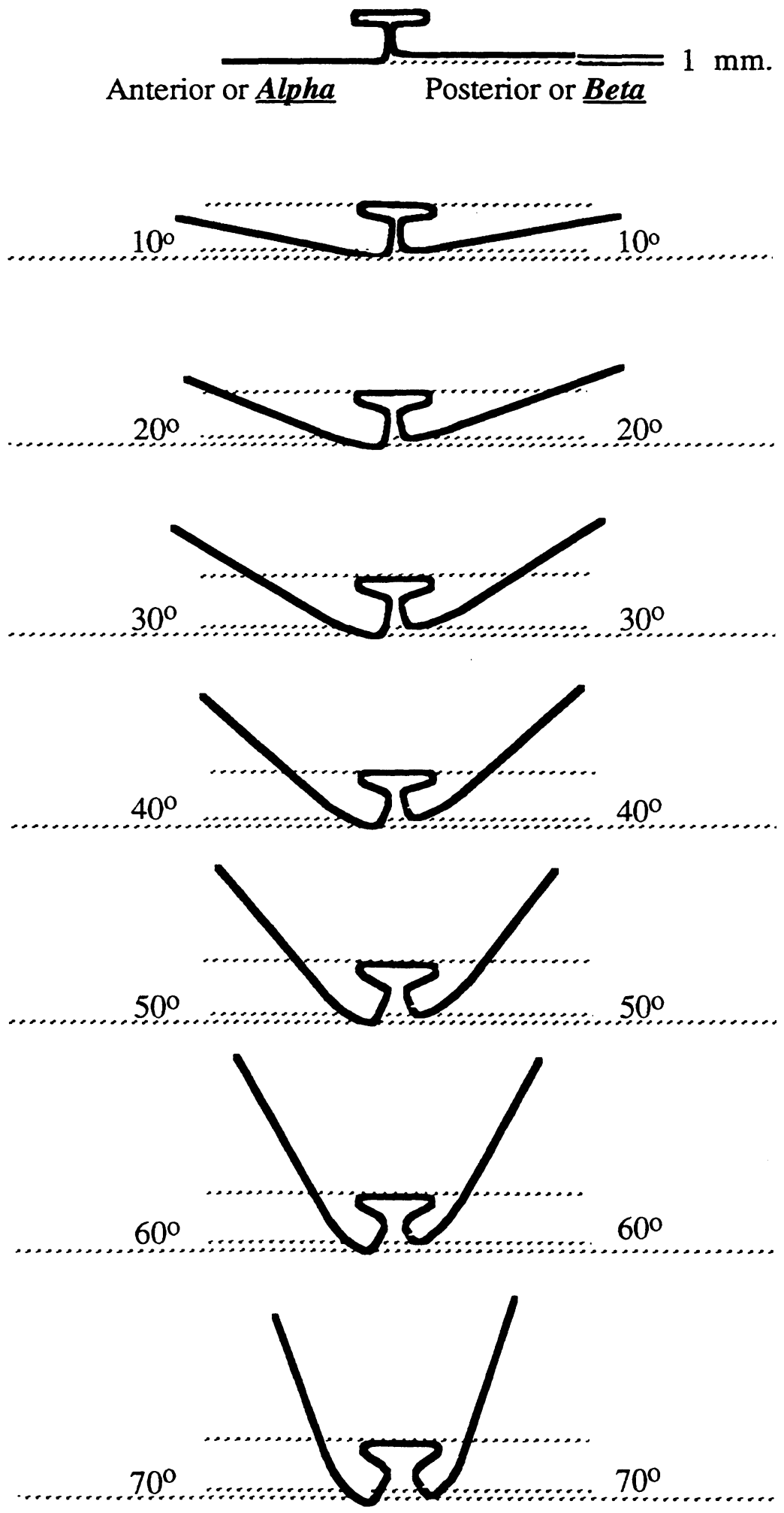

FIGURE 4: Templates for T-loop Springs with Symmetric Angulation and Centered Position 


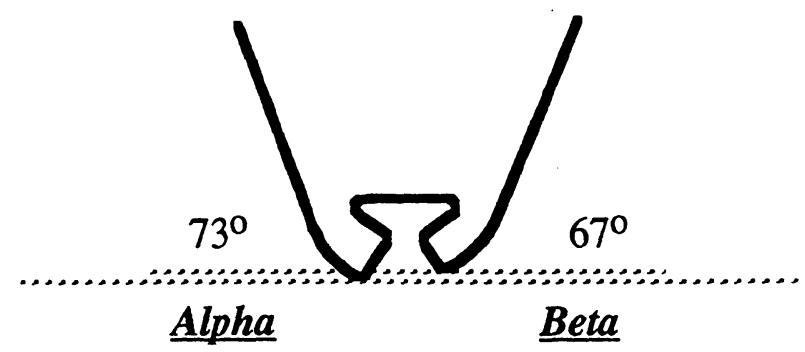

FIGURE 5: Templates for T-loop Springs producing Symmetric Moments in the Centered Position, Used for Off-Centered Positioning 

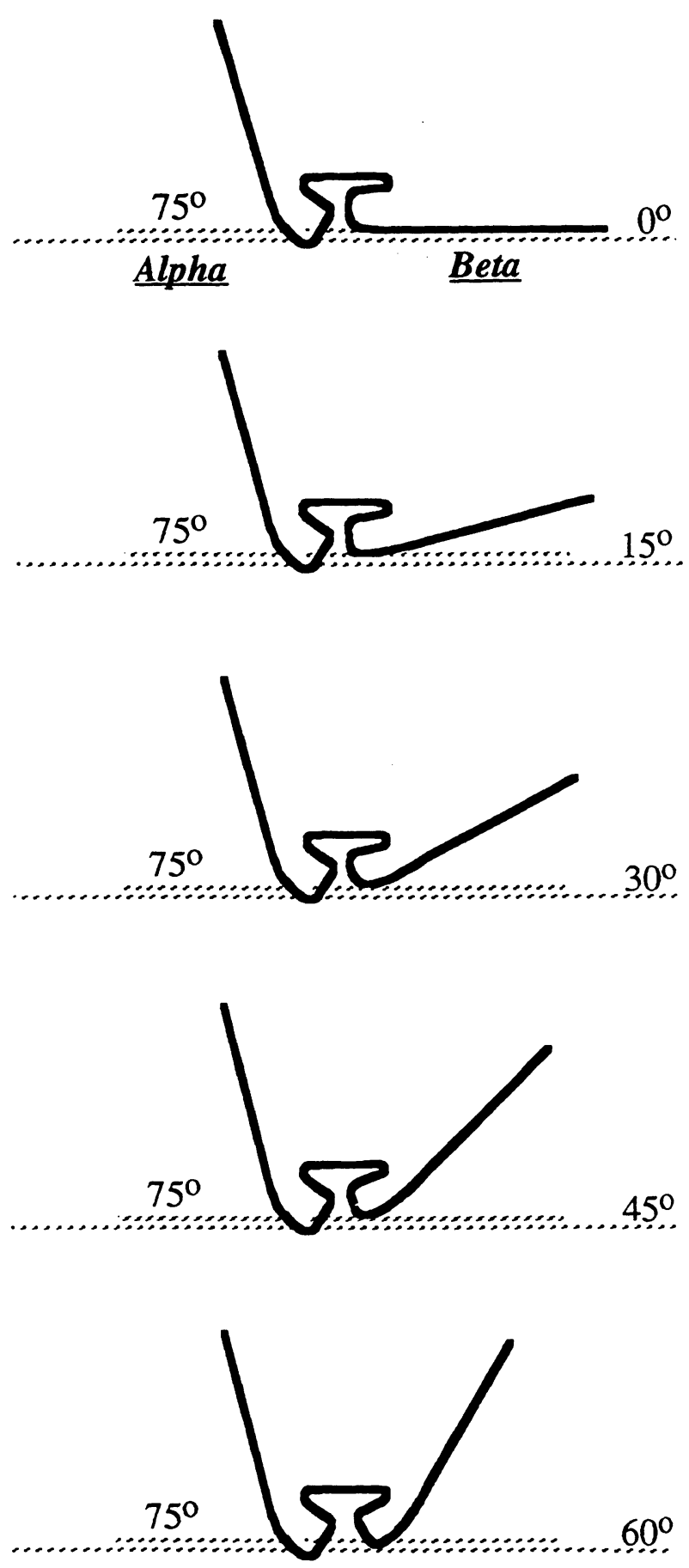

FIGURE 6: Templates for T-loop Springs with Asymmetric Angulation, Constant Alpha Angulation, Varying Beta Angulation 

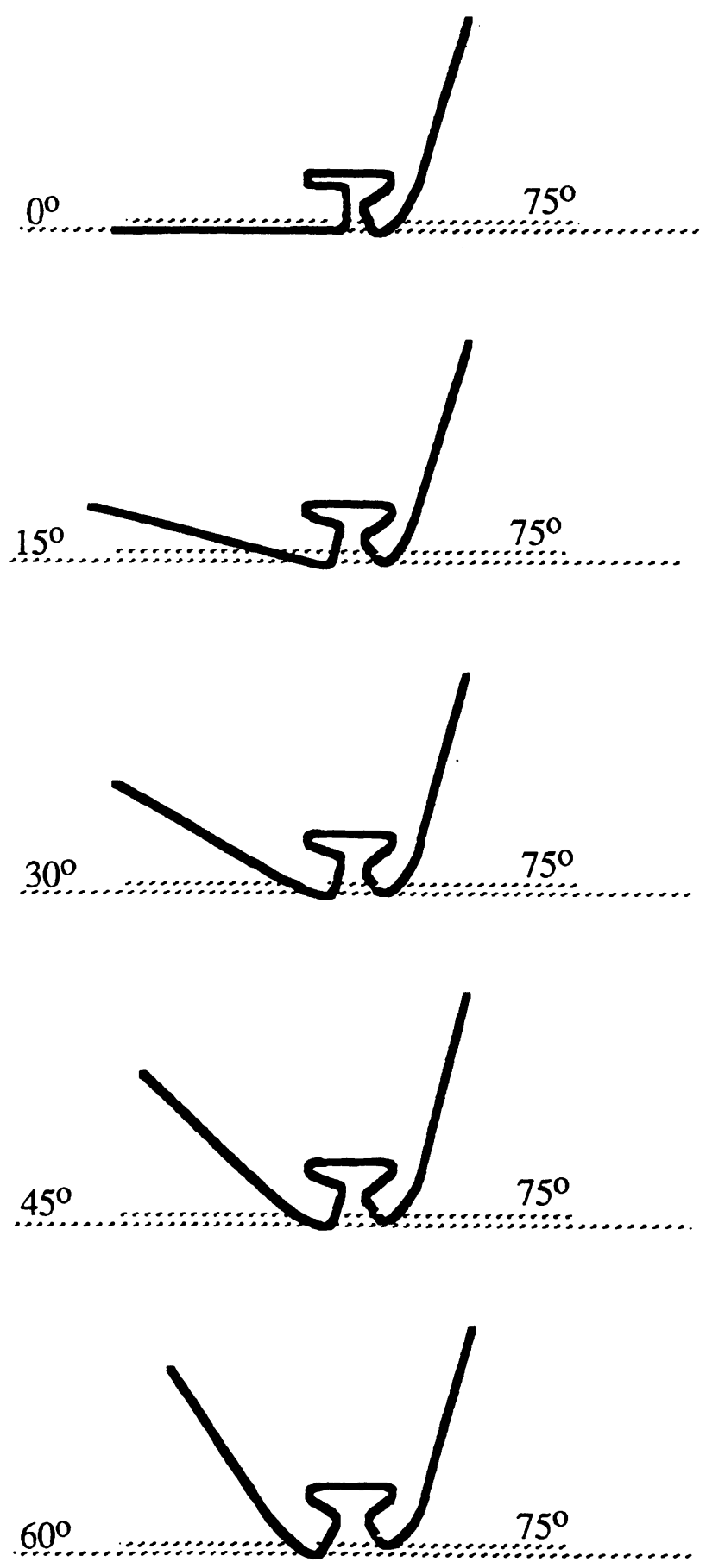

FIGURE 7: Templates for T-loop Springs with Asymmetric Angulation, Constant Beta Angulation, Varying Alpha Angulation 


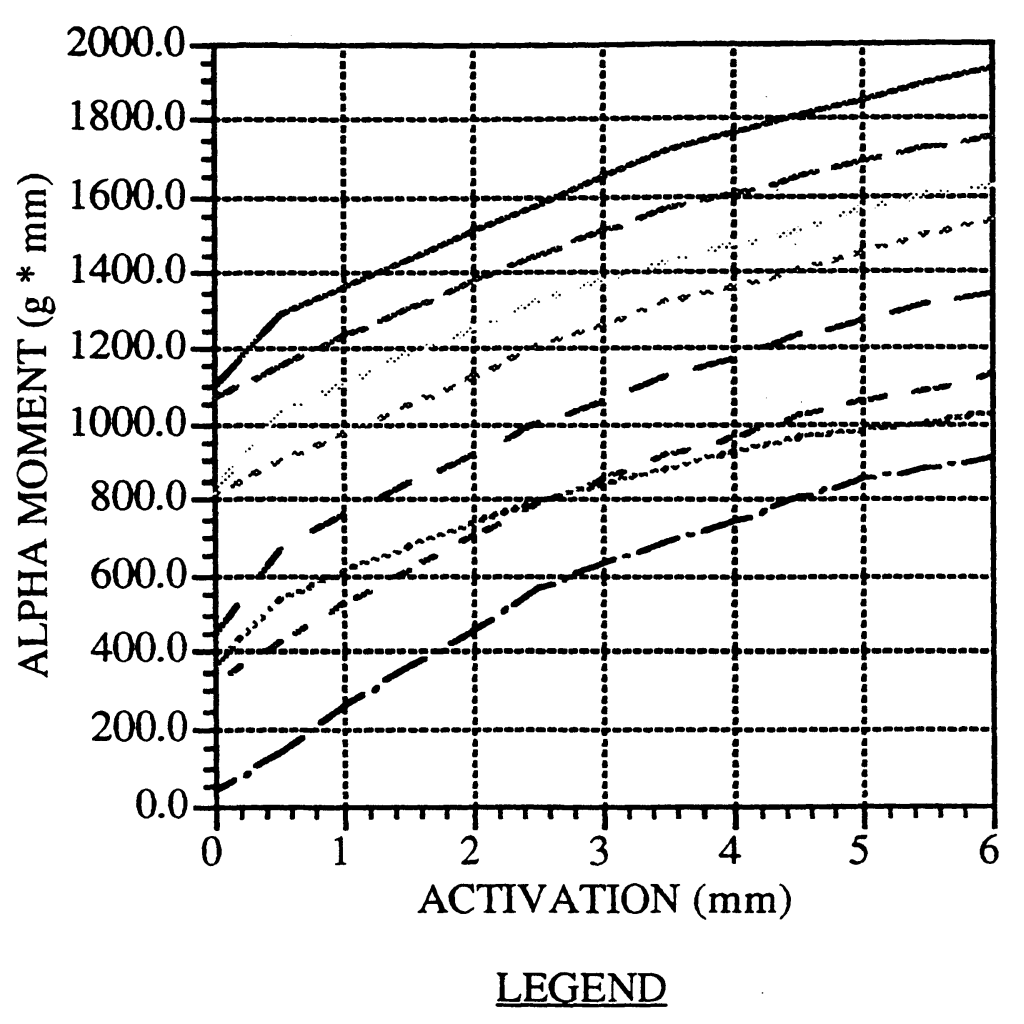

--. 0 DEGREES

- - 10 DEGREES

-........ 20 DEGREES

- 30 DEGREES

..... 40 DEGREES

50 DEGREES

--60 DEGREES

70 DEGREES

FIGURE 8: Alpha moment versus spring activation for "T-loop" springs with symmetric alpha and beta angulation and centered positioning. 


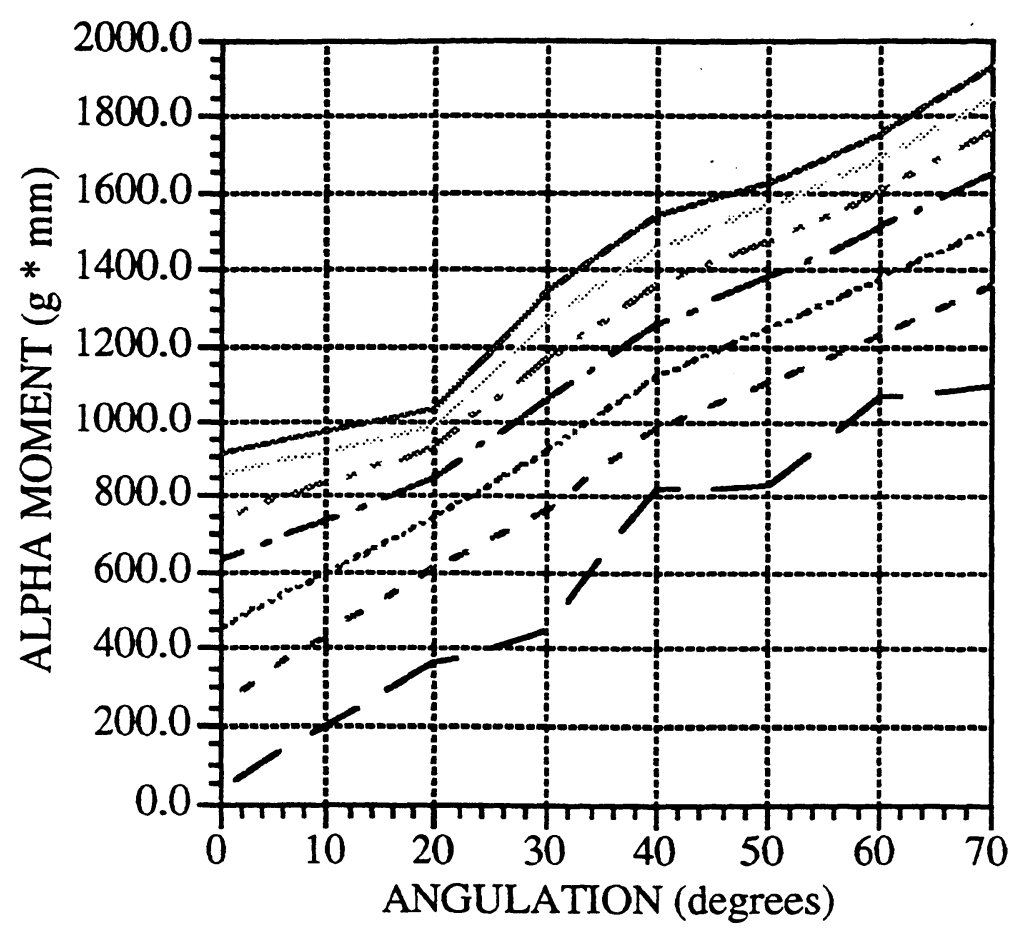

\section{LEGEND}

\begin{tabular}{|c|c|}
\hline-- & $0 \mathrm{~mm}$ ACTIVATION \\
\hline$\ldots--$ & $1 \mathrm{~mm}$ ACTIVATION \\
\hline & 2 mm ACTIVATION \\
\hline 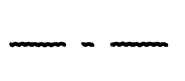 & $3 \mathrm{~mm}$ ACTIVATION \\
\hline$m \ldots$ & $4 \mathrm{~mm}$ ACTIVATION \\
\hline & $5 \mathrm{~mm}$ ACTIVATION \\
\hline & $6 \mathrm{~mm}$ ACTIVATION \\
\hline
\end{tabular}

FIGURE 9: Alpha moment versus spring angulation for "T-loop" springs with symmetric alpha and beta angulation and centered positioning. 

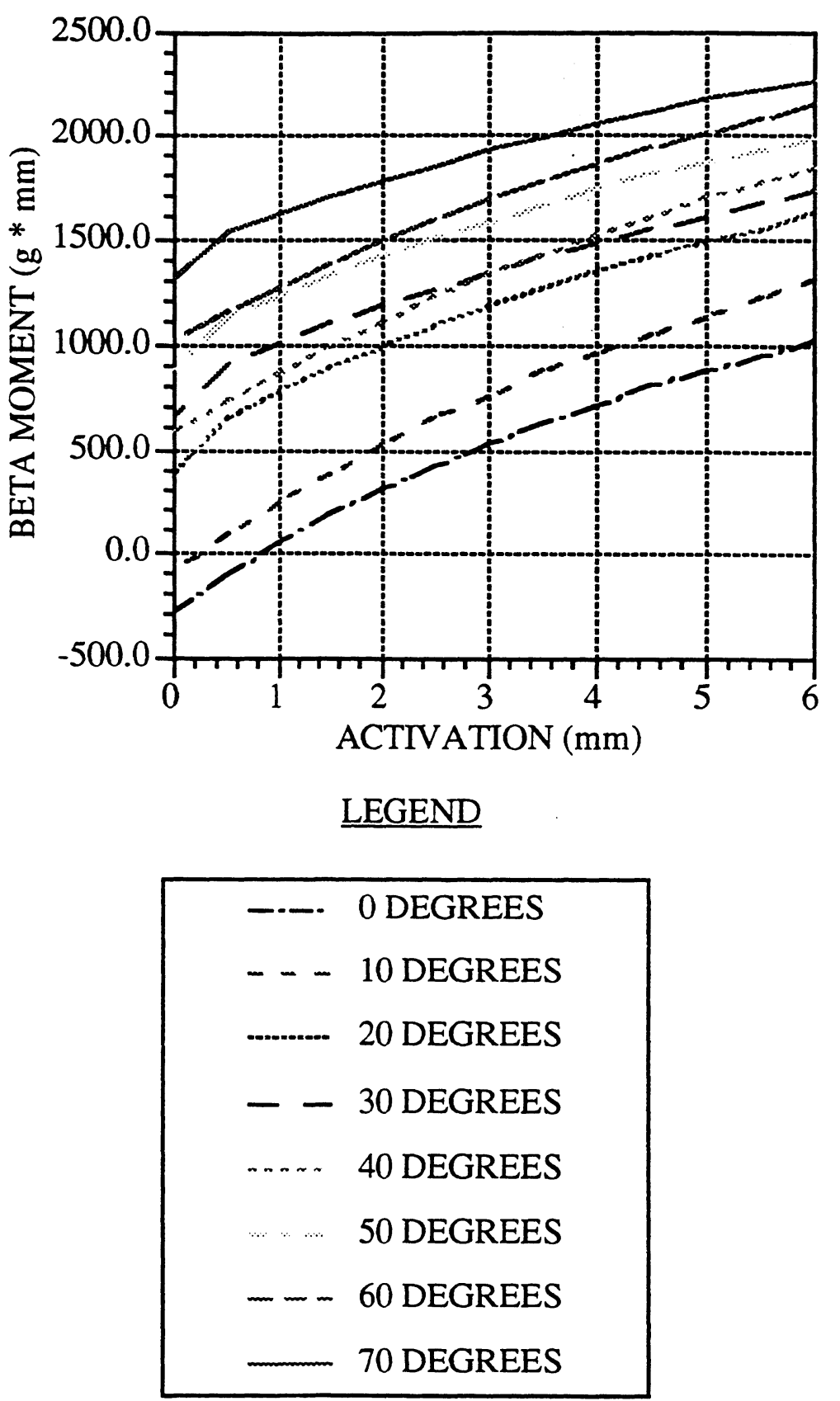

FIGURE 10: Beta moment versus spring activation for "T-loop" springs with symmetric alpha and beta angulation and centered positioning. 


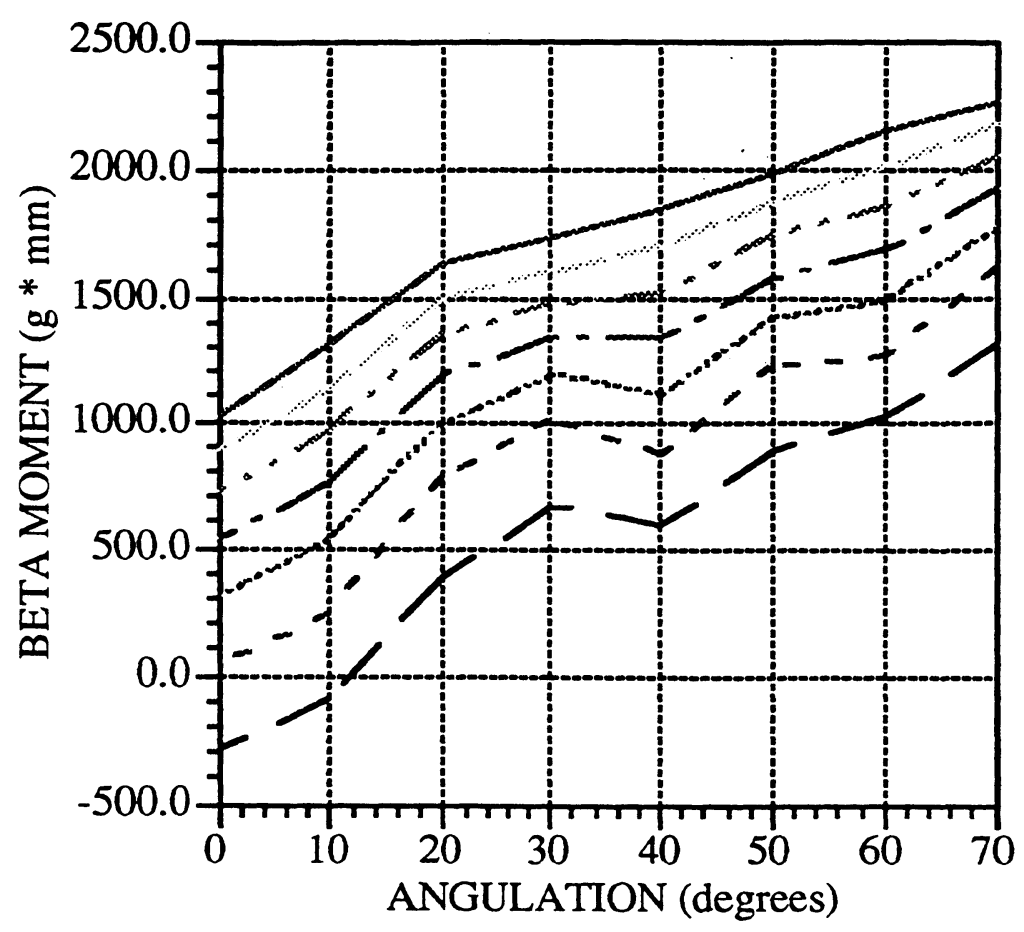

\section{LEGEND}

$$
\begin{aligned}
& \text { - }-0 \mathrm{~mm} \text { ACTIVATION } \\
& \text { - - - } 1 \mathrm{~mm} \text { ACTIVATION } \\
& 2 \mathrm{~mm} \text { ACTIVATION } \\
& \text { - - } 3 \mathrm{~mm} \text { ACTIVATION } \\
& 4 \text { mm ACTIVATION } \\
& 5 \mathrm{~mm} \text { ACTIVATION } \\
& 6 \mathrm{~mm} \text { ACTIVATION }
\end{aligned}
$$

FIGURE 11: Beta moment versus spring angulation for "T-loop" springs with symmetric alpha and beta angulation and centered positioning. 


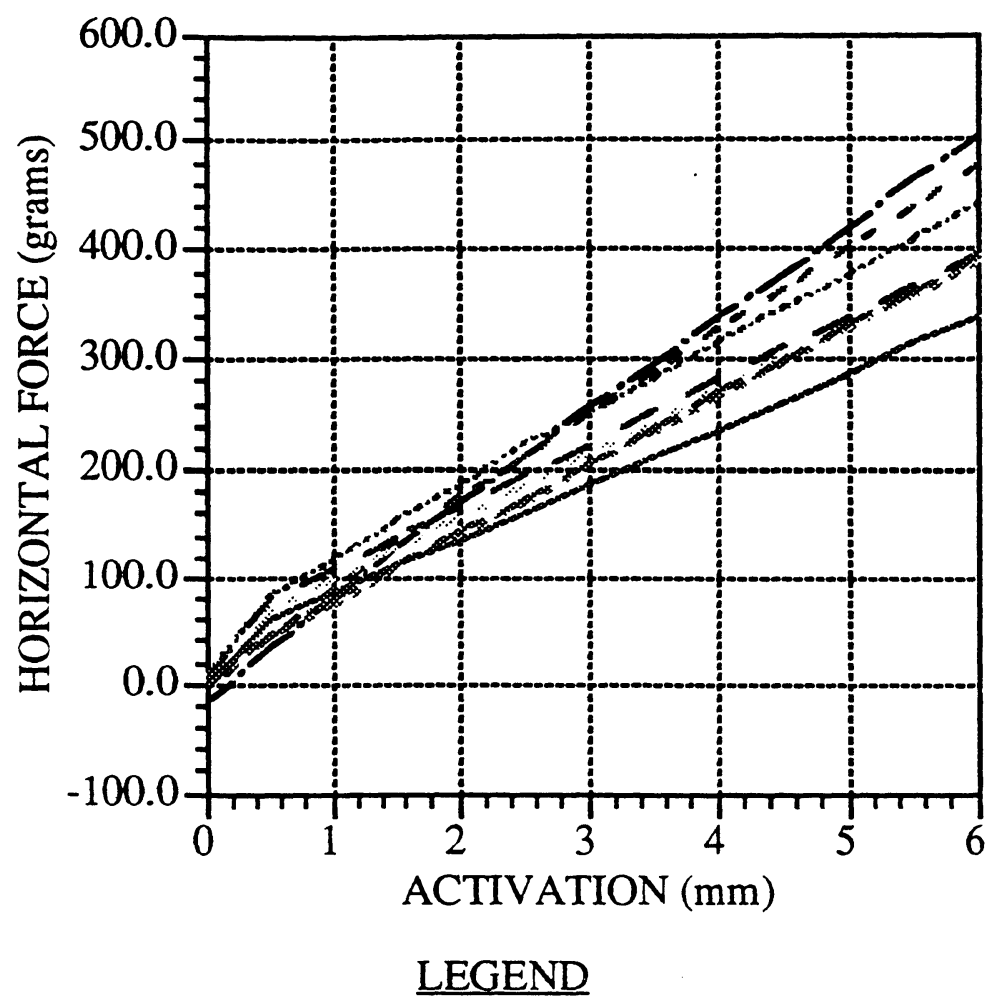

-.- O DEGREES

- - 10 DEGREES

......... 20 DEGREES

- 30 DEGREES

..... 40 DEGREES

50 DEGREES

- -60 DEGREES

70 DEGREES

FIGURE 12: Horizontal force versus spring activation for "T-loop" springs with symmetric alpha and beta angulation and centered positioning. 


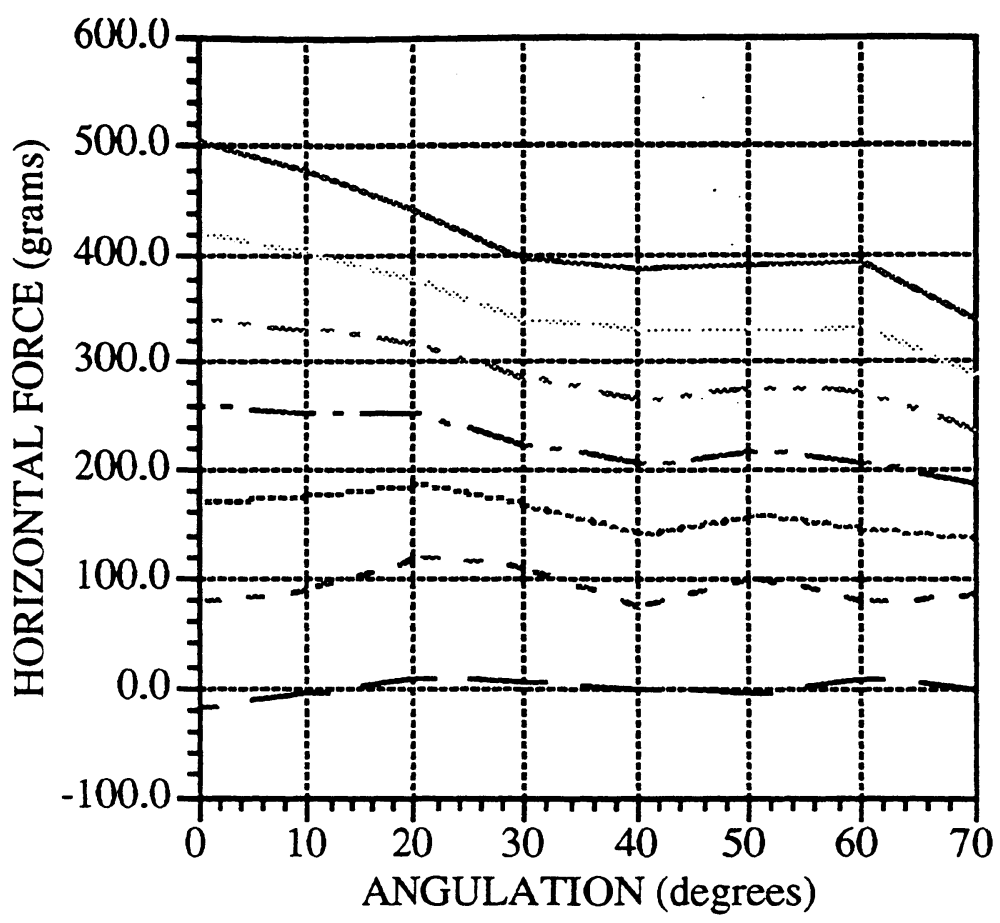

LEGEND

$$
\begin{aligned}
& \text { - - } 0 \mathrm{~mm} \text { ACTIVATION } \\
& \text { _. } \ldots 1 \mathrm{~mm} \text { ACTIVATION } \\
& 2 \text { mm ACTIVATION } \\
& --3 \mathrm{~mm} \text { ACTIVATION } \\
& \ldots \ldots \text { mm ACTIVATION } \\
& 5 \text { mm ACTIVATION } \\
& 6 \mathrm{~mm} \text { ACTIVATION }
\end{aligned}
$$

FIGURE 13: Horizontal force versus spring angulation for "T-loop" springs with symmetric alpha and beta angulation and centered positioning. 

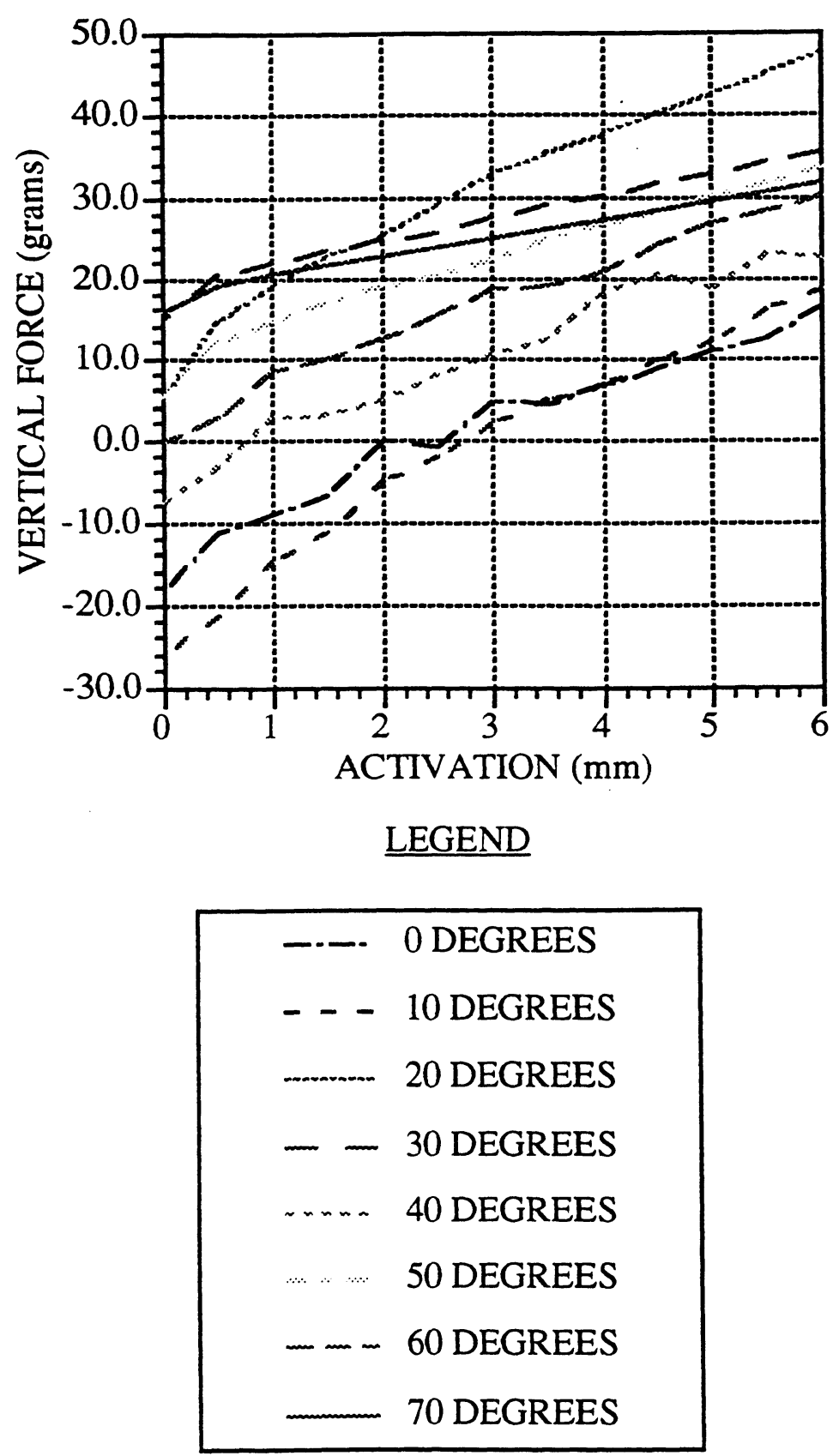

FIGURE 14: Vertical force versus spring activation for "T-loop" springs with symmetric alpha and beta angulation and centered positioning. 


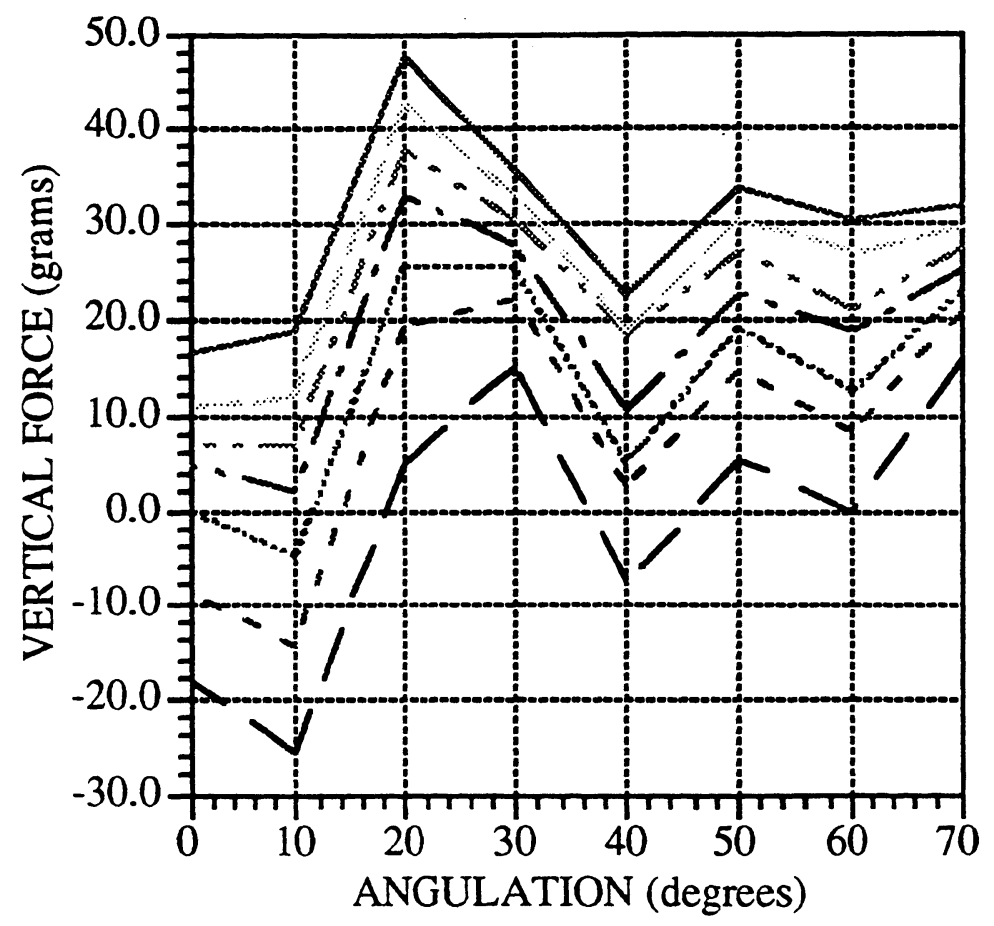

\section{LEGEND}

\begin{tabular}{|c|c|}
\hline- - & $0 \mathrm{~mm}$ ACTIVATION \\
\hline & $1 \mathrm{~mm}$ ACTIVATION \\
\hline & $2 \mathrm{~mm}$ ACTIVATION \\
\hline & $3 \mathrm{~mm}$ ACTIVATION \\
\hline & $4 \mathrm{~mm}$ ACTIVATION \\
\hline & $5 \mathrm{~mm}$ ACTIVATION \\
\hline & $6 \mathrm{~mm}$ ACTIVATION \\
\hline
\end{tabular}

FIGURE 15: Vertical force versus spring angulation for "T-loop" springs with symmetric alpha and beta angulation and centered positioning. 


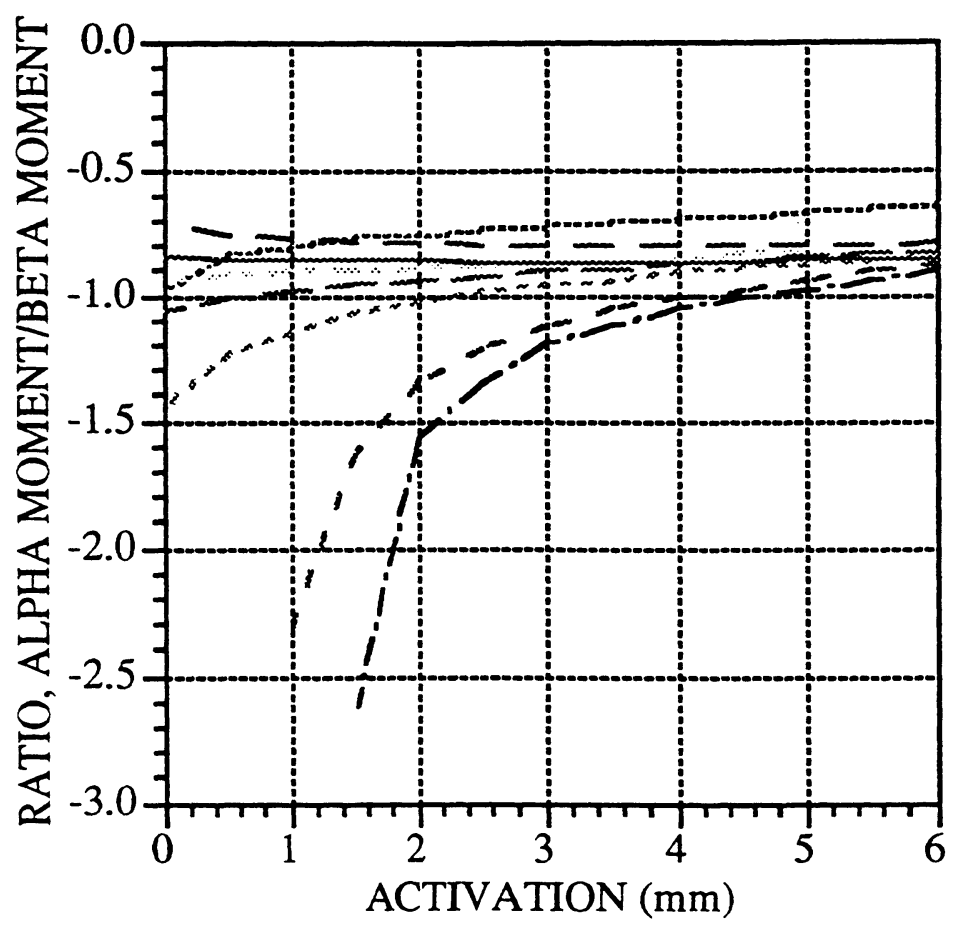

LEGEND

\begin{tabular}{|cc|}
\hline$-\cdots$ & 0 DEGREES \\
-- & 10 DEGREES \\
$\cdots \cdots \cdots$ & 20 DEGREES \\
- & 30 DEGREES \\
$\ldots \sim$ & 40 DEGREES \\
$\ldots \ldots$ & 50 DEGREES \\
$\ldots-$ & 60 DEGREES \\
& 70 DEGREES
\end{tabular}

FIGURE 16: Ratio of thealpha moment/beta moment versus spring activation for "Tloop" springs with symmetric alpha and beta angulation and centered positioning. 


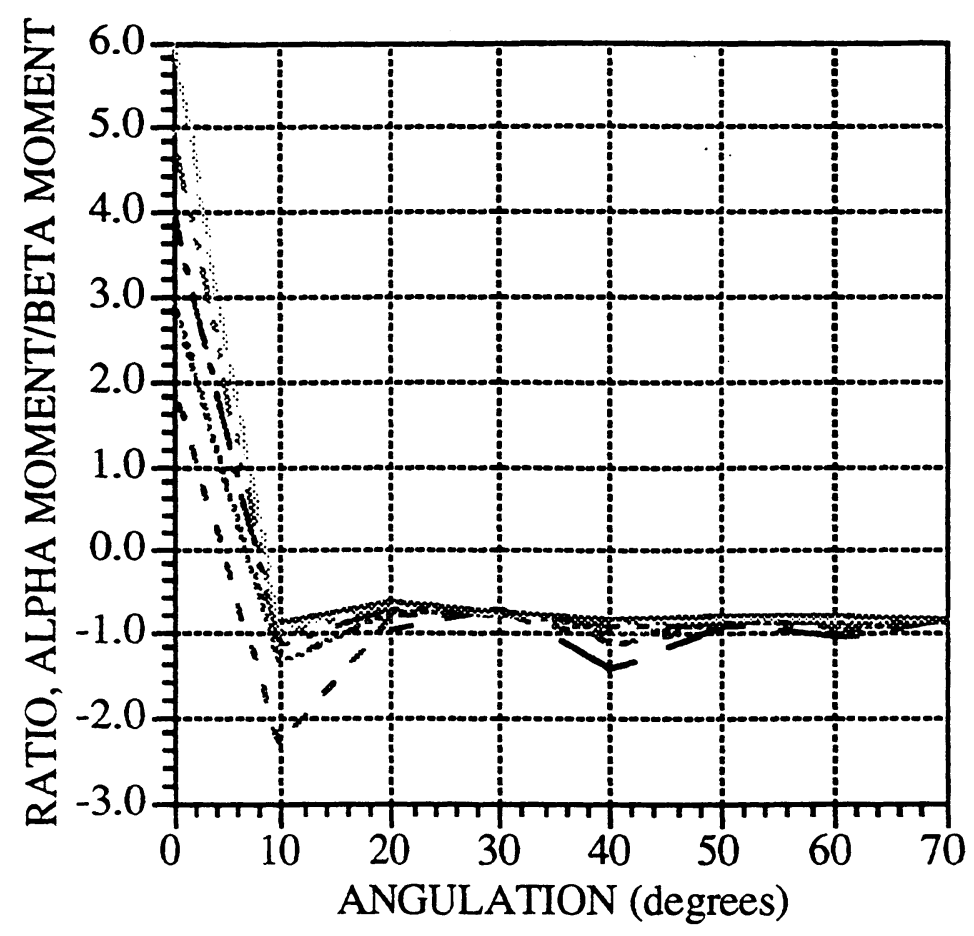

\section{LEGEND}

$$
\begin{aligned}
& \text { - }-0 \mathrm{~mm} \text { ACTIVATION } \\
& \text { _.. - } 1 \mathrm{~mm} \text { ACTIVATION } \\
& 2 \text { mm ACTIVATION } \\
& \text { - } 3 \text { mm ACTIVATION } \\
& 4 \text { mm ACTIVATION } \\
& 5 \mathrm{~mm} \text { ACTIVATION } \\
& 6 \mathrm{~mm} \text { ACTIVATION }
\end{aligned}
$$

FIGURE 17: Ratio of the alpha moment/beta moment versus spring angulation for "Tloop" springs with symmetric alpha and beta angulation and centered positioning. 


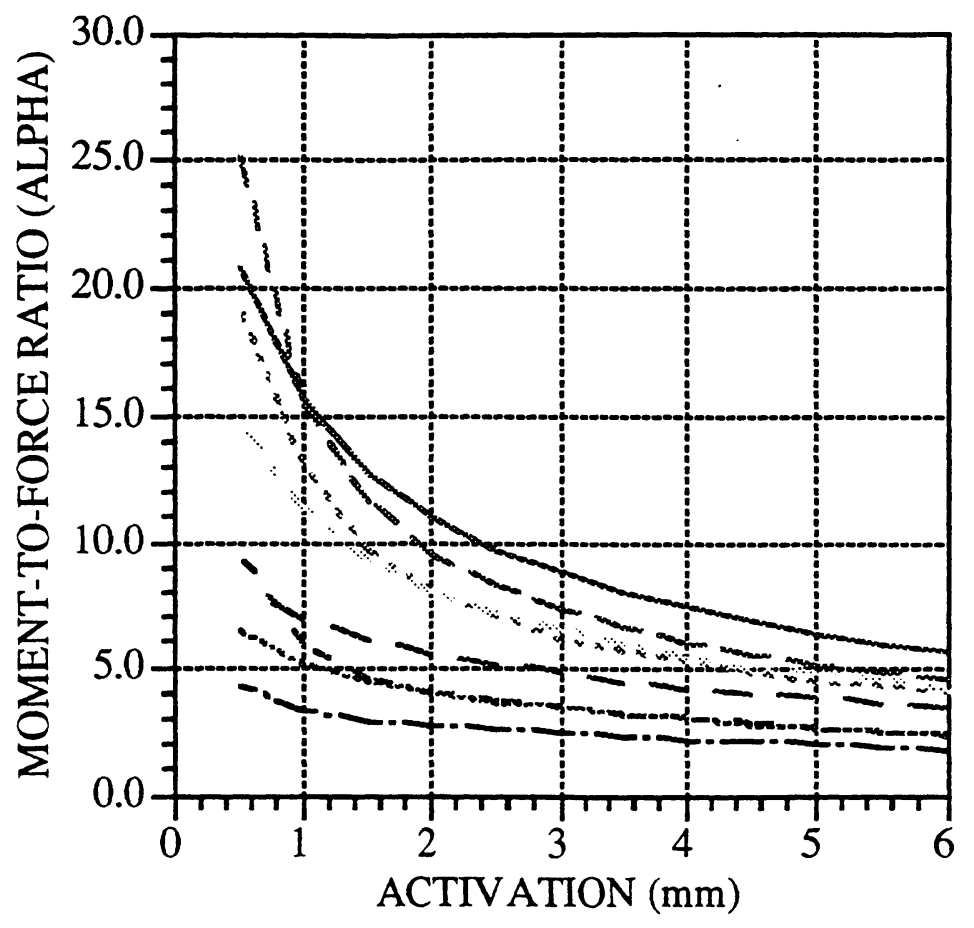

LEGEND

\begin{tabular}{|c|c|}
\hline-- & $0 \mathrm{~mm}$ ACTIVATION \\
\hline- & $1 \mathrm{~mm}$ ACTIVATION \\
\hline & 2 mm ACTIVATION \\
\hline & $3 \mathrm{~mm}$ ACTIVATION \\
\hline & $4 \mathrm{~mm}$ ACTIVATION \\
\hline . & 5 mm ACTIVATION \\
\hline & $6 \mathrm{~mm}$ ACTIVATION \\
\hline
\end{tabular}

FIGURE 18: Alpha moment-to-force ratio versus spring activation for "T-loop" springs with symmetric alpha and beta angulation and centered positioning. 


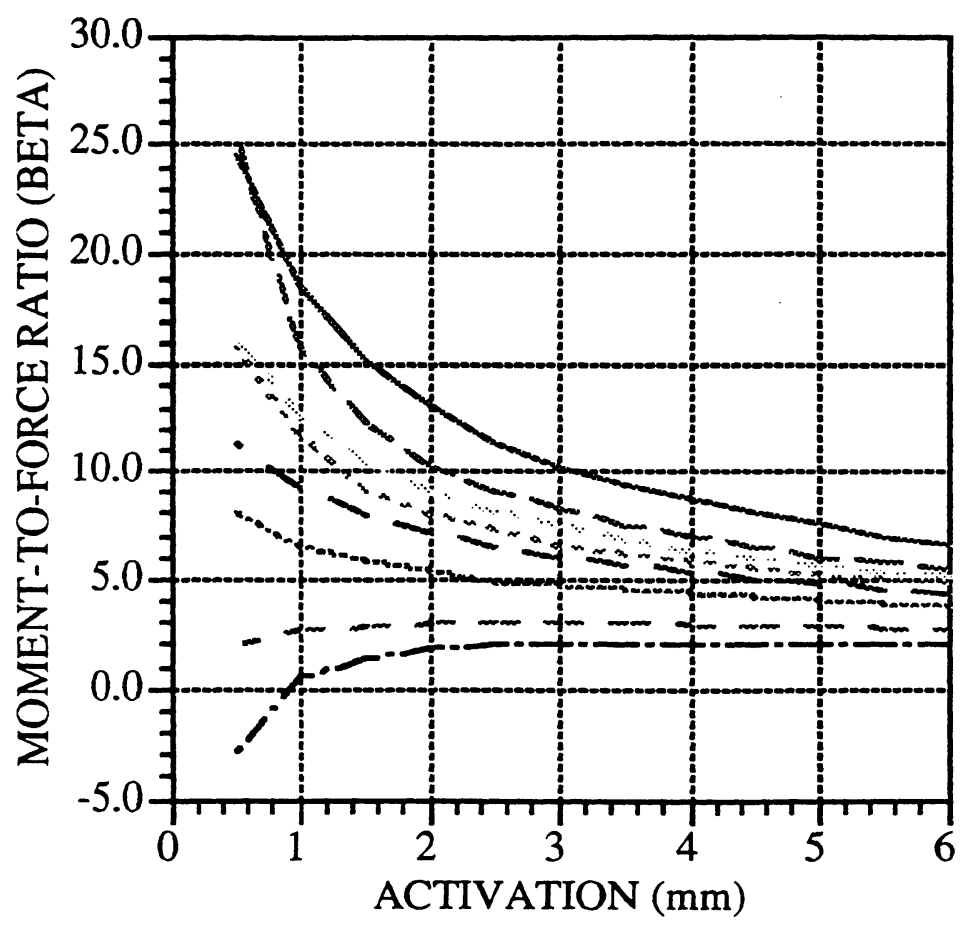

LEGEND

0 DEGREES

- - 10 DEGREES

20 DEGREES

- 30 DEGREES

. 40 DEGREES

50 DEGREES

- -60 DEGREES 70 DEGREES

FIGURE 19: Beta moment-to-force ratio versus spring activation for "T-loop" springs with symmetric alpha and beta angulation and centered positioning. 


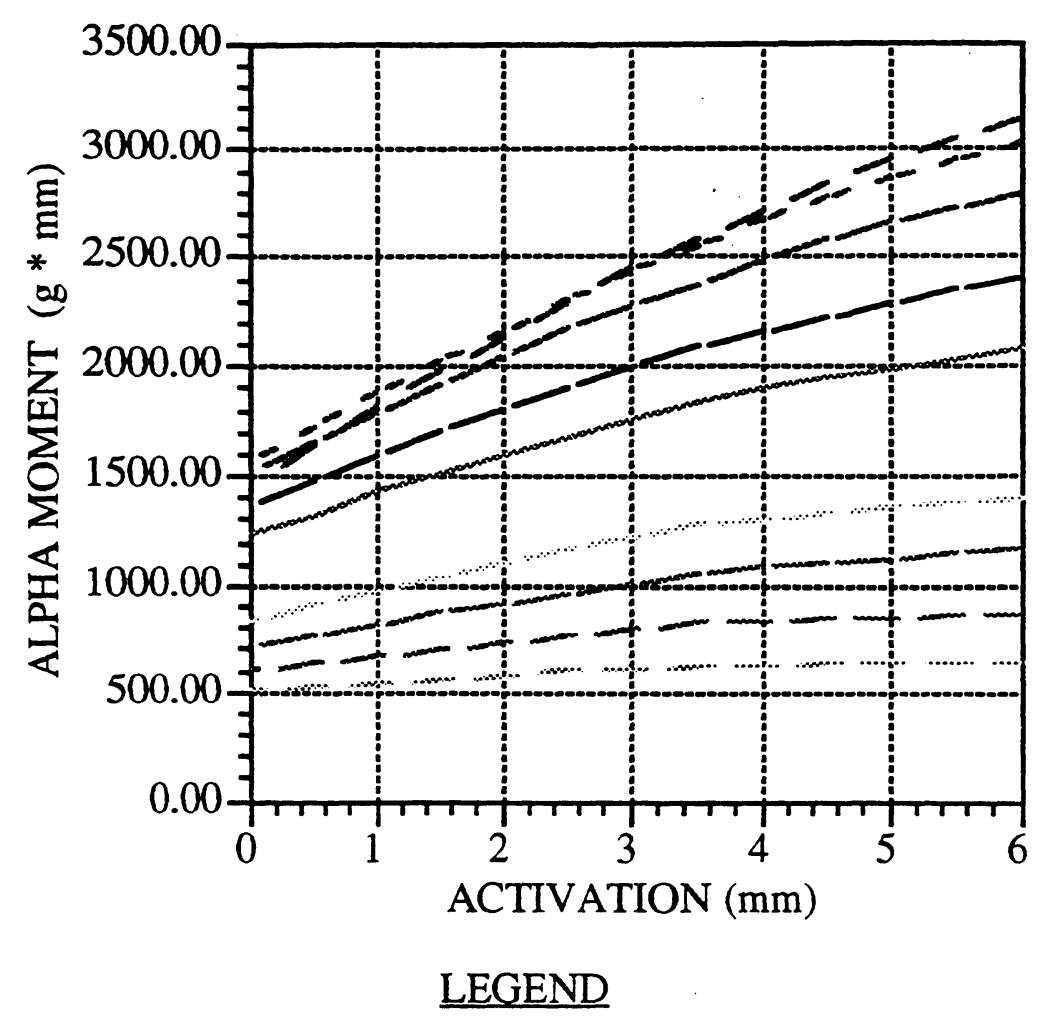

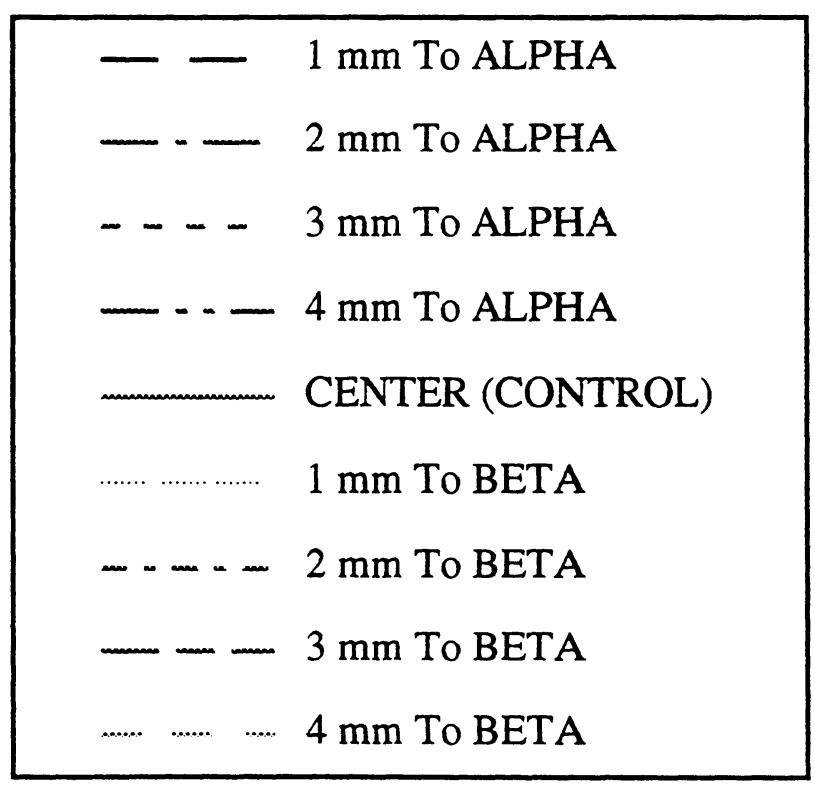

FIGURE 20: Alpha moment versus spring activation for symmetric "T-loop" springs (springs produce symmetric moments in centered position) at various off-centered positions. 


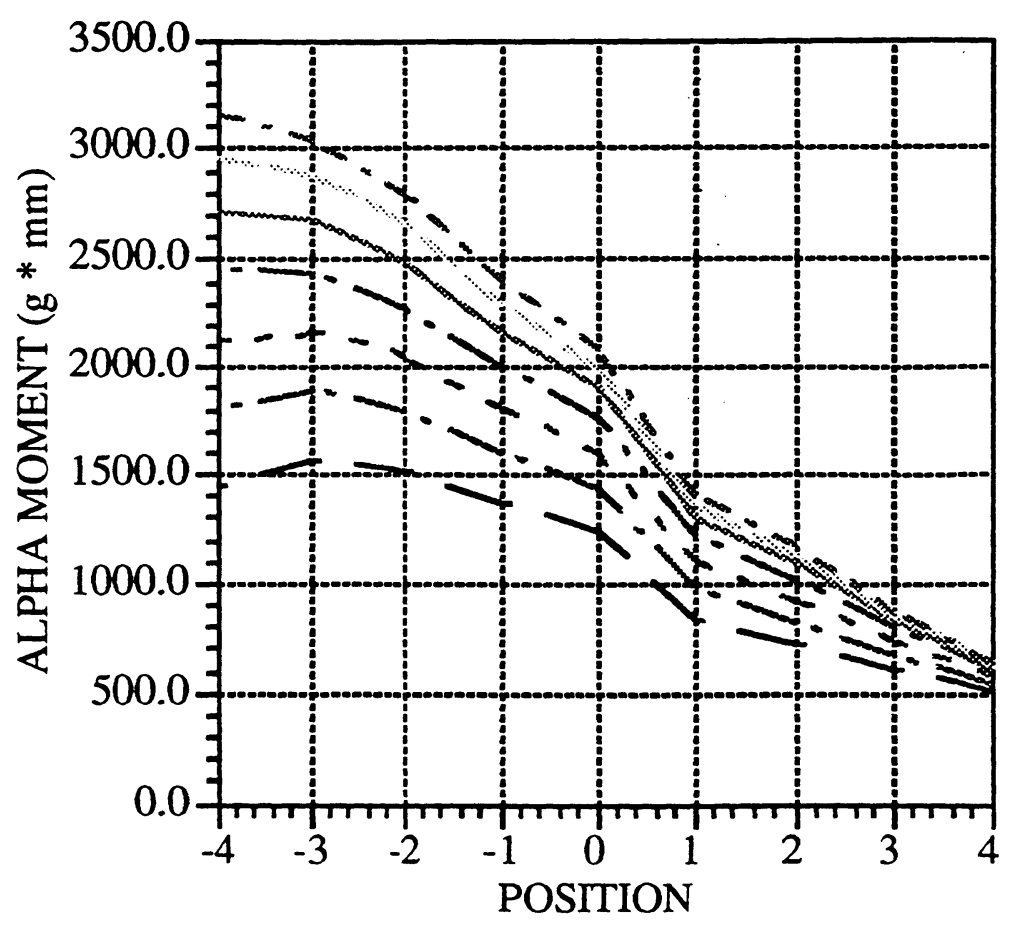

LEGEND

$$
\begin{array}{r}
--0 \mathrm{~mm} \text { ACTIVATION } \\
-\cdots-1 \mathrm{~mm} \text { ACTIVATION } \\
---2 \mathrm{~mm} \text { ACTIVATION } \\
---3 \mathrm{~mm} \text { ACTIVATION } \\
-6 \mathrm{~mm} \text { ACTIVATION } \\
-6 \mathrm{~mm} \text { ACTIVATION }
\end{array}
$$

FIGURE 21: Alpha moment versus spring position for symmetric "T-loop" springs (springs produce symmetric moments in centered position). 


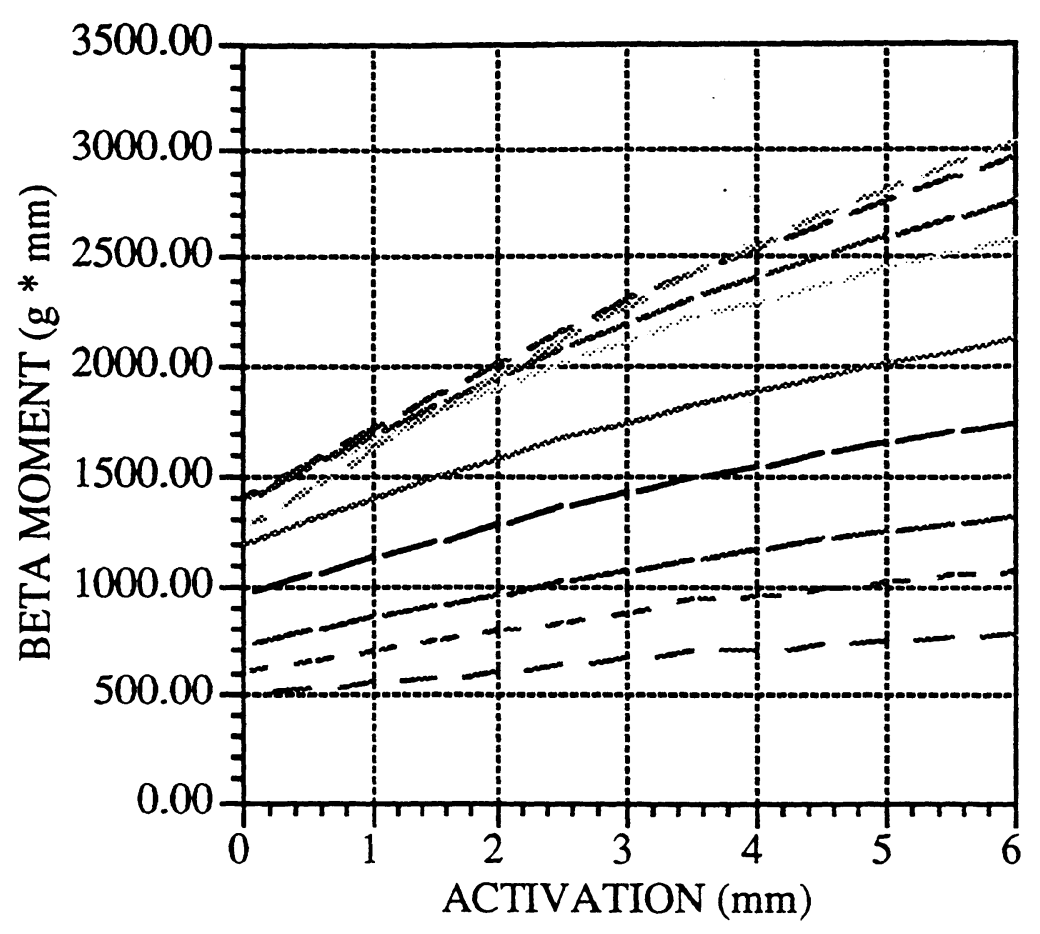

\section{LEGEND}

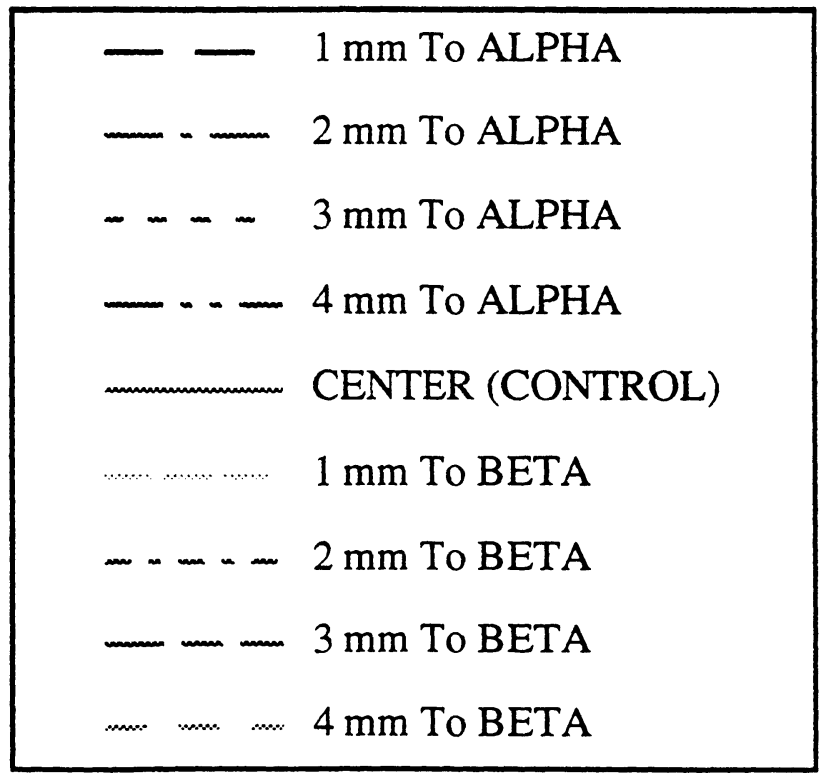

FIGURE 22: Beta moment versus spring activation for symmetric "T-loop" springs (springs produce symmetric moments in centered position) at various off-centered positions. 


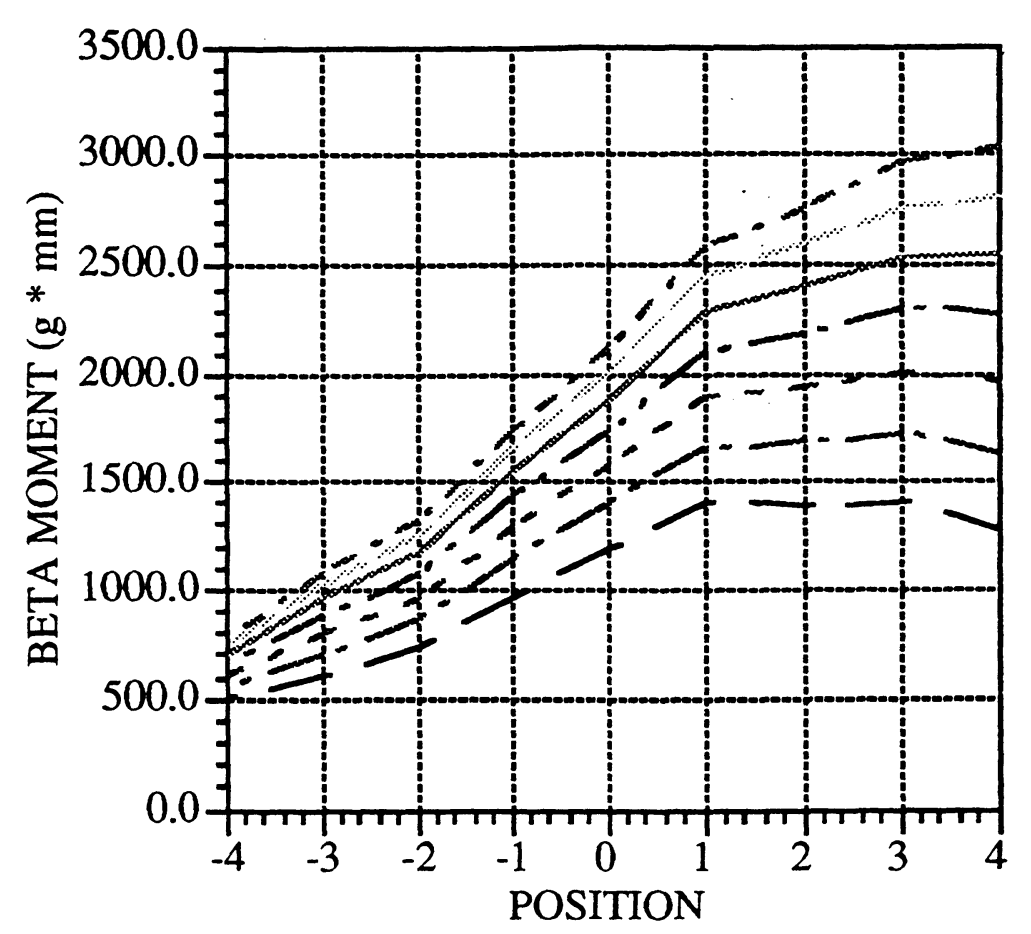

\section{LEGEND}

\begin{tabular}{|}
$--0 \mathrm{~mm}$ ACTIVATION \\
$--1 \mathrm{~mm}$ ACTIVATION \\
$-\ldots-2 \mathrm{~mm}$ ACTIVATION \\
$---3 \mathrm{~mm}$ ACTIVATION \\
$-4 \mathrm{~mm}$ ACTIVATION \\
$5 \mathrm{~mm}$ ACTIVATION \\
\hline
\end{tabular}

FIGURE 23: Beta moment versus spring position for symmetric "T-loop" springs (springs produce symmetric moments in centered position). 


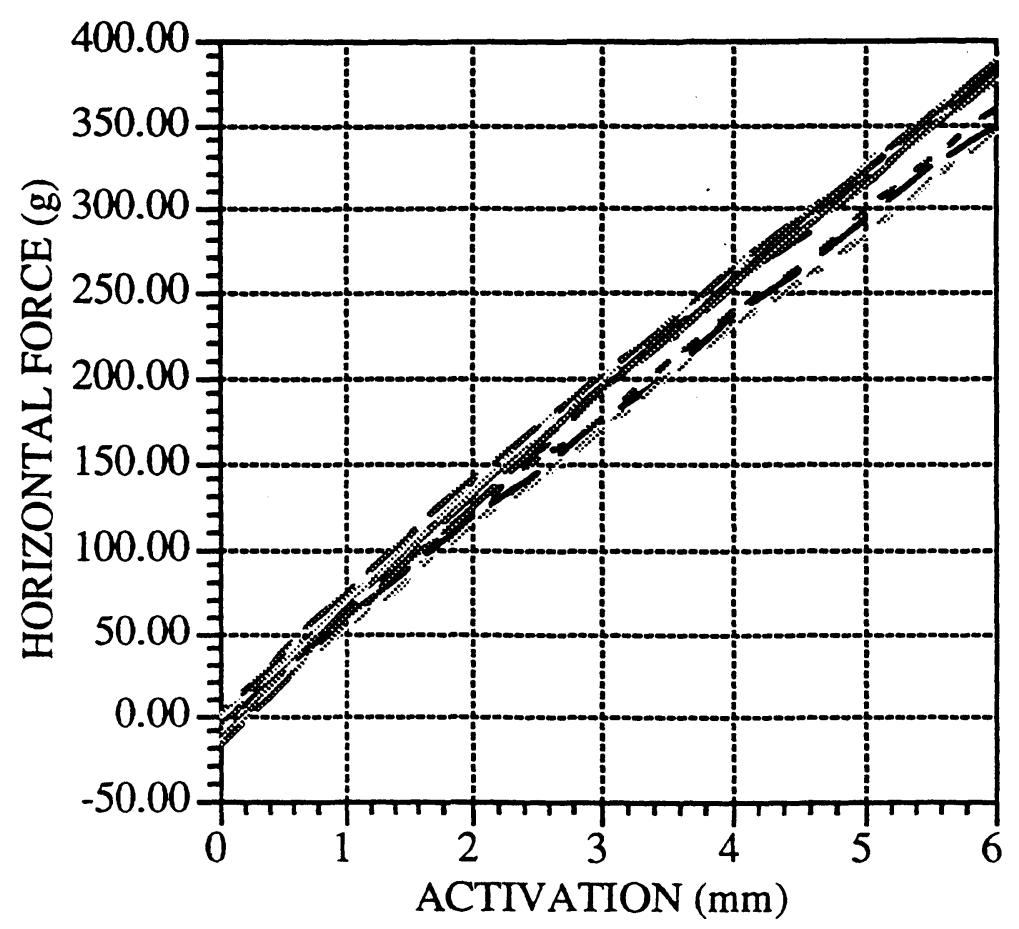

\section{$\underline{\text { LEGEND }}$}

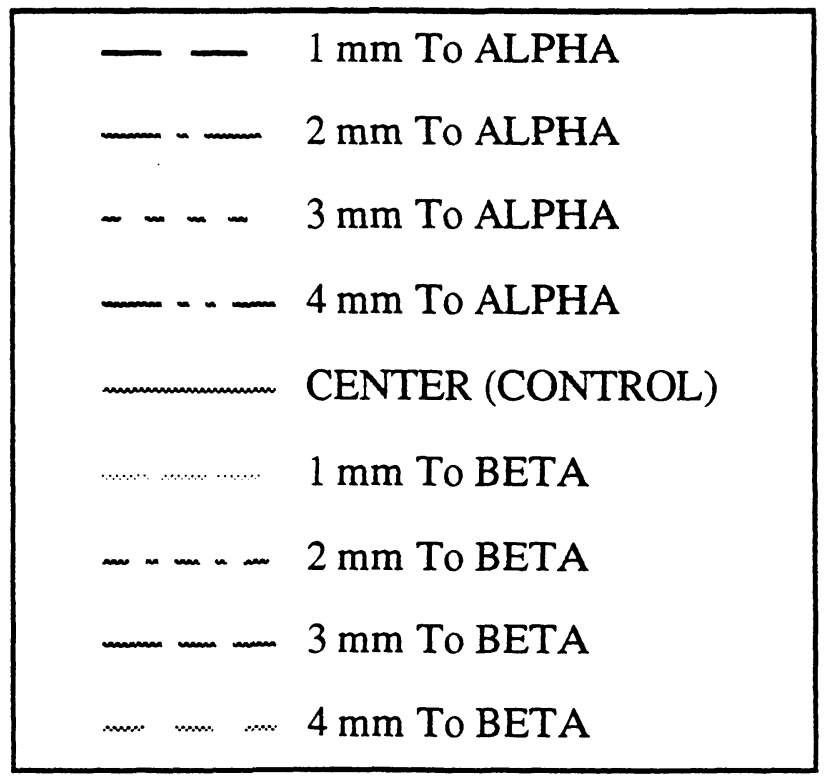

FIGURE 24: Horizontal force versus spring activation for symmetric "T-loop" springs (springs produce symmetric moments in centered position) at various off-centered positions. 


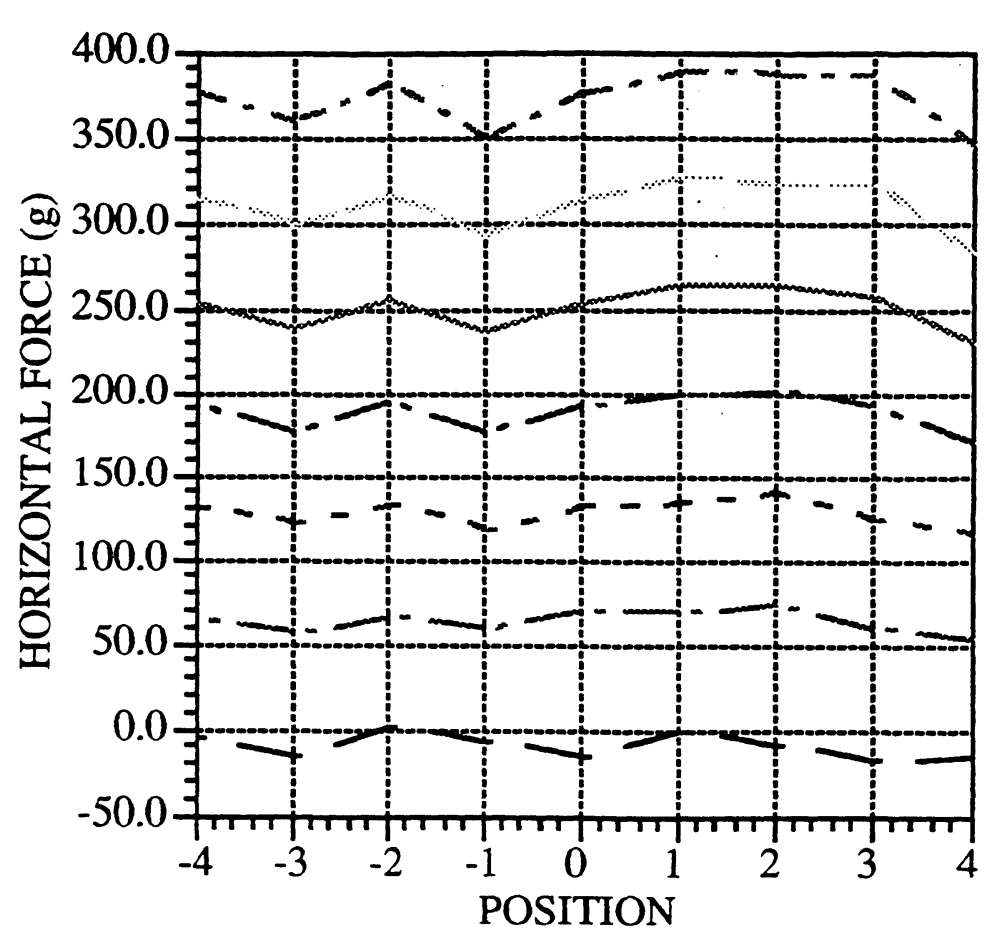

\section{LEGEND}

\begin{tabular}{|c|c|}
\hline-- & $0 \mathrm{~mm}$ ACTIVATION \\
\hline س & $1 \mathrm{~mm}$ ACTIVATION \\
\hline--- & $2 \mathrm{~mm}$ ACTIVATION \\
\hline-- & $3 \mathrm{~mm}$ ACTIVATION \\
\hline & $4 \mathrm{~mm}$ ACTIVATION \\
\hline$\ldots \ldots \ldots \ldots \ldots$ & $5 \mathrm{~mm}$ ACTIVATION \\
\hline$-\cdots$ & $6 \mathrm{~mm}$ ACTIVATION \\
\hline
\end{tabular}

FIGURE 25: Horizontal force versus spring position for symmetric "T-loop" springs (springs produce symmetric moments in centered position). 


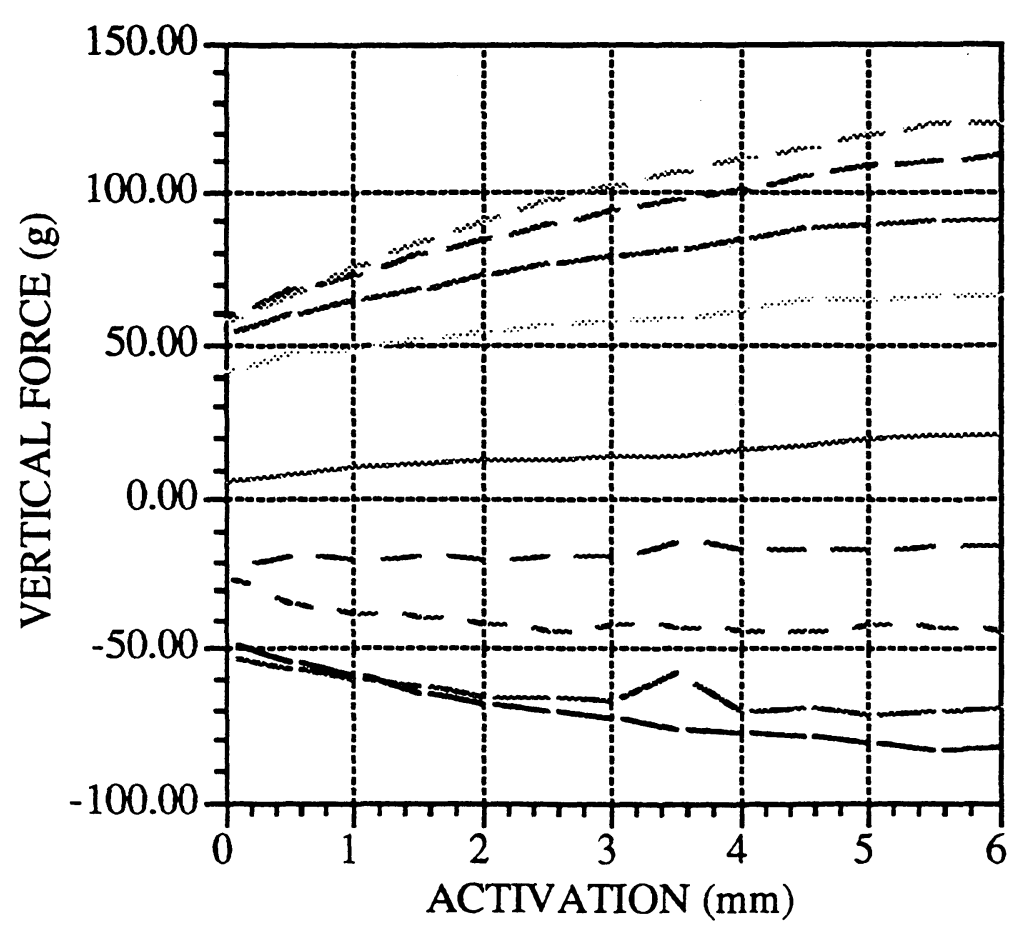

\section{LEGEND}

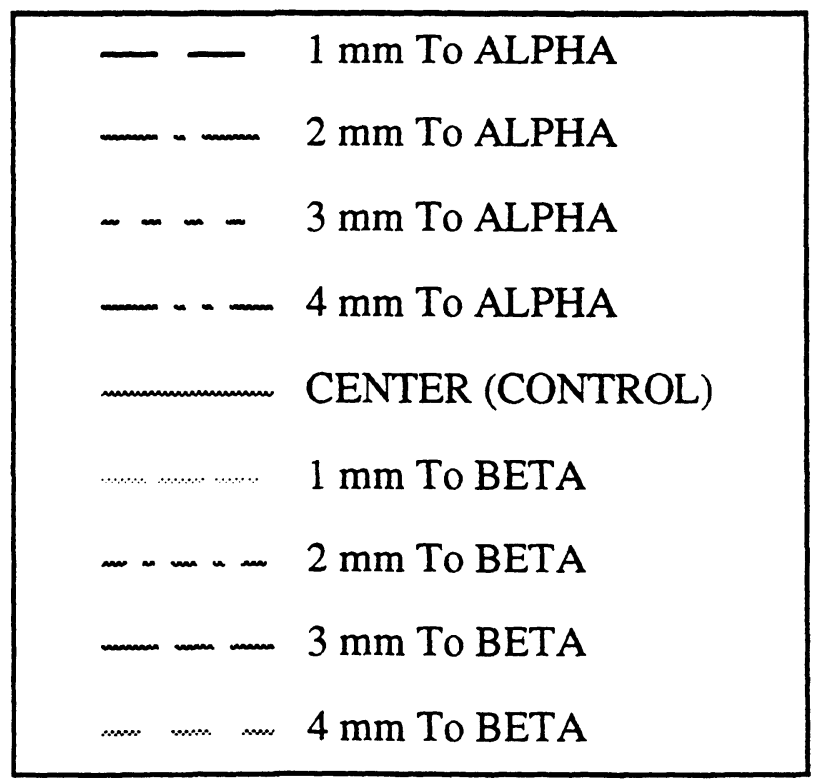

FIGURE 26: Vertical force versus spring activation for symmetric "T-loop" springs (springs produce symmetric moments in centered position) at various off-centered positions. 


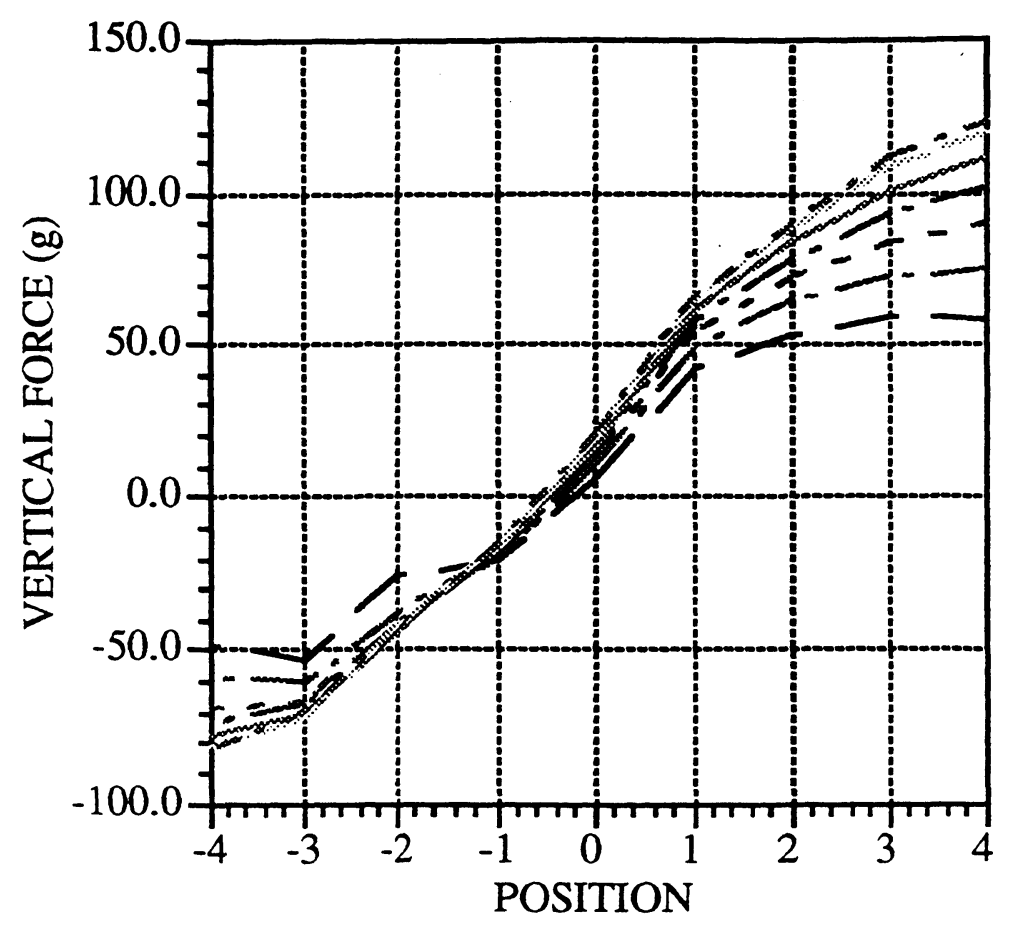

\section{LEGEND}

$$
\begin{aligned}
& \text { - }-0 \mathrm{~mm} \text { ACTIVATION } \\
& -\cdots 1 \mathrm{~mm} \text { ACTIVATION } \\
& \text { - - - } 2 \mathrm{~mm} \text { ACTIVATION } \\
& ---3 \mathrm{~mm} \text { ACTIVATION } \\
& 4 \mathrm{~mm} \text { ACTIVATION } \\
& 5 \mathrm{~mm} \text { ACTIVATION } \\
& \ldots-6 \mathrm{~mm} \text { ACTIVATION }
\end{aligned}
$$

FIGURE 27: Vertical force versus spring position for symmetric "T-loop" springs (springs produce symmetric moments in centered position). 


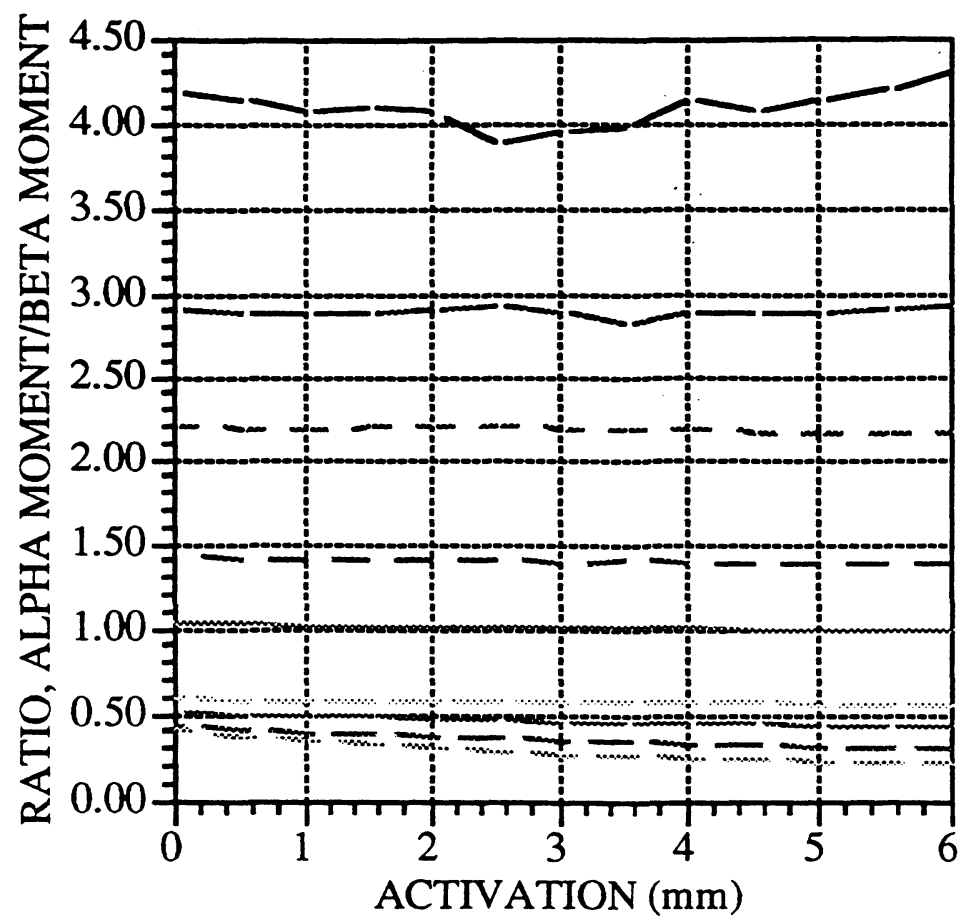

\section{$\underline{\text { LEGEND }}$}

$$
\begin{aligned}
& \text { — — } 1 \mathrm{~mm} \text { To ALPHA } \\
& \text { - } 2 \mathrm{~mm} \text { To ALPHA } \\
& \text { _ _ _ } 3 \text { mm To ALPHA } \\
& \text { - . - } 4 \mathrm{~mm} \text { To ALPHA } \\
& \text { CENTER (CONTROL) } \\
& 1 \mathrm{~mm} \text { To BETA } \\
& \ldots \ldots \ldots \text { mm To BETA } \\
& -3 \mathrm{~mm} \text { To BETA } \\
& \text { m } \quad 4 \mathrm{~mm} \text { To BETA }
\end{aligned}
$$

FIGURE 28: Ratio of the alpha moment/beta moment versus spring activation for symmetric "T-loop" springs (springs produce symmetric moments in centered position) at various off-centered positions. 


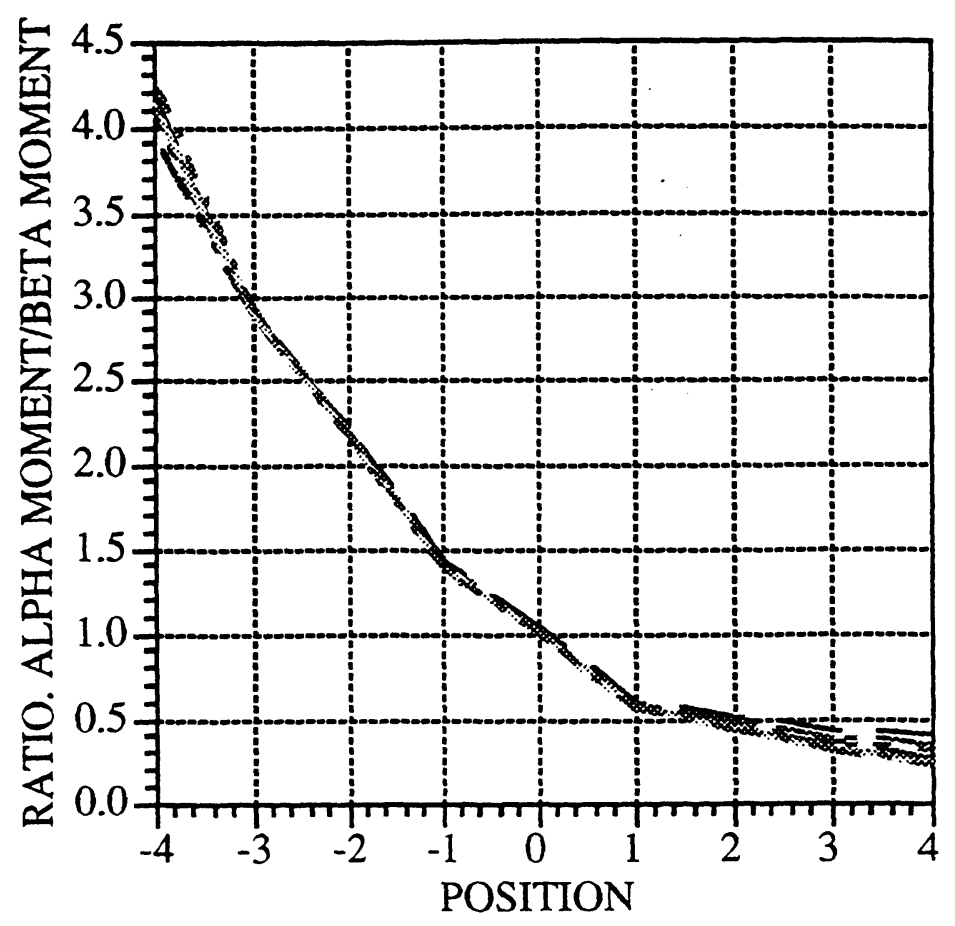

\section{LEGEND}

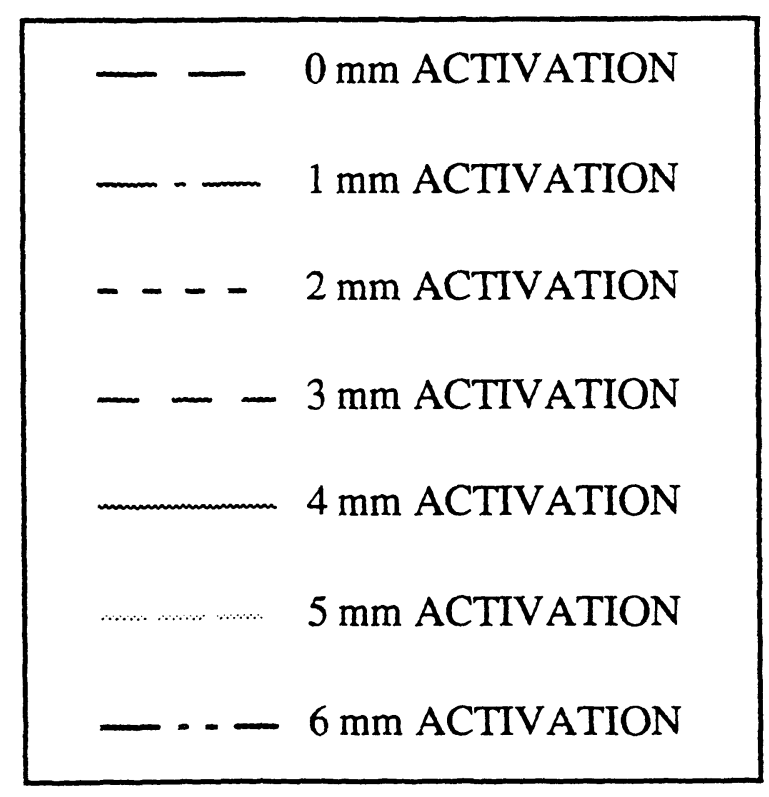

FIGURE 29: Ratio of the alpha moment/beta moment versus spring position for symmetric "T-loop" springs (springs produce symmetric moments in centered position). 


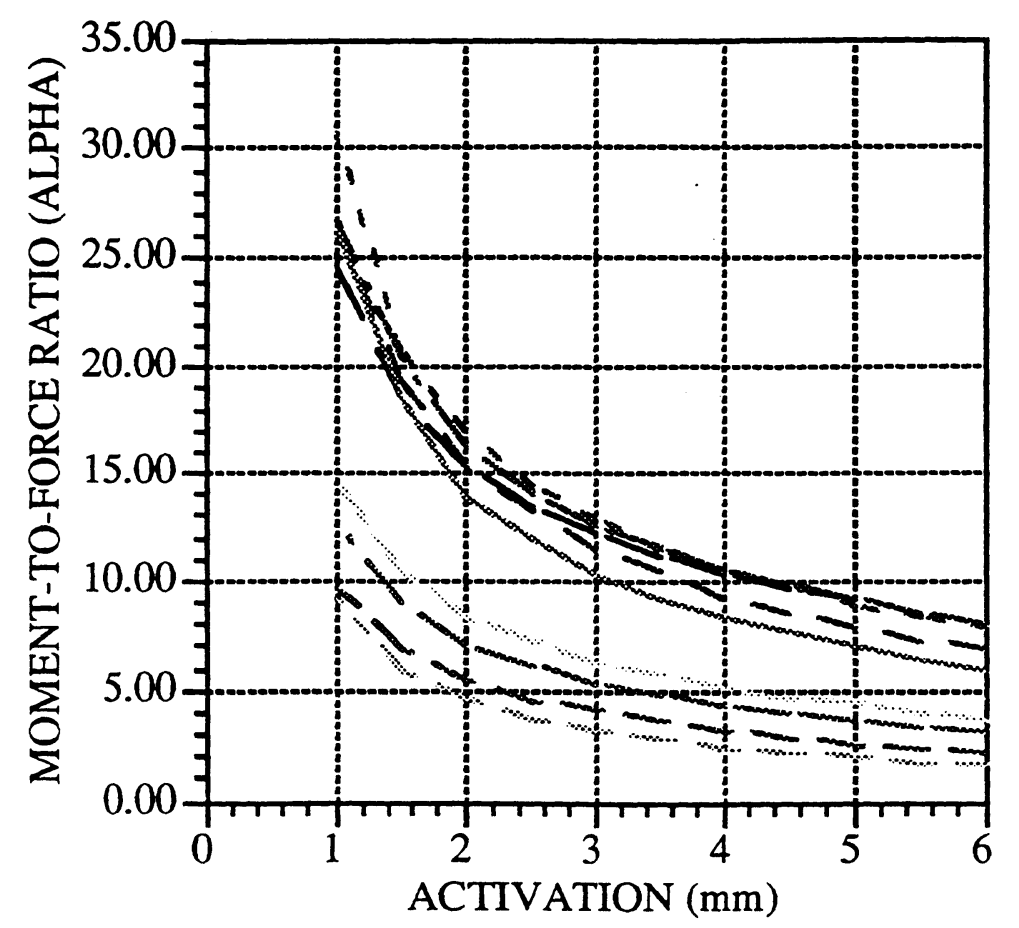

\section{LEGEND}

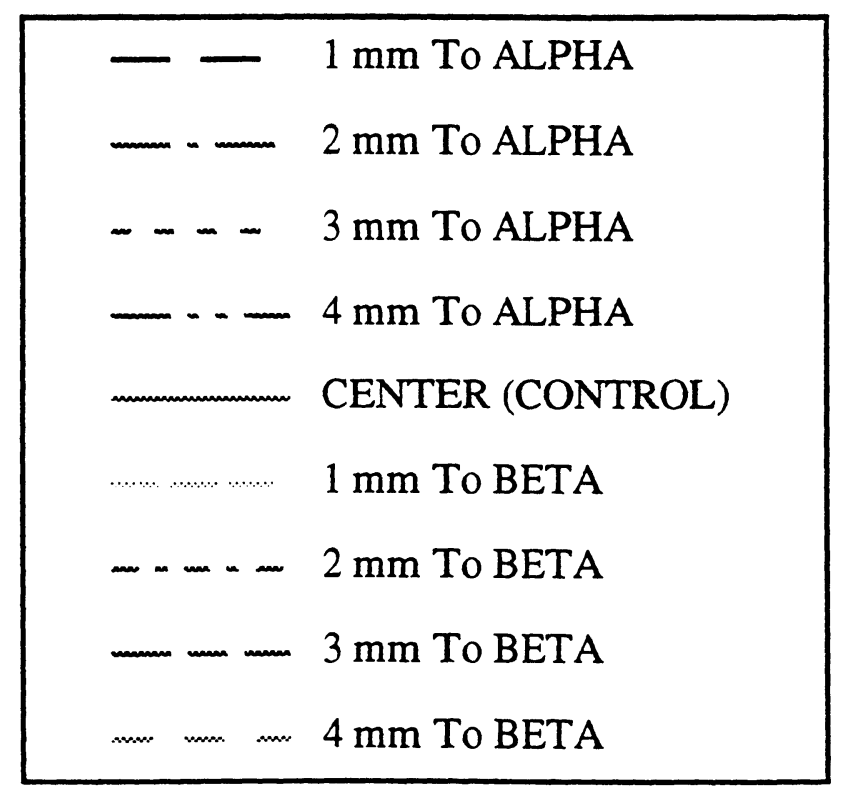

FIGURE 30: Alpha moment-to-force ratio versus spring activation for symmetric "Tloop" springs (springs produce symmetric moments in centered position) at various offcentered positions. 

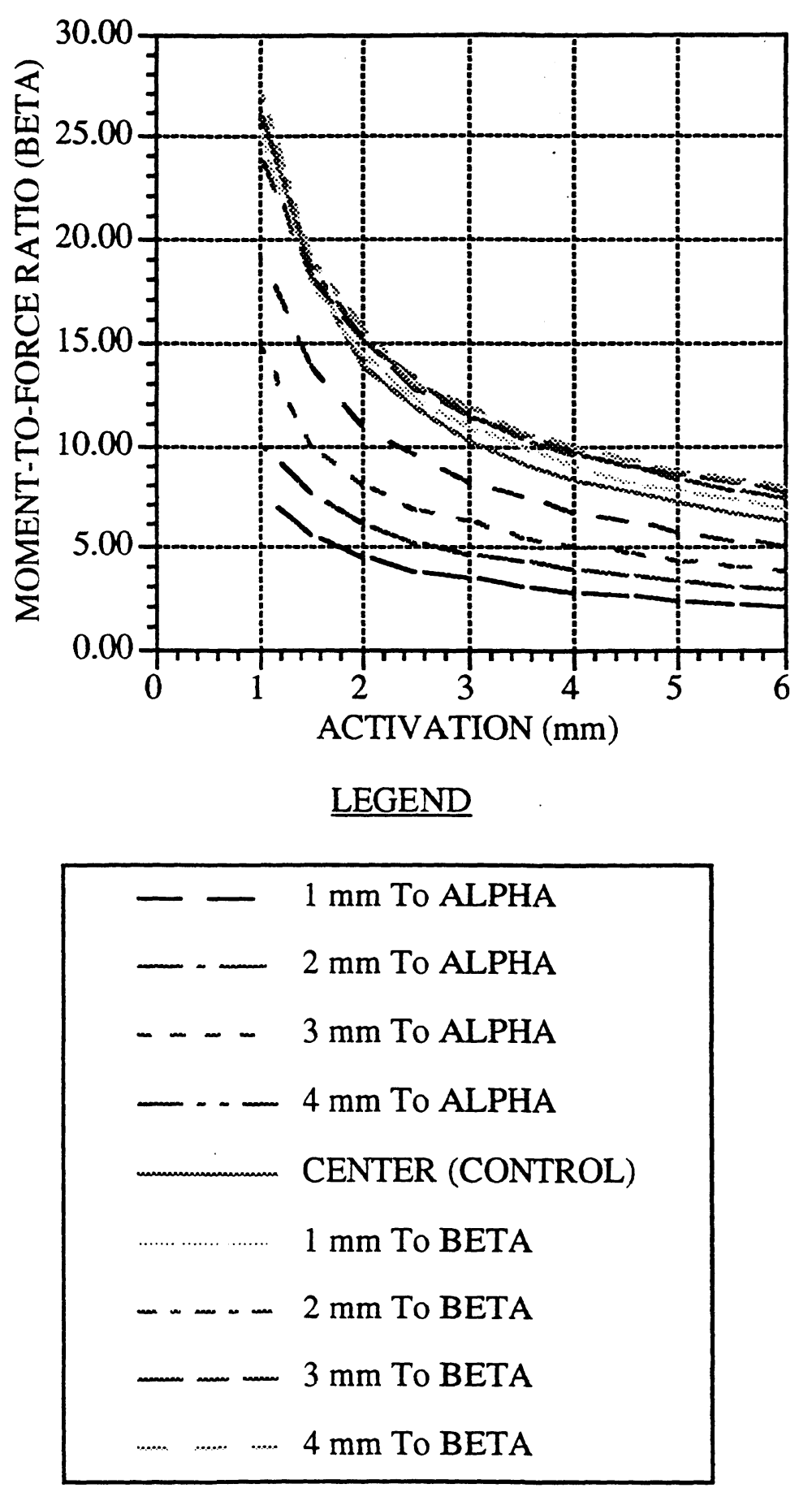

FIGURE 31: Beta moment-to-force ratio versus spring activation for symmetric "T-loop" springs (springs produce symmetric moments in centered position) at various off-centered positions. 

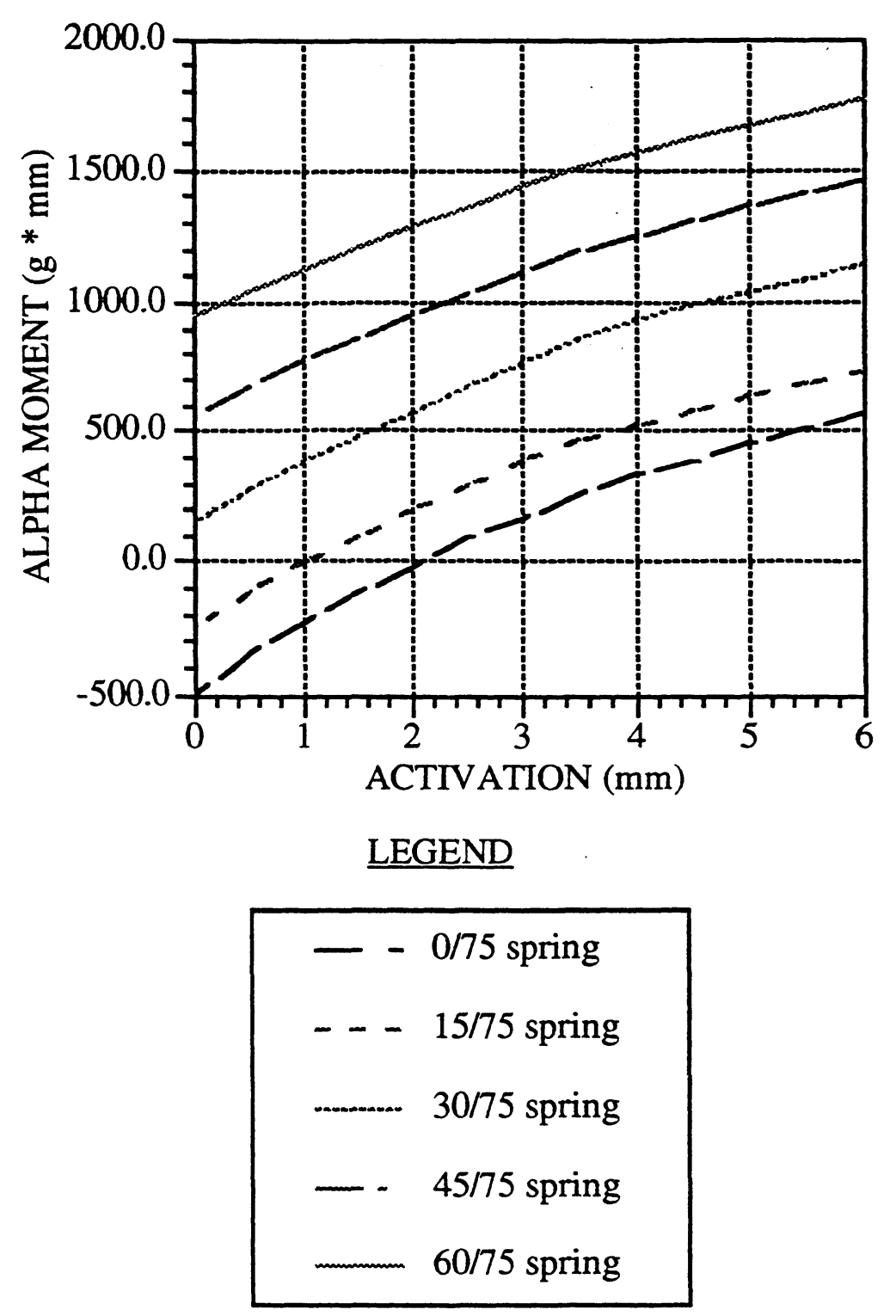

FIGURE 32: Alpha moment versus spring activation for "T-loop" springs with asymmetric alpha and beta angulation and centered position, variation of the alpha angulation $(0,15,30,45$ and 60 degrees) with a constant beta angulation ( 75 degrees) . 

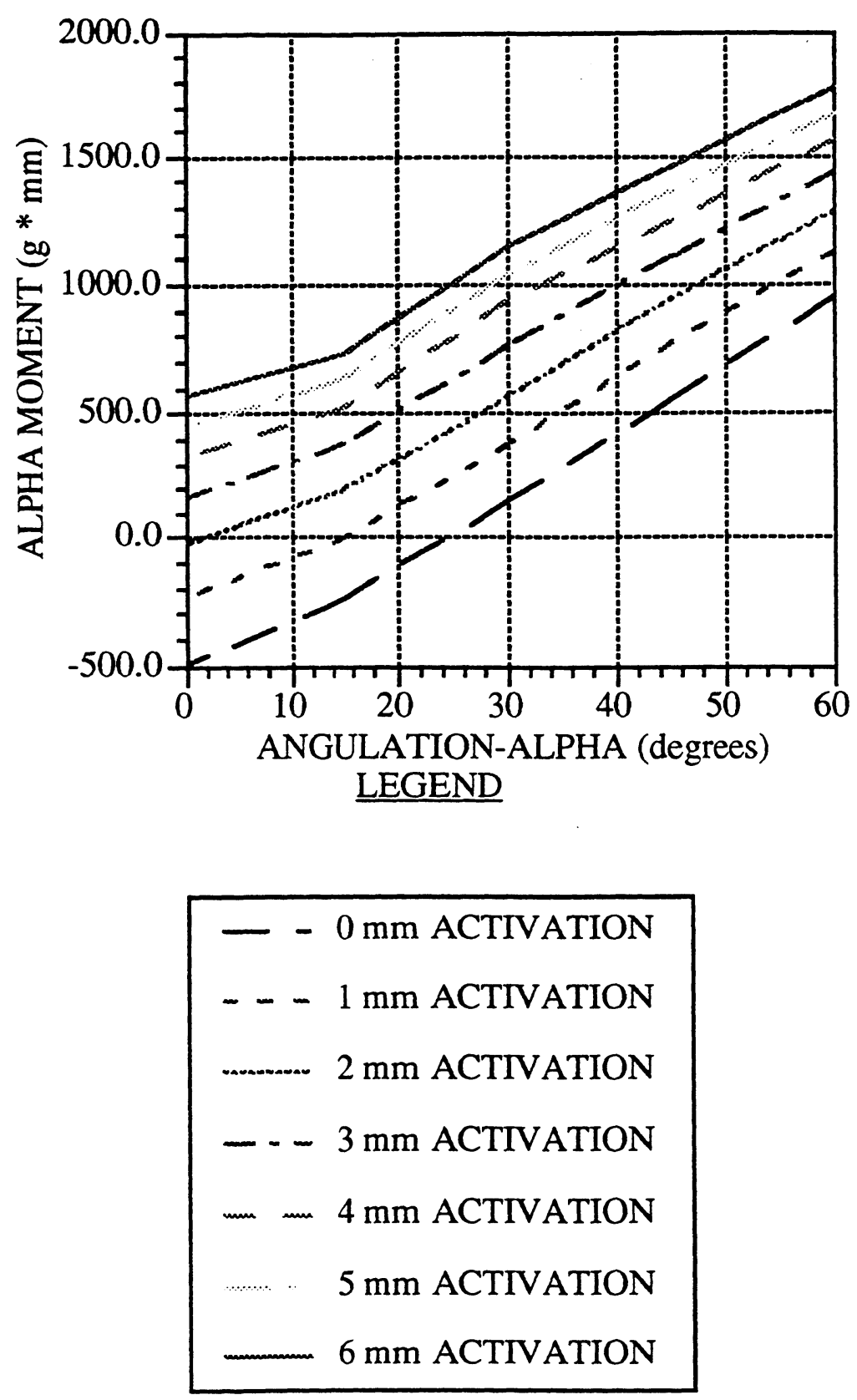

FIGURE 33: Alpha moment versus alpha angulation for "T-loop" springs with asymmetric alpha and beta angulation and centered position, variation of the alpha angulation $(0,15,30,45$ and 60 degrees) with a constant beta angulation ( 75 degrees). 

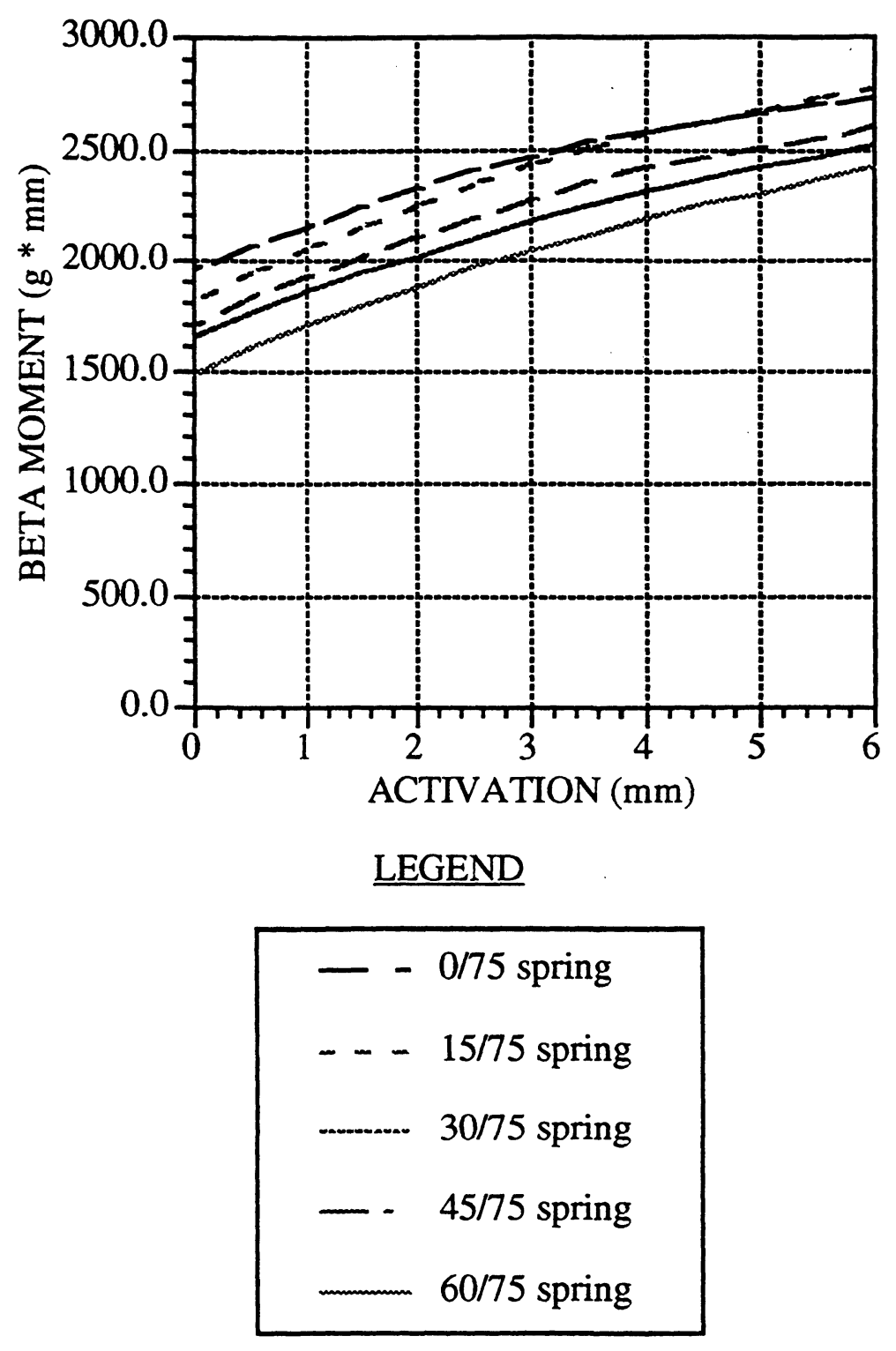

FIGURE 34: Beta moment versus spring activation for "T-loop" springs with asymmetric alpha and beta angulation and centered position, variation of the alpha angulation $(0,15,30,45$ and 60 degrees) with a constant beta angulation (75 degrees) . 

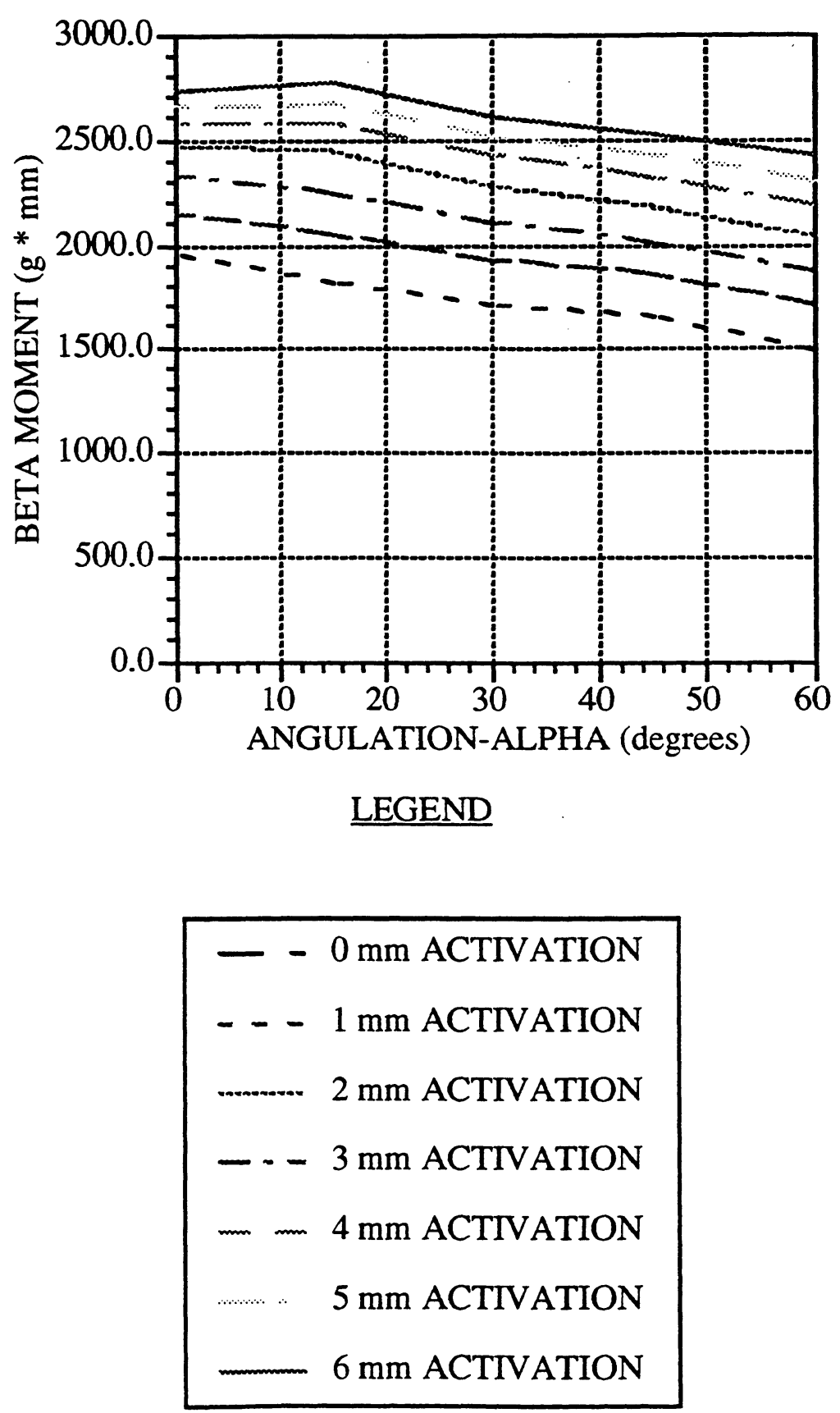

FIGURE 35: beta moment versus alpha angulation for "T-loop" springs with asymmetric alpha and beta angulation and centered position, variation of the alpha angulation $(0,15,30,45$ and 60 degrees) with a constant beta angulation (75 degrees). 


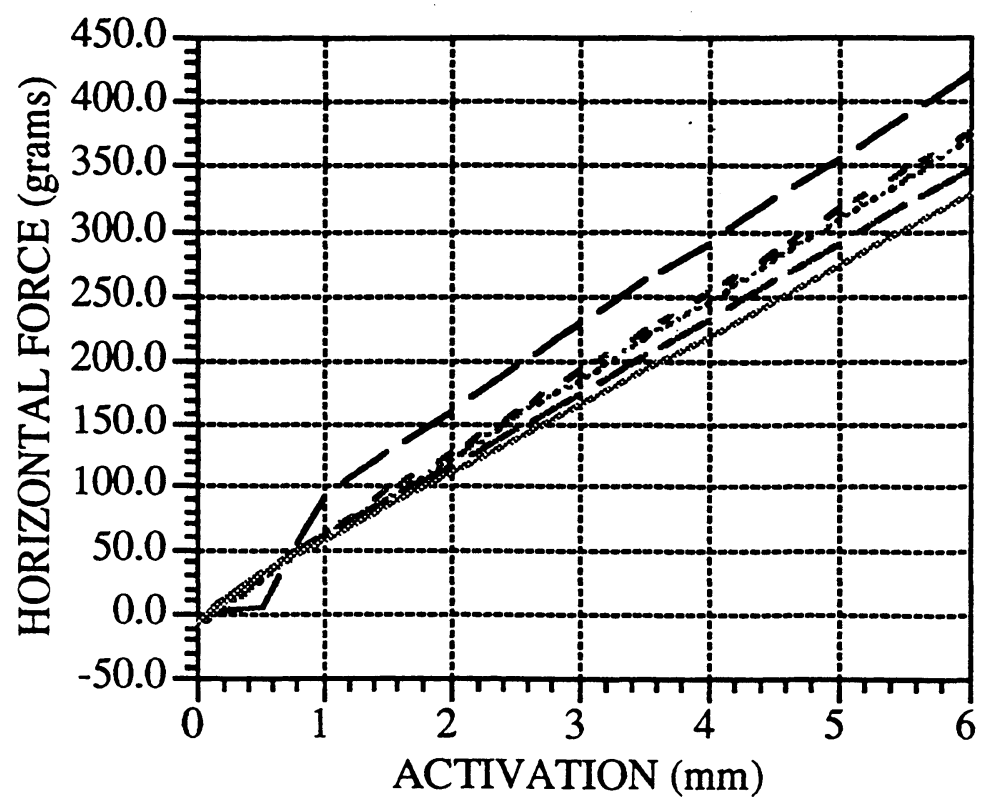

LEGEND

- 0/75 spring

_ - $15 / 75$ spring

30/75 spring

- $45 / 75$ spring $60 / 75$ spring

FIGURE 36: Horizontal force versus spring activation for "T-loop" springs with asymmetric alpha and beta angulation and centered position, variation of the alpha angulation $(0,15,30,45$ and 60 degrees) with a constant beta angulation (75 degrees). 

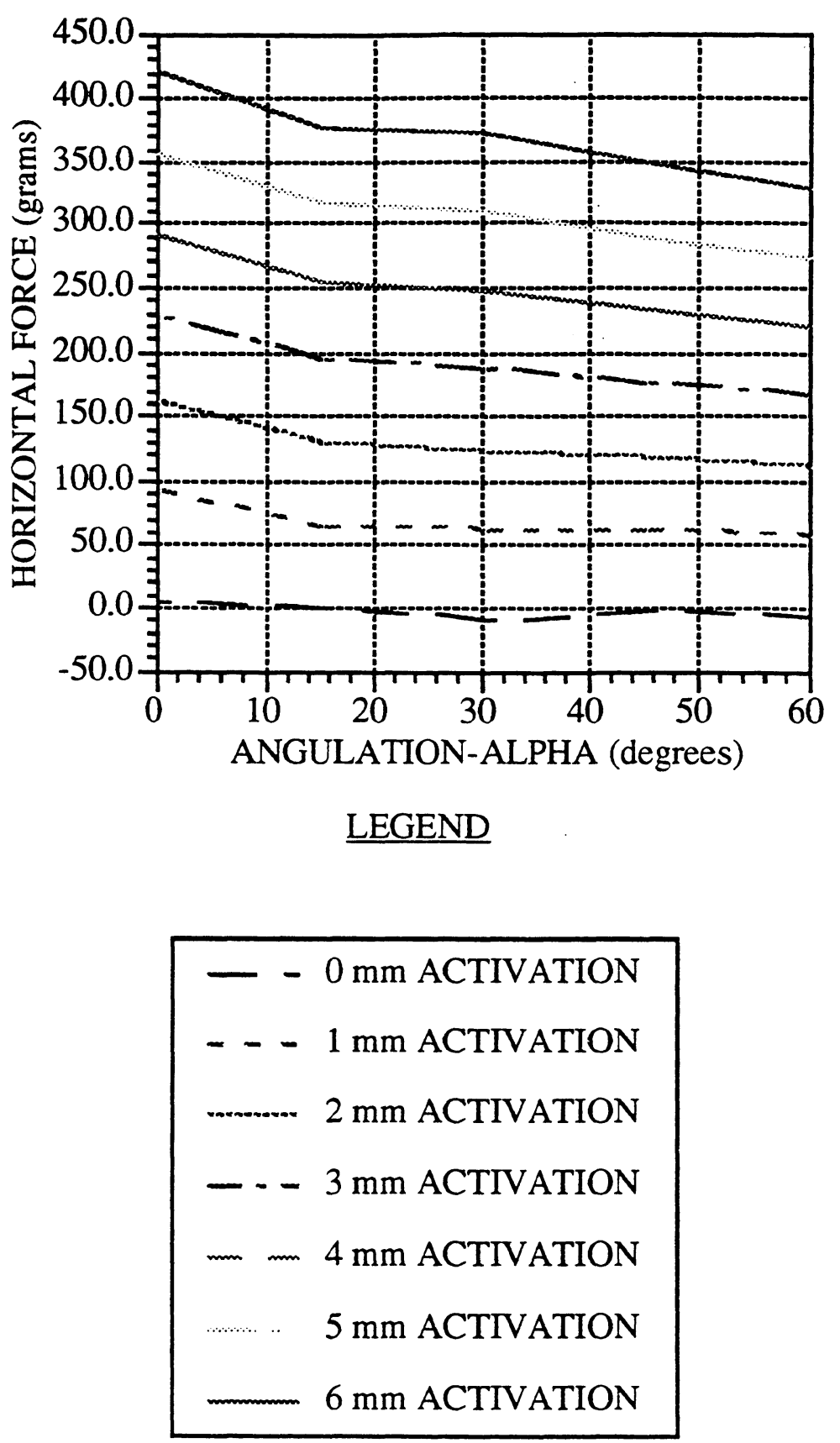

FIGURE 37: Horizontal force versus alpha angulation for "T-loop" springs with asymmetric alpha and beta angulation and centered position, variation of the alpha angulation $(0,15,30,45$ and 60 degrees) with a constant beta angulation (75 degrees) . 


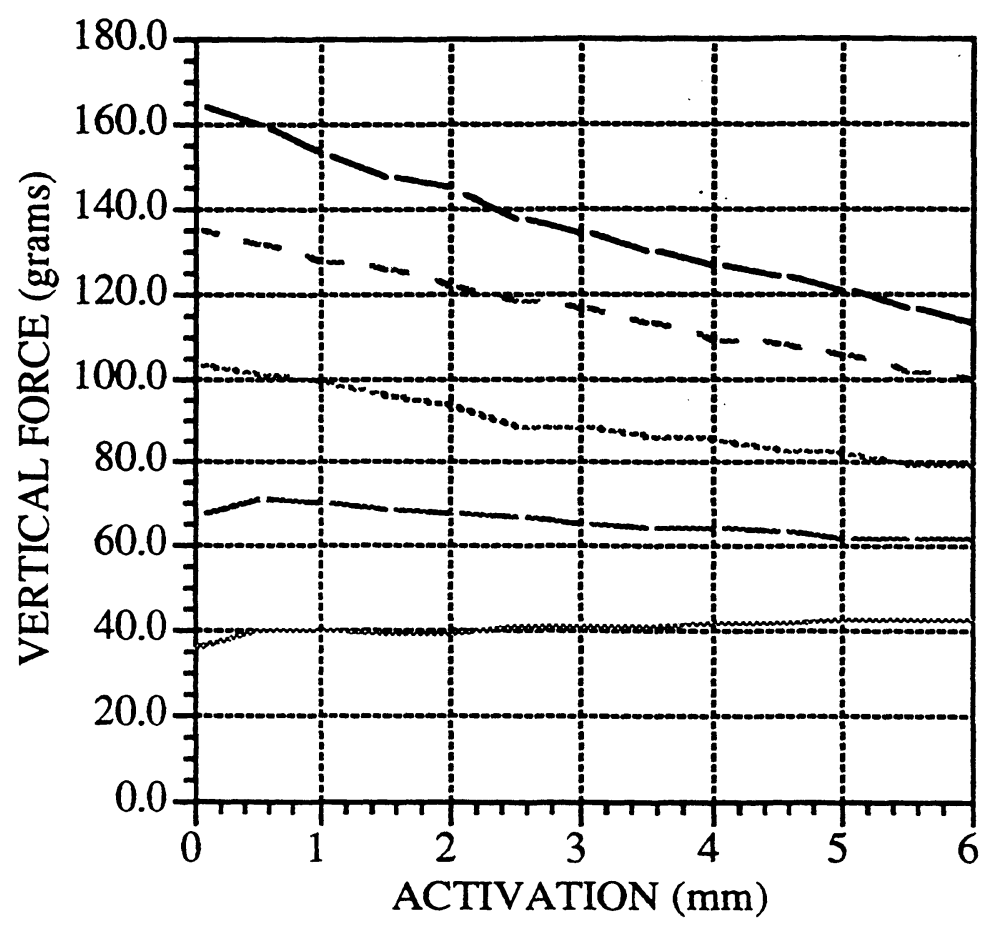

LEGEND

- $0 / 75$ spring

- - $15 / 75$ spring

30/75 spring

- $45 / 75$ spring

$60 / 75$ spring

FIGURE 38: Vertical force versus spring activation for "T-loop" springs with asymmetric alpha and beta angulation and centered position, variation of the alpha angulation $(0,15,30,45$ and 60 degrees) with a constant beta angulation (75 degrees) . 


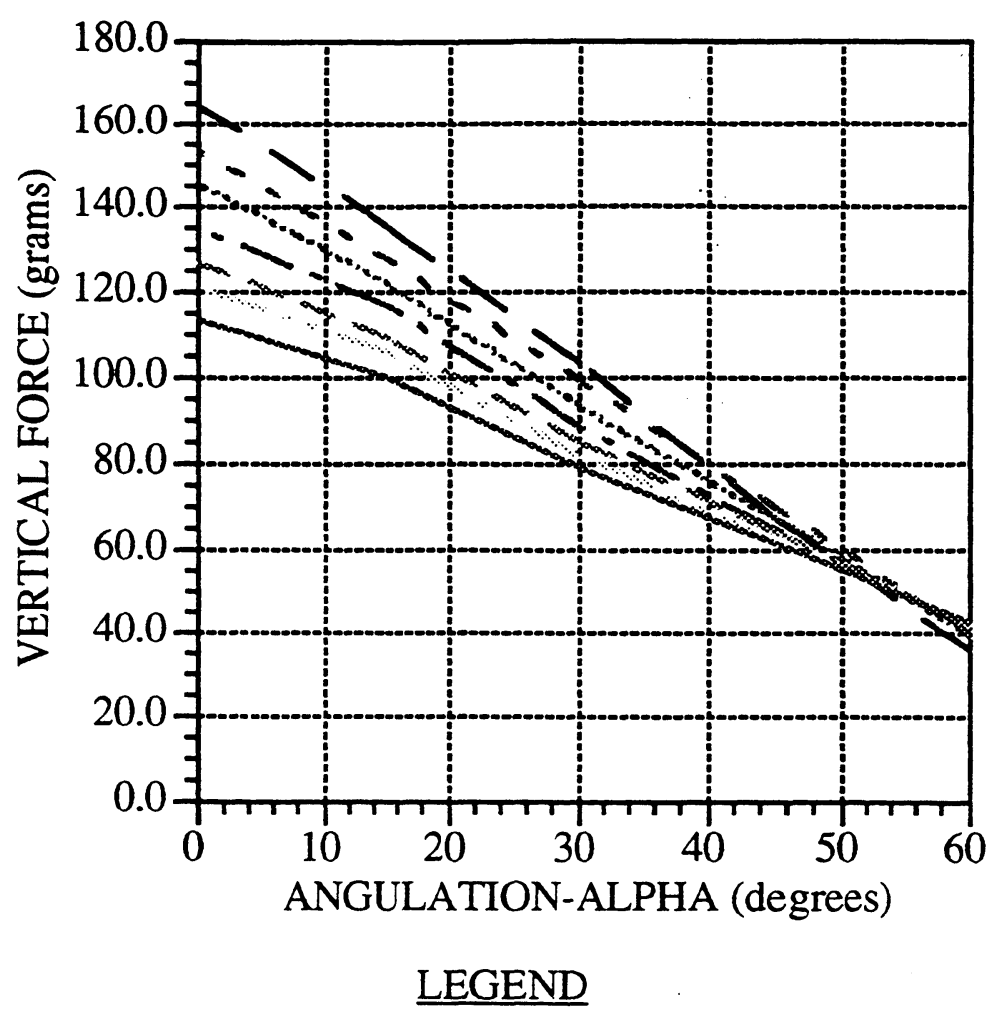

$$
\begin{aligned}
& \text { - }-0 \mathrm{~mm} \text { ACTIVATION } \\
& \text { - - - } 1 \mathrm{~mm} \text { ACTIVATION } \\
& \text { ……... } 2 \text { mm ACTIVATION } \\
& \text { - - } 3 \text { mm ACTIVATION } \\
& m-m \text { mm ACTIVATION } \\
& 5 \mathrm{~mm} \text { ACTIVATION } \\
& \text { - } 6 \mathrm{~mm} \text { ACTIVATION }
\end{aligned}
$$

FIGURE 39: Vertical force versus alpha angulation for "T-loop" springs with asymmetric alpha and beta angulation and centered position, variation of the alpha angulation $(0,15,30,45$ and 60 degrees) with a constant beta angulation ( 75 degrees) . 

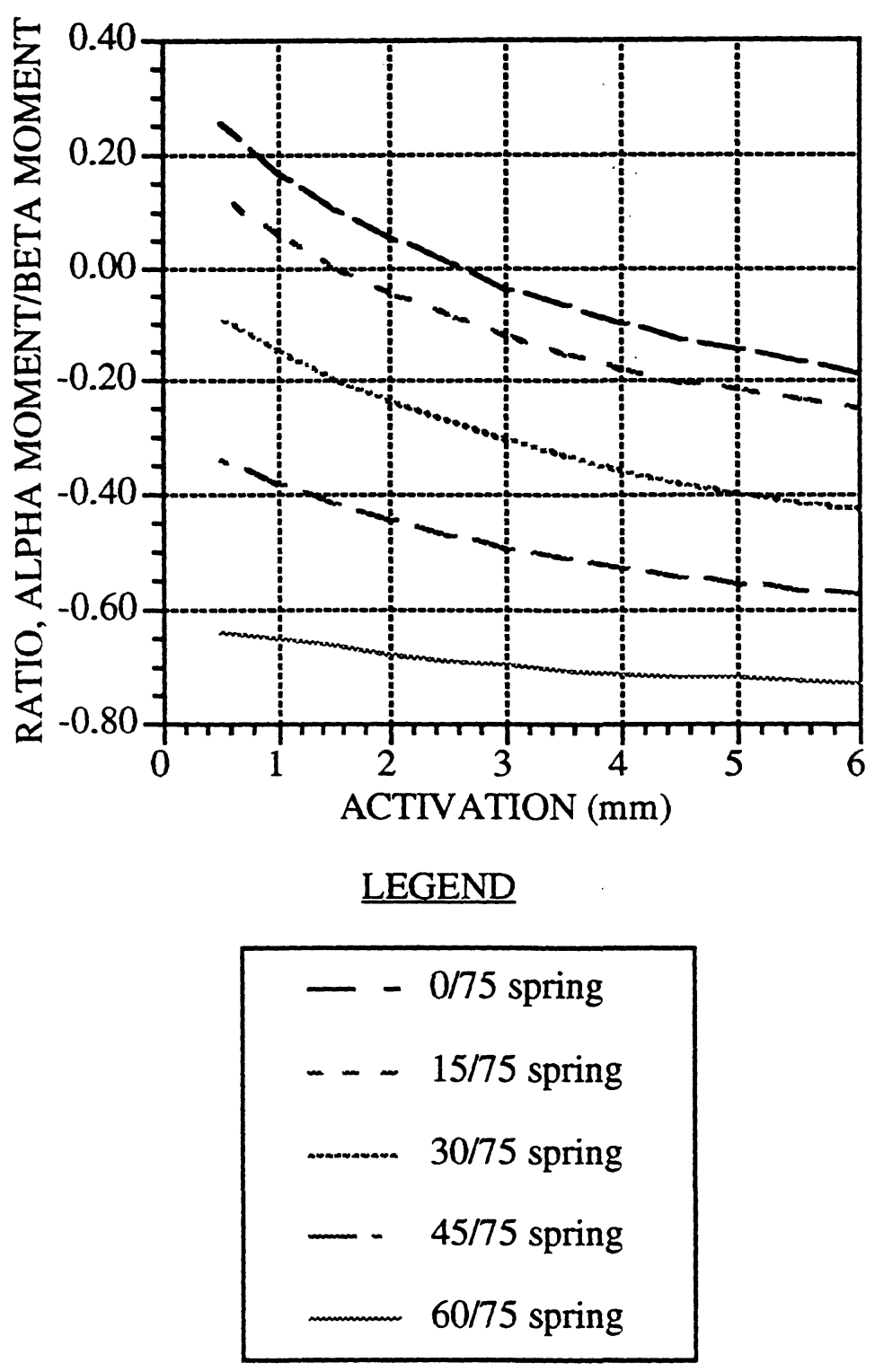

FIGURE 40: Ratio of the alpha moment/beta moment versus spring activation for "Tloop" springs with asymmetric alpha and beta angulation and centered position, variation of the alpha angulation $(0,15,30,45$ and 60 degrees) with a constant beta angulation (75 degrees). 

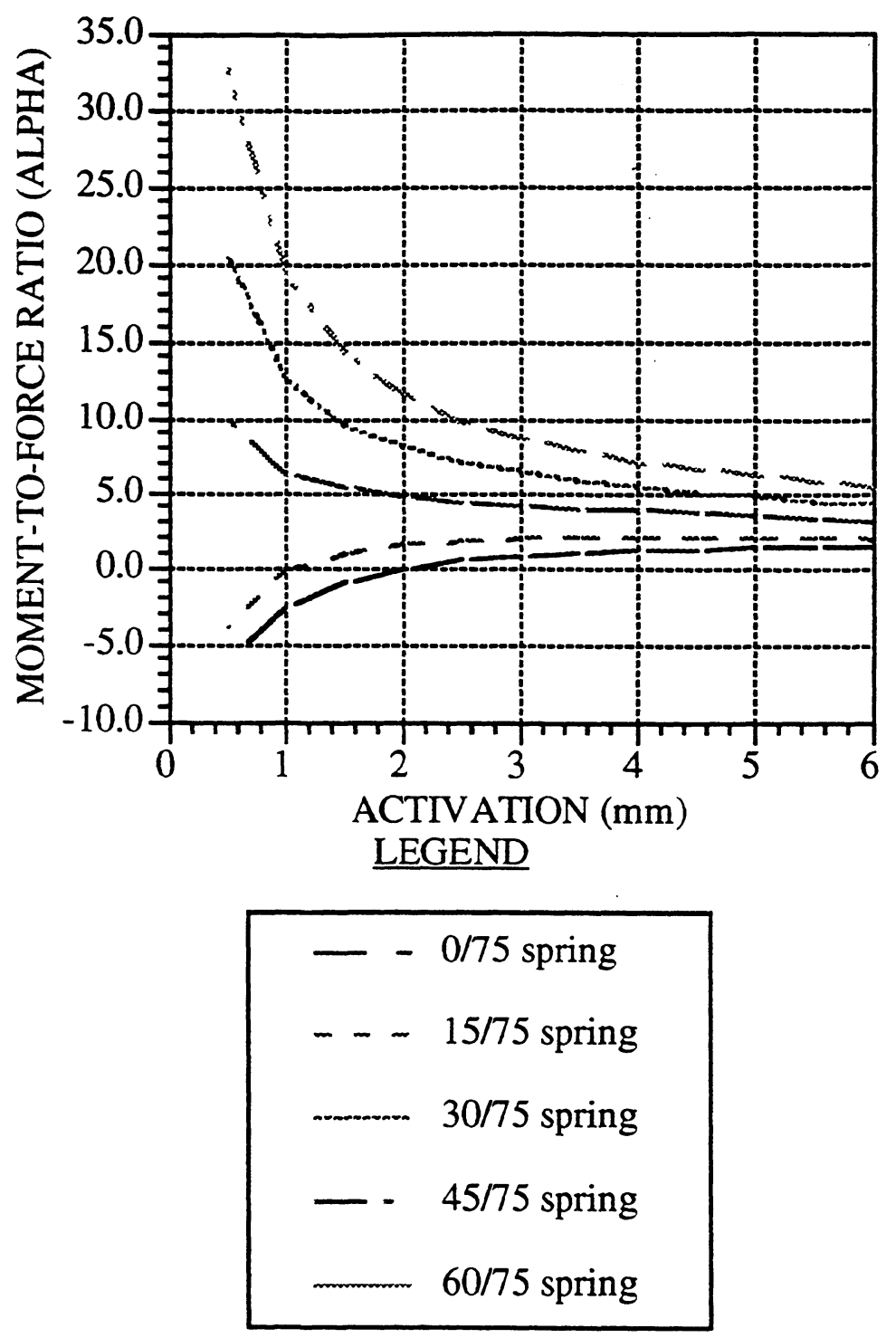

FIGURE 41: Alpha moment-to-force ratio versus spring activation for "T-loop" springs with asymmetric alpha and beta angulation and centered position, variation of the alpha angulation $(0,15,30,45$ and 60 degrees) with a constant beta angulation ( 75 degrees) . 

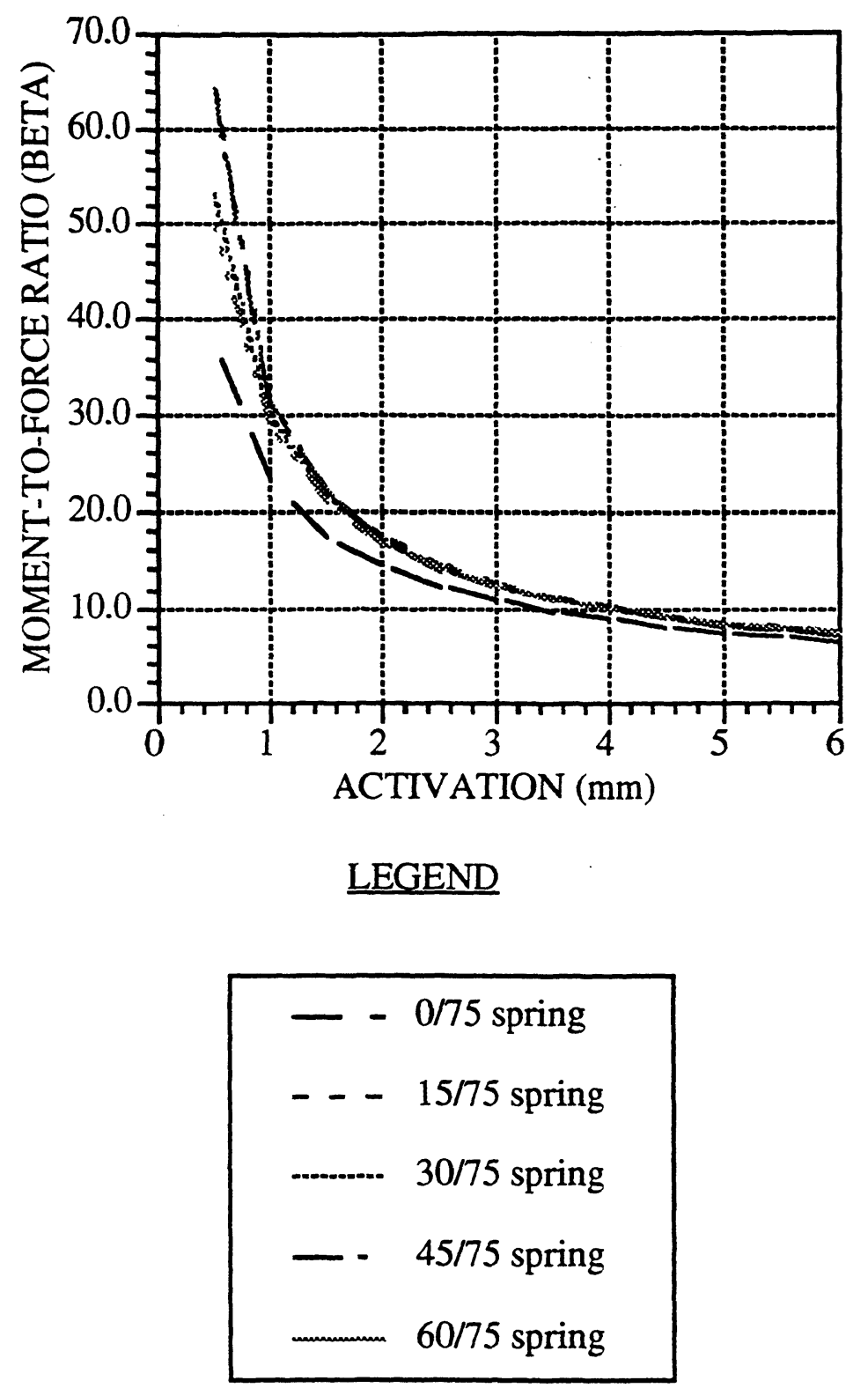

FIGURE 42: Beta moment-to-force ratio versus spring activation for "T-loop" springs with asymmetric alpha and beta angulation and centered position, variation of the alpha angulation $(0,15,30,45$ and 60 degrees) with a constant beta angulation (75 degrees) . 


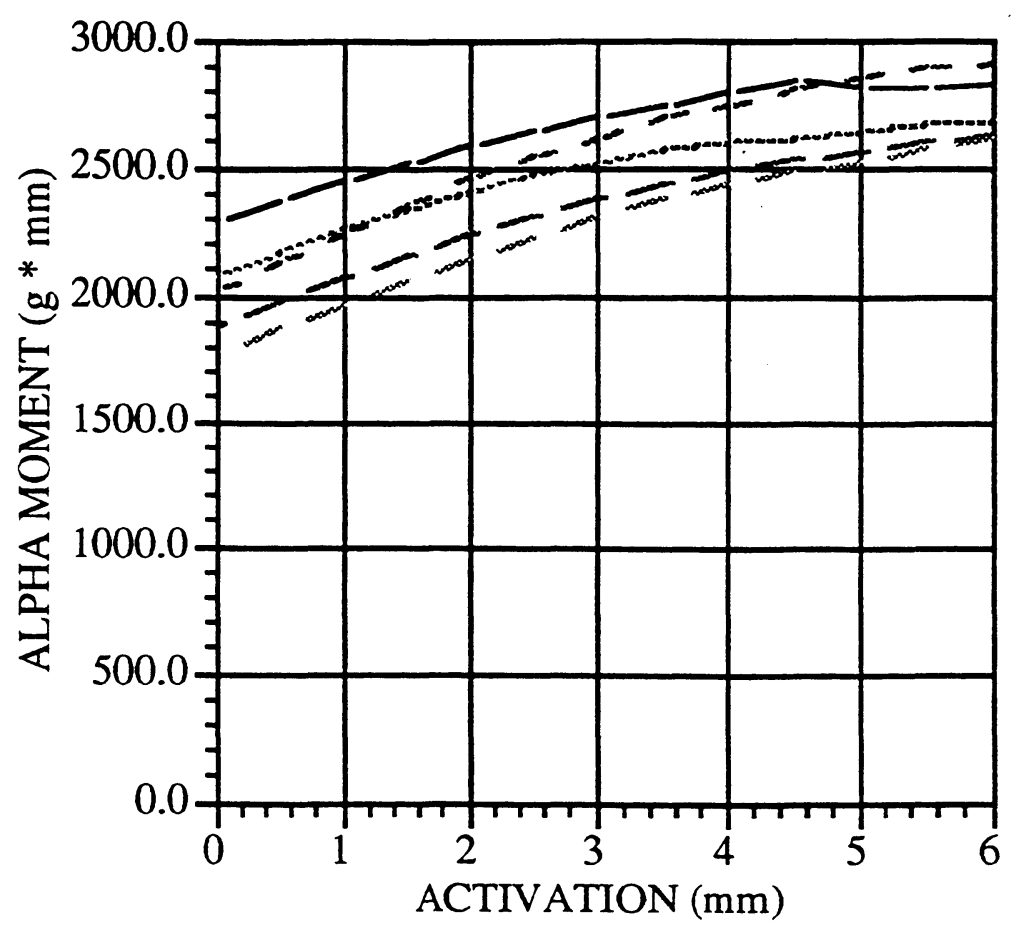

LEGEND

$$
\begin{array}{r}
--0 \mathrm{~mm} \text { ACTIVATION } \\
--\quad 1 \mathrm{~mm} \text { ACTIVATION } \\
-2 \mathrm{~mm} \text { ACTIVATION } \\
--3 \mathrm{~mm} \text { ACTIVATION } \\
-\quad 4 \mathrm{~mm} \text { ACTIVATION } \\
5 \mathrm{~mm} \text { ACTIVATION } \\
\hline
\end{array}
$$

FIGURE 43: Alpha moment versus spring activation for "T-loop" springs with asymmetric alpha and beta angulation and centered position, variation of the beta angulation $(0,15,30,45$ and 60 degrees) with a constant alpha angulation ( 75 degrees) . 


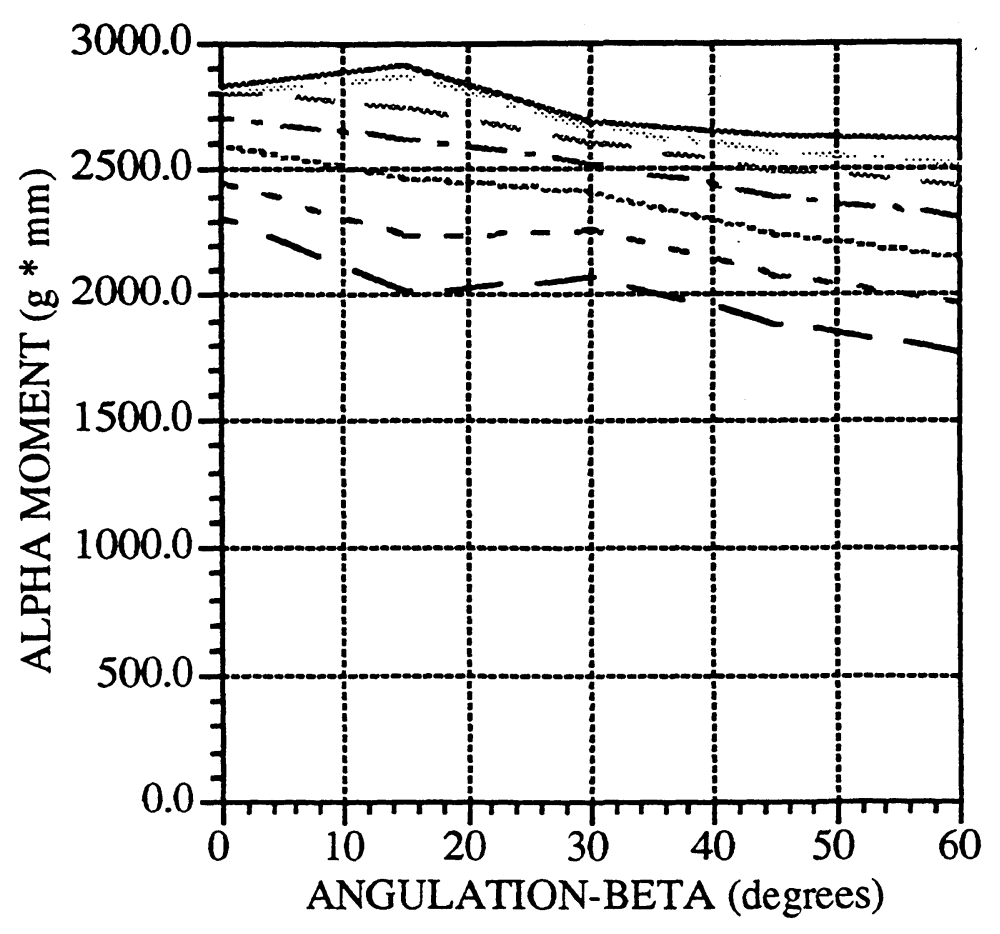

LEGEND

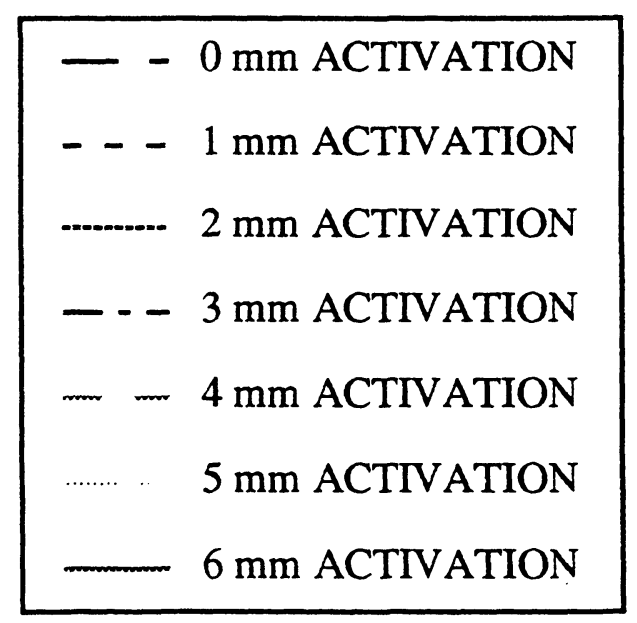

FIGURE 44: Alpha moment versus Beta angulation for "T-loop" springs with asymmetric alpha and beta angulation and centered position, variation of the beta angulation $(0,15,30,45$ and 60 degrees) with a constant alpha angulation (75 degrees). 


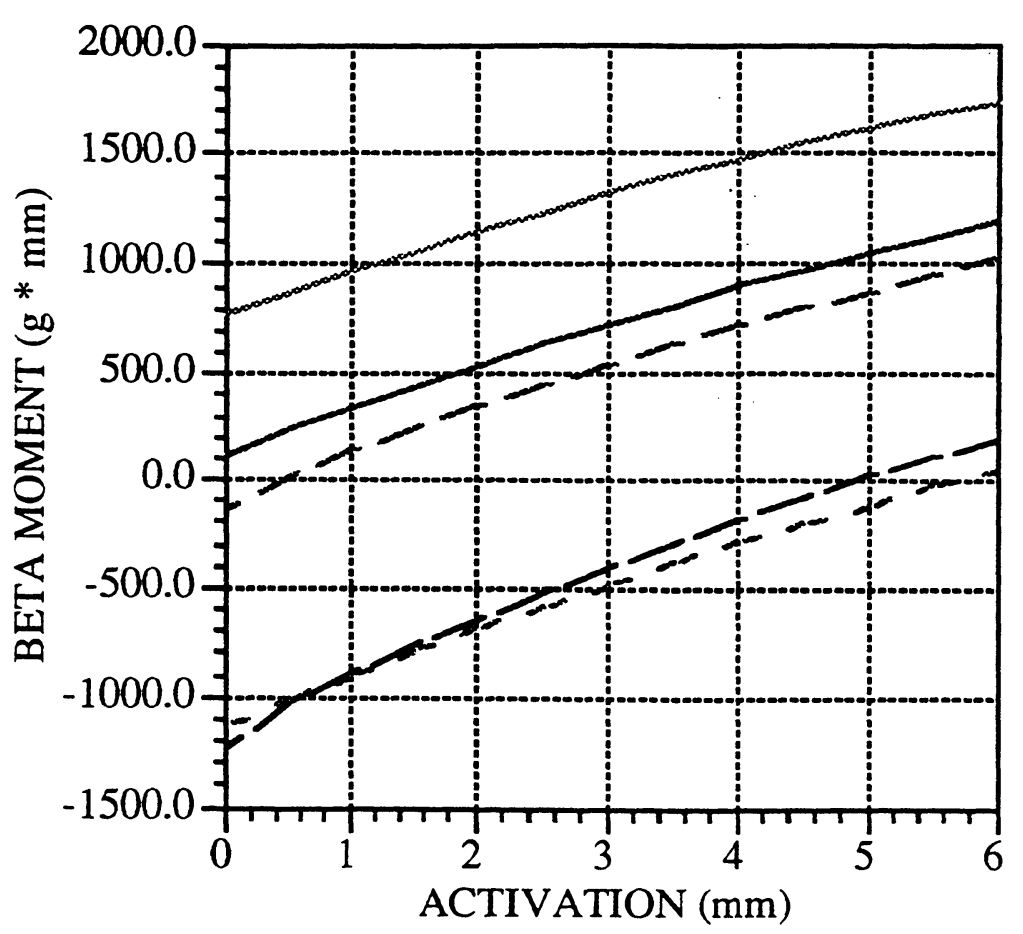

\section{LEGEND}

$$
\begin{aligned}
& \text { - } 75 / 0 \text { SPRING } \\
& \ldots \text { 75/15 SPRING } \\
& \ldots \text { 75/30 SPRING } \\
& \ldots \text { 75/45 SPRING } \\
& -\ldots \text { 75/60 SPRING }
\end{aligned}
$$

FIGURE 45: Beta moment versus spring activation for "T-loop" springs with asymmetric alpha and beta angulation and centered position, variation of the beta angulation $(0,15,30,45$ and 60 degrees) with a constant alpha angulation ( 75 degrees). 


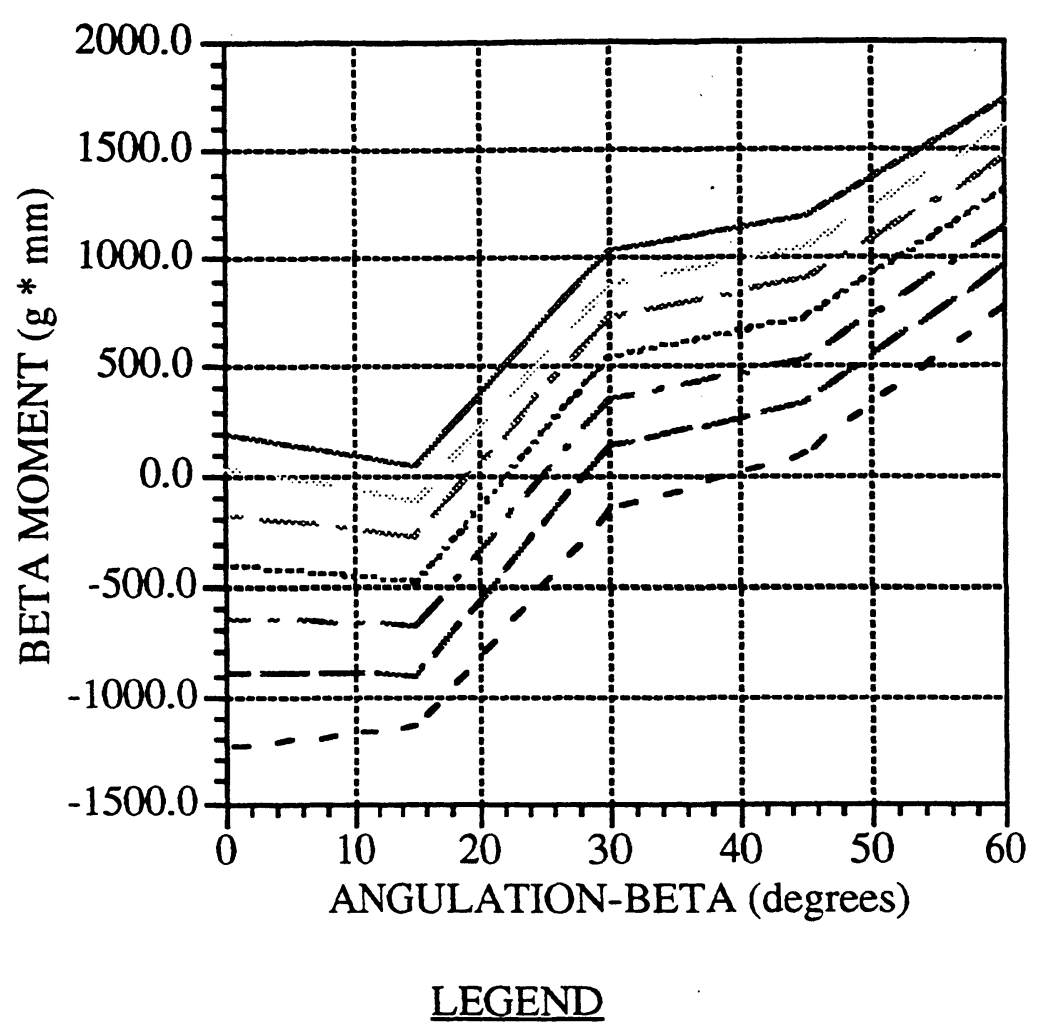

\begin{tabular}{|}
\hline$--0 \mathrm{~mm}$ ACTIVATION \\
$---1 \mathrm{~mm}$ ACTIVATION \\
$\cdots--2 \mathrm{~mm}$ ACTIVATION \\
$---3 \mathrm{~mm}$ ACTIVATION \\
$--4 \mathrm{~mm}$ ACTIVATION \\
$\cdots \cdots$ \\
\hline$-\ldots \mathrm{mm}$ ACTIVATION \\
\hline
\end{tabular}

FIGURE 46: Beta moment versus beta angulation for "T-loop" springs with asymmetric alpha and beta angulation and centered position, variation of the beta angulation $(0,15$, 30,45 and 60 degrees) with a constant alpha angulation ( 75 degrees) . 


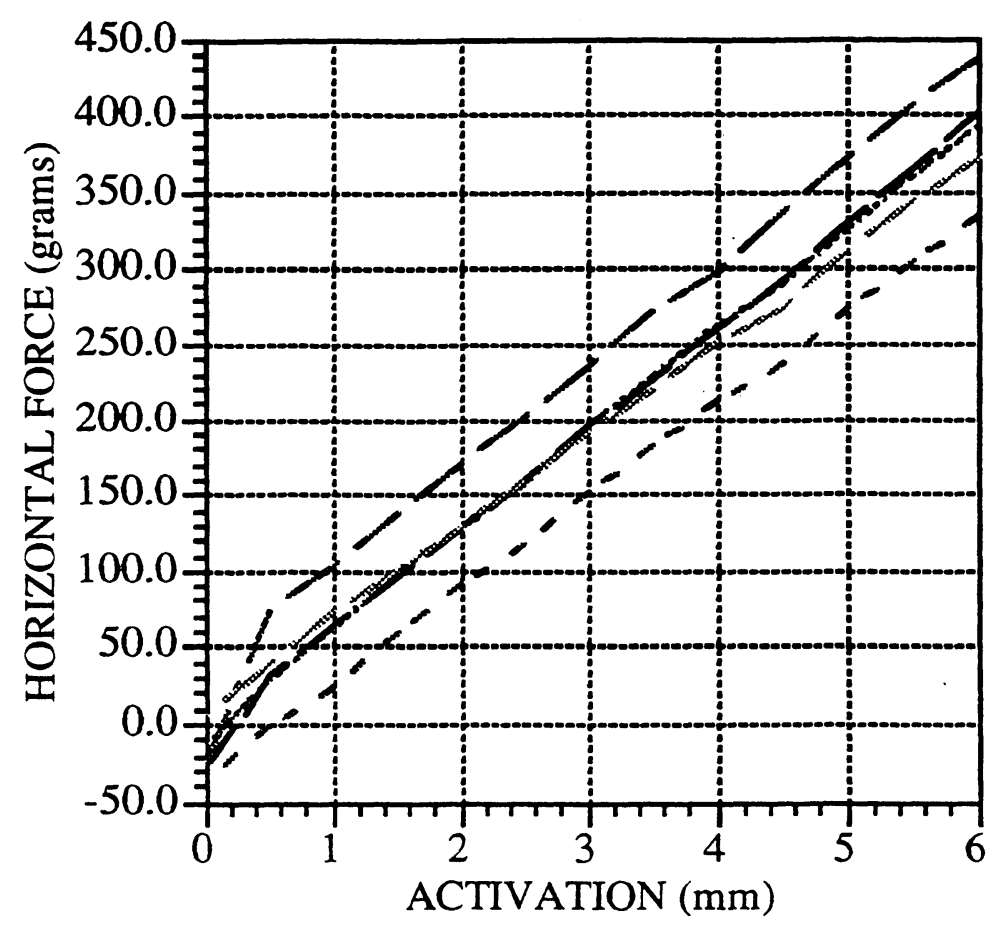

LEGEND

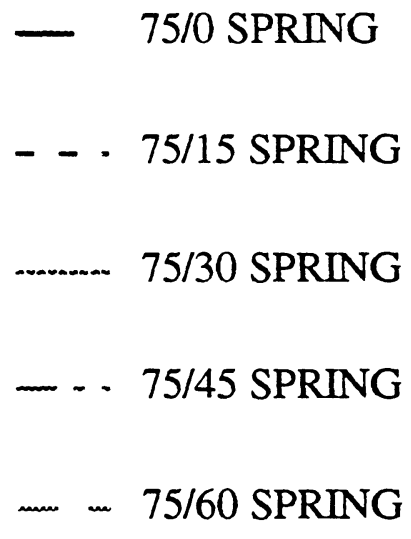

FIGURE 47: Horizontal force versus spring activation for "T-loop" springs with asymmetric alpha and beta angulation and centered position, variation of the beta angulation $(0,15,30,45$ and 60 degrees) with a constant alpha angulation ( 75 degrees). 


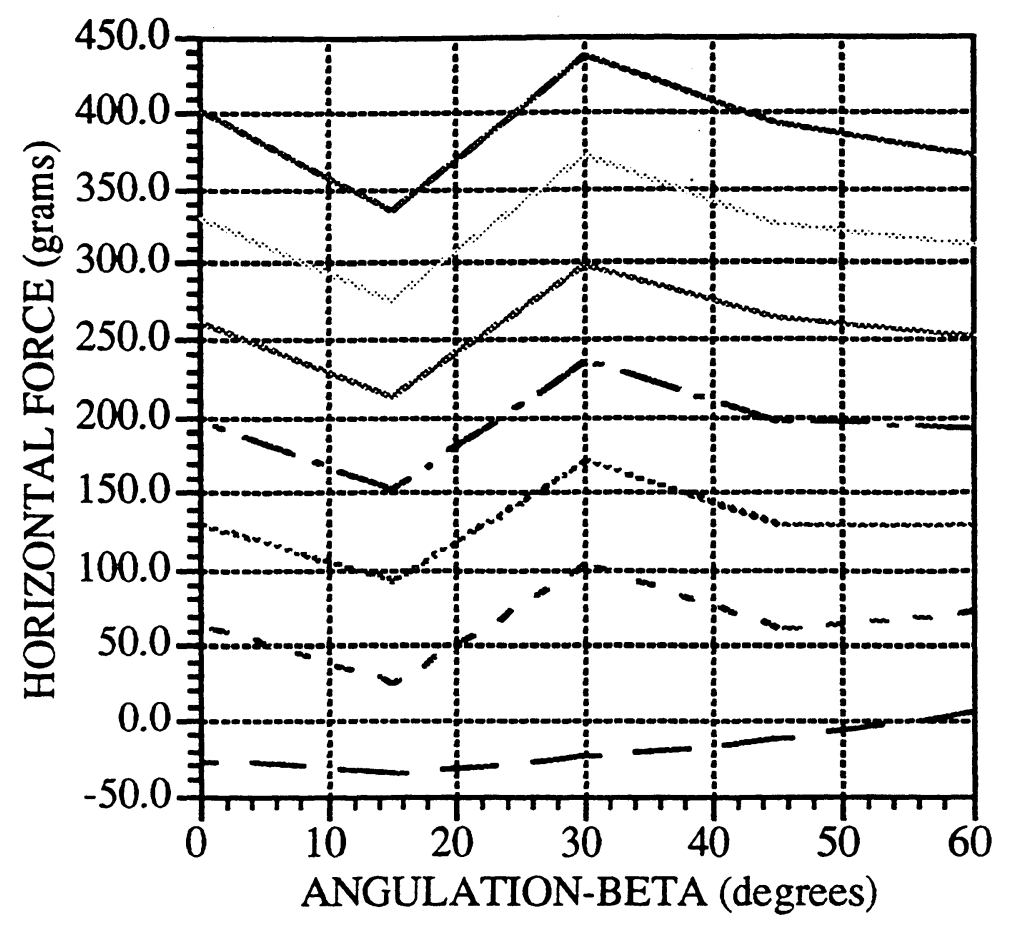

LEGEND

\begin{tabular}{|}
\hline$--0 \mathrm{~mm}$ ACTIVATION \\
$---1 \mathrm{~mm}$ ACTIVATION \\
$--.2 \mathrm{~mm}$ ACTIVATION \\
$---3 \mathrm{~mm}$ ACTIVATION \\
$--4 \mathrm{~mm}$ ACTIVATION \\
$\cdots \cdots \cdots$ \\
\hline$-6 \mathrm{~mm}$ ACTIVATION \\
\hline
\end{tabular}

FIGURE 48: Horizontal force versus beta angulation for "T-loop" springs with asymmetric alpha and beta angulation and centered position, variation of the beta angulation $(0,15,30,45$ and 60 degrees) with a constant alpha angulation (75 degrees). 

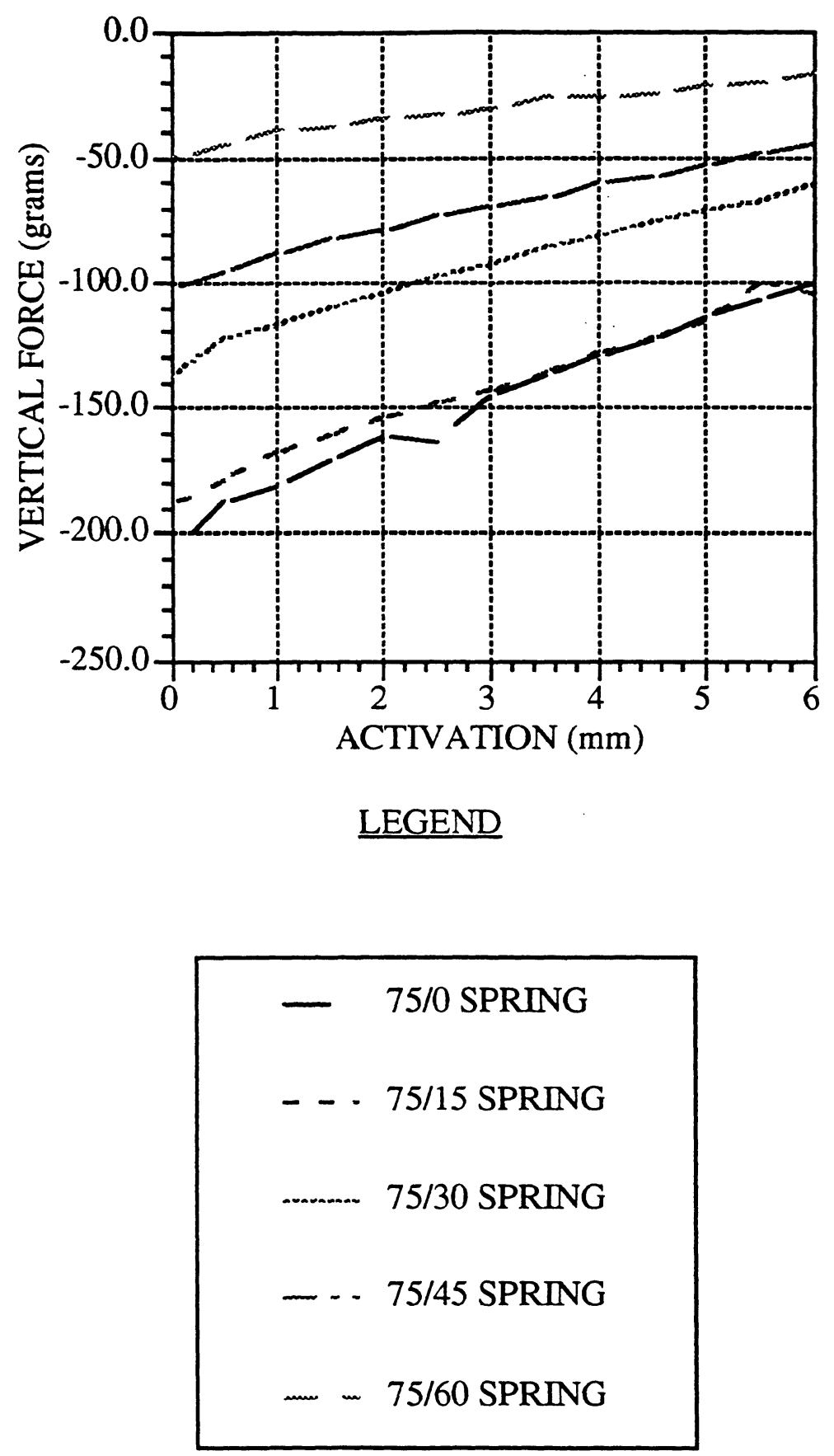

FIGURE 49: Vertical force versus spring activatioation for "T-loop" springs with asymmetric alpha and beta angulation and centered position, variation of the beta angulation $(0,15,30,45$ and 60 degrees) with a constant alpha angulation (75 degrees) . 

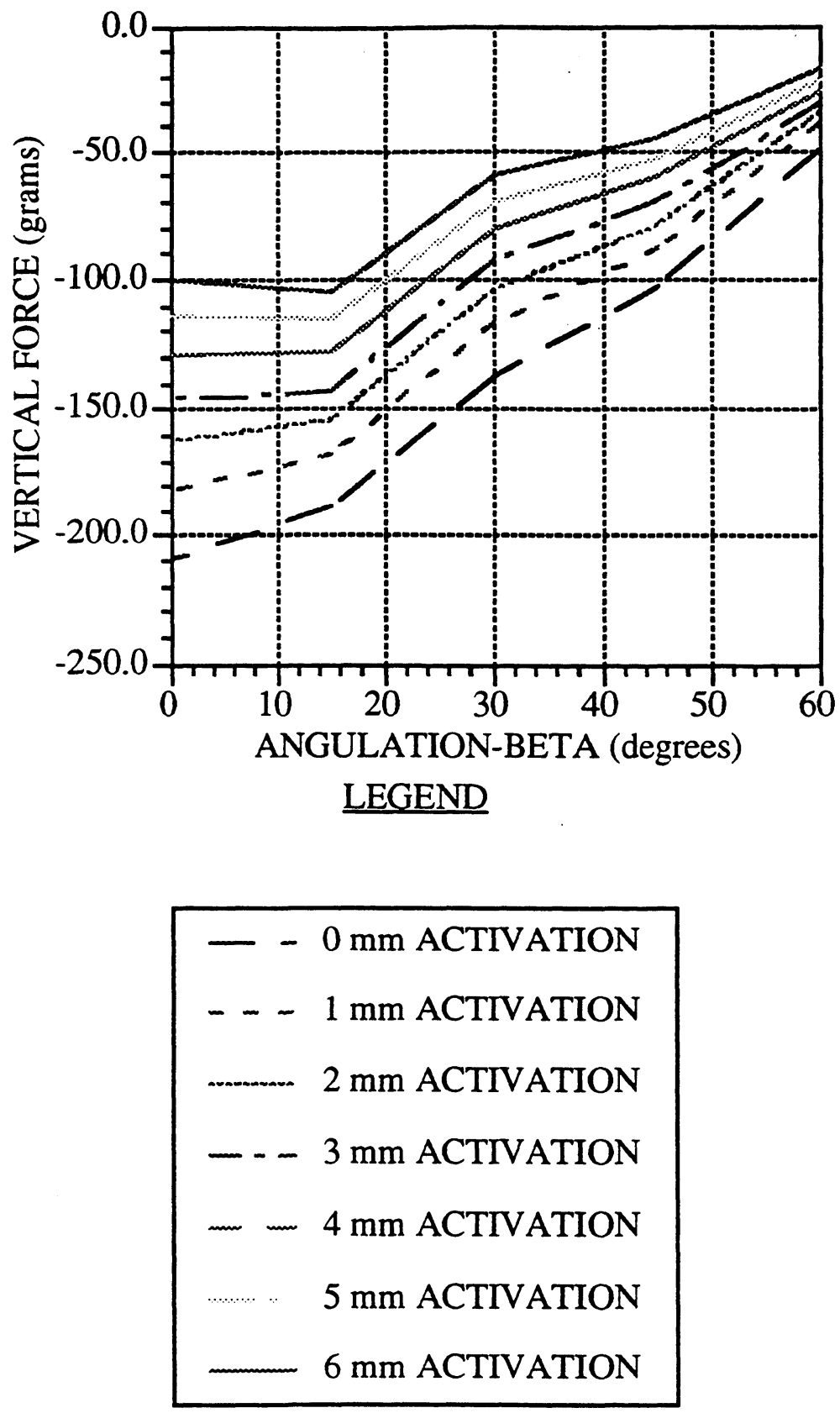

FIGURE 50: Vertical force versus beta angulation for "T-loop" springs with asymmetric alpha and beta angulation and centered position, variation of the beta angulation $(0,15$, 30,45 and 60 degrees) with a constant alpha angulation (75 degrees). 

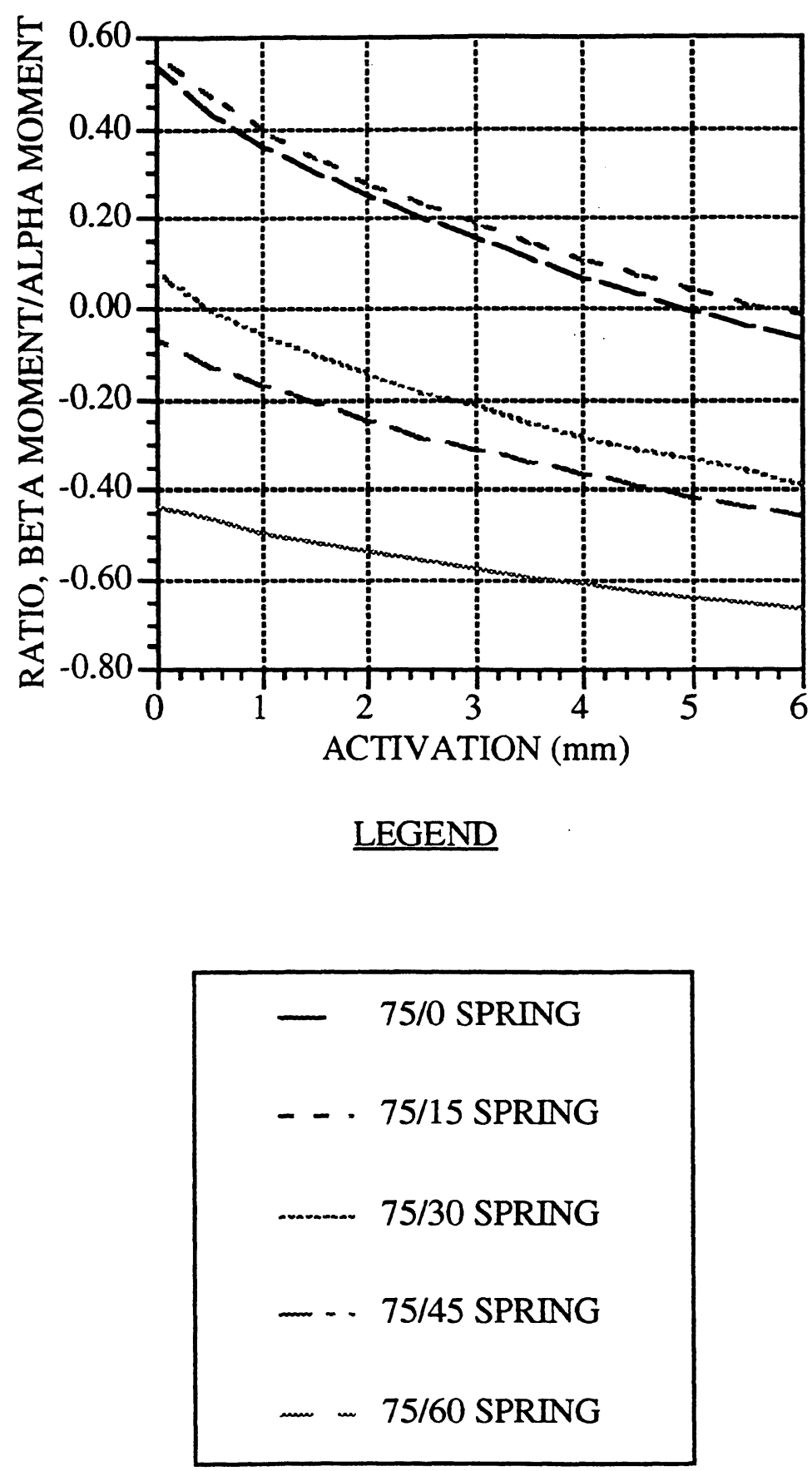

FIGURE 51: Ratio of the alpha moment/beta moment versus spring activation for "Tloop" springs with asymmetric alpha and beta angulation and centered position, variation of the beta angulation $(0,15,30,45$ and 60 degrees) with a constant alpha angulation (75 degrees). 


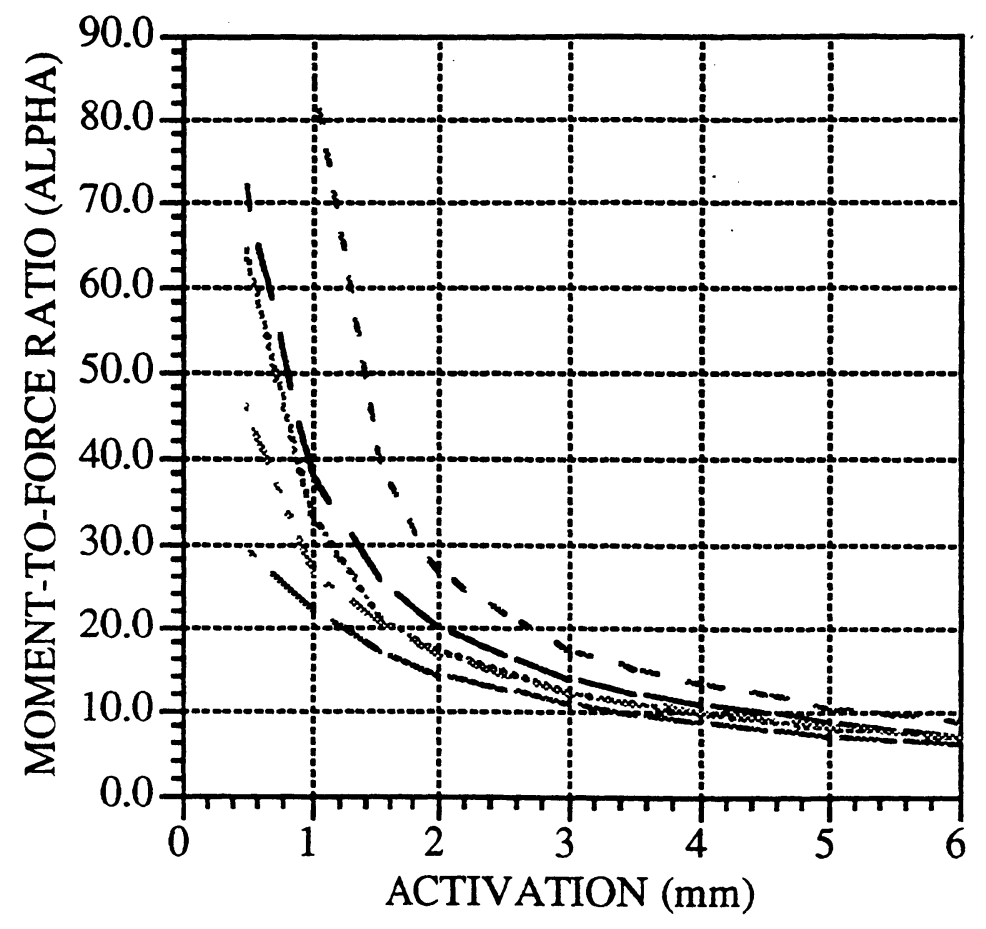

LEGEND

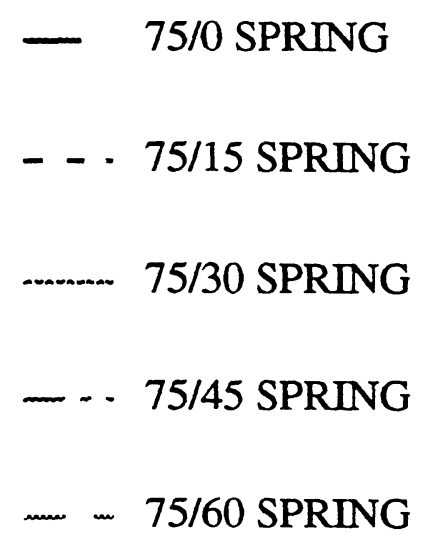

FIGURE 53: Alpha moment-to-force ratio versus spring activation for "T-loop" springs with asymmetric alpha and beta angulation and centered position, variation of the beta angulation $(0,15,30,45$ and 60 degrees) with a constant alpha angulation (75 degrees) . 


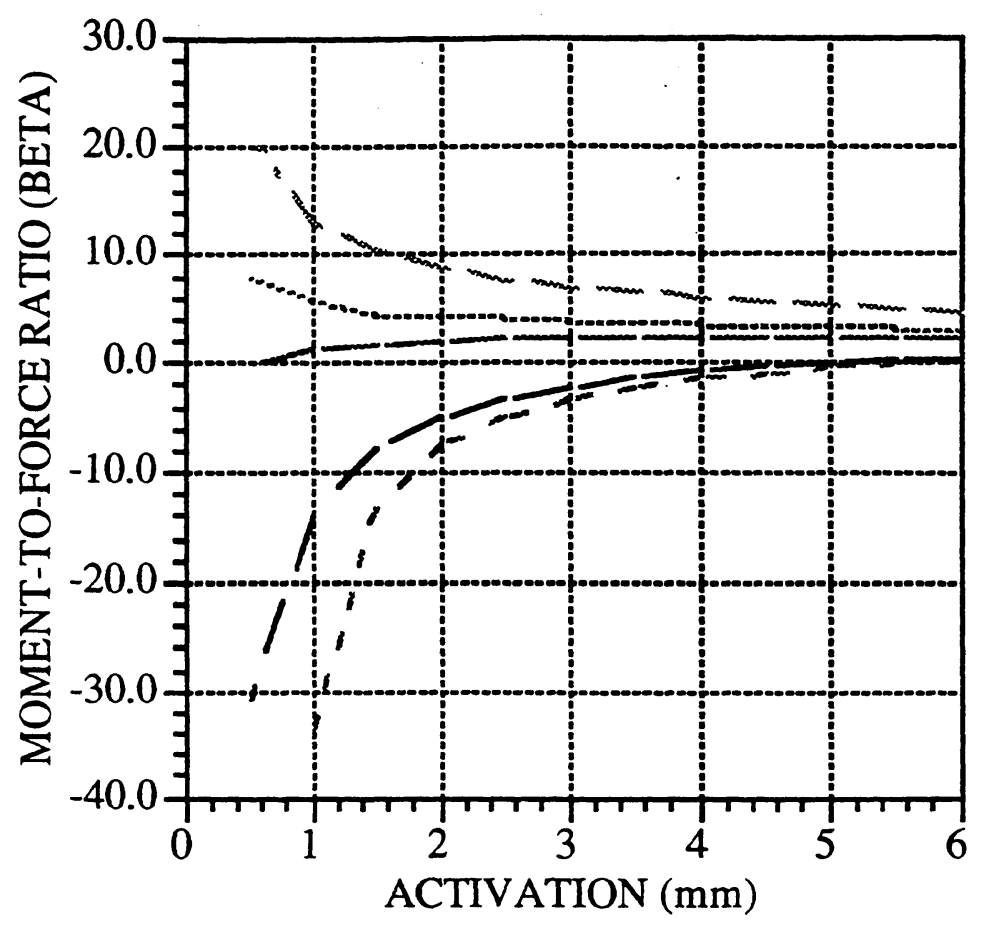

\section{LEGEND}

$$
\begin{aligned}
& \text { 75/0 SPRING } \\
& \ldots \text { 75/15 SPRING } \\
& \ldots \text { 75/30 SPRING } \\
& \ldots \text { 7... 75/45 SPRING } \\
& \ldots \\
& \ldots
\end{aligned}
$$

FIGURE 54: Beta moment-to-force ratio versus spring activation for "T-loop" springs with asymmetric alpha and beta angulation and centered position, variation of the beta angulation $(0,15,30,45$ and 60 degrees) with a constant alpha angulation (75 degrees). 